$\mathrm{DOE} / \mathrm{NV} / 13052-042$

ITLV/13052-042

UC-700

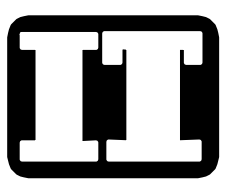

Report and Analysis of the BULLION ForcedGradient Experiment

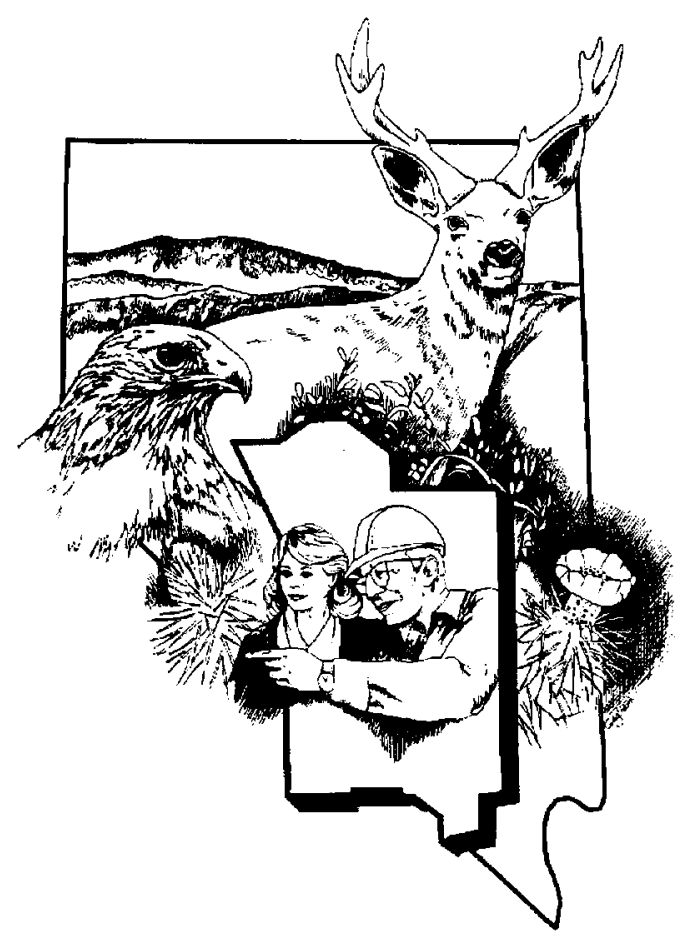

Revision No.: 0

August 1998 
This report has been reproduced directly from the best available copy.

Available to DOE and DOE contractors from the Office of Scientific and Technical Information, P.O. Box 62, Oak Ridge, TN 37831; prices available from (423) 576-8401.

Available to the public from the National Technical Information Service, U.S. Department of Commerce, 5285 Port Royal Road, Springfield, VA 22161, telephone (703) 487-4650. 


\section{REPORT AND ANALYSIS OF THE BULLION FORCED-GRADIENT EXPERIMENT}

Revision No.: 0

August 1998

IT CORPORATION

2621 Losee Road

Building B-1, Suite 3050-01

North Las Vegas, Nevada 89030

Prepared for U.S. Department of Energy, Nevada Operations Office under contract No. DE-AC08-97NV13052

Approved for public release; further dissemination unlimited 


\section{REPORT AND ANALYSIS OF THE BULLION FORCED-GRADIENT EXPERIMENT}
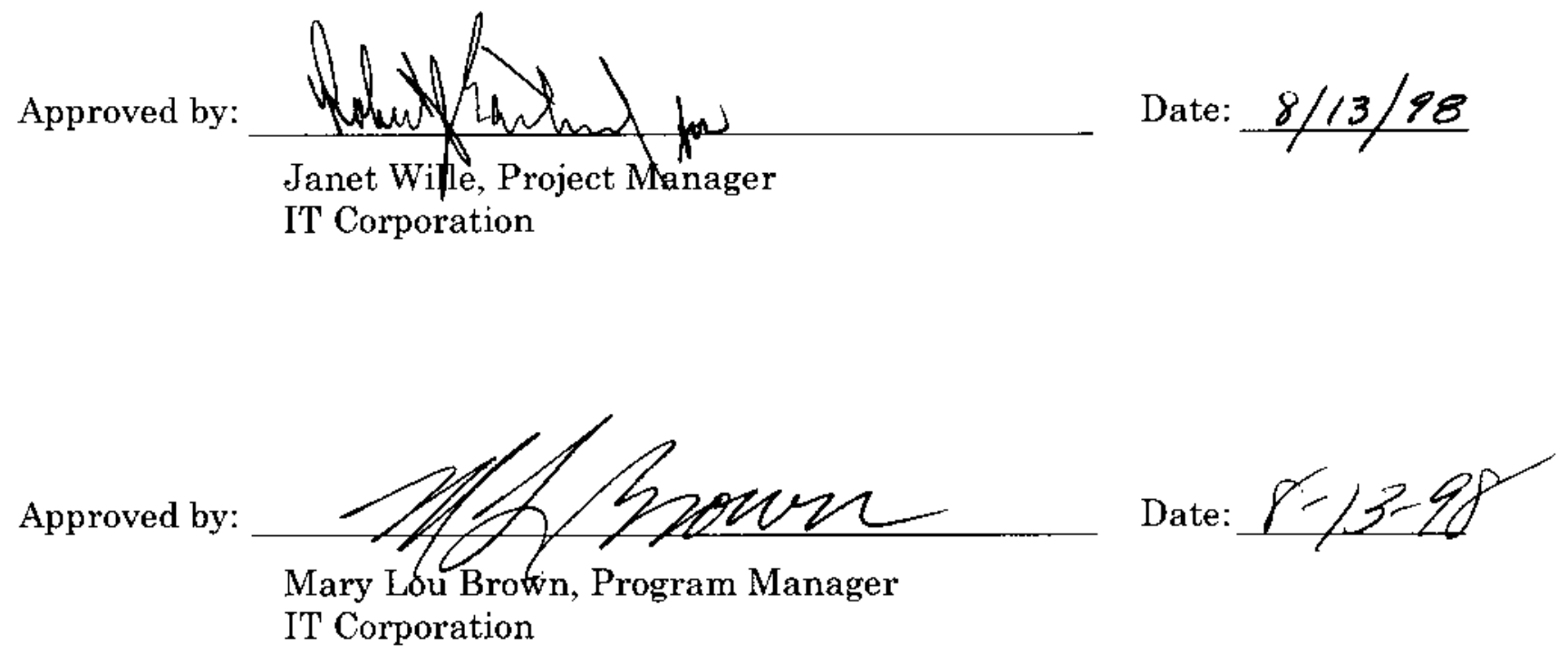


\section{Table of Contents}

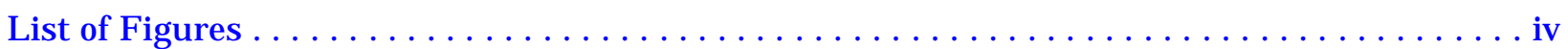

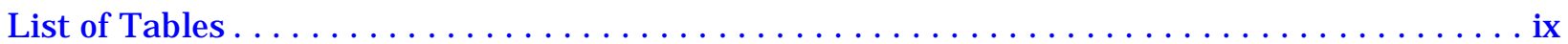

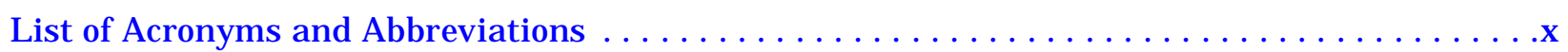

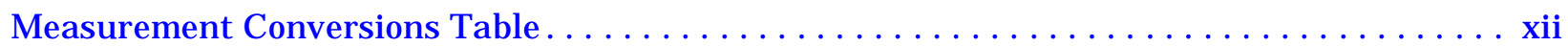

$1.0 \quad$ Introduction. . . . . . . . . . . . . . . . .

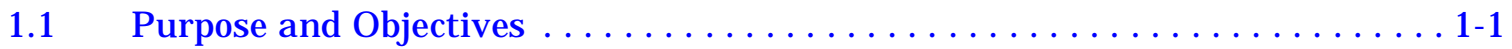

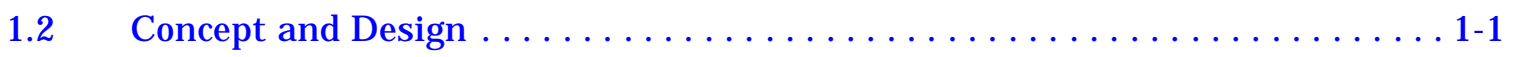

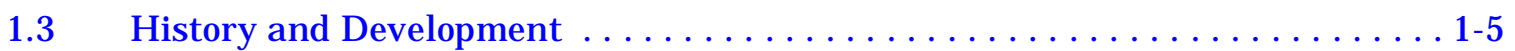

1.4 Participants. . . . . . . . . . . . .

1.5 Report Organization. . . . . . . . . . . . . . . .

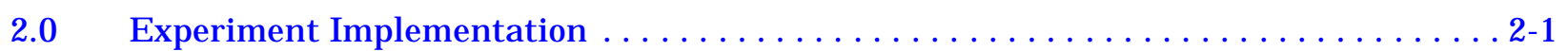

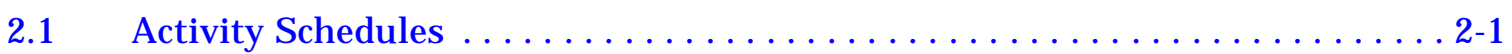

2.1.1 Technical Change N otices . . . . . . . . . . . . . . . . . 2-7

2.1.2 Delay of Tracer Injection into Well ER-20-6 \#1 . . . . . . . . . . 2-7

2.1.3 Extension of Experiment Duration . . . . . . . . . . . . . . . . 2-7

2.1.4 Periodically Stopping Pumping of Wells ER-20-6 \#1 and \#2 . . . . . . . 2-8

2.1.5 Changes to Sampling and Analysis Schedules. . . . . . . . . . . . 2-8

2.1.6 Field Microsphere Monitoring . . . . . . . . . . . . . . . 2-9

2.2 Pumping Continuity. . . . . . . . . . . . . . . .

2.2.1 Power Interruptions. . . . . . . . . . . . . . . . . . . . .

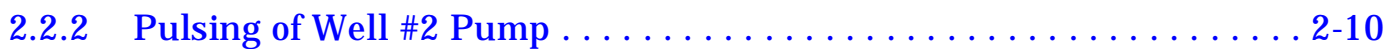

2.3 Summary. . . . . . . . . . . .

2.4 How the Results Differed from Predictions. . . . . . . . . . . . . . . 2-11

3.0 Data Collection . . . . . . . . . . . . . . . . . . . . . . . . . . . . . . . 3-1

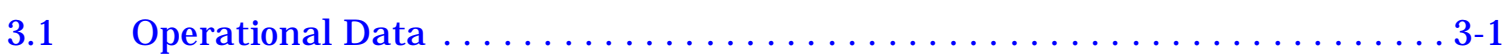

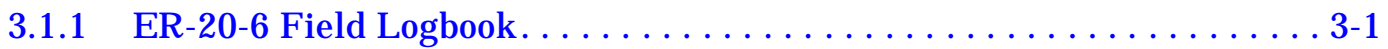

3.1 .2 Pumping Rate. . . . . . . . . . . . . . . . . .

3.1.3 Discharge Monitoring. . . . . . . . . . . . . . . . . . . . .3

3.2 Hydraulic Response Data. . . . . . . . . . . . . . . . . . . . . . .

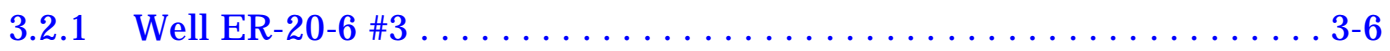

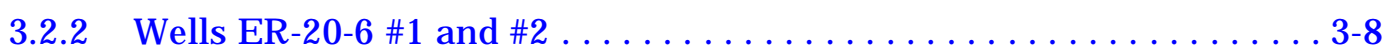

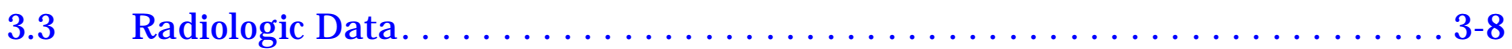

3.3.1 IT Radionuclide Sample Results . . . . . . . . . . . . . . 3-8

3.3.2 LLNL Radionuclide Samples...................... 3-11 


\section{Table of Contents (Continued)}

3.3.3 LANL Radionuclide Samples. . . . . . . . . . . . . . . . . 3-11

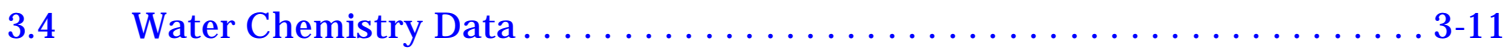

3.4.1 Baseline Chemistry . . . . . . . . . . . . . . . . . . . .

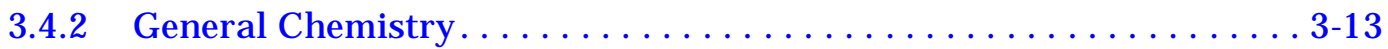

3.4.3 Groundwater Characterization . . . . . . . . . . . . . . . 3-17

3.5 Tracer Data. . . . . . . . . . . . . . . . . . . . . . . . . . . . . . 3-20

3.5.1 Well ER-20-6 \#2 Injectate . . . . . . . . . . . . . . . . 3-20

3.5.2 Well ER-20-6 \#1 Injectate . . . . . . . . . . . . . . . . 3-21

3.5.3 Injectate Concentration Determination . . . . . . . . . . . 3-22

3.5.4 HPLC System Components . . . . . . . . . . . . . . . . . . . 3-23

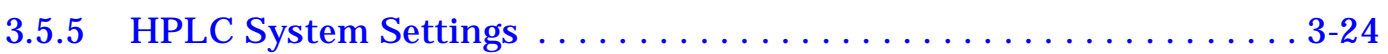

3.5.6 HPLC Mobile Phase Composition . . . . . . . . . . . . . . . . . 3-24

3.5.7 Standards Preparation and Quality Control . . . . . . . . . . . . . . 3-24

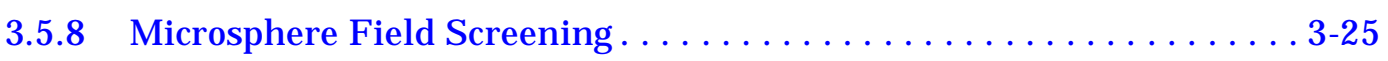

3.5.9 Tracer-Data Time. . . . . . . . . . . . . . . . . . . . . . . 3-25

3.5.10 Tracer Concentration Plots . . . . . . . . . . . . . . . . . .

3.5.11 Tracer Recoveries. . . . . . . . . . . . . . . . . . . . 3-26

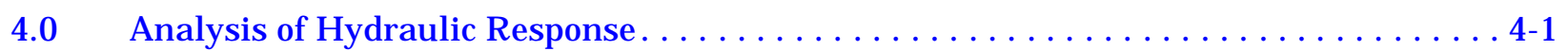

4.1 Theis Analysis. . . . . . . . . . . . . . . . . . . . . . . . 4-4

4.2 Dual-Porosity Analysis. . . . . . . . . . . . . . . . .

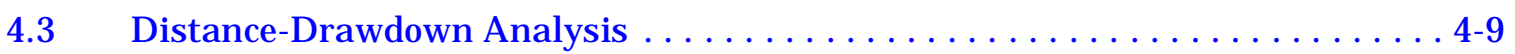

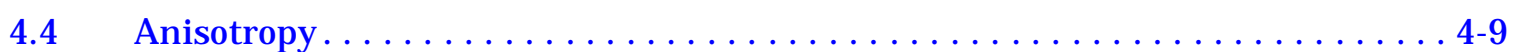

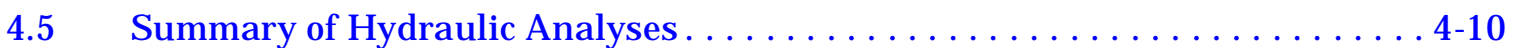

5.0 Analytical Solutions to Tracer Transport $\ldots \ldots \ldots \ldots \ldots \ldots \ldots \ldots \ldots \ldots \ldots \ldots$

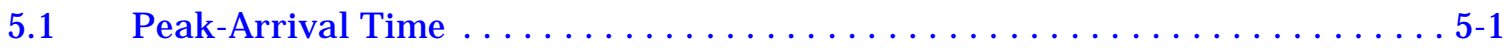

5.2 LANL Semi-Analytical Method . . . . . . . . . . . . . . .

$6.0 \quad$ Numerical Modeling - Flow Calibration . . . . . . . . . . . . . . . . 6-1

6.1 MODFLOWT with Dual Porosity . . . . . . . . . . . . . . . .

6.2 Geologic Model ................................ 6-4

6.2 .1 Construction of the Geologic Layers . . . . . . . . . . . . . . 6-6

6.2.2 Adjustments to the Geol ogic M odel . . . . . . . . . . . . . . . . . . . . 6-8

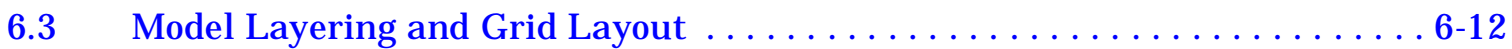

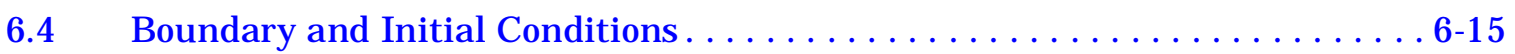

$6.5 \quad$ Hydraulic Calibration. . . . . . . . . . . . . . . . . . . . . . . . . 6-17

6.5.1 Steady State Flow Calibration . . . . . . . . . . . . . . . 6-17

6.5.2 Transient Calibration ...................... 6-20 
7.0 Numerical Modeling - Tracer Transport Calibration . . . . . . . . . . . . . 7-1

7.1 Tracer Calibration Results. . . . . . . . . . . . . . . . . . . .

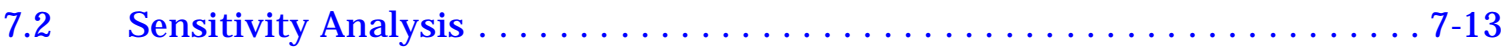

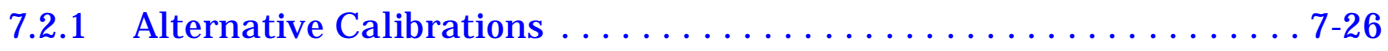

7.3 Second Microsphere Peaks. . . . . . . . . . . . . . . . . . . . . .

8.0 Summary and Conclusions. . . . . . . . . . . . . .

8.1 Summary of Flow and Transport Model Results $\ldots \ldots \ldots \ldots \ldots \ldots \ldots \ldots$ 8-1

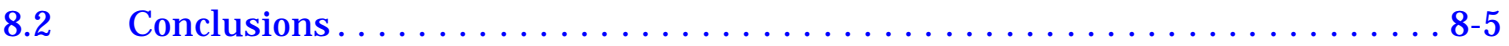

8.2.1 Groundwater Chemistry . . . . . . . . . . . . . . . . . 8-5

8.2.2 Geology and Aquifer Hydraulics . . . . . . . . . . . . . . . . 8-6

8.2.3 Radionuclide Transport from the BULLION Cavity . . . . . . . . . . 8-6

8.2.4 Tracer and Solute Transport . . . . . . . . . . . . . . . . . . . . . 8-7

8.2.5 Microsphere/Colloid Transport . . . . . . . . . . . . . . . . 8-8

8.3 Implications of the BULLION FGE Results for CAU Scale Modeling . . . . . . 8-8

9.0 References . . . . . . . . . . . . . . . . . . . . . . . . . . . . . . . . . 9-1

Appendix A - Geologic Model for the BULLION FGE Model . . . . . . . . . . . . . A-1 
Number

Title

Page

1-1 Location of Well ER-20-6 Site on Pahute Mesa, Nevada Test Site. . . . . . . . . . . 1-2

1-2 Hydrogeologic Setting for the BULLION FGE...................

1-3 Well ER-20-6 Site Configuration. . . . . . . . . . . . . . . . . . . . . . 1-4

1-4 Schematic of the BULLION Forced-Gradient Experiment ............... 1-6

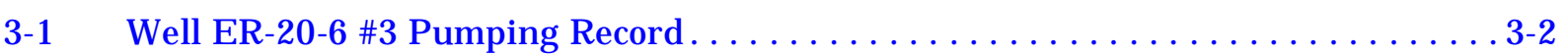

3-2 Well ER-20-6 \#3 Cumulative Average Pumping Rate . . . . . . . . . . . . . 3-4

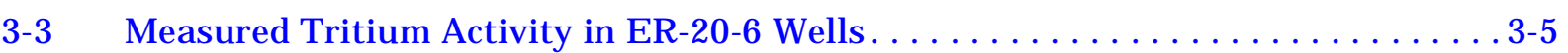

3-4 Well ER-20-6 \#3 Drawdown Record . . . . . . . . . . . . . . . . . . . . . . . . 3-7

3-5 Well \#1 Drawdown Record. . . . . . . . . . . . . . . . . . . . . . . . . . . . . 3-9

3-6 Well \#2 Drawdown Record. . . . . . . . . . . . . . . . . . . . . . . . . . . 3-10

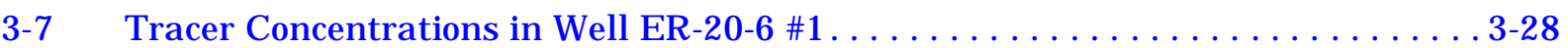

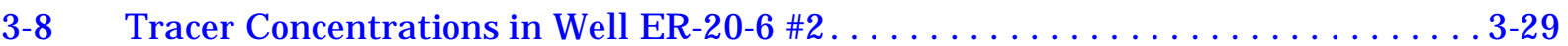

3-9 Tracer Concentrations in Well ER-20-6 \#3 ...................... $3-30$

3-10 Microsphere Concentrations in Well ER-20-6 $\# 1 \ldots \ldots \ldots \ldots \ldots \ldots \ldots \ldots \ldots .31$

3-11 Microsphere Concentrations in Well ER-20-6 \#2 . . . . . . . . . . . . . . . 3-32

3-12 Microsphere Concentrations in Well ER-20-6 \#3 . . . . . . . . . . . . . . . 3-33

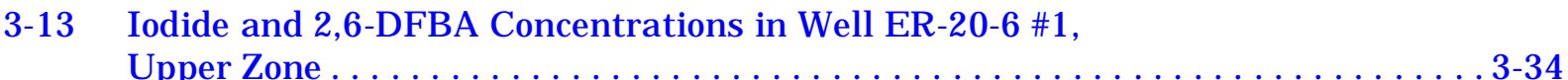

3-14 Iodide and 2,6-DFBA Concentrations in Well ER-20-6 \#1,

Lower Zone............................................ . 3-35

3-15 PFBA, lodide and 2,6-DFBA Concentrations in Well ER-20-6 \#2,

Upper Zone......................................... .

3-16 PFBA, lodide and 2,6-DFBA Concentrations in Well ER-20-6 \#2,

Lower Zone ............................................ . 37

4-1 Well \#1 Drawdown Record................................

$4-2 \quad$ Well \#2 Drawdown Record. ..................................

4-3 Well ER-20-6 \#1 Theis Analysis $\ldots \ldots \ldots \ldots \ldots \ldots \ldots \ldots \ldots \ldots \ldots \ldots \ldots .4$

4-4 ER-20-6 \#2 Theis Analysis. . . . . . . . . . . . . . . . . . . . . . . 4-5

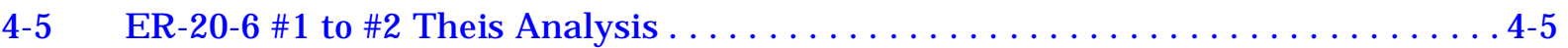

4-6 ER-20-6 \#1 Recovery Analysis. . . . . . . . . . . . . . . . . . . . . . 4-6

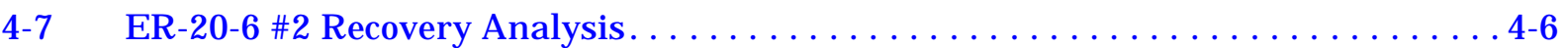

4-8 ER-20-6 \#1 Dual Porosity Analysis . . . . . . . . . . . . . . . . . . . . 
Number

4-9 ER-20-6 \#2 Dual Porosity Analysis . . . . . . . . . . . . . . . . . . . 4

4-10 ER-20-6 \#1 to \#2 Dual Porosity Analysis . . . . . . . . . . . . . . . . . . 4-8

4-11 Distance-Drawdown at 0.25 Days .........................

6-1 Geologic Cross Section through the BULLION FGE Site ................. 6-5

6-2 Areal Extent of the FGE Geologic Model ........................ 6-7

6-3 Structure Contour Map of the Top of the Calico Hills

Zeol itized Composite Unit . . . . . . . . . . . . . . . . . . . . . . . . . . . 6-9

6-4 East-West Cross Section through the Geologic Model Area . . . . . . . . . . . . 6-10

6-5 Southwest-N orthwest Cross Section through the BULLI ON F GE Site........ 6-11

6-6 BULLION FGE Model Grid............................... 6-13

6-7 Estimated Water-Table Contour Map. ....................... 6-14

6-8 BULLION FGE Model Boundary Configuration ................... 6-16

6-9 Simulated Steady-State Water Table Map. . . . . . . . . . . . . . . . . . . . . 6-21

6-10 Final Calibrated Drawdowns ............................... 6.

6-11 Drawdowns with West Greeley Fault Treated as No Flow Boundary . . . . . . . 6-26

6-12 Drawdowns with Higher Conductivity for West Greeley Fault Boundary . . . . . . 6-26

7-1 Breakthrough Curve at Well \#3 for DFBA $\ldots \ldots \ldots \ldots \ldots \ldots \ldots \ldots \ldots \ldots \ldots \ldots \ldots \ldots, 2$

7-2 Breakthrough Curve at Well \#3 for Iodide.....................

7-3 Breakthrough Curve at Well \#3 for PFBA ......................

7-4 Breakthrough Curves at Well \#2 for DFBA and Iodide................ 7-4

7-5 DFBA and Iodide Concentration Decline in Well \#1 .................. 7-5

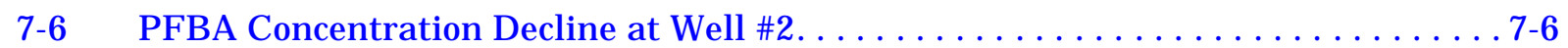

7-7 Early-Time Tracer Concentration Decline in Well \#1 .................. 7-7

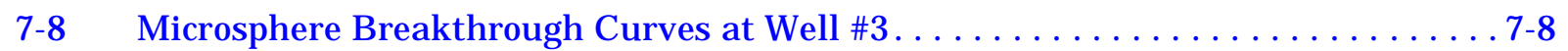

7-9 HSU 4 DFBA Normalized Concentration Contours
at the End of Well $\# 1$ Injection $\ldots \ldots \ldots \ldots \ldots \ldots \ldots \ldots \ldots \ldots \ldots \ldots \ldots \ldots$

7-10 HSU 6 DFBA Normalized Concentration Contours at the End of Well \#1 Injection . . . . . . . . . . . . . . . . . . . . . .

7-11 HSU 4 DFBA Normalized Concentration Contours

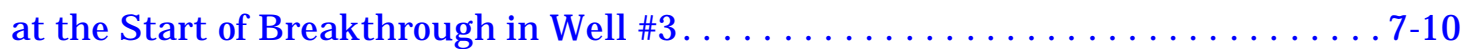

7-12 HSU 6 DFBA Normalized Concentration Contours

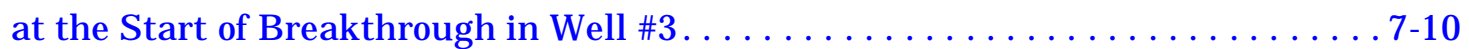


Number

Title

Page

7-13 HSU 4 DF BA N ormalized Concentration Contours at the

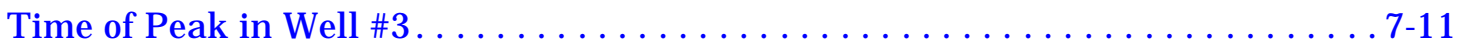

7-14 HSU 6 DFBA Normalized Concentration Contours at the Time of Peak in Well \#3. . . . . . . . . . . . . . . . . . . . . .

7-15 Drawdowns in Well \#3 with I ncreased Storage Coefficient. . . . . . . . . . . . . . 7-14

7-16 DFBA Breakthrough Curve at Well \#3 for the West Greeley Fault

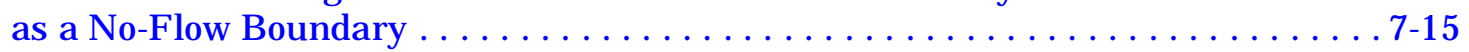

7-17 DFBA Breakthrough Curve for Well \#3 with Increased

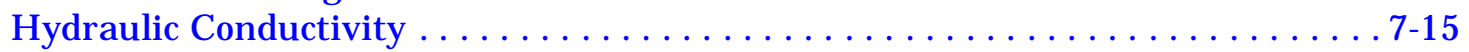

7-18 DFBA Breakthrough Curve for Well \#3 with Decreased Hydraulic Conductivity . . . . . . . . . . . . . . . . . . . . .

7-19 Simulated Breakthrough Curve of DFBA for Well \#3 without the High Conductivity Zone. . . . . . . . . . . . . . . . 7-17

7-20 Simulated Breakthrough Curve of DF BA for Well \#2 without the High Conductivity Zone. . . . . . . . . . . . . . . . . 7-17

7-21 Simulated Breakthrough Curve of DFBA for Well \#1 without the High Conductivity Zone. . . . . . . . . . . . . . . . . .

7-22 Simulated Drawdowns without the High Conductivity Zone . . . . . . . . . . . . . . 7-18

7-23 Simulated Breakthrough of DFBA for Well \#3

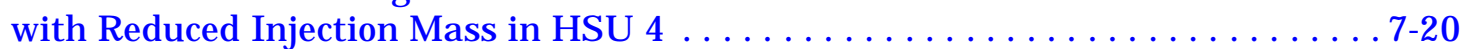

7-24 Simulated Breakthrough of DFBA for Well \#2

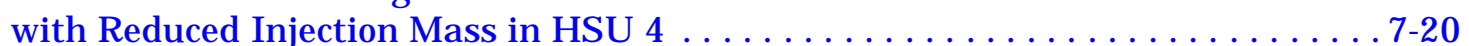

7-25 Simulated Breakthrough of DFBA for Well \#1

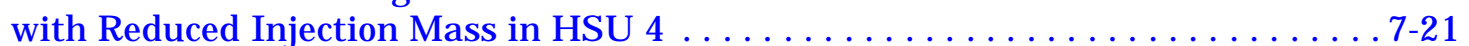

7-26 Simulated Breakthrough of DFBA for Well \#3 with Decreased Porosity . . . . . . . . . . . . . . . . . . . . . . . . . . 7-21

7-27 Simulated Breakthrough of DFBA for Well \#3

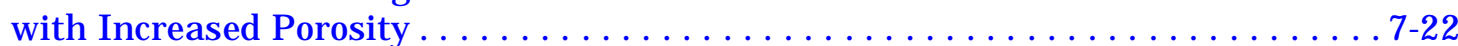

7-28 Simulated Breakthrough of DFBA for Well \#3 for Increased Dispersivities. . . . . . . . . . . . . . . . . . . 7-22

7-29 Simulated Breakthrough of DFBA for Well \#2

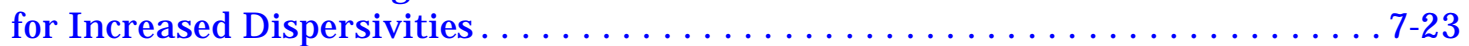

7-30 Simulated Breakthrough of DFBA for Well \#1 for Increased Dispersivities . . . . . . . . . . . . . . . . . . . .

7-31 Simulated Breakthrough of DFBA for Well \#3 for Decreased Dispersivities . . . . . . . . . . . . . . . . . . . . 
Number

7-32 Simulated Breakthrough of DFBA for Well \#2

for Decreased Dispersivities .............................. 7-24

7-33 Simulated Breakthrough of DF BA for Well \#1

for Decreased Dispersivities .............................. 7-25

7-34 Simulated Breakthrough of DFBA for Well \#3 Alternative Calibration $1 \ldots \ldots$. 7-27

7-35 Simulated Breakthrough of DFBA for Well \#2 Alternative Calibration $1 \ldots \ldots$. . 7-27

7-36 Simulated Breakthrough of DFBA for Well \#1 Alternative Calibration $1 \ldots \ldots \ldots$ 7-28

7-37 Simulated Breakthrough of DFBA for Well \#3 Alternative Calibration $2 \ldots \ldots \ldots$ 7-28

7-38 Simulated Breakthrough of DFBA for Well \#2 Alternative Calibration $2 \ldots \ldots$. . 7-29

7-39 Simulated Breakthrough of DFBA for Well \#1 Alternative Calibration 2 . . . . . . 7-29

7-40 Simulated Breakthrough of DFBA for Well \#3 Alternative Calibration 3 . . . . . 7-30

7-41 Simulated Breakthrough of DFBA for Well \#2 Alternative Calibration 3 . . . . . . 7-31

7-42 Simulated Breakthrough of DFBA for Well \#1 Alternative Calibration 3 . . . . . 7-31

7-43 Simulated Breakthrough of DFBA for Well \#3 Alternative Calibration $4 \ldots \ldots \ldots$ 7-32

7-44 Simulated Breakthrough of DFBA for Well \#2 Alternative Calibration 4 . . . . . . 7-32

7-45 Simulated Breakthrough of DFBA for Well \#1 Alternative Calibration 4 . . . . . . 7-33

7-46 Simulated Breakthrough of DFBA for Well \#3 Alternative Calibration 5 . . . . . . 7-34

7-47 Simulated Breakthrough of DFBA for Well \#3 Alternative Calibration $6 \ldots \ldots$. . 7-34

7-48 Simulated Breakthrough of DFBA for Well \#2 Alternative Calibration $6 \ldots \ldots$. . 7-35

7-49 Simulated Breakthrough of DFBA for Well \#1 Alternative Calibration $6 \ldots \ldots$. 7-35

7-50 Pumping and Drawdown Records for Well \#3 . . . . . . . . . . . . . . . . . . 7-37

7-51 Yellow Microsphere Concentrations for Well \#3 Versus the

Drawdown Record ......................................... 7-37

7-52 Red Microsphere Concentrations for Well \#3 Versus the

Drawdown Record .................................... 7-38

A-1 Location of BULLION Geologic Model Cross Sections.................. A-3

A-2 BULLION Geologic Model Cross-Section, North-South ................ A-4

A-3 BULLION Geologic M odel Cross-Section, East-West ................. A-5

A-4 BULLION Geologic M odel Cross-Section, Southwest-Northeast . . . . . . . . . . A-6

A-5 BULLION Geologic M odel Cross-Section, Southeast-N orthwest . . . . . . . . . . A-7

A-6 BULLION Geologic M odel Cross-Section, Southwest-N ortheast Well Cluster ... A A-8

A-7 Top of Layer 1 for BULLION FGE Model. .................... A-9 
Number

Title

Page

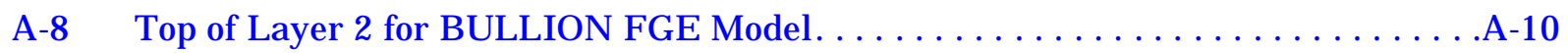

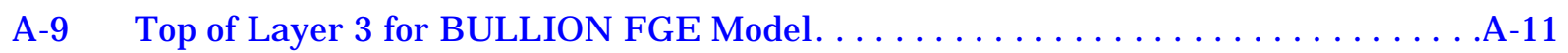

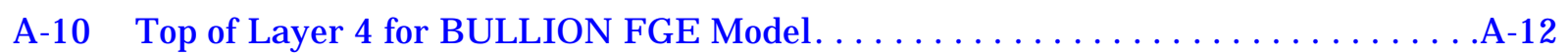

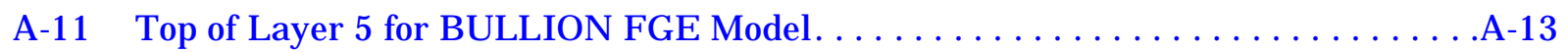

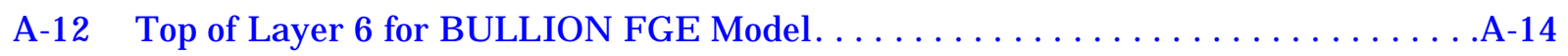

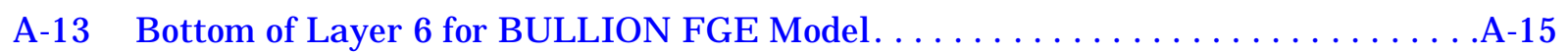

A-14 Detail of the Downhole and Surface Locations of the Wells . . . . . . . . . . . A-16

A-15 Hydraulic Conductivity Zone for Model Layer $1 \ldots \ldots \ldots \ldots$. . . . . . . . . A-17

A-16 Hydraulic Conductivity Zone for Model Layer $2 \ldots \ldots \ldots \ldots \ldots$. . . . . . . . . . . A-18

A-17 Hydraulic Conductivity Zone for Model Layer 3 . . . . . . . . . . . . . . . . . . . . . . A-19

A-18 Hydraulic Conductivity Zone for Model Layer 4, Large Scale Features. . . . . . . . . A-20

A-19 Detail of the Hydraulic Conductivity Zones in Layer 4 Around

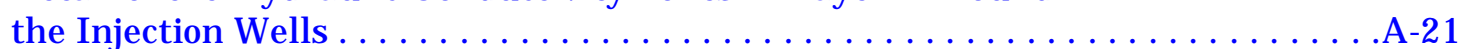

A-20 Detail of the Hydraulic Conductivity Zones in Model Layer $6 \ldots \ldots \ldots \ldots \ldots$. . . A-22

A-21 Hydraulic Conductivity Zones for Model Layer $6 \ldots \ldots \ldots \ldots \ldots \ldots \ldots \ldots \ldots$. . . . . . . . . . 


\section{List of Tables}

Number

Title

Page

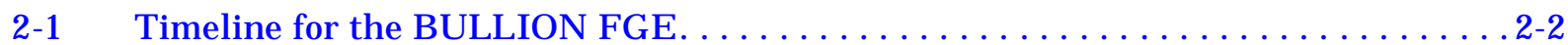

2-2 Pumping Schedule for the BULLION FGE $\ldots \ldots \ldots \ldots \ldots \ldots \ldots \ldots \ldots \ldots$

2-3 Comparison of Predicted and Observed Tracer Breakthroughs . . . . . . . . . . . 2-12

3-1 Strontium-90 Isotope Analysis Results $(\mathrm{pCi} / \mathrm{L}) \ldots \ldots \ldots \ldots \ldots \ldots \ldots \ldots$. . . . . . . . . .

3-2 Baseline Chemistry of Samples Taken J une 2, $1997 \ldots \ldots \ldots \ldots$. . . . . . . . . . . . . . 3-12

3-3 General Chemistry Results of Well ER-20-6 \#1 Water . . . . . . . . . . . . . . . . . 3-14

3-4 General Chemistry Results of Well ER-20-6 \#2 Water . . . . . . . . . . . . . . . 3-15

3-5 General Chemistry Results of Well ER-20-6 \#3 Water . . . . . . . . . . . . 3-16

3-6 Groundwater Characterization Results of Well ER-20-6 Water . . . . . . . . . . . 3-18

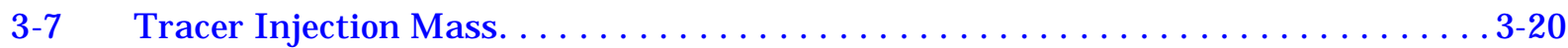

3-8 Tracer I njectate Concentrations (micrograms per liter) $\ldots \ldots \ldots \ldots \ldots \ldots \ldots \ldots$. $\ldots \ldots$

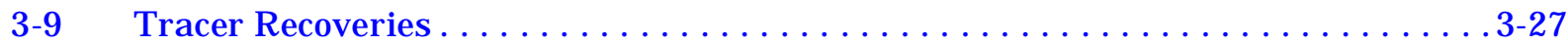

4-1 ER-20-6 Hydraulic Parameter Values. . . . . . . . . . . . . . . . . . . . . . . . . 4-3

5-1 Estimates of Effective Porosity Based on Time to Peak Concentration in Well \#3 of PFBA from Well \#2 and DFBA from Well \#1 . . . . . . . . . . . 5-2

5-2 Parameters for the Application of the Semi-Analytical Method

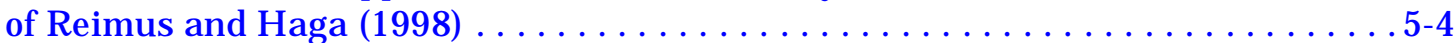

6-1 Stratigraphic, Lithologic, and Hydrogeologic Units for the ER-20-6 Cross Section . . . . . . . . . . . . . . . . . . . . . . . .

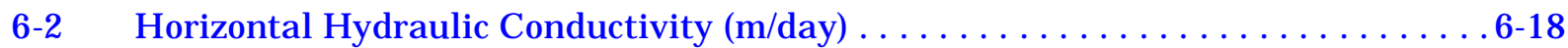

6-3 Stress Periods Used for Modeling the BULLION FGE $\ldots \ldots \ldots \ldots \ldots \ldots \ldots \ldots 6-22$

7-1 Transport Parameter Values Determined via Calibration of the BULLION FGE Model . . . . . . . . . . . . . . . . . . .

7-2 Parameters of the Alternative Calibrations for Transport from Well \#1 and Well \#3 ...........................

8-1 Transport Parameter Values Determined via Calibration of the BULLION FGE Model ............................... 8-3 


\section{List of Acronyms and Abbreviations}

\begin{tabular}{|c|c|}
\hline $\mathrm{BN}$ & Bechtel Nevada \\
\hline $\mathrm{cm}$ & Centimeter(s) \\
\hline $\mathrm{CH}_{3} \mathrm{CN}$ & Acetonitrile \\
\hline DOE & U.S. Department of Energy \\
\hline DFBA & Difluorobenzoic acid \\
\hline DRI & Desert Research Institute \\
\hline FGE & Forced-gradient experiment \\
\hline$g$ & Gram(s) \\
\hline GHB & General head boundary \\
\hline gpm & Gallon(s) per minute \\
\hline $\mathrm{HRC}$ & Harry Reid Center \\
\hline HPLC & High Performance Liquid Chromatography \\
\hline FMP & Fluid Management Plan \\
\hline HSU & Hydrostratigraphic unit(s) \\
\hline$I^{-}$ & Iodide \\
\hline IT & IT Corporation \\
\hline $\mathrm{kg}$ & Kilogram(s) \\
\hline $\mathrm{KH}_{2} \mathrm{PO}_{4}$ & Potassium Phosphate \\
\hline $\mathrm{L}$ & Liter(s) \\
\hline LANL & Los Alamos National Laboratory \\
\hline LLNL & Lawrence Livermore National Laboratory \\
\hline $\mathrm{m}$ & Meter(s) \\
\hline M & Molar \\
\hline $\mathrm{m} / \mathrm{d}$ & Meter(s) per day \\
\hline $\mathrm{m}^{2} / \mathrm{d}$ & Square meter(s) per day \\
\hline $\mathrm{m}^{3} / \mathrm{d}$ & Cubic meter(s) per day \\
\hline $\mathrm{mg} / \mathrm{L}$ & Milligram(s) per liter \\
\hline $\mathrm{mL}$ & Milliliter(s) \\
\hline $\mathrm{mm} / \mathrm{yr}$ & Millimeter(s) per year \\
\hline Mohm & Mega-ohm \\
\hline
\end{tabular}




\section{List of Acronyms and Abbreviations (Continued)}

$\begin{array}{ll}\text { NA } & \text { Not applicable } \\ \text { NaOH } & \text { Sodium hydroxide } \\ \text { NIST } & \text { National Institute of Standards and Technology } \\ \text { pCi/L } & \text { Picocurie(s) per liter } \\ \text { PFBA } & \text { Pentafluorobenzoic acid } \\ \text { RPM } & \text { Revolution(s) per minute } \\ \text { TCN } & \text { Technical Change N otice } \\ \text { TWG } & \text { Technical Working Group } \\ \text { UGTA } & \text { Underground Test Area } \\ \text { VSD } & \text { Variable speed drive } \\ \mu \mathrm{g} / \mathrm{L} & \text { Microgram(s) per liter } \\ \mu \mathrm{L} & \text { Microliter(s) } \\ \mu \mathrm{m} & \text { Micrometer(s) } \\ \mu \mathrm{mhos} / \mathrm{cm} & \text { Micromhos per centimeter }\end{array}$


Measurement Conversions Table

\begin{tabular}{|l||}
\hline $\mathrm{m}^{3} / \mathrm{d} \times 5.450993=\mathrm{gpm}$ \\
\hline $\mathrm{m} \times 3.280840=\mathrm{ft}$ \\
\hline $\mathrm{m}^{2} / \mathrm{d} \times 1.076391 \mathrm{E} 1=\mathrm{ft}^{2} / \mathrm{d}$ \\
\hline $\mathrm{m} / \mathrm{d} \times 3.280840=\mathrm{ft} / \mathrm{d}$ \\
\hline liter $\times 2.641720 \mathrm{E}-1=\mathrm{gallons}$ \\
\hline $\mathrm{cm}^{2} / \mathrm{sec} \times 9.342928 \mathrm{E} 1=\mathrm{ft}^{2} / \mathrm{d}$ \\
\hline $\mathrm{kg} \times 2.204622=\mathrm{lbs}$ \\
\hline Source: ASTM, 1985 \\
\hline
\end{tabular}




\subsection{Introduction}

The BULLION Forced-Gradient Experiment (FGE) was conducted in the summer of 1997, starting J une 2 and ending August 28. The site of the experiment was the ER-20-6 well field adjacent to the BULLION test. Figure 1-1 shows the location of this site on Pahute Mesa in Area 20 of the Nevada Test Site. Figure 1-2 shows the ER-20-6 site within the Pahute Mesa hydrogeologic framework, and Figure 1-3 shows the site layout with respect to the BULLION test.

\subsection{Purpose and Objectives}

The purpose of the BULLION FGE was to provide information relevant to the transport of radionuclides in groundwater. Transport of radionuclides from Pahute $M$ esa is of special concern due to the potential for rapid movement of groundwater in the fractured volcanic rocks comprising the Mesa and formations al ong the anticipated downgradient path of groundwater. The objective was specifically to observe the transport process and characterize transport parameters (e.g., effective porosity, dispersivity and matrix diffusion) for use in predictive modeling of contaminant transport. Additional objectives were to characterize the hydrologic source term and the relative mobility of mobile radionuclides.

\subsection{Concept and Design}

This experiment was designed to use tracer migration in groundwater to provide information on transport parameters. Both solute and particulate (microspheres) tracers were employed to simulate dissolved and colloidal transport of radionuclides. A set of three wells was installed into a vol canic aquifer, primarily fractured lava, in alignment with the orientation of the major fracture system. This system of wells was located nearby, downgradient of the BULLION nuclear test; hence, the name of the experiment. The well furthest downgradient was pumped at a rate sufficient to create an artificial gradient toward this well exceeding the natural gradient, thereby controlling flow in the aquifer. Tracers were injected into the other two wells, and tracer breakthrough curves were captured for the three different flowpath segments. Radionuclides originating from the BULLION test were also expected to serve as tracers, and the analysis of groundwater samples 


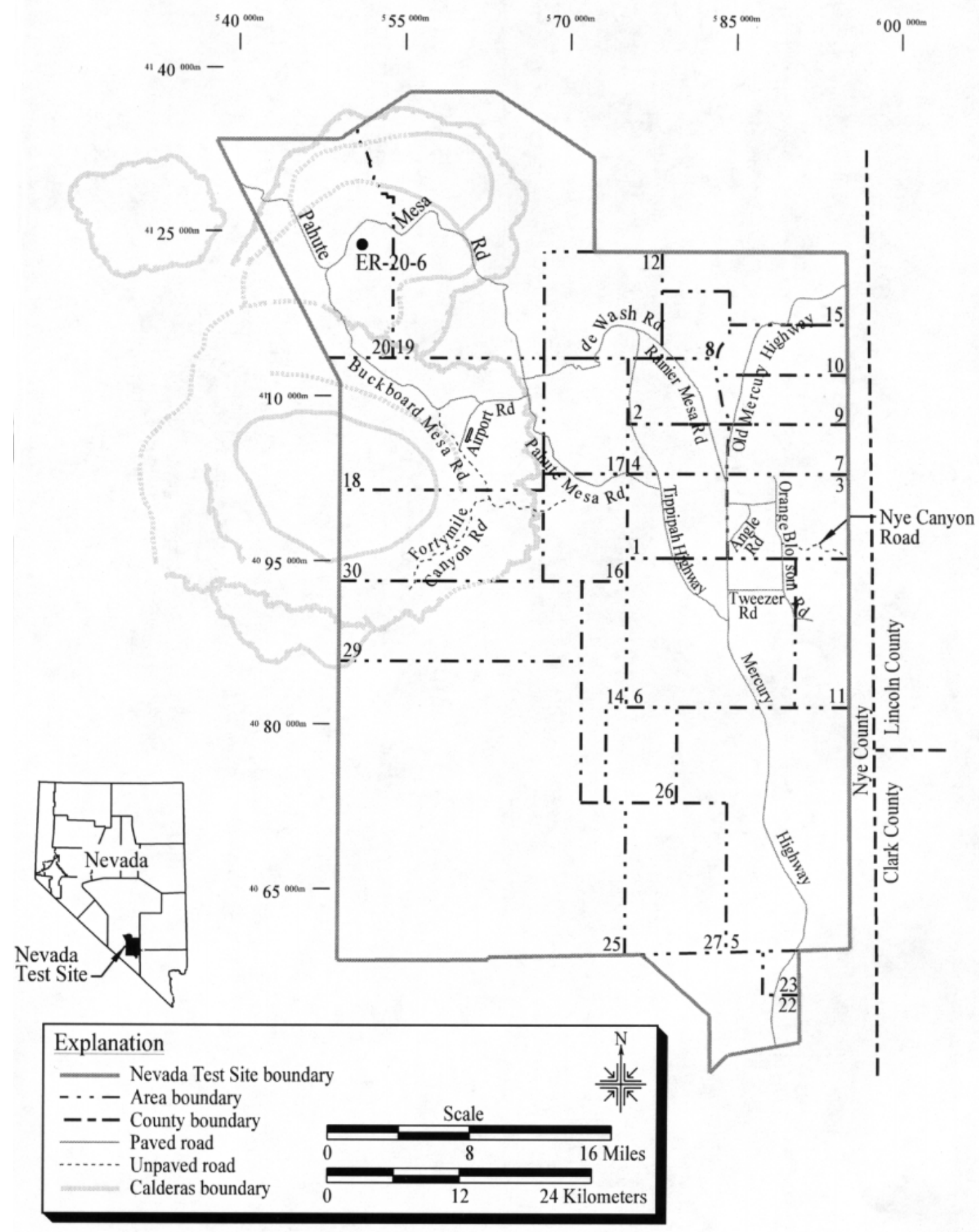

Figure 1-1

Location of Well ER-20-6 Site on Pahute Mesa, Nevada Test Site 


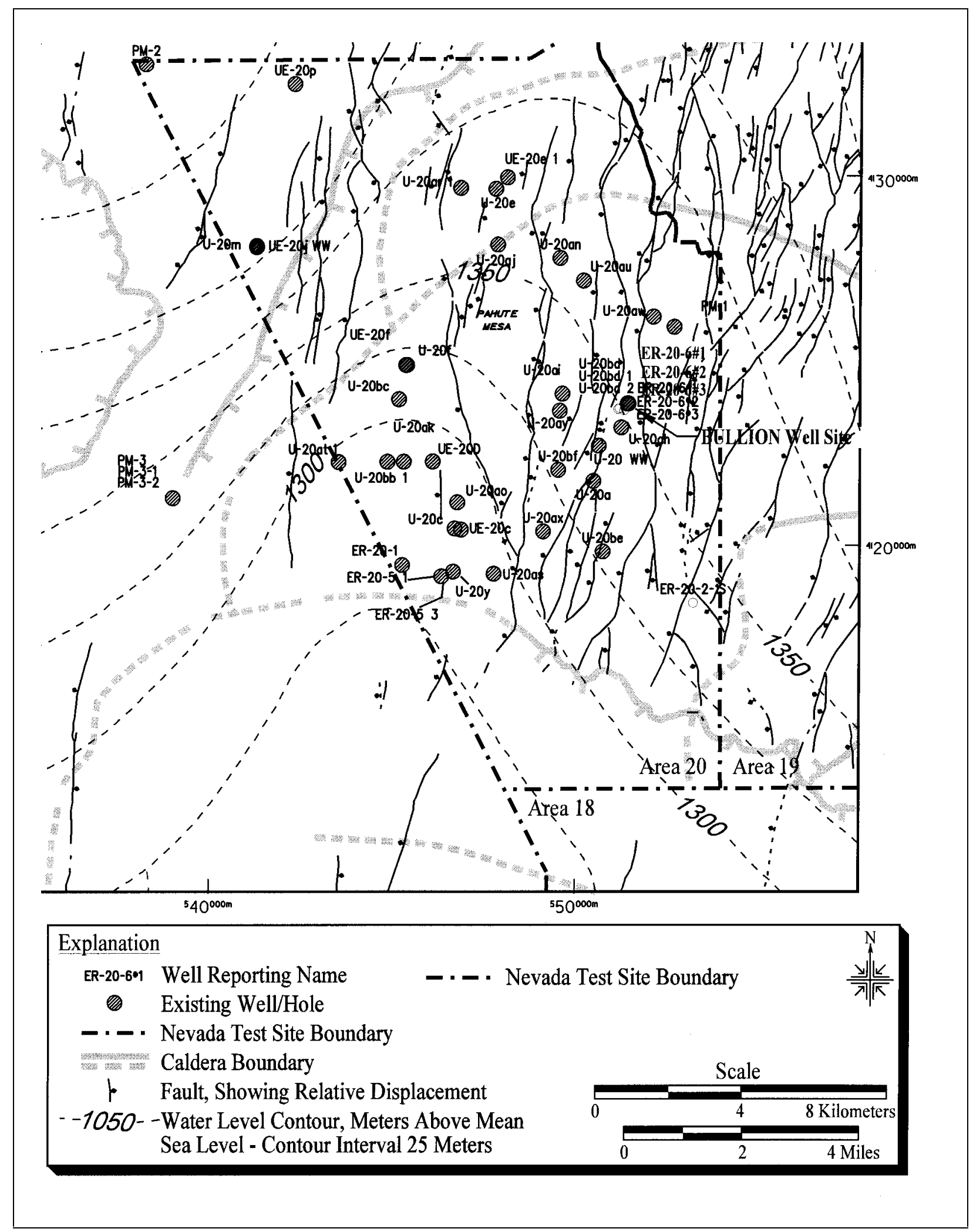

Figure 1-2

Hydrogeologic Setting for the BULLION FGE 

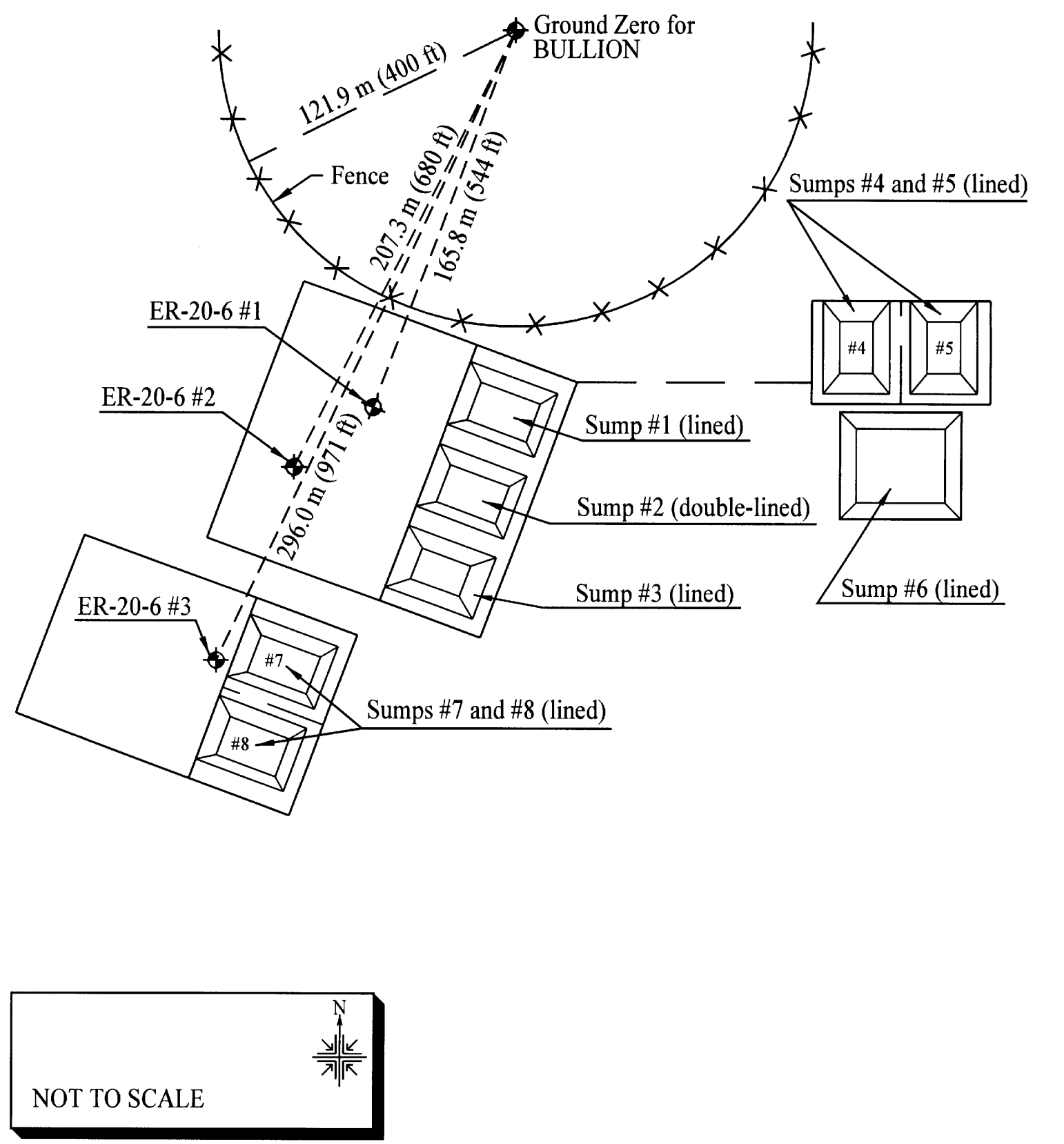

Figure 1-3

Well ER-20-6 Site Configuration 
was expected to provide information on the mobile-radionuclide source-term from BULLION.

The concept is illustrated in Figure 1-4, which shows the arrangement of wells installed for the experiment and their relationship to the BULLION test, the local groundwater gradient, and the major fracture system orientation. Tracer migration is illustrated as a series of closed bounding-concentration contours al ong the two distinct flowpaths, showing the idealized movement of the tracer mass with time. Well ER-20-6 \#3 was pumped at an average rate of 632.32 cubic meters per day $\left(\mathrm{m}^{3} /\right.$ day) during the experiment to create a strong gradient from Wells ER-20-6 \#1 and \#2 to ER-20-6 \#3. Tracers were injected into Wells ER-20-6 \#1 and \#2, and the breakthrough curves of these tracers in Wells ER-20-6 \#2 and \#3 were characterized with time-series sampling. A complete explanation of the design, and details of the geology, wells and experiment procedure can be found in the supporting documents Criteria for the F orced-Gradient Experiment at the BULLION Event Location (IT, 1996), BULLION Forced-Gradient Experiment I mplementation PIan (IT, 1997), and Completion Report for Well Cluster ER-20-6 (DOE/NV, 1998).

\subsection{History and Development}

The BULLION FGE was proposed by the Underground Test Area (UGTA) Technical Working Group (TWG). The Well ER-20-6 site, located adjacent to the BULLION test, was selected for the experiment based on selection criteria related to the orientation of the fracture system and local groundwater gradient as well as the age of the test. The intent was to locate a site where transport of radionuclides from the test cavity would not have advanced a great distance, and the imposed gradient would simply increase the rate of transport along the natural transport path. The ER-20-6 wells were drilled in the winter and spring of 1996. Following completion of the E R-20-6 wells and analysis of the geology at the site, detailed design of the experiment was began in the summer of 1996. A BULLION FGE Working Group was formed under the auspices of the UGTA TWG, including representatives from HSI GeoTrans, IT Corporation (IT), Bechtel Nevada (BN), the Desert Research I nstitute (DRI), Los Alamos National Laboratory (LANL), Lawrence Livermore National Laboratory (LLNL), and the Harry Reid Center (HRC) for Environmental Research at the University of Nevada. Based on the specifications devel oped by the working group, an implementation plan was issued in May 1997.

The experiment began J une 2,1997 , and was initially scheduled to end J uly 2, 1997. The experiment was extended until August 28, 1997, to accommodate the observed sl ower-than-predicted pace of tracer breakthrough, and the rate of data collection was proportionately reduced. Analysis of tracer samples, water chemistry, and 


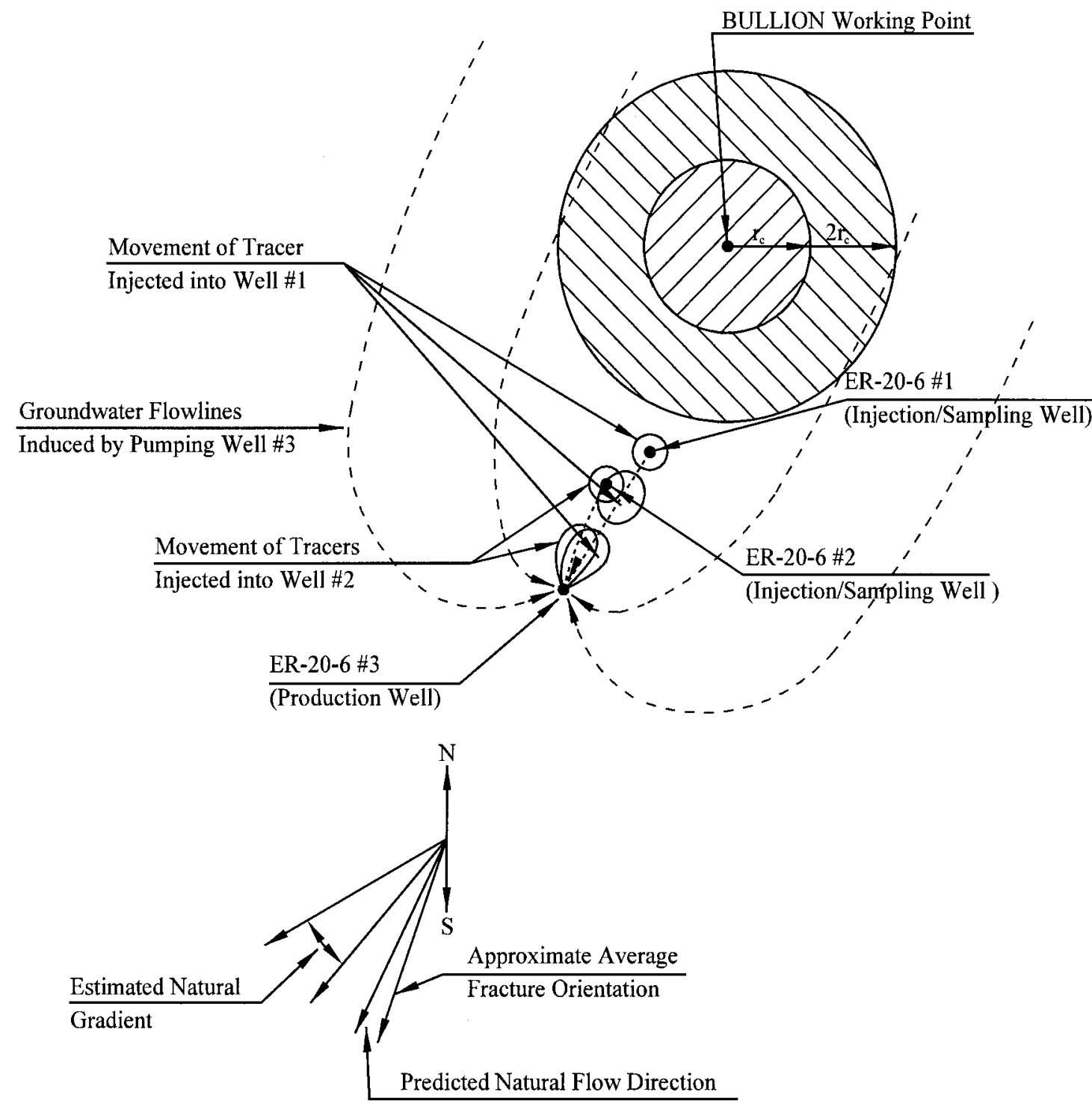

Explanation
$\mathbf{r}_{\mathbf{c}}=$ Cavity Radius

Not to Scale

Figure 1-4

Schematic of the BULLION Forced-Gradient Experiment 
radiochemistry samples continued through the fall of 1997, and analysis of the experiment data was conducted in the winter and spring 1998.

\subsection{Participants}

The field implementation of the BULLION FGE was a cooperative effort of IT, BN, DRI, LANL, and LLNL, with assistance from HRC. IT personnel led the technical implementation and staffing of the experiment, and BN provided and maintained the field facilities and major power equipment, as well as radiologic monitoring. The other organizations contributed both manpower and specialized expertise and capabilities for analysis. In particular, LANL provided equipment and staff for field analysis of microsphere concentrations, as well as follow-on laboratory analysis of microsphere concentrations. DRI supplied equipment and staff for the downhole discreet sampling of wells. LLNL and DRI provided various radiochemical analyses.

\subsection{Report Organization}

The following sections present a summary of how the experiment was conducted (Section 2.0), presentation of the data collected (Section 3.0), analysis of the data (Section 4.0 through Section 7.0), and conclusions (Section 8.0). 


\section{This Page Intentionally Left Blank}




\subsection{Experiment Implementation}

The activity schedule, technical changes, problems encountered, and the results of the experiment are discussed in this section.

The BULLION FGE was initially implemented according to the specifications in the BULLION Forced-Gradient Experiment I mplementation PIan (IT, 1997), with minor adjustments in the schedules of activities. The experiment was extended to a total duration of 87 days to accommodate slower-than-predicted breakthrough of the tracers, and an adjusted schedule of sampling and analysis was instituted.

\subsection{Activity Schedules}

Table 2-1 presents the timeline of major activities during the experiment. Table 2-2 contains the complete pumping schedule for all three wells and also shows the tracer injection times for Wells ER-20-6 \#1 and \#2.

The pumping schedule conforms closely to the original implementation plan during the originally scheduled duration, except for short interruptions in pumping. These interruptions accommodated maintenance and repair of the generator used to power the pumps and the site facilities. Likewise, the sampling schedule conforms closely to the original plan for the originally scheduled duration, with major modifications starting toward the end of that period as the nature of the tracer response became evident. The experiment duration was then extended with some variation in the pumping scheme for Wells ER-20-6 \#1 and \#2. Technical Change Notices (TCNs) were issued for all significant changes to specifications in the implementation plan, which was a controlled document. 
Table 2-1

Timeline for the BULLION FGE

(Page 1 of 3 )

\begin{tabular}{|c|c|c|}
\hline Date & Day \# & Description of Activities \\
\hline $6 / 2$ & 1 & $\begin{array}{l}\text { - Begin the experiment: start Well \#3 pump at } 1200 \text { hours. } \\
\text { - Begin tritium and lead sampling at } 1217 \text { hours: sampling for tritium hourly, and for } \\
\text { lead every } 8 \text { hours. } \\
\text { - Start Well \#2 pump at } 1800 \text {; water at surface at } 1815 \text {. }\end{array}$ \\
\hline $6 / 3$ & 2 & $\begin{array}{l}\text { - Start Well \#1 pump; water at surface in } 6 \text { minutes. } \\
\text { - Collect baseline samples for Well \#2 and shut down pump. } \\
\text { - Collect baseline discrete bailer samples from Well \#2 } \\
\text { - Collect baseline discrete bailer samples from Well \#1 } \\
\text { - Collect baseline sample from Well \#1 and shut down pump. } \\
\text { - Begin tracer injection into Well \#2 at } 1720 \text {; completed at } 2245.23 .58 \mathrm{~m}^{3} \text { injected } \\
\text { over } 5 \text { hrs and } 25 \text { minutes at an average rate of } 104.39 \mathrm{~m}^{3} / \mathrm{d} \\
\text { - Begin tracer sampling from Well \#3 at the same time as tracer injection into } \\
\text { Well \#2; sampling every half hour. } \\
\text { - Collect Well \#2 discrete bailer samples immediately after completing tracer } \\
\text { injection. }\end{array}$ \\
\hline $6 / 4$ & 3 & $\begin{array}{l}\text { - Change Well \#3 tracer sampling to hourly intervals. } \\
\text { - } \mathrm{TCN}^{*} \text { No. } 1 \text { : change schedule for Well \#1 tracer injection to day shift on 6/6/97. } \\
\text { - Collect discrete bailer samples from Well \#2 }\end{array}$ \\
\hline $6 / 5$ & 4 & $\begin{array}{l}\text { - Start Well \#1 pump, collect tracer sample for tritium and gamma analysis, shut } \\
\text { down pump. }\end{array}$ \\
\hline $6 / 6$ & 5 & $\begin{array}{l}\text { - Collect discrete bailer samples from Well \#2. } \\
\text { - Begin tracer injection into Well \#1 at } 1107 \text { hours. } \\
\text { - Start Well \#2 pump at } 1117 \text {. } \\
\text { - Begin sampling Well \#2 every } 15 \text { minutes at } 1345 \text { hours. } \\
\text { - Complete Well \#1 tracer injection at } 1615 \text { hours. } 23.17 \mathrm{~m}^{3} \text { injected over } 5 \text { hours } \\
8 \text { minutes at an average rate of } 111.20 \mathrm{~m}^{3} / \mathrm{d} \text {. } \\
\text { - Change Well \#3 tracer sampling to every other hour. } \\
\text { - Collect discrete bailer samples from well \#1. }\end{array}$ \\
\hline $6 / 7$ & 6 & $\begin{array}{l}\text { - Change Well \#2 tracer sampling to every half hour at } 0145 \text {. Well \#3 tracer } \\
\text { sampling every other hour. } \\
\text { - Collect an extra discrete bailer sample from the bottom of the lower zone in } \\
\text { Well \#2. } \\
\text { - Change Well \#2 to hourly tracer sampling at } 1345 \text {. } \\
\text { - Collect discrete bailer samples from Well \#1. }\end{array}$ \\
\hline $6 / 8$ & 7 & $\begin{array}{l}\text { - Start Well \#1 pump. } \\
\text { - Collect discrete bailer samples from Well \#2. } \\
\text { - Start Well \#1 tracer sampling at } 1345 \text { hours; samples collected at } 15 \text { minute } \\
\text { intervals. } \\
\text { - At } 1730 \text { hours, switch Well \#2 to hourly tracer sampling, and Well \#3 to sampling } \\
\text { every } 4 \text { hours. } \\
\text { - Collect discrete bailer samples from Well \#1. }\end{array}$ \\
\hline $6 / 9$ & 8 & $\begin{array}{l}\text { - Change Well \#1 tracer sampling to every half hour. } \\
\text { - Change Well \#1 tracer sampling to hourly, and Well \#2 sampling to every other } \\
\text { hour. }\end{array}$ \\
\hline
\end{tabular}


Table 2-1

Timeline for the BULLION FGE

(Page 2 of 3 )

\begin{tabular}{|c|c|c|}
\hline Date & Day \# & Description of Activities \\
\hline $6 / 10$ & 9 & $\begin{array}{l}\text { - Collect discrete bailer samples from Well \#2 } \\
\text { - Collect radiological samples and general parameter samples. } \\
\text { - Collect discrete bailer samples from Well \#1 }\end{array}$ \\
\hline $6 / 11$ & 10 & $\begin{array}{l}\text { - Change Well \#1 tracer sampling to every other hour, and Well \#2 sampling to } \\
\text { every } 4 \text { hours. }\end{array}$ \\
\hline $6 / 12$ & 11 & - Collect discrete bailer samples from Well \#2 and Well \#1. \\
\hline $6 / 13$ & 12 & $\begin{array}{l}\text { - Change Well \#1 tracer sampling to every } 4 \text { hours, and continue at every } 4 \text { hours } \\
\text { for well \#2 and well \#3. }\end{array}$ \\
\hline $6 / 16$ & 15 & - Collect discrete bailer samples from Well \#1 and Well \#2. \\
\hline $6 / 20$ & 19 & $\begin{array}{l}\text { - TCN No. } 2 \text { - Change tracer sampling interval for Wells \#1 and \#2 to every } 8 \text { hours. } \\
\text { Continued tracer sampling Well \#3 every } 4 \text { hours until 6/25/97, where the } \\
\text { frequency will become every } 8 \text { hours. } \\
\text { - TCN No. } 3 \text { - Suspend radioisotope sampling and gamma scan analysis until } \\
\text { tritium activity in Wells \#1 and \#2 exceed } 40,000 \mathrm{pCi} / \mathrm{L} \text { or tritium activity in } \\
\text { Well \#3 exceeds } 20,000 \mathrm{pCi} / \mathrm{L} \text {. } \\
\text { - Collect discrete bailer samples from Well \#1 and Well \#2. }\end{array}$ \\
\hline $6 / 23$ & 22 & $\begin{array}{l}\text { - TCN No. } 4 \text { - Collect samples from Well \#3 every } 4 \text { hours. Continue to collect } \\
\text { Tritium FMP** samples hourly and lead samples every } 8 \text { hours. Discontinue } \\
\text { on-site microsphere analysis. Water quality analysis is reduced to } \mathrm{pH} \text {, Eh, and } \\
\text { DO (Eh only to be performed only when } \mathrm{DO} \text { is }<2 \mathrm{mg} / \mathrm{L} \text { ). Tracer analysis rates } \\
\text { for Well \#1: } 1 / \text { day, for Well \#2: } 3 / \text { day, for Well \#3: } 3 / \text { day. }\end{array}$ \\
\hline $6 / 24$ & 23 & - Collect discrete bailer samples from Well \#1 and Well \#2. \\
\hline $7 / 1$ & 30 & $\begin{array}{l}\text { - TCN No. } 5 \text { - Duration of BULLION FGE will be indefinite. Starting 7/2, switch to } \\
\text { day shift only w/samples collected twice per day. Tracer analyses performed } \\
\text { twice or more per week. General water quality analyses to be performed three } \\
\text { more times evenly spaced over the remainder of the experiment. Two more } \\
\text { discrete bailer samples to be collected from Wells \#1 and \#2, evenly spaced over } \\
\text { the remainder of the experiment. FMP tritium and lead samples will be collected } \\
\text { once a day. }\end{array}$ \\
\hline $7 / 7$ & 36 & - Collect samples from Well \#1, Well \#2, and Well \#3. \\
\hline $7 / 10$ & 39 & $\begin{array}{l}\text { - TCN No. } 6 \text { - Well \#1 and Well \#2 will be turned off for periods of time during the } \\
\text { remainder of the experiment to perturb the flow system. During the off periods, } \\
\text { inactive wells will not be sampled. } \\
\text { - Well \#1 pump shut off. }\end{array}$ \\
\hline $7 / 13$ & 42 & - Collect samples from Well \#2 and Well \#3. \\
\hline $7 / 15$ & 44 & - Collect samples from Well \#2 and Well \#3. \\
\hline $7 / 16$ & 45 & - Start Well \#1 pump. \\
\hline $7 / 17$ & 46 & $\begin{array}{l}\text { - Collect characterization samples from Well \#2 and Well \#3. } \\
\text { - Collect samples from Well \#1, Well \#2 and Well \#3. Shut down Well \#1 and } \\
\text { Well \#2 pumps. }\end{array}$ \\
\hline $7 / 21$ & 50 & - Collect samples from Well \#3 \\
\hline $7 / 23$ & 52 & - Collect samples from Well \#3 \\
\hline $7 / 25$ & 54 & $\begin{array}{l}\text { - TCN No. } 7 \text { - Change the schedule for sampling to Monday, Wednesday, and } \\
\text { Friday of each week. } \\
\text { - Collect samples from Well \#3 }\end{array}$ \\
\hline $7 / 28$ & 57 & $\begin{array}{l}\text { - Start Well \#1 and Well \#2 pumps. Collect samples from Well \#1, Well \#2, and } \\
\text { Well \#3. }\end{array}$ \\
\hline $7 / 30$ & 59 & $\begin{array}{l}\text { - Collect discrete bailer samples from Well \#1 and Well \#2. } \\
\text { - Collect samples from Well \#1, Well \#2, and Well \#3. }\end{array}$ \\
\hline $8 / 1$ & 61 & - Collect samples from Well \#1, Well \#2, and Well \#3. \\
\hline $8 / 6$ & 66 & - Collect samples from Well \#1, Well \#2, and Well \#3. \\
\hline
\end{tabular}


Table 2-1

Timeline for the BULLION FGE

(Page 3 of 3 )

\begin{tabular}{|c|c|l||}
\hline Date & Day \# & \\
\hline \hline $8 / 7$ & 67 & $\cdot$ Shut down Well \#1 and Well \#2 pumps. \\
\hline $8 / 8$ & 68 & $\cdot$ Collect samples from Well \#3 \\
\hline $8 / 11$ & 71 & $\cdot$ Collect samples from Well \#3 \\
\hline $8 / 13$ & 73 & $\cdot$ Collect samples from Well \#3 \\
\hline $8 / 15$ & 75 & $\cdot$ Collect samples from Well \#3 \\
\hline $8 / 18$ & 78 & $\begin{array}{l}\cdot \text { Start Well \#1 and Well \#2 pumps. } \\
\text { Collect samples from Well \#3 }\end{array}$ \\
\hline $8 / 20$ & 80 & $\cdot$ Collect samples from Wells \#1, \#2, and \#3 \\
\hline $8 / 22$ & 82 & $\cdot$ Collect samples from Wells \#1, \#2, and \#3 \\
\hline $8 / 25$ & 85 & $\cdot$ Collect samples from Wells \#1, \#2, and \#3 \\
\hline $8 / 27$ & 87 & $\begin{array}{l}\cdot \text { Collect samples from Wells \#1, \#2, and \#3 } \\
\text { Collect characterization sample from Well \#1 }\end{array}$ \\
\hline $8 / 28$ & 88 & $\begin{array}{l}\cdot \text { Shut down Well \#1 and Well \#2 pumps. } \\
\text { Shut down Well \#3 pump. End of experiment. }\end{array}$ \\
\hline $9 / 2$ & 93 & $\cdot$ Stop data collection from pressure transducers \\
\hline
\end{tabular}

* TCN - Technical Change Notice

${ }^{\star *}$ FMP - Fluid Management Plan

$\mathrm{m}^{3}$ - Cubic meters

$\mathrm{m}^{3} / \mathrm{d}$ - Cubic meters per day

DO - Dissolved Oxygen

Table 2-2

Pumping Schedule for the BULLION FGE

(Page 1 of 3 )

\begin{tabular}{|c|c|c|c|c|c|c|c|}
\hline Date & $\begin{array}{c}\text { Julian } \\
\text { Day }\end{array}$ & $\mathrm{Hr} / \mathrm{Min}$ & $\begin{array}{l}\text { Julian } \\
\text { Time }\end{array}$ & $\begin{array}{c}\text { Elapsed } \\
\text { Time } \\
\text { (days) }\end{array}$ & Activity & Parameters & $\begin{array}{c}\text { Rate } \\
\left(\mathrm{m}^{3} / \mathrm{d}\right)^{*}\end{array}$ \\
\hline $6 / 2$ & 153 & $12: 04$ & 153.5028 & 0.0000 & start well \#3 & long-term average & 632.32 \\
\hline $6 / 2$ & 153 & $18: 01$ & 153.7507 & 0.2479 & start well \#2 & $472 \mathrm{rpm}$ & 130.82 \\
\hline $6 / 2$ & 153 & $19: 40$ & 153.8194 & 0.3167 & reduce rate \#2 & $220 \mathrm{rpm}$ & 44.15 \\
\hline $6 / 2$ & 153 & $20: 29$ & 153.8535 & 0.3507 & reduce rate \#2 & $174 \mathrm{rpm}$ & 28.35 \\
\hline $6 / 3$ & 154 & $0: 04$ & 154.0028 & 0.5000 & start well \#1 & $400 \mathrm{rpm}$ & 106.29 \\
\hline $6 / 3$ & 154 & $1: 11$ & 154.0493 & 0.5465 & reduce rate \#1 & $200 \mathrm{rpm}$ & 37.61 \\
\hline $6 / 3$ & 154 & $2: 32$ & 154.1056 & 0.6028 & reduce rate $\# 1$ & $159 \mathrm{rpm}$ & 23.44 \\
\hline $6 / 3$ & 154 & $5: 10$ & 154.2153 & 0.7125 & stop \#2 & & 0.00 \\
\hline $6 / 3$ & 154 & $11: 45$ & 154.4896 & 0.9868 & stop \#1 & & 0.00 \\
\hline $6 / 3$ & 154 & $17: 20$ & 154.7222 & 1.2194 & start injection into \#2 & average rate & 104.66 \\
\hline $6 / 3$ & 154 & $22: 45$ & 154.9479 & 1.4451 & finish injection into \#2 & $6230 \mathrm{gal}$ injected & 0.00 \\
\hline $6 / 5$ & 156 & $8: 00$ & 156.3333 & 2.8306 & start \#1 & $160 \mathrm{rpm}$ & 23.98 \\
\hline $6 / 5$ & 156 & $13: 00$ & 156.5417 & 3.0389 & stop \#1 & & 0.00 \\
\hline $6 / 6$ & 157 & 11:07 & 157.4632 & 3.9604 & start injection into \#1 & average rate & 108.47 \\
\hline $6 / 6$ & 157 & $12: 38$ & 157.5264 & 4.0236 & start \#2 & $184 \mathrm{rpm}$ & 32.16 \\
\hline $6 / 6$ & 157 & $13: 18$ & 157.5542 & 4.0514 & increase rate \#2 & $220 \mathrm{rpm}$ & 44.15 \\
\hline
\end{tabular}


Table 2-2

Pumping Schedule for the BULLION FGE

(Page 2 of 3 )

\begin{tabular}{|c|c|c|c|c|c|c|c|}
\hline Date & $\begin{array}{c}\text { Julian } \\
\text { Day }\end{array}$ & $\mathrm{Hr} / \mathrm{Min}$ & $\begin{array}{l}\text { Julian } \\
\text { Time }\end{array}$ & $\begin{array}{c}\text { Elapsed } \\
\text { Time } \\
\text { (days) }\end{array}$ & Activity & Parameters & $\begin{array}{c}\text { Rate } \\
\left(\mathrm{m}^{3} / \mathrm{d}\right)^{*}\end{array}$ \\
\hline $6 / 6$ & 157 & $14: 13$ & 157.5924 & 4.0896 & reduce rate $\# 2$ & $205 \mathrm{rpm}$ & 39.25 \\
\hline $6 / 6$ & 157 & $15: 26$ & 157.6431 & 4.1403 & reduce rate \#2 & $171 \mathrm{rpm}$ & 27.25 \\
\hline $6 / 6$ & 157 & $16: 15$ & 157.6771 & 4.1743 & finish injection into \#1 & 6120 gal injected & 0.00 \\
\hline $6 / 8$ & 159 & $11: 17$ & 159.4701 & 5.9674 & start \#1 & $160 \mathrm{rpm}$ & 23.98 \\
\hline $6 / 8$ & 159 & $12: 38$ & 159.5264 & 6.0236 & $\# 1$ rate reduced & eratic rate, $54 \mathrm{rpm}$ ave & 0.00 \\
\hline $6 / 8$ & 159 & $15: 15$ & 159.6354 & 6.1326 & $\# 1$ rate increased & $158 \mathrm{rpm}$ & 22.89 \\
\hline $6 / 13$ & 164 & $5: 44$ & 164.2389 & 10.7361 & pump \#1,2,3 off & generator problem & 0.00 \\
\hline $6 / 13$ & 164 & $5: 56$ & 164.2472 & 10.7444 & pump \#3 on & long-term average & 632.32 \\
\hline $6 / 13$ & 164 & $5: 59$ & 164.2493 & 10.7465 & pump \#1 on & $175 \mathrm{rpm}$ & 28.89 \\
\hline $6 / 13$ & 164 & $5: 59$ & 164.2493 & 10.7465 & pump \#2 on & $175 \mathrm{rpm}$ & 28.89 \\
\hline $6 / 13$ & 164 & $15: 36$ & 164.6500 & 11.1472 & pump \#1,2,3 off & generator problem & 0.00 \\
\hline $6 / 13$ & 164 & $15: 44$ & 164.6556 & 11.1528 & pump \#1 on & $174 \mathrm{rpm}$ & 28.35 \\
\hline $6 / 13$ & 164 & $15: 44$ & 164.6556 & 11.1528 & pump \#2 on & $175 \mathrm{rpm}$ & 28.89 \\
\hline $6 / 13$ & 164 & $15: 44$ & 164.6556 & 11.1528 & pump \#3 on & long-term average & 632.32 \\
\hline $6 / 17$ & 168 & $17: 25$ & 168.7257 & 15.2229 & pump \#3 off & generator problem & 0.00 \\
\hline $6 / 17$ & 168 & $17: 30$ & 168.7292 & 15.2264 & pump \#3 on & long-term average & 632.32 \\
\hline $6 / 23$ & 174 & $10: 35$ & 174.4410 & 20.9382 & pump \#1,2,3 off & generator changeout & 0.00 \\
\hline $6 / 23$ & 174 & $10: 50$ & 174.4514 & 20.9486 & pump \#1 on & $173 \mathrm{rpm}$ & 28.35 \\
\hline $6 / 23$ & 174 & $10: 50$ & 174.4514 & 20.9486 & pump \#2 on & $174 \mathrm{rpm}$ & 28.35 \\
\hline $6 / 23$ & 174 & $10: 50$ & 174.4514 & 20.9486 & pump \#3 on & long-term average & 632.32 \\
\hline $6 / 23$ & 174 & $15: 20$ & 174.6389 & 21.1361 & pump \#3 off & VSD shutdown & 0.00 \\
\hline $6 / 23$ & 174 & $15: 22$ & 174.6403 & 21.1375 & pump \#3 on & long-term average & 632.32 \\
\hline $6 / 23$ & 174 & $16: 55$ & 174.7049 & 21.2021 & pump \#3 off & generator problem & 0.00 \\
\hline $6 / 23$ & 174 & $17: 05$ & 174.7118 & 21.2090 & pump \#3 on & long-term average & 632.32 \\
\hline $6 / 23$ & 174 & $18: 00$ & 174.7500 & 21.2472 & pump \#1,2 off & generator problem & 0.00 \\
\hline $6 / 23$ & 174 & $18: 40$ & 174.7778 & 21.2750 & pump \#1 on & $174 \mathrm{rpm}$ & 28.35 \\
\hline $6 / 23$ & 174 & $18: 40$ & 174.7778 & 21.2750 & pump \#2 on & $175 \mathrm{rpm}$ & 28.89 \\
\hline $7 / 2$ & 183 & $8: 40$ & 183.3611 & 29.6104 & pump \#1,2,3 off & generator problem & 0.00 \\
\hline $7 / 2$ & 183 & 9:55 & 183.4132 & 29.6625 & pump \#3 on & long-term average & 632.32 \\
\hline $7 / 2$ & 183 & $9: 55$ & 183.4132 & 29.6625 & pump \#1 on & $171 \mathrm{rpm}$ & 27.25 \\
\hline $7 / 2$ & 183 & $9: 55$ & 183.4132 & 29.6625 & pump \#2 on & $173 \mathrm{rpm}$ & 28.35 \\
\hline $7 / 3$ & 184 & 13:35 & 184.5660 & 31.0632 & pump \#1,2,3 off & generator changeout & 0.00 \\
\hline $7 / 3$ & 184 & $13: 40$ & 184.5694 & 31.0667 & pump \#1 on & $171 \mathrm{rpm}$ & 27.25 \\
\hline $7 / 3$ & 184 & $13: 40$ & 184.5694 & 31.0667 & pump \#2 on & $173 \mathrm{rpm}$ & 28.35 \\
\hline $7 / 3$ & 184 & $13: 40$ & 184.5694 & 31.0667 & pump \#3 on & long-term average & 632.32 \\
\hline $7 / 4$ & 185 & 17:05 & 185.7118 & 32.2090 & pump \#1,2,3 off & generator problem & 0.00 \\
\hline $7 / 5$ & 186 & 0:05 & 186.0035 & 32.5007 & pump \#3 on & long-term average & 632.32 \\
\hline $7 / 5$ & 186 & $0: 30$ & 186.0208 & 32.5181 & pump \#1 on & $174 \mathrm{rpm}$ & 28.35 \\
\hline $7 / 5$ & 186 & $0: 30$ & 186.0208 & 32.5181 & pump \#2 on & $175 \mathrm{rpm}$ & 28.89 \\
\hline $7 / 5$ & 186 & $7: 15$ & 186.3021 & 32.7993 & pump \#1,2,3 off & generator problem & 0.00 \\
\hline $7 / 5$ & 186 & $7: 35$ & 186.3160 & 32.8132 & pump \#3 on & long-term average & 632.32 \\
\hline $7 / 5$ & 186 & $8: 10$ & 186.3403 & 32.8375 & pump \#2 on & $173 \mathrm{rpm}$ & 28.35 \\
\hline
\end{tabular}


Table 2-2

Pumping Schedule for the BULLION FGE

(Page 3 of 3 )

\begin{tabular}{|c|c|c|c|c|c|c|c|}
\hline Date & $\begin{array}{c}\text { Julian } \\
\text { Day }\end{array}$ & Hr/Min & $\begin{array}{l}\text { Julian } \\
\text { Time }\end{array}$ & $\begin{array}{c}\text { Elapsed } \\
\text { Time } \\
\text { (days) }\end{array}$ & Activity & Parameters & $\begin{array}{c}\text { Rate } \\
\left(\mathrm{m}^{3} / \mathrm{d}\right)^{\star}\end{array}$ \\
\hline $7 / 5$ & 186 & $8: 20$ & 186.3472 & 32.8444 & pump \#1 on & $172 \mathrm{rpm}$ & 27.80 \\
\hline $7 / 8$ & 189 & $9: 20$ & 189.3889 & 35.8861 & pump \#1,2,3 off & generator changeout & 0.00 \\
\hline $7 / 8$ & 189 & $9: 25$ & 189.3924 & 35.8896 & pump \#1 on & 173 rpm & 28.35 \\
\hline $7 / 8$ & 189 & $9: 25$ & 189.3924 & 35.8896 & pump \#2 on & $175 \mathrm{rpm}$ & 28.89 \\
\hline $7 / 8$ & 189 & $9: 25$ & 189.3924 & 35.8896 & pump \#3 on & long-term average & 632.32 \\
\hline $7 / 10$ & 191 & $11: 19$ & 191.4715 & 37.9688 & pump \#1 off & start off-period & 0.00 \\
\hline $7 / 16$ & 197 & $13: 40$ & 197.5694 & 44.0667 & pump \#1 on & $173 \mathrm{rpm}$ & 28.35 \\
\hline $7 / 17$ & 198 & $13: 20$ & 198.5556 & 45.0528 & pump \#1 off & start off-period & 0.00 \\
\hline $7 / 17$ & 198 & $13: 25$ & 198.5590 & 45.0563 & pump \#3 off & generator changeout & 0.00 \\
\hline $7 / 17$ & 198 & $13: 30$ & 198.5625 & 45.0597 & pump \#2 off & start off-period & 0.00 \\
\hline $7 / 17$ & 198 & $13: 40$ & 198.5694 & 45.0667 & pump \#3 on & long-term average & 632.32 \\
\hline $7 / 17$ & 198 & $14: 20$ & 198.5972 & 45.0944 & pump \#3 off & generator problem & 0.00 \\
\hline $7 / 17$ & 198 & $14: 25$ & 198.6007 & 45.0979 & pump \#3 on & long-term average & 632.32 \\
\hline $7 / 22$ & 203 & $6: 20$ & 203.2639 & 49.7611 & pump \#3 off & generator problem & 0.00 \\
\hline $7 / 22$ & 203 & $8: 20$ & 203.3472 & 49.8444 & pump \#3 on & long-term average & 632.32 \\
\hline $7 / 22$ & 203 & $11: 30$ & 203.4792 & 49.9764 & pump \#3 off & generator problem & 0.00 \\
\hline $7 / 22$ & 203 & $12: 10$ & 203.5069 & 50.0042 & pump \#3 on & long-term average & 632.32 \\
\hline $7 / 22$ & 203 & $14: 15$ & 203.5938 & 50.0910 & pump \#3 off & generator problem & 0.00 \\
\hline $7 / 22$ & 203 & $14: 20$ & 203.5972 & 50.0944 & pump \#3 on & long-term average & 632.32 \\
\hline $7 / 22$ & 203 & $21: 00$ & 203.8750 & 50.3722 & pump \#3 off & generator problem & 0.00 \\
\hline $7 / 23$ & 204 & $0: 05$ & 204.0035 & 50.5007 & pump \#3 on & long-term average & 632.32 \\
\hline $7 / 28$ & 209 & $9: 50$ & 209.4097 & 55.9069 & pump \#3 off & generator changeout & 0.00 \\
\hline $7 / 28$ & 209 & $10: 05$ & 209.4201 & 55.9174 & pump \#3 on & long-term average & 632.32 \\
\hline $7 / 28$ & 209 & $10: 15$ & 209.4271 & 55.9243 & pump \#1 on & $174 \mathrm{rpm}$ & 28.35 \\
\hline $7 / 28$ & 209 & $10: 20$ & 209.4306 & 55.9278 & pump \#2 on & $176 \mathrm{rpm}$ & 29.44 \\
\hline $8 / 7$ & 219 & $10: 00$ & 219.4167 & 65.9139 & pump \#1,2,3 off & generator changeout & 0.00 \\
\hline $8 / 7$ & 219 & $10: 15$ & 219.4271 & 65.9243 & pump \#3 on & long-term average & 632.32 \\
\hline $8 / 18$ & 230 & $10: 00$ & 230.4167 & 76.9139 & pump \#3 off & generator changeout & 0.00 \\
\hline $8 / 18$ & 230 & $10: 10$ & 230.4236 & 76.9208 & pump \#1 on & $172 \mathrm{rpm}$ & 27.80 \\
\hline $8 / 18$ & 230 & $10: 10$ & 230.4236 & 76.9208 & pump \#3 on & long-term average & 632.32 \\
\hline $8 / 18$ & 230 & $10: 20$ & 230.4306 & 76.9278 & pump \#2 on & $173 \mathrm{rpm}$ & 28.35 \\
\hline $8 / 27$ & 239 & $11: 30$ & 239.4792 & 85.9764 & pump \#2 off & end of pumping & 0.00 \\
\hline $8 / 27$ & 239 & $14: 45$ & 239.6146 & 86.1118 & pump \#1 off & end of pumping & 0.00 \\
\hline $8 / 28$ & 240 & $14: 45$ & 240.6146 & 87.1118 & pump \#3 off & end of pumping & 0.00 \\
\hline
\end{tabular}

${ }^{*} \mathrm{~m}^{3} / \mathrm{d}$ - Cubic meters per day

VSD - Variable speed drive

rpm - Revolutions per minute 


\subsubsection{Technical Change Notices}

Seven TCN s were issued and are summarized below.

1. J une 4, 1997: Delay tracer injection into Well \#1 by approximately $10 \mathrm{hrs}$ so that the work takes place during daylight hours. Various sampling schedules adjusted to accommodate this change.

2. J une 20, 1997: Reduce rate of sampling of all three wells in response to the slower rate of tracer breakthrough observed.

3. J une 20, 1997: Suspend radioisotope sampling and gamma scans until such time as tritium concentration exceed trigger levels similar to their initial concentrations.

4. J une 23, 1997: Adjust sampling rate for Well \#3, discontinue on-site microsphere analysis, reduce or discontinue some benchtop water quality monitoring, reduce analysis rates of tracer samples.

5. J uly 1, 1997: Extend duration of the experiment indefinitely, adjust sampling and analysis rates to long-term schedules.

6. J uly 10, 1997: Introduce on/off schedule for Wells \#1 and \#2 to perturb the system; response to be used in calibration of analysis modeling.

7. J uly 25, 1997: Adjust sampling schedule to weekdays only.

\subsubsection{Delay of Tracer Injection into Well ER-20-6 \#1}

The first change, TCN \#1, reflects the realities of working in the field. The revisions to the schedule were dictated by the actual times required for various activities and other operational constraints. The sequence of activities and requirements for spacing between activities were preserved.

\subsubsection{Extension of Experiment Duration}

Tracer concentrations for each well were determined at dosely spaced intervals throughout the experiment to define the breakthrough curves. The development of each breakthrough curve was evaluated daily and compared to the original predictions. The breakthrough curves for Well ER-20-6 \#3 became asymptotic approaching their peaks, and then exhibited considerable tailing, making the peak-time difficult to discern without long-term data. In addition, it was hoped to 
observe the cross-over of the tails of the tracer concentration curves of the paired tracers, which should result from the differing matrix diffusion coefficients. These characteristics of the data collected made it desirable to keep the experiment going as long as possible to aid in data analysis. The experiment was extended from the planned duration of 30 days to 87 days, at which point the rising limbs and peaks of all the breakthrough curves had been captured. It also became clear that the tailing behavior of the paired tracers in ER-20-6 \#3 would not soon exhibit into crossing of the tails. The experiment was subsequently terminated. The characteristics of the breakthrough curves, especially the non-ideal features, will be discussed in detail in Section 4.0 .

It had also been expected that radionuclides from the BULLION test, in particular tritium, might eventually arrive at the wells. The planning modeling indicated that the main tritium breakthrough from the test cavity would not arrive in the planned time frame of the experiment. However, the modeling did indicate that an initial tritium peak from the fracture zone surrounding the cavity could arrive, and it was planned to characterize this tritium breakthrough. This prediction was predicated on the assumption that the tritium concentrations observed in Wells ER-20-6 \#1 and \#2 during drilling and development represented the leading edge of a tritium plume emanating from the BULLION test. However, during the course of the experiment tritium concentrations in Wells ER-20-6 \#1 and \#2, rather than increasing, decreased to low concentrations. Tritium concentrations in Well ER-20-6 \#3 started and finished at a lower level than the final levels in Wells ER-20-6 \#1 and \#2, only increasing slightly during the experiment. Radionuclide monitoring was not a factor in the extension or termination of the experiment.

\subsubsection{Periodically Stopping Pumping of Wells ER-20-6 \#1 and \#2}

TCN \#6 specified a schedule for periodically stopping pumping of Wells ER-20-6 \#1 and \#2. This was done for two reasons: (1) a concern that the pumping of these wells was holding tracer locally around each well, creating the long tailing of the breakthrough curves, and (2) to perturb the system, altering both the hydraulic conditions and tracer transport. The perturbations were expected to show up in the data records and provide specific markers for use in calibration of the model used in analysis of the experiment.

\subsubsection{Changes to Sampling and Analysis Schedules}

Changes detailed in TCNs 2 through 5 and 7 specified adjustments to sampling and analysis schedules. Schedules were proportionately reduced to preserve adequate characterization of the breakthrough 
curves; while reducing manpower requirements. The original criteria specified 100 data points to define each breakthrough curve; the quantity of data collected far exceeds this criterion, defining the curves in great detail. Also, the tritium and lead monitoring schedule for discharge of the water from Well ER-20-6 \#3 was reduced after J uly 1 based on the history of those parameters during the experiment. Since tritium concentrations in Wells ER-20-6 \#1 and \#2 declined to levels bel ow which other radionuclides may be expected to be present, radionuclide monitoring and sampling were substantially reduced.

\subsubsection{Field Microsphere Monitoring}

The field monitoring methodology for microsphere field analysis was originally specified in the implementation plan and was further devel oped in the field to provide a more quantitative result. A LANL representative conducted the microsphere monitoring during the first month with IT support. The methodology involved serial dilution of the samples and filtration. The microspheres on the filter paper were counted in six fields under the microscope. The results were reported as the average count per field for each sample and were plotted to exhibit the developing breakthrough curve. This method was sufficiently more quantitative than the originally specified method to track the progress of breakthrough, but the results were too inconsistent for use in a quantitative analysis. The on-site microsphere monitoring was discontinued on J une 20 when it was determined that the on-site monitoring had served the intended purpose to determine when the microspheres were breaking through.

\subsection{Pumping Continuity}

Several pumping equipment problems were encountered during the experiment, but were not significantly detrimental to the field operation or the data quality. This information is induded to explain some features of the data that may be confusing.

\subsubsection{Power Interruptions}

Power interruptions include both scheduled replacement of generators for maintenance purposes and unplanned generator shutdowns. The impact of power interruptions on the experiment was primarily the cessation of pumping. Generators were replaced approximately every 10 days, with adjustments to that schedule to avoid weekends and to accommodate other circumstances. The pumps were generally off for periods of less than 45 minutes, mostly much shorter periods. There were two substantially longer power interruptions, approximately 3 hours and 7 hours. The periods when pumping stopped are not 
thought to have any significant impact on the experiment. During these periods, the flow field would recover to the natural gradient and movement in the aquifer would slow to a much reduced rate. Since the induced flow along the line of wells is thought to be similar to the natural flow direction and the distance of transport during the interruptions would be very short, the interruptions are not thought to have introduced any spurious result. The longer pumping interruptions were simulated in the flow and transport modeling for the experiment analysis.

\subsubsection{Pulsing of Well \#2 Pump}

The pump in Well ER-20-6 \#2 produced a severe pulsing output due to sticking of the pump rotor, which caused problems for monitoring the production rate and drawdown. The pulsing interfered somewhat with flowmeter operation. Also, the pulsed well head pressure exceeded the bypass pressure setting for the well head safety pressure-relief system, resulting in the discharge being split into two streams. The bypass stream was not metered. The desired average production rate appears to have been maintained based on a record of pump speed, but the el ectronic records of flow rate are not complete. There is al so a great deal of noise in the drawdown record when this pump was running due to the pulsing.

\subsection{Summary}

Tracer decay and breakthrough curves were well-characterized for tracer transport along all three flow paths. Tracer breakthroughs in Well ER-20-6 \#3 were significantly slower than predicted and the peaks were flattened with substantial tailing, making it difficult to judge the peak arrival time. The experiment was extended from the original 30 days to 87 days to ensure capture of sufficient breakthrough information for analysis. During the experiment, radionuclide concentrations in all three wells declined from initial concentrations rather than increasing as expected. Radionuclide transport to the experiment wells was minimal; consequently little information was gained on the hydrologic source term. This may be the result of poor connection between the BULLION cavity and the aquifer or insufficient time for transport from the cavity. The location and extent of a pre-existing plume of radionudides from the BULLION cavity was not well established, so the expectation for radionuclides was speculative. This result suggests that the initially observed tritium may, in fact, have been leaked from an overlying formation containing tritium.

The lack of radionuclides was fortuitous for the tracer part of the experiment. The extension of pumping for the experiment was possible because the low tritium concentrations allowed continued discharge of 
pumped water from Well ER-20-6 \#3 to an infiltration basin. Otherwise, the duration would have been limited to the original 30 days by the capacity of the lined sumps.

\subsection{How the Results Differed from Predictions}

The predictions of breakthrough times based on the planning model incorporated an order of magnitude range in the estimated effective porosity, from 0.001 to 0.01 , to accommodate uncertainty. Also, this model did not incorporate matrix diffusion, which would slow the sol ute tracers. The microspheres would be expected to best fit the prediction model since they are not retarded by matrix diffusion. The time for breakthrough of the microspheres from Well ER-20-6 \#1 to \#2 and from \#1 to \#3 was within the predicted range, but transport from Well ER-20-6 \#2 to \#3 was longer than predicted. Table 2-3 shows the predictions and the actual results. The well pairs for tracer transport are listed in order of increasing time to breakthrough for the predicted times. In summary, the time to breakthrough for the microspheres from Well ER-20-6 \#1 to \#2 was in the lower half of the predicted range while the time to breakthrough from Well ER-20-6 \#1 to \#3 was in the upper half, and from Well ER-20-6 \#2 to \#3 was approximately twice the greatest predicted time to breakthrough. The chemical tracers were substantially sl ower than the microspheres, and they also became relatively slower in the same well-pair order as the microsphere breakthroughs became slower.

The solute tracer peak concentrations were approximately one order of magnitude less than the predictions, and the microsphere peak concentrations were about two orders of magnitude less. M easurement of these concentrations was still well within the capability of the analysis methods. The predictions had not incor porated matrix diffusion for the solute tracers, or filtration for the microspheres. N or had any tracer mass loss been anticipated. Tracer recoveries ranged from a low of about 2.5 percent for microspheres injected into Well ER-20-1 \#1 to a high of about 31 percent for the pentafluorobenzoic acid (PFBA) injected into Well ER-20-6 \#2. Recovery of tracers injected into Well ER-20-6 \#2 was about three times the recovery of the tracers injected into Well ER-20-6 \#1.

These comparisons to the predictions from the planning modeling are for reference purposes for understanding the original schedules in the plan, and are not offered as an analysis. The planning model was based on a simpler operational scenario and different pumping rates from the final operation plan, and those results had been simply scaled to provide a general time frame. Section 4.0 contains the results of modeling of the experiment as it was run. 
Table 2-3

Comparison of Predicted and Observed Tracer Breakthroughs

\begin{tabular}{|c|c|c|c|c|c|c|c|}
\hline \multirow{2}{*}{$\begin{array}{c}\begin{array}{c}\text { Tracer } \\
\text { Breakthroughs }\end{array} \\
\begin{array}{c}\text { (Time from } \\
\text { injection of tracer) }\end{array}\end{array}$} & \multicolumn{2}{|c|}{$\begin{array}{c}\text { Time to Peak } \\
\text { Concentration (hrs) }\end{array}$} & \multicolumn{2}{|c|}{$\begin{array}{c}\text { Normalized Peak } \\
\text { Concentration }{ }^{\star}\end{array}$} & \multicolumn{3}{|c|}{ Peak Concentration } \\
\hline & Predicted & Actual & Predicted & Actual & Predicted & Actual & Unit \\
\hline Well \#1 to Well \#2, I & $29-288$ & 1113 & $.00220-.0220$ & .00025 & $5500-55,000$ & $\overline{524}$ & $\mu \mathrm{g} / \mathrm{L}$ \\
\hline $\begin{array}{l}\text { Well \#1 to Well \#2, } \\
\text { 2,6 DFBA }\end{array}$ & $29-288$ & 113 & $.00220-.0220$ & .00028 & $5500-55,000$ & 706 & $\mu \mathrm{g} / \mathrm{L}$ \\
\hline $\begin{array}{l}\text { Well \#1 to Well \#2, } \\
\text { Red microspheres }\end{array}$ & $29-288$ & 79 & $.00220-.0220$ & .00025 & 1.5E5-1.5E6 & 17,409 & $\# / \mathrm{mL}$ \\
\hline Well \#1 to Well \#3, I & $48-480$ & 1294 & $.00036-.0036$ & .00005 & $900-9,000$ & 109 & $\mu \mathrm{g} / \mathrm{L}$ \\
\hline $\begin{array}{c}\text { Well \#1 to Well \#3, } \\
2,6 \text { DFBA }\end{array}$ & $48-480$ & 990 & $.00036-0036$ & .00006 & $900-9,000$ & 151 & $\mu \mathrm{g} / \mathrm{L}$ \\
\hline $\begin{array}{l}\text { Well \#1 to Well \#3, } \\
\text { Red microspheres }\end{array}$ & $48-480$ & 354 & $.00036-.0036$ & .000006 & 2.5E4-2.5E5 & 418 & $\# / \mathrm{mL}$ \\
\hline $\begin{array}{c}\text { Well \#2 to Well \#3, } \\
\text { PFBA }\end{array}$ & $18-180$ & 625 & $.00060-.0060$ & .00018 & $1500-15,000$ & 394 & $\mu \mathrm{g} / \mathrm{L}$ \\
\hline $\begin{array}{l}\text { Well \#2 to Well \#3, } \\
\text { Yellow microspheres }\end{array}$ & $18-180$ & 348 & $.00060-.0060$ & .000013 & 4.4E4-4.4E5 & 948 & $\# / \mathrm{mL}$ \\
\hline
\end{tabular}

${ }^{*}$ Normalized by injection concentration

I - lodide

2,6 DFBA - Difluorobenzoic acid

PFBA - Pentafluorobenzoic acid

$\mu \mathrm{g} / \mathrm{L}$ - Micrograms per liter

$\# / \mathrm{mL}$ - Milliliter 


\subsection{Data Collection}

Data collection can be classified into five categories: operational data, hydraulic response data, radiologic data, water chemistry data, and tracer data. The basic data collected during the experiment are presented in this section in graphical summary form.

\subsection{Operational Data}

Operational data includes the day-to-day records of the activities that were conducted to accomplish the experiment. This includes general site operations, and pumping and discharge monitoring of the three wells.

\subsubsection{ER-20-6 Field Logbook}

A general logbook was kept which contains a record of the day-to-day operations of the experiment. In addition there is an electronic logbook for the early part of the experiment with additional details, broken down by category. Logs and logbooks were also kept for individual operations, and will be discussed under the respective data types.

\subsubsection{Pumping Rate}

As Table 2-2 shows, the pump schedules and rates for all three wells followed an elaborate schedule that was driven by a variety of objectives. The E R-20-6 field logbooks contain basic information on changes to pump operation during the course of the experiment, but detailed information on pumping rate versus time was recorded electronically. Dataloggers recorded the production rate from flowmeters on each well discharge, and also the rotation rate in revolutions per minute (rpm) for the M oyno pumps in Wells E R-20-6 \#1 and \#2. The flowmeter data was periodically processed in the field and loaded into a spreadsheet.

The pumping record for Well ER-20-6 \#3, shown in Figure 3-1, is complete for the course of the experiment. The record shows that the pumping rate consistently dedined with time, and was periodically adjusted back to the target rate by increasing the frequency of the 


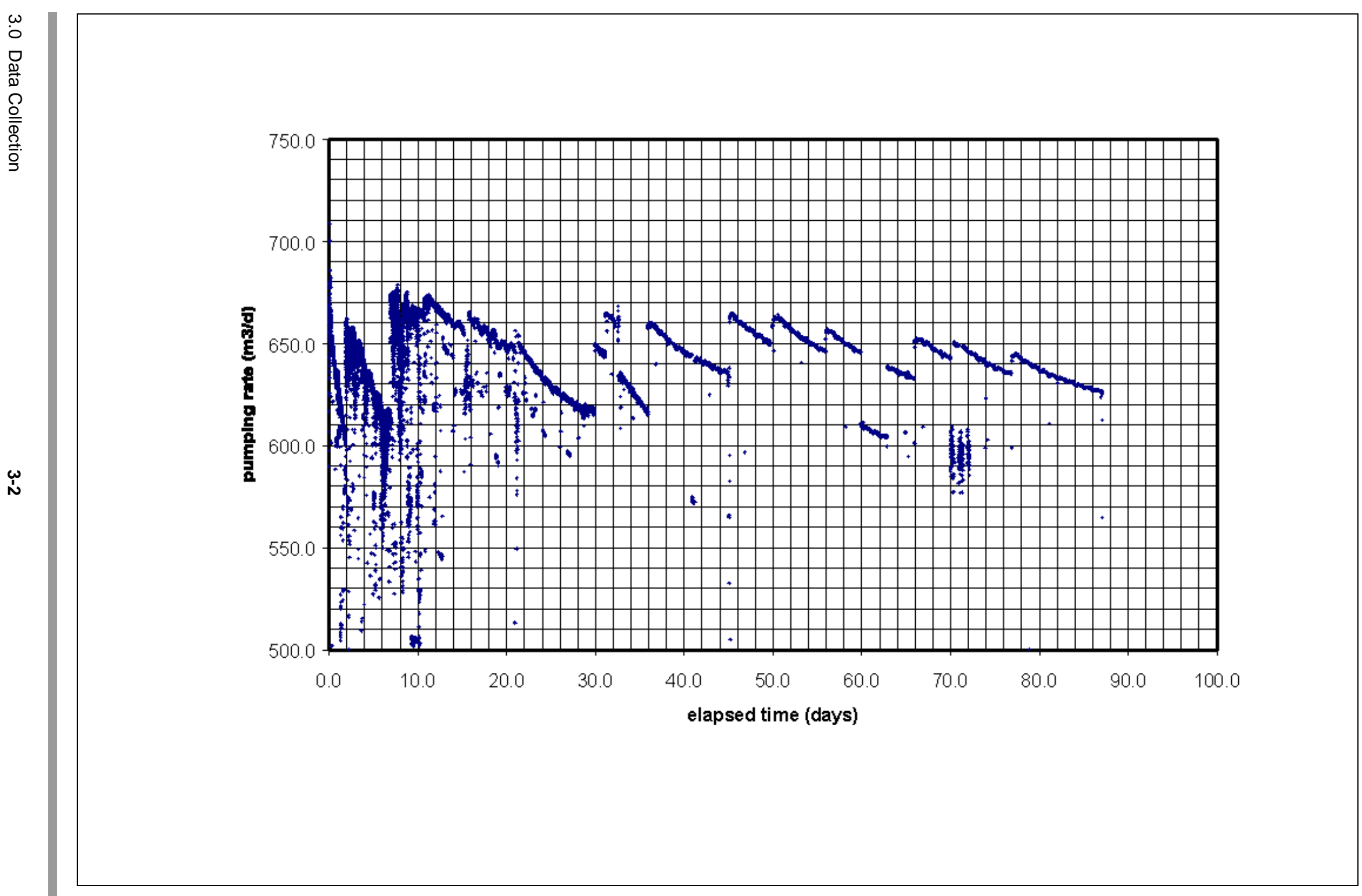

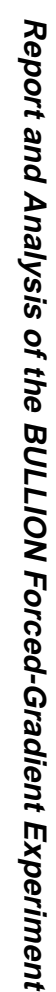

Figure 3-1

Well ER-20-6 \#3 Pumping Record 
power to the pump. The reason for the declining rate is not known, but was not the result of increasing drawdown or drift of the power settings for the pump. Figure 3-2 shows the cumulative average pumping rate for Well E R-20-6 \#3 during the course of the experiment. This provides an overall perspective on the consistency of the pumping rate, and shows a long-term average of $632.32 \mathrm{~m}^{3} /$ day (116 gallons per minute [gpm]).

The discharge rates from Wells E R-20-6 \#1 and \#2 were monitored with both flowmeters and revolutions-per-minute counters on the M oyno pumps. The records for Well \#1 are complete and consistent, but the flowmeter record for Well \#2 is poor due to problems with the pump. Binding of the Well \#2 pump created a pulsing discharge that constantly tripped the wellhead safety bypass and disturbed flowmeter operation, resulting in an erratic flowmeter record. However, the rpm record is good on an average basis. The discharge rate from the flowmeter can be calibrated to rpm for both wells where the records are good, and agree closely with the manufacturers performance curve for that model pump. The pumping rates for Wells \#1 and \#2 listed in Table 2-2 are based on the rpm records. The values given represent the typical discharge during the various pumping periods.

\subsubsection{Discharge Monitoring}

The produced water from Wells ER-20-6 \#1 and \#2 was discharged into lined sumps at the ER-20-6 site, and no discharge monitoring was required. However, samples for these wells were periodically analyzed for tritium to observe a tritium breakthrough and to guide other radiologic sampling. Produced water from Well ER-20-6 \#3 was discharged to an infiltration basin located approximately 1,000 meters (m) south of the ER-20-6 site, and periodic monitoring for tritium and lead concentrations were required. I nitially, the tritium concentration was checked hourly and the lead concentration checked every eight hours. A TCN was issued on J uly 1 reducing the rate of monitoring for both parameters to once per work shift. A progressively decreasing schedule for manning the site was al so started J uly 1 . Both of these changes were instituted in response to the slower-than-anticipated rate of tracer breakthrough and the lack of an increasing trend for tritium or lead.

Figure 3-3 shows tritium concentrations for all three wells during the experiment. As this graph shows, the peak tritium activity observed during the experiment was about 90,000 picocuries per liter $(\mathrm{pCi} / \mathrm{L})$, and occurred in Well \#2 on J une 3, 1998, approximately 24 hours after the start of the experiment. The tritium activity for this well sharply declined and by J une 15, 1998, measured below $20,000 \mathrm{pCi} / \mathrm{L}$, the National Primary Drinking Water Regulation. The tritium activity for Well \#1 was below 20,000 pCi/L for the entire course of the experiment except for one measurement just over $20,000 \mathrm{pCi} / \mathrm{L}$, and generally 


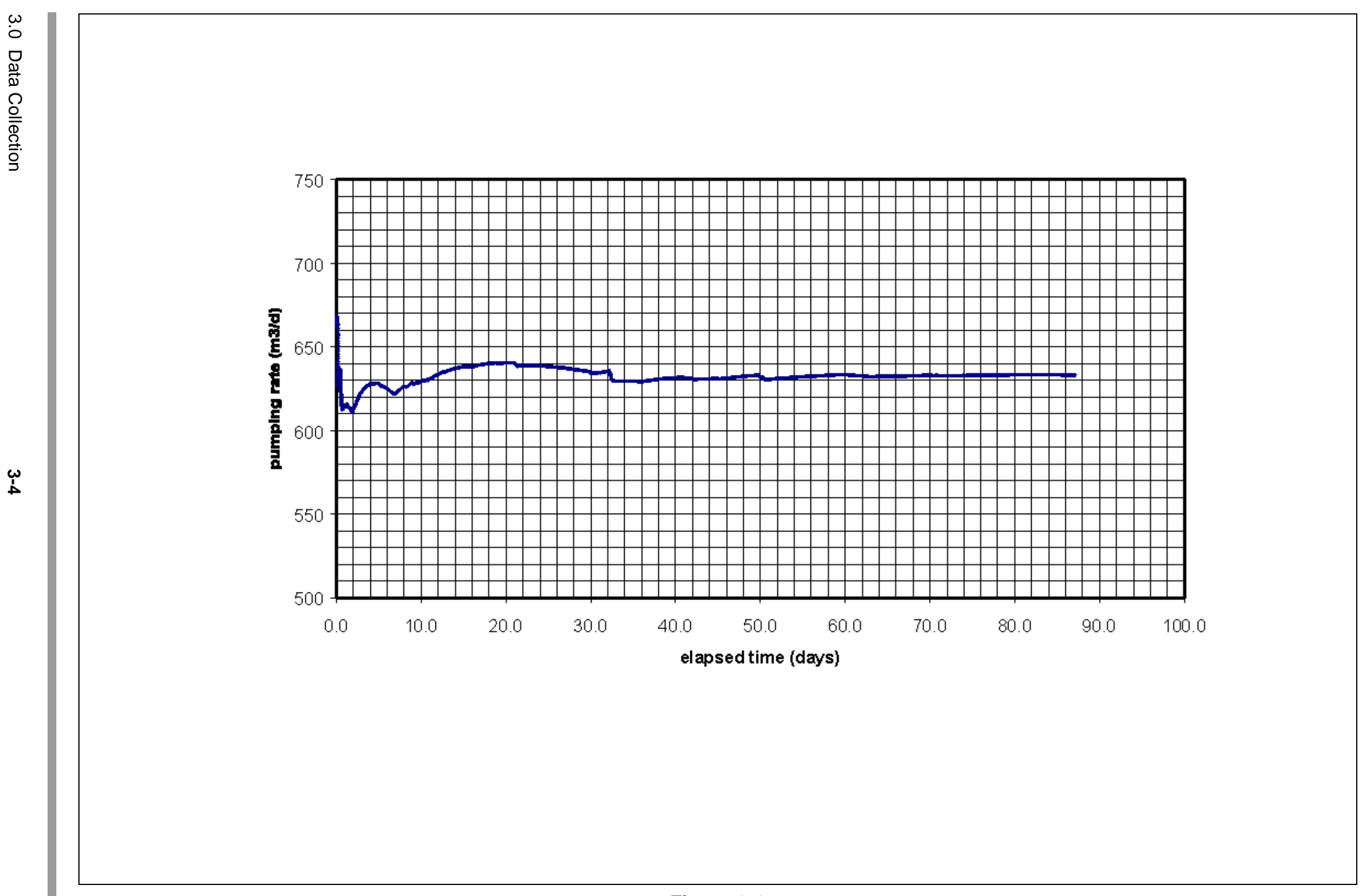

Figure 3-2

Well ER-20-6 \#3 Cumulative Average Pumping Rate 


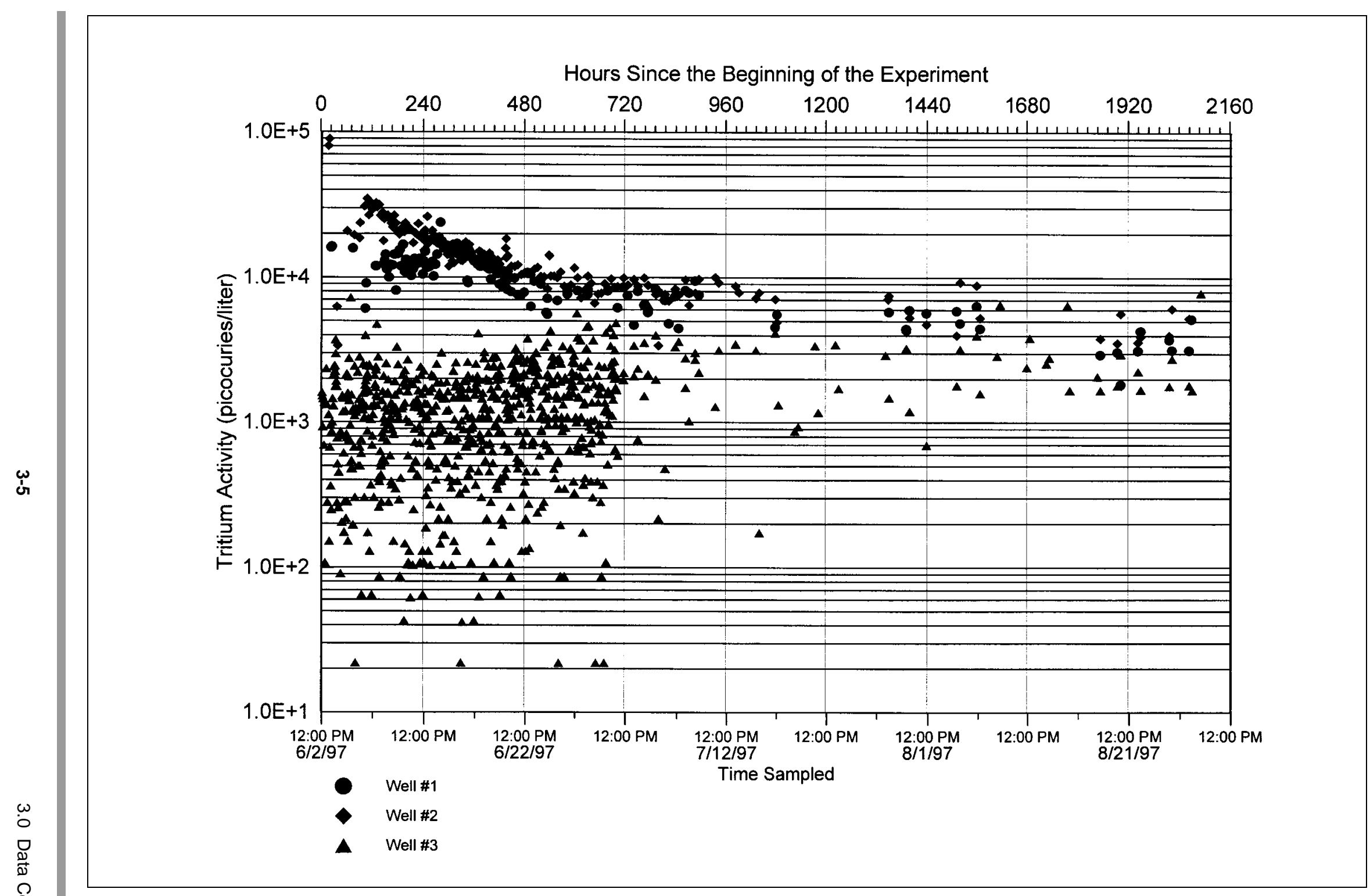

Figure 3-3

Measured Tritium Activity in ER-20-6 Wells 
declined with time. Well \#3 tritium activity was well below $20,000 \mathrm{pCi} / \mathrm{L}$ for the entire course of the experiment, but appeared to be slowly increasing. The data for Well \#3 appear very scattered compared to the data for the other two wells. This is partly a function of the log scale used to portray all three wells on one graph. The actual scatter of the Well \#3 data is similar. The analysis method/parameters used for field monitoring is also not highly accurate and consistent at the low values measured for Well \#3.

Lead concentrations were monitored several times daily for each well and found very low concentrations. The average concentration of lead for all of the samples was less than one microgram per liter $(\mu \mathrm{g} / \mathrm{L})$. The highest lead concentration obtained throughout the course of the experiment was $1.5 \mu \mathrm{g} / \mathrm{L}$, well bel ow the $250 \mu \mathrm{g} / \mathrm{L}$ limit for discharge into an unlined infiltration basin as delineated in the Underground Test Area Subproject Waste Management PIan (DOE/NV, 1996).

\subsection{Hydraulic Response Data}

The head in each of the wells was monitored using downhole pressure transducers to provide a record of the hydraulic response to pumping. The transducer response data was periodically processed in the field and loaded into a spreadsheet. The processed data were checked against several independent measures and conformed to observations and expections.

\subsubsection{Well ER-20-6 \#3}

The drawdown record for Well ER-20-6 \#3, shown in Figure 3-4, is continuous for the entire experiment. Features of the record include the recovery and drawdown response each time pumping temporarily stopped due to power disruption. The record shows a series of short-term recovery trends superimposed on the long-term record, especially evident in the beginning of the test. These trends correlate to changes in the pumping rate (refer to Figure 3-1). As mentioned, the pumping rate would constantly decline, and was periodically adjusted back to the target rate to compensate. The record also shows two major step-recoveries in the head following pump shutdowns, as well as several minor ones. This phenomenon will be discussed in Section 4.0. There are several periods of the record which are very noisy. The noise, appearing as a thick band on the record, was due to el ectrical interference with the power supply system rather than reflecting any actual pumping rate variation. 


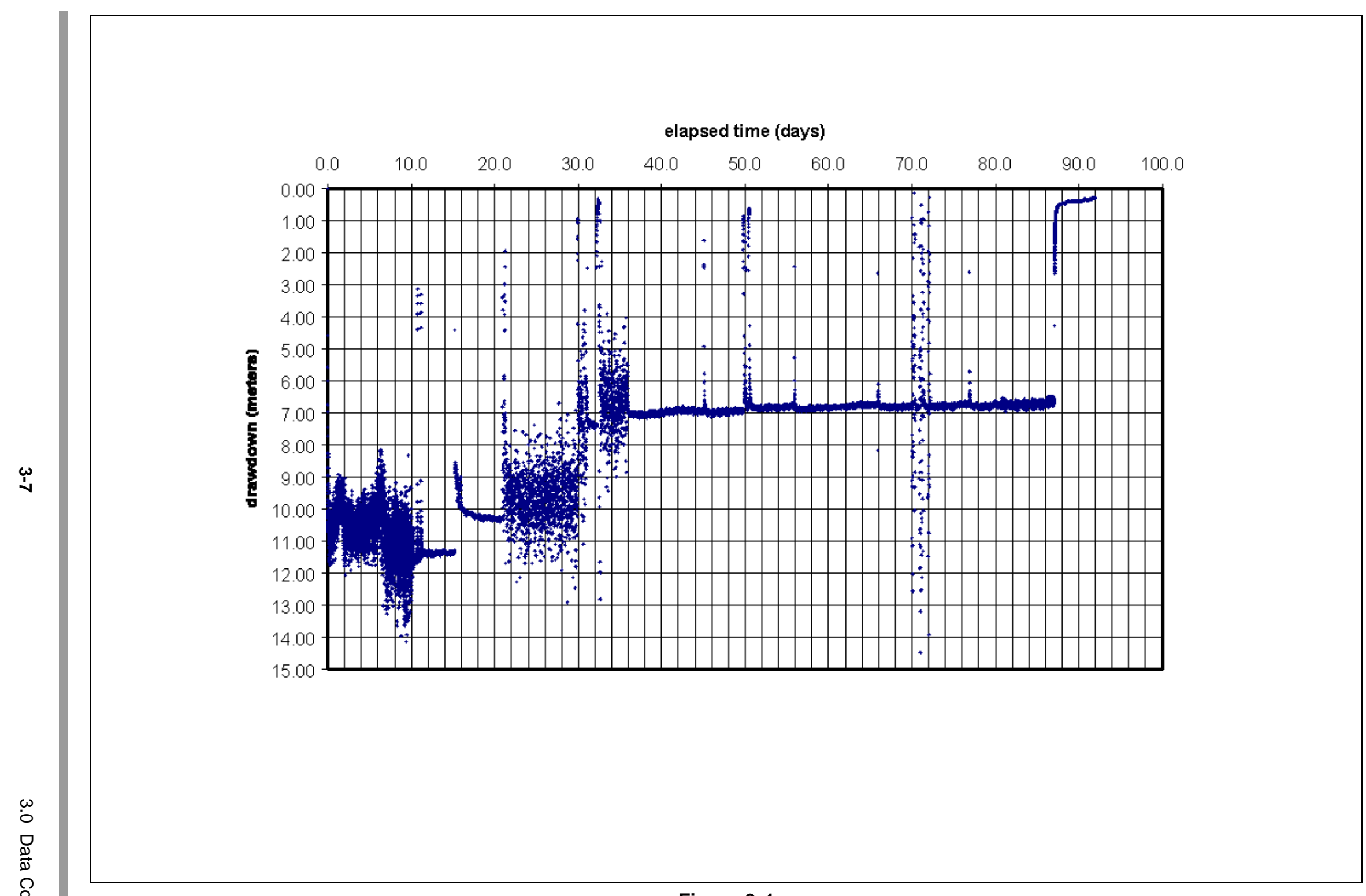

Figure 3-4

Well ER-20-6 \#3 Drawdown Record

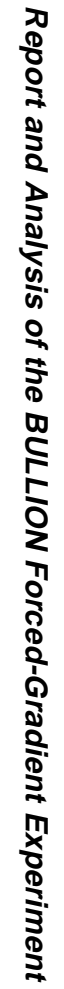




\subsubsection{Wells ER-20-6 \#1 and \#2}

The head records for Wells ER-20-6 \#1 and \#2 are shown on Figure 3-5 and Figure 3-6 respectively. Due to the need to use the access tubes in Wells ER-20-6 \#1 and \#2 for downhole discrete sampling, the pressure transducers had to be removed just before tracer injection for about one month, until discreet sampling was discontinued. During this time water-level measurements were made with a wireline unit, shown as discrete data points. These measurements generally fill in the trends during this period; however, the uncertainty in such measurements does not provide a smooth record. The relative alignment of the later transducer record with the earlier record was based on the water-level measurements that were made when the transducers were reinstalled.

Reference to Table 2-2 indicates these wells were operated at consistent rates for the term of the experiment after initial start-up. The drawdown response in these wells is dominated by the response to pumping in Well \#3. This can clearly be seen in the latter part of the records when the pumping of these wells was periodically stopped and restarted. Pumping in Well \#1 and \#2 produced a minimal response, approximately $0.1 \mathrm{~m}$, superimposed on the drawdown resulting from pumping in Well \#3. Table 2-2 identifies those times when Well \#1 was pumping. The problem with the pump in Well $\# 2$ produced a great deal of noise when the pump was on, appearing as a wide band in the record. The additional drawdown from pumping in Well \#2 is estimated at the centerline of the wide band of data. Examination of the components of the drawdown response in Well \#2 indicates about $0.2 \mathrm{~m}$ drawdown attributable to Well \#2 pumping and $0.1 \mathrm{~m}$ to Well \#1 pumping.

\subsection{Radiologic Data}

A variety of sampling and analyses for radiologic parameters was planned in consideration of the expected radionudide transport from the BULLION test cavity. However, radionuclides did not appear as expected and the amount of radiologic sampling was reduced.

\subsubsection{IT Radionuclide Sample Results}

IT personnel collected groundwater samples from each well over a 12-day period from J une 8 through J une 20, 1997, for off-sitelaboratory analysis for strontium-90 isotope. The results and associated error (+or -) are presented in Table 3-1. The concentrations were below the detection limit in all cases with the exception of the J une 18, 1997, Well \#3 result which was $0.12 \mathrm{pCi} / \mathrm{L}$ above the detection limit. 


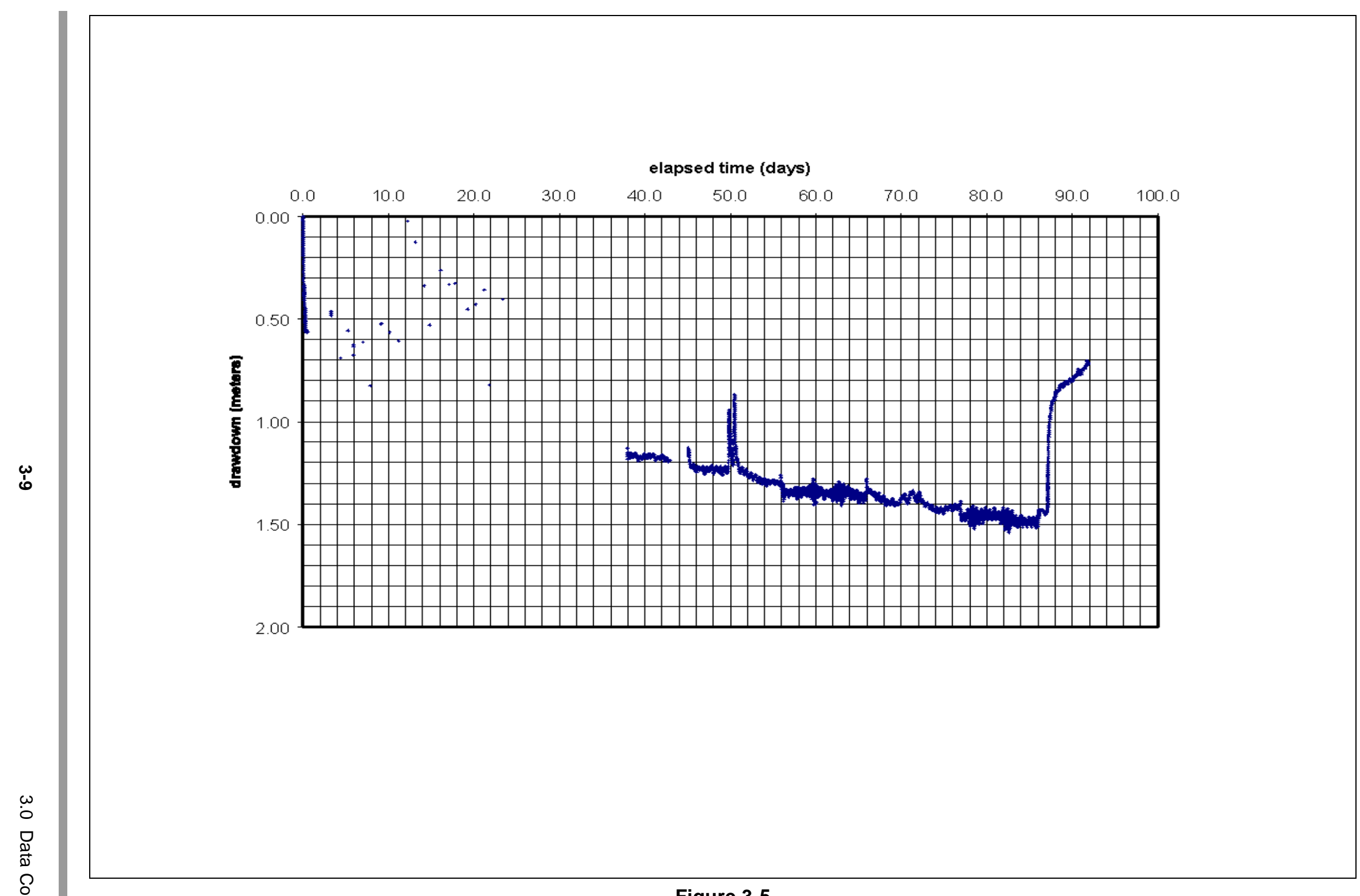

Figure 3-5

Well \#1 Drawdown Record

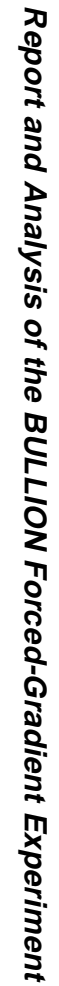




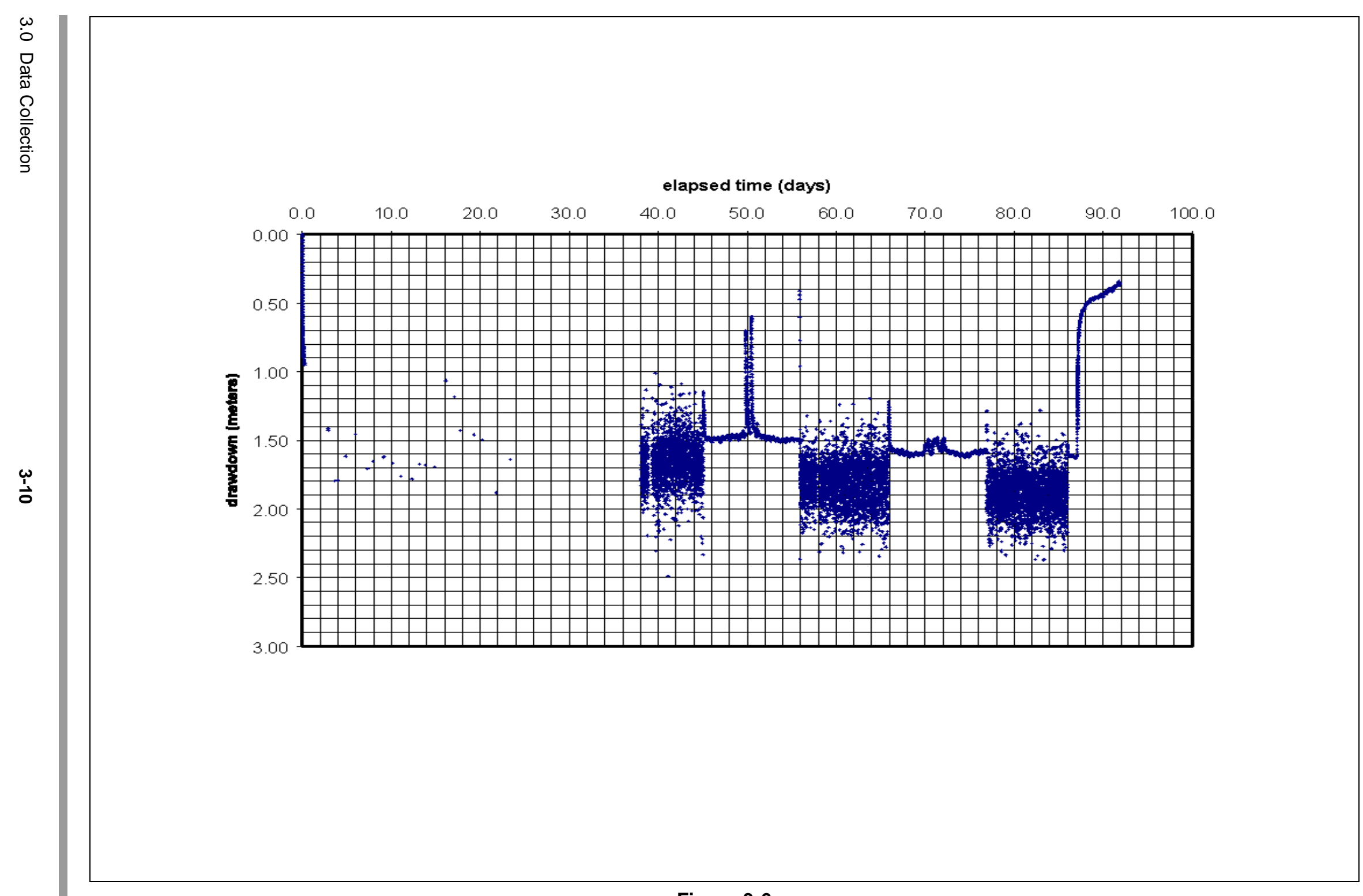

Figure 3-6

Well \#2 Drawdown Record 
Table 3-1

Strontium-90 Isotope Analysis Results (pCi/L)

\begin{tabular}{|c|c|c|c|c|c|c|}
\hline Date Sampled & Well \#1 & Error ( \pm ) & Well \#2 & Error ( $( \pm)$ & Well \#3 & Error ( $( \pm)$ \\
\hline June 8, 1997 & -0.17 & 0.46 & $\sim$ & $\sim$ & $\sim$ & $\sim$ \\
\hline June 10, 1997 & -0.12 & 0.46 & -0.24 & 0.36 & -0.09 & 0.35 \\
\hline June 12, 1997 & -0.18 & 0.30 & 0.01 & 0.32 & -0.11 & 0.30 \\
\hline June 14,1997 & 0.03 & 0.29 & -0.36 & 0.34 & -0.07 & 0.32 \\
\hline June 14, 1997 & -0.05 & 0.31 & $\sim$ & $\sim$ & $\sim$ & $\sim$ \\
\hline June 16, 1997 & $\sim$ & $\sim$ & -0.11 & 0.32 & -0.09 & 0.31 \\
\hline June 18, 1997 & 0.15 & 0.51 & -0.08 & 0.47 & 0.60 & 0.48 \\
\hline June 20, 1997 & 0.34 & 0.51 & 0.07 & 0.44 & -0.32 & 0.42 \\
\hline
\end{tabular}

$\sim$ Not analyzed

\subsubsection{LLNL Radionuclide Samples}

Groundwater grab samples for radionuclide analyses were collected for LLNL on various dates throughout the course of the BULLION FGE. The results for the analyses are presented separately by LLNL and are not a part of this report.

\subsubsection{LANL Radionuclide Samples}

Groundwater grab samples for radionuclide analyses were collected for LANL on various dates throughout the course of the BULLION FGE. The results for the analyses are presented separately by LANL and are not a part of this report.

\subsection{Water Chemistry Data}

A variety of water chemistry analyses were conducted throughout the experiment. Samples were collected at the beginning of the experiment after purging of each well, and analyzed to characterize the water chemistry. During the course of the experiment, $\mathrm{pH}$, conductivity, and dissolved oxygen were periodically measured in the field. The average $\mathrm{pH}$ measured in Well \#1 was 8.11; in Well \#2, 8.08, and in Well \#3, 8.10. The average specific conductivity in each well was approximately $300 \mathrm{mi}$ cromhos per centimeter $(\mu \mathrm{mhos} / \mathrm{cm})$ throughout the course of the experiment. The dissolved oxygen in each well varied between 5 and 8 milligrams per liter (mg/L), indicating a well-oxygenated system. 


\subsubsection{Baseline Chemistry}

Groundwater samples were collected from each well on J une 2, 1997, to obtain a baseline chemistry of the groundwater prior to the any experimental activities. The parameters and results are tabulated in Table 3-2.

The baseline results indicate that the groundwaters are a sodium-bicarbonate type with very low total dissolved solids, as confirmed by the field measurements of conductivity. This water type is typical of volcanic terrains and is the dominant type seen in wells on Pahute Mesa. The concentrations of total and dissolved aluminum are quite variable. However, this is to be expected in a silicate dominated system where the presence of day-size alumino-silicate minerals can positively skew the analytical results.

The dissolved Resource Conservation and Recovery Act metals (e.g., arsenic, cadmium, chromium, lead, mercury, selenium and silver) are at or near their detection level and are not of regulatory concern. Fluoride levels, while higher than normally observed in groundwater, are most likely due to the very low concentrations of calcium. The solubility of fluorite, a calcium fluorine mineral, generally controls the concentration of fluorine in groundwater: lower levels of calcium, permit higher levels of fluorine to occur.

Table 3-2

Baseline Chemistry of Samples Taken June 2, 1997

(Page 1 of 2)

\begin{tabular}{|c|c|c|c|c||}
\hline Parameter & Units & Well \#1 & Well \#2 & Well \#3 \\
\hline \hline Aluminum, total & $\mu \mathrm{g} / \mathrm{L}$ & 1,300 & 6,570 & 157 \\
\hline Aluminum, dissolved & $\mu \mathrm{g} / \mathrm{L}$ & 598 & 2,330 & 169 \\
\hline Arsenic, total & $\mu \mathrm{g} / \mathrm{L}$ & 27.7 & 63.2 & 4.0 \\
\hline Arsenic, dissolved & $\mu \mathrm{g} / \mathrm{L}$ & 31.9 & 62 & 3.8 \\
\hline Cadmium, total & $\mu \mathrm{g} / \mathrm{L}$ & $<1.0$ & $<1.0$ & $<1.0$ \\
\hline Cadmium, dissolved & $\mu \mathrm{g} / \mathrm{L}$ & $<1.0$ & $<1.0$ & $<1.0$ \\
\hline Calcium, total & $\mu \mathrm{g} / \mathrm{L}$ & 6,890 & 8,000 & 10,200 \\
\hline Calcium, dissolved & $\mu \mathrm{g} / \mathrm{L}$ & 6,830 & 7120 & 10,300 \\
\hline Chromium, total & $\mu \mathrm{g} / \mathrm{L}$ & $<2.0$ & 61.9 & $<2.0$ \\
\hline Chromium, dissolved & $\mu \mathrm{g} / \mathrm{L}$ & $<1.0$ & $<1.0$ & $<1.0$ \\
\hline Iron, total & $\mu \mathrm{g} / \mathrm{L}$ & 487 & 5,470 & 642 \\
\hline Iron, dissolved & $\mu \mathrm{g} / \mathrm{L}$ & 163 & 763 & 535 \\
\hline Lead, total & $\mu \mathrm{g} / \mathrm{L}$ & $<1.3$ & 22.7 & $<2$ \\
\hline Lead, dissolved & $\mu \mathrm{g} / \mathrm{L}$ & $<1.0$ & 8.1 & $<1.0$ \\
\hline Lithium, total & $\mu \mathrm{g} / \mathrm{L}$ & 53.2 & 53.8 & 49.3 \\
\hline Lithium, dissolved & $\mu \mathrm{g} / \mathrm{L}$ & 36.6 & 40.8 & 37 \\
\hline Magnesium, total & $\mu \mathrm{g} / \mathrm{L}$ & 483 & 721 & 719 \\
\hline Magnesium, dissolved & $\mu \mathrm{g} / \mathrm{L}$ & 514 & 735 & 727 \\
\hline Manganese, total & $\mu \mathrm{g} / \mathrm{L}$ & 21.2 & 148 & 42.9 \\
\hline Manganese, dissolved & $\mu \mathrm{g} / \mathrm{L}$ & 10.8 & 52.6 & 41.3 \\
\hline Mercury, total & $\mu \mathrm{g} / \mathrm{L}$ & $<0.20$ & $<0.20$ & $<0.20$ \\
\hline
\end{tabular}


Table 3-2

Baseline Chemistry of Samples Taken June 2, 1997

(Page 2 of 2)

\begin{tabular}{|c|c|c|c|c|}
\hline Parameter & Units & Well \#1 & Well \#2 & Well \#3 \\
\hline Mercury, dissolved & $\mu \mathrm{g} / \mathrm{L}$ & $<0.20$ & $<0.20$ & $<0.20$ \\
\hline Phosphorus, total & $\mathrm{mg} / \mathrm{L}$ & 0.038 & 0.074 & 0.025 \\
\hline Potassium, total & $\mu \mathrm{g} / \mathrm{L}$ & 2,940 & 4,830 & 2,810 \\
\hline Potassium, dissolved & $\mu \mathrm{g} / \mathrm{L}$ & 3,380 & 5,290 & 3,100 \\
\hline Selenium, total & $\mu \mathrm{g} / \mathrm{L}$ & $<4.0$ & $<4.0$ & $<4.0$ \\
\hline Selenium, dissolved & $\mu \mathrm{g} / \mathrm{L}$ & $<3.0$ & $<3.0$ & $<3.0$ \\
\hline Silicon, total & $\mu \mathrm{g} / \mathrm{L}$ & 26,200 & 36,900 & 21,500 \\
\hline Silicon, dissolved & $\mu \mathrm{g} / \mathrm{L}$ & 22,500 & 29,600 & 20,600 \\
\hline Silver, total & $\mu \mathrm{g} / \mathrm{L}$ & $<1.0$ & $<1.0$ & $<1.0$ \\
\hline Silver, dissolved & $\mu \mathrm{g} / \mathrm{L}$ & $<1.0$ & $<1.0$ & $<1.0$ \\
\hline Sodium, total & $\mu \mathrm{g} / \mathrm{L}$ & 60,700 & 61,500 & 53,100 \\
\hline Sodium, dissolved & $\mu \mathrm{g} / \mathrm{L}$ & 58,300 & 62,400 & 54,400 \\
\hline Strontium, total & $\mu \mathrm{g} / \mathrm{L}$ & 15.7 & 18.5 & 28.5 \\
\hline Strontium, dissolved & $\mu \mathrm{g} / \mathrm{L}$ & 15.4 & 13.9 & 28.2 \\
\hline Uranium, total & $\mu \mathrm{g} / \mathrm{L}$ & 3.3 & 18.3 & 2.8 \\
\hline Uranium, dissolved & $\mu \mathrm{g} / \mathrm{L}$ & 3.3 & 9.2 & 2.7 \\
\hline Ammonia (as N), total & $\mathrm{mg} / \mathrm{L}$ & 0.050 & 0.050 & 0.050 \\
\hline Bicarbonate as $\mathrm{CaCO}$, total $_{3}$ & $\mathrm{mg} / \mathrm{L}$ & 83.3 & 89.3 & 92.6 \\
\hline Bromide, dissolved & $\mathrm{mg} / \mathrm{L}$ & 0.064 & 0.064 & 0.063 \\
\hline Carbonate as $\mathrm{CaCO}$, total ${ }_{3}$ & $\mathrm{mg} / \mathrm{L}$ & $<10$ & $<10$ & $<10$ \\
\hline Chloride, dissolved & $\mathrm{mg} / \mathrm{L}$ & 11.9 & 11.5 & 13.8 \\
\hline Cyanide, total & $\mathrm{mg} / \mathrm{L}$ & $<0.0030$ & $<0.0030$ & $<0.0030$ \\
\hline Fluoride, dissolved & $\mathrm{mg} / \mathrm{L}$ & 2.39 & 3.65 & 2.11 \\
\hline Nitrate/Nitrite & $\mathrm{mg} / \mathrm{L}$ & 0.43 & 0.444 & 0.437 \\
\hline Sulfate, dissolved & $\mathrm{mg} / \mathrm{L}$ & 30.5 & 29.3 & 30.2 \\
\hline Total Dissolved Solids & $\mathrm{mg} / \mathrm{L}$ & 227 & 312 & 211 \\
\hline Total Inorganic Carbon & $\mathrm{mg} / \mathrm{L}$ & 7.4 & 11.1 & 9.6 \\
\hline Total Kjeldahl Nitrogen & $\mathrm{mg} / \mathrm{L}$ & $<0.20$ & $<0.20$ & $<0.20$ \\
\hline Total Organic Carbon & $\mathrm{mg} / \mathrm{L}$ & 0.35 & $<0.30$ & $<0.30$ \\
\hline $\begin{array}{c}\text { Total Organic Carbon, } \\
\text { dissolved }\end{array}$ & $\mathrm{mg} / \mathrm{L}$ & 0.56 & 0.91 & 0.31 \\
\hline $\mathrm{pH}(\mathrm{lab})$ & $\mathrm{pH}$ units & 8.31 & 8.42 & 8.74 \\
\hline Specific Conductance (lab) & $\mu \mathrm{mhos} / \mathrm{cm}$ & 280 & 275 & 276 \\
\hline
\end{tabular}

$\mu \mathrm{g} / \mathrm{L}$ - Micrograms per liter

$\mathrm{mg} / \mathrm{L}$ - Milligrams per liter

$\mu \mathrm{mhos} / \mathrm{cm}$ - Micromhos per centimeter

$<$ Less than reported value

\subsubsection{General Chemistry}

After the tracers were injected, groundwater samples were collected from each well for three consecutive weeks (i.e., J une 10, 17, and 24, 1997) and analyzed for general chemistry parameters by LAS 
laboratory. The parameters and results are tabulated in Table 3-3, Table 3-4, and Table 3-5.

Meaningful overall changes in the chemistry of each well over time were not observed. The system appears to have maintained equilibrium and injection and pumping have not perturbed the chemistry of the flow system. The variable concentrations of aluminum and iron are attributable to clays and colloid-size particles variously present in the samples.

It should be noted that in each of the wells, the final sample collected on J une 24, 1997 (Tables 3-3 through 3-5) has a reported bicarbonate concentration twice that of the other samples, including the baseline samples (Table 3-2). All the analyses from this date also have a higher reported laboratory $\mathrm{pH}$, suggesting an analytical problem occurred on this date with the sample aliquot for carbonate and $\mathrm{pH}$. This apparent problem is not evident in the other analyses.

Table 3-3

General Chemistry Results of Well ER-20-6 \#1 Water

(Page 1 of 2)

\begin{tabular}{|c|c|c|c|c|}
\hline Parameter & Units & June 10, 1997 & June 17,1997 & June 24, 1997 \\
\hline Aluminum, total & $\mu \mathrm{gg} / \mathrm{L}$ & 172 & 79.6 & 88.9 \\
\hline Aluminum, dissolved & $\mu \mathrm{g} / \mathrm{L}$ & 151 & 80.8 & 49.9 \\
\hline Arsenic, total & $\mu \mathrm{g} / \mathrm{L}$ & 11.1 & 4.5 & 6.8 \\
\hline Arsenic, dissolved & $\mu \mathrm{g} / \mathrm{L}$ & 12.4 & 8.5 & 9.4 \\
\hline Calcium, total & $\mu \mathrm{g} / \mathrm{L}$ & 5490 & 5940 & 5510 \\
\hline Calcium, dissolved & $\mu \mathrm{g} / \mathrm{L}$ & 5430 & 5890 & 5470 \\
\hline Chromium, dissolved & $\mu \mathrm{g} / \mathrm{L}$ & $\sim$ & $\sim$ & 3.7 \\
\hline Iron, total & $\mu \mathrm{g} / \mathrm{L}$ & 113 & 48.5 & 214 \\
\hline Iron, dissolved & $\mu \mathrm{g} / \mathrm{L}$ & 49.3 & 19 & 152 \\
\hline Lithium, total & $\mu \mathrm{g} / \mathrm{L}$ & 57.6 & 60.4 & 69 \\
\hline Lithium, dissolved & $\mu \mathrm{g} / \mathrm{L}$ & 44.9 & 49 & 86.3 \\
\hline Magnesium, total & $\mu \mathrm{g} / \mathrm{L}$ & 369 & 400 & 394 \\
\hline Magnesium, dissolved & $\mu \mathrm{g} / \mathrm{L}$ & 358 & 386 & 329 \\
\hline Manganese, total & $\mu \mathrm{g} / \mathrm{L}$ & $<3.1$ & $\sim$ & $<1.9$ \\
\hline Manganese, dissolved & $\mu \mathrm{g} / \mathrm{L}$ & $\sim$ & $\sim$ & $<1.3$ \\
\hline Phosphorus, total & $\mathrm{mg} / \mathrm{L}$ & 0.02 & 0.027 & 0.011 \\
\hline Potassium, total & $\mu \mathrm{g} / \mathrm{L}$ & 2370 & 1690 & 2460 \\
\hline Potassium, dissolved & $\mu \mathrm{g} / \mathrm{L}$ & 1970 & 2290 & 1510 \\
\hline Silicon, total & $\mu g / L$ & 24400 & 24300 & 20400 \\
\hline Silicon, dissolved & $\mu \mathrm{g} / \mathrm{L}$ & 23000 & 22000 & 21500 \\
\hline Sodium, total & $\mu \mathrm{g} / \mathrm{L}$ & 62200 & 63500 & 61300 \\
\hline Sodium, dissolved & $\mu \mathrm{g} / \mathrm{L}$ & 64600 & 61700 & 59500 \\
\hline Strontium, total & $\mu \mathrm{g} / \mathrm{L}$ & 13.2 & 15 & 14.1 \\
\hline Strontium, dissolved & $\mu \mathrm{g} / \mathrm{L}$ & 12.4 & 14 & 15.8 \\
\hline Uranium, total & $\mu \mathrm{g} / \mathrm{L}$ & 3 & 3 & 2.9 \\
\hline Uranium, dissolved & $\mu \mathrm{g} / \mathrm{L}$ & 2.8 & 3 & 3.1 \\
\hline
\end{tabular}


Table 3-3

General Chemistry Results of Well ER-20-6 \#1 Water

(Page 2 of 2)

\begin{tabular}{|c|c|c|c|c|}
\hline Parameter & Units & June 10, 1997 & June 17, 1997 & June 24, 1997 \\
\hline \hline Bicarbonate as $\mathrm{CaCO}_{3}$ & $\mathrm{mg} / \mathrm{L}$ & 87.1 & 87.2 & 45.3 \\
\hline Bromide, dissolved & $\mathrm{mg} / \mathrm{L}$ & 0.099 & 1.41 & 0.057 \\
\hline Chloride, dissolved & $\mathrm{mg} / \mathrm{L}$ & 11.6 & 11.6 & 12.3 \\
\hline Fluoride, dissolved & $\mathrm{mg} / \mathrm{L}$ & 2.58 & 2.57 & 2.61 \\
\hline Nitrate/Nitrite & $\mathrm{mg} / \mathrm{L}$ & 0.352 & 0.421 & 0.267 \\
\hline Sulfate, dissolved & $\mathrm{mg} / \mathrm{L}$ & 30.5 & 30.3 & 31.5 \\
\hline Dissolved Inorganic Carbon & $\mathrm{mg} / \mathrm{L}$ & 1.31 & 5.2 & 2.48 \\
\hline Total Dissolved Solids & $\mathrm{mg} / \mathrm{L}$ & 249 & 227 & 235 \\
\hline Total Kjeldahl Nitrogen & $\mathrm{mg} / \mathrm{L}$ & 3.22 & 3.41 & 4.11 \\
\hline & & & & 9.1 \\
\hline
\end{tabular}

$\mu \mathrm{g} / \mathrm{L}$ - Micrograms per liter

$\mathrm{mg} / \mathrm{L}$ - Milligrams per liter

$\sim$ Not analyzed

$\mu \mathrm{mhos} / \mathrm{cm}$ - Micromhos per centimeter

$<$ Less than reported value

Table 3-4

General Chemistry Results of Well ER-20-6 \#2 Water

(Page 1 of 2)

\begin{tabular}{|c|c|c|c|c|}
\hline Parameter & Units & June 10, 1997 & June 17, 1997 & June 24, 1997 \\
\hline Aluminum, total & $\mu \mathrm{g} / \mathrm{L}$ & 2300 & 2380 & 2590 \\
\hline Aluminum, dissolved & $\mu \mathrm{g} / \mathrm{L}$ & 1410 & 941 & 1340 \\
\hline Arsenic, total & $\mu g / L$ & 23.1 & 16 & 16.1 \\
\hline Arsenic, dissolved & $\mu \mathrm{g} / \mathrm{L}$ & 24 & 19 & 18.9 \\
\hline Calcium, total & $\mu \mathrm{g} / \mathrm{L}$ & 9220 & 9670 & 9100 \\
\hline Calcium, dissolved & $\mu \mathrm{g} / \mathrm{L}$ & 9060 & 9270 & 8880 \\
\hline Chromium, total & $\mu \mathrm{g} / \mathrm{L}$ & 209 & 36.8 & 44.6 \\
\hline Chromium, dissolved & $\mu g / L$ & $\sim$ & $\sim$ & $<6.5$ \\
\hline Iron, total & $\mu \mathrm{g} / \mathrm{L}$ & 3810 & 2640 & 3280 \\
\hline Iron, dissolved & $\mu \mathrm{g} / \mathrm{L}$ & 835 & 426 & 659 \\
\hline Lead, total & $\mu g / L$ & 18.6 & 4.5 & 13.1 \\
\hline Lead, dissolved & $\mu g / L$ & 5.1 & 2.6 & 3.6 \\
\hline Lithium, total & $\mu g / L$ & 53.5 & 51 & 57.9 \\
\hline Lithium, dissolved & $\mu g / L$ & 40.8 & 40.1 & 64.9 \\
\hline Magnesium, total & $\mu \mathrm{g} / \mathrm{L}$ & 723 & 737 & 738 \\
\hline Magnesium, dissolved & $\mu \mathrm{g} / \mathrm{L}$ & 730 & 733 & 713 \\
\hline Manganese, total & $\mu \mathrm{g} / \mathrm{L}$ & 69.4 & 58.4 & 60 \\
\hline Manganese, dissolved & $\mu \mathrm{g} / \mathrm{L}$ & 34.4 & 26.1 & 32.2 \\
\hline Mercury, total & $\mu g / L$ & $\sim$ & $\sim$ & 0.24 \\
\hline Mercury, dissolved & $\mu \mathrm{g} / \mathrm{L}$ & $\sim$ & $\sim$ & 0.33 \\
\hline Phosphorus, total & $\mathrm{mg} / \mathrm{L}$ & 0.072 & 0.046 & 0.028 \\
\hline Potassium, total & $\mu \mathrm{g} / \mathrm{L}$ & 2720 & 2760 & 3870 \\
\hline Potassium, dissolved & $\mu \mathrm{g} / \mathrm{L}$ & 3680 & 2780 & 3050 \\
\hline Silicon, total & $\mu g / L$ & 28500 & 28400 & 23600 \\
\hline
\end{tabular}


Table 3-4

General Chemistry Results of Well ER-20-6 \#2 Water

(Page 2 of 2)

\begin{tabular}{|c|c|c|c|c|}
\hline Parameter & Units & June 10, 1997 & June 17, 1997 & June 24, 1997 \\
\hline Silicon, dissolved & $\mu \mathrm{g} / \mathrm{L}$ & 24800 & 24700 & 22400 \\
\hline Sodium, total & $\mu g / L$ & 58800 & 56400 & 55900 \\
\hline Sodium, dissolved & $\mu \mathrm{g} / \mathrm{L}$ & 59500 & 57900 & 53900 \\
\hline Strontium, total & $\mu \mathrm{g} / \mathrm{L}$ & 17.7 & 18.5 & 18.5 \\
\hline Strontium, dissolved & $\mu g / L$ & 15.8 & 17.5 & 20.8 \\
\hline Uranium, total & $\mu \mathrm{g} / \mathrm{L}$ & 8.9 & 8.7 & 8.6 \\
\hline Uranium, dissolved & $\mu \mathrm{g} / \mathrm{L}$ & 6.4 & 5.4 & 7.8 \\
\hline Bicarbonate as $\mathrm{CaCO}_{3}$ & $\mathrm{mg} / \mathrm{L}$ & 93.1 & 90.2 & 46.9 \\
\hline Bromide, dissolved & $\mathrm{mg} / \mathrm{L}$ & 0.172 & 0.096 & 0.046 \\
\hline Chloride, dissolved & $\mathrm{mg} / \mathrm{L}$ & 11.5 & 11.6 & 11.4 \\
\hline Fluoride, dissolved & $\mathrm{mg} / \mathrm{L}$ & 3.01 & 2.92 & 2.96 \\
\hline Nitrate/Nitrite & $\mathrm{mg} / \mathrm{L}$ & 0.393 & 0.402 & 0.283 \\
\hline Sulfate, dissolved & $\mathrm{mg} / \mathrm{L}$ & 29.9 & 29.7 & 30.4 \\
\hline Dissolved Inorganic Carbon & $\mathrm{mg} / \mathrm{L}$ & 3.84 & 2.92 & 3.3 \\
\hline Total Dissolved Solids & $\mathrm{mg} / \mathrm{L}$ & 269 & 254 & 322 \\
\hline Total Kjeldahl Nitrogen & $\mathrm{mg} / \mathrm{L}$ & 3.09 & 2.85 & 4.06 \\
\hline $\mathrm{pH}$ (lab) & $\mathrm{pH}$ units & 8.14 & 8.18 & 9.21 \\
\hline Specific Conductance (lab) & $\mu \mathrm{mhos} / \mathrm{cm}$ & 282 & 282 & 273 \\
\hline
\end{tabular}

$\mu \mathrm{g} / \mathrm{L}$ - Micrograms per liter

$\mathrm{mg} / \mathrm{L}$ - Milligrams per liter

$<$ Less than reported value

$\mu \mathrm{mhos} / \mathrm{cm}$ - Micromhos per centimeter

$\sim$ Not analyzed

Table 3-5

General Chemistry Results of Well ER-20-6 \#3 Water

(Page 1 of 2)

\begin{tabular}{|c|c|c|c|c|}
\hline Parameter & Units & June 10, 1997 & June 17, 1997 & June 24, 1997 \\
\hline Aluminum, total & $\mu \mathrm{g} / \mathrm{L}$ & 128 & 181 & 202 \\
\hline Aluminum, dissolved & $\mu \mathrm{g} / \mathrm{L}$ & 154 & 137 & 59.8 \\
\hline Arsenic, total & $\mu \mathrm{g} / \mathrm{L}$ & 6.1 & 4.5 & 5.3 \\
\hline Arsenic, dissolved & $\mu \mathrm{g} / \mathrm{L}$ & 4.1 & 4.2 & $\sim$ \\
\hline Calcium, total & $\mu \mathrm{g} / \mathrm{L}$ & 10200 & 10300 & 9440 \\
\hline Calcium, dissolved & $\mu g / L$ & 9810 & 9890 & 9350 \\
\hline Chromium, dissolved & $\mu \mathrm{g} / \mathrm{L}$ & $\sim$ & $\sim$ & $<2.8$ \\
\hline Iron, total & $\mu \mathrm{g} / \mathrm{L}$ & 249 & 97.9 & 299 \\
\hline Iron, dissolved & $\mu \mathrm{g} / \mathrm{L}$ & 231 & 90.7 & 199 \\
\hline Lithium, total & $\mu g / L$ & 49.2 & 48.7 & 55.1 \\
\hline Lithium, dissolved & $\mu g / L$ & 38.5 & 34.3 & 59.4 \\
\hline Magnesium, total & $\mu g / L$ & 788 & 760 & 752 \\
\hline Magnesium, dissolved & $\mu g / L$ & 741 & 762 & 701 \\
\hline Manganese, total & $\mu \mathrm{g} / \mathrm{L}$ & 15.1 & 6.2 & 6.1 \\
\hline Manganese, dissolved & $\mu \mathrm{g} / \mathrm{L}$ & 15 & 6.6 & 4.7 \\
\hline
\end{tabular}


Table 3-5

General Chemistry Results of Well ER-20-6 \#3 Water

(Page 2 of 2)

\begin{tabular}{|c|c|c|c|c|}
\hline Parameter & Units & June 10, 1997 & June 17, 1997 & June 24, 1997 \\
\hline Phosphorus, total & $\mathrm{mg} / \mathrm{L}$ & 0.02 & 0.017 & 0.014 \\
\hline Potassium, total & $\mu \mathrm{g} / \mathrm{L}$ & 3160 & 2590 & 3120 \\
\hline Potassium, dissolved & $\mu \mathrm{g} / \mathrm{L}$ & 2780 & 3540 & 2750 \\
\hline Silicon, total & $\mu g / L$ & 22300 & 22500 & 19600 \\
\hline Silicon, dissolved & $\mu g / L$ & 20300 & 21000 & 19800 \\
\hline Sodium, total & $\mu g / L$ & 51400 & 51200 & 52700 \\
\hline Sodium, dissolved & $\mu \mathrm{g} / \mathrm{L}$ & 52600 & 53600 & 50700 \\
\hline Strontium, total & $\mu \mathrm{g} / \mathrm{L}$ & 22.7 & 22.7 & 21.7 \\
\hline Strontium, dissolved & $\mu g / L$ & 21.8 & 21.3 & 22.1 \\
\hline Uranium, total & $\mu \mathrm{g} / \mathrm{L}$ & 2.7 & 2.7 & 2.6 \\
\hline Uranium, dissolved & $\mu g / L$ & 2.8 & 2.7 & 2.7 \\
\hline Bicarbonate as $\mathrm{CaCO}_{3}$ & $\mathrm{mg} / \mathrm{L}$ & 80.7 & 84.5 & 43 \\
\hline Bromide, dissolved & $\mathrm{mg} / \mathrm{L}$ & 0.104 & 0.08 & 0.046 \\
\hline Chloride, dissolved & $\mathrm{mg} / \mathrm{L}$ & 11.5 & 11.3 & 11 \\
\hline Fluoride, dissolved & $\mathrm{mg} / \mathrm{L}$ & 2.41 & 2.47 & 2.51 \\
\hline Nitrate/Nitrite & $\mathrm{mg} / \mathrm{L}$ & 0.418 & 0.435 & 0.39 \\
\hline Sulfate, dissolved & $\mathrm{mg} / \mathrm{L}$ & 29.3 & 29.4 & 29.8 \\
\hline Dissolved Inorganic Carbon & $\mathrm{mg} / \mathrm{L}$ & 3.65 & 3.63 & 5.07 \\
\hline Total Dissolved Solids & $\mathrm{mg} / \mathrm{L}$ & 222 & 215 & 188 \\
\hline Total Kjeldahl Nitrogen & $\mathrm{mg} / \mathrm{L}$ & 2.75 & 2.95 & 3.89 \\
\hline $\mathrm{pH}$ (lab) & pH units & 8.29 & 8.26 & 9.95 \\
\hline Specific Conductance (lab) & $\mu \mathrm{mhos} / \mathrm{cm}$ & 274 & 275 & 269 \\
\hline
\end{tabular}

$\mu \mathrm{g} / \mathrm{L}$ - Micrograms per liter)

$\mathrm{mg} / \mathrm{L}$ - Milligrams per liter

$\sim$ Not analyzed

$\mu \mathrm{mhos} / \mathrm{cm}$ - Micromhos per centimeter

$<$ Less than reported value

\subsubsection{Groundwater Characterization}

Prior to the completion of the experiment, groundwater characterization samples were obtained on August 27, 1997 for Well \#1, and J uly 18, 1997, for Well \#2 and Well \#3. The parameters and results are tabulated in Table 3-6.

There were no significant changes in the overall chemistry of the groundwater. 
Table 3-6

Groundwater Characterization Results of Well ER-20-6 Water

(Page 1 of 2)

\begin{tabular}{|c|c|c|c|c|}
\hline Parameter & Units & Well \#1 & Well \#2 & Well \#3 \\
\hline Aluminum, total & $\mu \mathrm{g} / \mathrm{L}$ & 61.5 & 2360 & 118 \\
\hline Aluminum, dissolved & $\mu \mathrm{g} / \mathrm{L}$ & $<35$ & 1290 & $<7.7$ \\
\hline Arsenic, total & $\mu \mathrm{g} / \mathrm{L}$ & 7.7 & 15.6 & 4 \\
\hline Arsenic, dissolved & $\mu \mathrm{g} / \mathrm{L}$ & 8.7 & 14.7 & $<5.9$ \\
\hline Barium, total & $\mu \mathrm{g} / \mathrm{L}$ & 2.4 & $\sim$ & $\sim$ \\
\hline Barium, dissolved & $\mu \mathrm{g} / \mathrm{L}$ & 1.9 & $\sim$ & $\sim$ \\
\hline Cadmium, total & $\mu \mathrm{g} / \mathrm{L}$ & $<3$ & $<1$ & $<1$ \\
\hline Cadmium, dissolved & $\mu \mathrm{g} / \mathrm{L}$ & $<3$ & $<1.1$ & $<1.1$ \\
\hline Calcium, total & $\mu \mathrm{g} / \mathrm{L}$ & 5,400 & $\sim$ & $\sim$ \\
\hline Calcium, dissolved & $\mu \mathrm{g} / \mathrm{L}$ & 5,420 & 9,020 & 9,750 \\
\hline Chromium, total & $\mu \mathrm{g} / \mathrm{L}$ & $<4$ & 296 & $<2$ \\
\hline Chromium, dissolved & $\mu \mathrm{g} / \mathrm{L}$ & $<4$ & $<4.4$ & $<2.6$ \\
\hline Iron, total & $\mu \mathrm{g} / \mathrm{L}$ & 54.7 & 12,500 & 257 \\
\hline Iron, dissolved & $\mu \mathrm{g} / \mathrm{L}$ & 19.5 & 730 & 179 \\
\hline Lead, total & $\mu \mathrm{g} / \mathrm{L}$ & $<2$ & 14.4 & $<1$ \\
\hline Lead, dissolved & $\mu \mathrm{g} / \mathrm{L}$ & $<2$ & 2.5 & $<1.1$ \\
\hline Lithium, total & $\mu \mathrm{g} / \mathrm{L}$ & 65.9 & 50 & 48.7 \\
\hline Lithium, dissolved & $\mu \mathrm{g} / \mathrm{L}$ & 61.5 & 66.3 & 64.4 \\
\hline Magnesium, total & $\mu \mathrm{g} / \mathrm{L}$ & 343 & $\sim$ & $\sim$ \\
\hline Magnesium, dissolved & $\mu \mathrm{g} / \mathrm{L}$ & 318 & 721 & 783 \\
\hline Manganese, total & $\mu \mathrm{g} / \mathrm{L}$ & $<2$ & 102 & 2.9 \\
\hline Manganese, dissolved & $\mu \mathrm{g} / \mathrm{L}$ & $<2$ & 31.6 & 3 \\
\hline Mercury, total & $\mu \mathrm{g} / \mathrm{L}$ & $<0.2$ & 0.23 & $<0.2$ \\
\hline Mercury, dissolved & $\mu \mathrm{g} / \mathrm{L}$ & $<0.2$ & 0.3 & $<0.2$ \\
\hline Potassium, dissolved & $\mu \mathrm{g} / \mathrm{L}$ & 1,670 & 3,030 & 3280 \\
\hline Selenium, total & $\mu \mathrm{g} / \mathrm{L}$ & $<3$ & $<4$ & $<4$ \\
\hline Selenium, dissolved & $\mu \mathrm{g} / \mathrm{L}$ & $<3$ & $<4.4$ & $<4.4$ \\
\hline Silicon, total & $\mu \mathrm{g} / \mathrm{L}$ & 21,900 & 20,000 & 17,000 \\
\hline Silicon, dissolved & $\mu \mathrm{g} / \mathrm{L}$ & 23,500 & 23,500 & 17,300 \\
\hline Silver, total & $\mu \mathrm{g} / \mathrm{L}$ & $<4$ & $<1$ & $<1$ \\
\hline Silver, dissolved & $\mu \mathrm{g} / \mathrm{L}$ & 4 & $<1.1$ & $<1.1$ \\
\hline Sodium, total & $\mu \mathrm{g} / \mathrm{L}$ & 60,000 & $\sim$ & $\sim$ \\
\hline Sodium, dissolved & $\mu \mathrm{g} / \mathrm{L}$ & 57,000 & 55,900 & 52,900 \\
\hline Strontium, total & $\mu \mathrm{g} / \mathrm{L}$ & 15.5 & 19.8 & 21.1 \\
\hline Strontium, dissolved & $\mu \mathrm{g} / \mathrm{L}$ & 14 & 18.7 & 21.8 \\
\hline Uranium, total & $\mu g / L$ & $\sim$ & 9.1 & 2.6 \\
\hline Uranium, dissolved & $\mu \mathrm{g} / \mathrm{L}$ & $\sim$ & 6.9 & 2.6 \\
\hline Actinium-228 & $\mathrm{pCi} / \mathrm{L}$ & -6 & -1 & 4 \\
\hline Bismuth-212 & $\mathrm{pCi} / \mathrm{L}$ & -22 & 20 & -7 \\
\hline Bismuth-214 & $\mathrm{pCi} / \mathrm{L}$ & 0 & 1.1 & 7 \\
\hline Carbon-14 & $\mathrm{pCi} / \mathrm{L}$ & 25 & -2 & -11 \\
\hline Cesium-134 & $\mathrm{pCi} / \mathrm{L}$ & -3.2 & -0.98 & -1.4 \\
\hline
\end{tabular}


Table 3-6

Groundwater Characterization Results of Well ER-20-6 Water (Page 2 of 2)

\begin{tabular}{|c|c|c|c|c|}
\hline Parameter & Units & Well \#1 & Well \#2 & Well \#3 \\
\hline Cesium-137 & $\mathrm{pCi} / \mathrm{L}$ & -1.9 & 0.5 & -2.5 \\
\hline Cobalt-57 & $\mathrm{pCi} / \mathrm{L}$ & -0.4 & 0.2 & -1.2 \\
\hline Cobalt-60 & $\mathrm{pCi} / \mathrm{L}$ & 1.8 & -0.39 & -2 \\
\hline lodine-129 & $\mathrm{pCi} / \mathrm{L}$ & 0.04 & 2.4 & 1 \\
\hline Lead-210 & $\mathrm{pCi} / \mathrm{L}$ & -30 & 90 & 70 \\
\hline Lead-212 & $\mathrm{pCi} / \mathrm{L}$ & -3.6 & 2.3 & -1.3 \\
\hline Lead-214 & $\mathrm{pCi} / \mathrm{L}$ & -1 & 3.9 & 9 \\
\hline Plutonium-239/240 & $\mathrm{pCi} / \mathrm{L}$ & 0.011 & 0.02 & -0.0027 \\
\hline Plutonium-238 & $\mathrm{pCi} / \mathrm{L}$ & 0.001 & $\sim$ & $\sim$ \\
\hline Potassium, total & $\mathrm{pCi} / \mathrm{L}$ & 1,890 & 0.007 & -0.014 \\
\hline Potassium-40 & $\mathrm{pCi} / \mathrm{L}$ & -3 & 15 & 19 \\
\hline Radium-226 & $\mathrm{pCi} / \mathrm{L}$ & 0 & -3 & 40 \\
\hline Strontium $89 / 90$ & $\mathrm{pCi} / \mathrm{L}$ & -0.01 & -0.03 & 0.32 \\
\hline Technetium-99 & $\mathrm{pCi} / \mathrm{L}$ & 0.5 & -0.7 & 1.6 \\
\hline Thallium-208 & $\mathrm{pCi} / \mathrm{L}$ & 0.5 & 2.8 & -1.2 \\
\hline Thorium-234 & $\mathrm{pCi} / \mathrm{L}$ & -26 & 12 & 11 \\
\hline Tritium & $\mathrm{pCi} / \mathrm{L}$ & 2,310 & 4,360 & 770 \\
\hline Uranium-235 & $\mathrm{pCi} / \mathrm{L}$ & -4 & 13 & -7 \\
\hline Gross Alpha, total & $\mathrm{pCi} / \mathrm{L}$ & 7.7 & 19 & 4.3 \\
\hline Gross Beta, total & $\mathrm{pCi} / \mathrm{L}$ & 2.1 & 8.4 & 3.6 \\
\hline Bicarbonate as $\mathrm{CaCO}_{3}$ & $\mathrm{mg} / \mathrm{L}$ & 92.7 & 81.9 & 85.9 \\
\hline Bromide, dissolved & $\mathrm{mg} / \mathrm{L}$ & 0.067 & 0.051 & 0.071 \\
\hline Carbonate as $\mathrm{CaCO}_{3}$ & $\mathrm{mg} / \mathrm{L}$ & $<10$ & $<10$ & $<10$ \\
\hline Chloride, dissolved & $\mathrm{mg} / \mathrm{L}$ & 12.3 & 12 & 11.8 \\
\hline Fluoride, dissolved & $\mathrm{mg} / \mathrm{L}$ & 2.86 & 2.91 & 2.52 \\
\hline Sulfide, total & $\mathrm{mg} / \mathrm{L}$ & 0.6 & 0.6 & 0.6 \\
\hline Sulfate, dissolved & $\mathrm{mg} / \mathrm{L}$ & 31.4 & 31.1 & 30.3 \\
\hline Total Dissolved Solids & $\mathrm{mg} / \mathrm{L}$ & 210 & 279 & 222 \\
\hline Total Organic Carbon, total & $\mathrm{mg} / \mathrm{L}$ & 0.3 & 0.37 & 0.34 \\
\hline Total Organic Carbon, dissolved & $\mathrm{mg} / \mathrm{L}$ & 0.3 & 0.56 & 0.78 \\
\hline $\mathrm{pH}$ (lab) & $\mathrm{pH}$ units & 7.99 & 8.46 & 8.52 \\
\hline Specific Conductance (lab) & $\mu \mathrm{mhos} / \mathrm{cm}$ & 303 & 301 & 288 \\
\hline
\end{tabular}

$\mu \mathrm{g} / \mathrm{L}$ - Micrograms per liter $\mathrm{mg} / \mathrm{L}$ - Milligrams per liter umhos/cm - Micromhos per centimeter

$\sim$ Not analyzed

pCi/L - Picocuries per liter

$<$ Less than reported value 


\subsection{Tracer Data}

Table 3-7 gives the amount of each tracer that was injected. N ote that for sodium iodide ( $\mathrm{Nal}$ ), the amount shown is for the iodide portion of the $\mathrm{Nal}$, which was actual tracer. The given amounts of microspheres in terms of the number of microspheres is computed based on the weight of the microspheres injected. This conversion was required because the analysis method for microspheres provides the concentration in terms of the number of microspheres per milliliter.

Table 3-7

Tracer Injection Mass

\begin{tabular}{|c|c|}
\hline Iodide & $48.26 \mathrm{~kg}$ \\
\hline 2,6 DFBA & $57.00 \mathrm{~kg}$ \\
\hline PFBA & $57.00 \mathrm{~kg}$ \\
\hline Red Microspheres & $1.46 \mathrm{E}+15$ (\# of microspheres) \\
\hline Yellow Microspheres & $1.48 \mathrm{E}+15$ (\# of microspheres) \\
\hline
\end{tabular}

2,6 DFBA - Difluorobenzoic acid PFBA - Pentafluorobenzoic acid

In order to minimize the impact of a foreign water source on the geol ogic formation, water from Well ER-20-6 \#3 was used for preparing the tracer injectates. The water was pumped into a clean tanker truck at the wellhead. The $\mathrm{pH}$ of the water was measured (Orion 290A pH meter) at $8.6 \pm 0.1$ standard $\mathrm{pH}$ units.

\subsubsection{Well ER-20-6 \#2 Injectate}

Well \#2 injectate consisted of a mixture of PFBA and fluorescent yellow/green dyed carboxylate modified latex polystyrene microspheres (yellow/green microspheres). The tracers were first mixed into a concentrate which was then mixed into the total injectate volume.

The concentrate was mixed in six plastic-lined drums, each filled with 114 liters $(\mathrm{L})$ of Well \#3 water. Sodium hydroxide $(\mathrm{NaOH})$ pellets (VWR Brand) were added to each of the drums (1,846 grams [g] in five of the drums and $1,300 \mathrm{~g}$ in the sixth drum). The $\mathrm{NaOH}$ was added in approximately equimol ar amounts to facilitate dissolution of the PFBA. The $\mathrm{NaOH}$ solution was mixed overnight using an air bubbling device until the pellets were completely dissolved. The PFBA (Oakwood Products, I nc., West Columbia, SC) was added to each of the drums (10 kilograms $[\mathrm{kg}]$ in the first five drums and $7 \mathrm{~kg}$ in the sixth drum). The solution was mixed for several hours using an air bubbling device until the powdered acid was completely dissolved and the solution remained clear. The $\mathrm{pH}$ of each of the solutions was measured and 85-87 percent phosphoric acid (J T Baker) was added until the $\mathrm{pH}$ was $8.6 \pm 0.1$ standard $\mathrm{pH}$ units. 
Standards of yellow/green microspheres (Interfacial Dynamics, Portland, OR) were prepared by serial dilution of the microsphere concentrate ( 2 percent $\mathrm{w} / \mathrm{v}$ [30 $\mathrm{g}$ in $1,500 \mathrm{~mL}]$ ). The four successive 100 -fold dilutions ranged from $1: 100$ to $1: 1,000,000$. Approximately $180 \mathrm{~mL}$ of each of the dilution standards were stored. The remaining solutions which total ed $29.6 \mathrm{~g}$ of yellow/green microspheres were combined and distributed equally among the six drums, about $1.5 \mathrm{~L}$ per drum, and mixed thoroughly.

The final drum concentrates, about $680 \mathrm{~L}$, were pumped into one of two interconnected tanker trucks that contained $21,955 \mathrm{~L}$ of Well \#3 water. The drums were rinsed with Well \#3 water. The rinsate water, about $76 \mathrm{~L}$, was also pumped into the tanker trucks which brought the total injectate volume in the tanker trucks up to $22,713 \mathrm{~L}$. The solution was circulated between the trucks for about two hours to ensure thorough mixing of the tracers. Solution samples were tested by high performance liquid chromatography (HPLC) every half hour until the concentration of two consecutive samples were within 10 percent deviation of one another.

\subsubsection{Well ER-20-6 \#1 Injectate}

Well \#1 injectate consisted of a mixture of 2,6 difluorobenzoic acid (DFBA), Nal and fluorescent Nile Red dyed carboxylate modified latex polystyrene microspheres (Nile Red microspheres). The sol ute tracers were first mixed into concentrates which were then mixed into the total injectate volume.

The 2,6 DFBA concentrate was mixed in six plastic-lined drums, each filled with $114 \mathrm{~L}$ of Well \#3 water. The $\mathrm{NaOH}$ pellets (VWR Brand) were added to each of the drums $(2,532 \mathrm{~g}$ in five of the drums and $1,772 \mathrm{~g}$ in the sixth drum). The $\mathrm{NaOH}$ was added in approximately equimolar amounts to facilitate dissolution of the 2,6-DFBA. The $\mathrm{NaOH}$ solution was mixed several hours using an air bubbling device until the pellets were completely dissolved. The 2,6-DFBA (Oakwood Products, Inc., West Columbia, SC) was added to each of the drums (10 kg in the first five drums and $7 \mathrm{~kg}$ in the sixth drum). The solution was mixed overnight using an air bubbling device. A large portion of the acid remained undissolved the following morning. The solutions in the drums were mixed mechanically with a stainless steel paddle attached to a power drill until the powdered acid was completely dissolved and the solution remained clear. The average measured $\mathrm{pH}$ of each of the solutions was about 10.3 standard pH units. Addition of 85-87 percent phosphoric acid (J T Baker) to lower the $\mathrm{pH}$ to the formation water $\mathrm{pH}$ proved futile since the 2,6-DFBA would precipitate out of solution during each acid addition. The $\mathrm{pH}$ nonadjusted solution was pumped into one of two interconnected tanker trucks. The drums were rinsed with about $76 \mathrm{~L}$ of Well \#3 water and the rinsate was also pumped into one of two interconnected tanker trucks. 
The Nal concentrate was also mixed in six plastic-lined drums, each filled with $114 \mathrm{~L}$ of Well \#3 water. The $\mathrm{Nal}$ (Aldrich) was added to each of the drums ( $10 \mathrm{~kg}$ in the first five drums and $7 \mathrm{~kg}$ in the sixth drum). The solution was mixed for about an hour using an air bubbling device until the salt was completely dissolved and the solution remained clear. The Nal solution was pumped into one of two interconnected tanker trucks. The drums were rinsed with about $76 \mathrm{~L}$ of Well \#3 water and the rinsate was then pumped into one of the two interconnected tanker trucks.

Standards of Nile Red microspheres (Interfacial Dynamics, Portland, OR) were prepared by serial dilution of the microsphere concentrate (4 percent $w / v$ [30 g in $750 \mathrm{~mL}$ ]). The four successive 100-fold dilutions ranged from 1:100 to $1: 1,000,000$. Approximately $180 \mathrm{~mL}$ of each of the dilution standards were stored. The remaining solutions, which totaled $29.2 \mathrm{~g}$ of Nile red microspheres, were combined and the mixture was poured directly into one of two interconnected tanker trucks. This approach was used because the LANL representative felt the microspheres might clump together if they were poured directly into the 2,6-DFBA concentrates or $\mathrm{Nal}$ concentrates due to the high ionic strengths of both solutions.

The total injectate volume in the tanker trucks was $22,713 \mathrm{~L}$. The solution was circulated between the trucks about two hours to ensure thorough mixing of the tracers. Solution samples were tested by HPLC every half hour until the concentration of two consecutive samples were within a 10 percent deviation of one another.

The $\mathrm{pH}$ of injectate samples was measured. The $\mathrm{pH}$ of the Well \#2 injectate was $8.7 \pm 0.1$ standard $\mathrm{pH}$ units. The $\mathrm{pH}$ of the Well \#1 injectate was $9.95 \pm 0.1$ standard $\mathrm{pH}$ units.

\subsubsection{Injectate Concentration Determination}

The concentration of the chemical tracers in the injectates was determined by HPLC independently by the IT field lab and the HRC laboratory. The values are compared in Table 3-8 as follows.

The relative percent difference between the concentration values obtained by each lab for iodide (I), 2,6-DF BA, and PFBA were 1.24 percent, 14.9 percent, and 7.09 percent, respectively. 
Table 3-8

Tracer Injectate Concentrations

(micrograms per liter)

\begin{tabular}{|c|c|c|c|c|}
\hline & $\begin{array}{c}\text { Analysis } \\
\text { Location }\end{array}$ & $\mathbf{I}$ & 2,6-DFBA & PFBA \\
\hline \hline Run 1 & field & 2,155 & 2,595 & 2,255 \\
\hline Run 2 & field & 2,120 & 2,587 & 2,207 \\
\hline Run 3 & field & 2,078 & 2,413 & 2,275 \\
\hline Run 4 & field & 2,094 & 2,360 & 2,250 \\
\hline Average & & 2,112 & 2,489 & 2,247 \\
\hline Standard Deviation & & 29 & 104 & 25 \\
\hline Percent Average Deviation & & $1.4 \%$ & $4.2 \%$ & $1.1 \%$ \\
\hline Run 1 & & & & \\
\hline Run 2 & HRC & 2138 & 2,144 & 2,393 \\
\hline Average & HRC & $\sim$ & $\sim$ & 2431 \\
\hline Standard Deviation & & 2,138 & 2,144 & 2,412 \\
\hline Percent Average Deviation & & NA & NA & 27 \\
\hline
\end{tabular}

HRC - Harry Reid Center

NA - Not applicable

$\sim$ Means not analyzed

\subsubsection{HPLC System Components}

The Spectra-Physics HPLC system (Thermo-Separation Products, Albuquerque, NM) consisted of the following components:

- P1500-020 Binary Isocratic Pump

- SC100-0234 Ultra-Violet-Visible Variable Wavelength HPLC Detector (Deuterium Lamp)

- A4523-110 ChromJet Intergrator with LABNET Interface

- A45052-010 Rheodyne 7125 Kit with Switch and Mount

- Rheodyne Sample Loops - Assorted (50 - 200 microliters $[\mu L]$ )

The col umn used with the HPLC system was a Supel cosil LC-ABZ $5 \mu \mathrm{m}$ $15 \mathrm{~cm} \times 4.6 \mathrm{~mm}$ HPLC column (Supelco).

Computer interface components for the HPLC system consisted of a Micron DX4-486 100M Hz PC and a HP LaserJ et III printer.

The computer interface software for the HPLC system was WINNER on Windows software (Thermo-Separation Products). 


\subsubsection{HPLC System Settings}

The following settings for the HPLC detector and pump were maintained throughout the experiment.

- Detector settings: wavelength, 230 nanometers; rise time, 0.3 seconds; AUF range, 0.002

- Pump setting: flow rate, $1.0 \mathrm{~mL} /$ minute ( $800-900$ pounds per square inch [psi])

\subsubsection{HPLC Mobile Phase Composition}

The nominal composition of the mobile phase solution for HPLC analysis of 2,6-DFBA, PFBA, and I was 62 percent 0.01 molar (M) potassium phosphate $\left(\mathrm{KH}_{2} \mathrm{PO}_{4}\right)$ buffer and 38 percent HPLC grade acetonitrile $\left(\mathrm{CH}_{3} \mathrm{CN}\right)$ (Burdick and J ackson) by volume at $\mathrm{pH} 2.35 \pm$ 0.15

The $0.01 \mathrm{M} \mathrm{KH}_{2} \mathrm{PO}_{4}$ buffer was obtained by dilution of a stock $0.05 \mathrm{M}$ $\mathrm{KH}_{2} \mathrm{PO}_{4}, \mathrm{pH} 2.5$, buffer solution prepared at the HRC. The $0.05 \mathrm{M}$ $\mathrm{KH}_{2} \mathrm{PO}_{4}$ solution was prepared from the addition of ultrapure potassium phosphate (J T Baker) to $\sim 18$ megaohm (M ohm) deionized water. All volumes and weights were $\mathrm{N}$ ational Institute of Standards and Technology (NIST) traceable. The pH was adjusted to $2.5 \pm 0.1$ with 85-87 percent phosphoric acid (J T Baker). The solution was degassed with helium, 99.9998 percent purity (Air Liquide).

\subsubsection{Standards Preparation and Quality Control}

A stock standard mixture consisting of $1,000 \mathrm{mg} / \mathrm{L}$ of each chemical tracer (i.e., 1,000 mg/L 2,6-DF BA, 1,000 mg/L PFBA, and 1,000 mg/L I-) was prepared at the HRC by IT personnel using the tracer chemicals dissolved in Well \#3 water. All volumes and weights were NIST traceable. Aliquots of the $1,000 \mathrm{mg} / \mathrm{L}$ stock solution were diluted to prepare standards which ranged from 10 to $250 \mu \mathrm{g} / \mathrm{L}$. In addition, HRC laboratory staff prepared a 1,000 mg/L mixed tracer verification standard which was diluted to appropriate standard concentrations. A high purity NIST traceable iodide standard (High-Purity Standards) was also used for verification purposes.

Calibration curves were prepared using linear regression techniques on a series of standards for each analyte. At the beginning of the experiment, when tracer concentrations were high, three point calibration curves were prepared using 50, 100, and $250 \mu \mathrm{g} / \mathrm{L}$ standard mix solutions and a 50 microliter $(\mu \mathrm{L})$ injection loop. As tracer concentration declined, a $200 \mu \mathrm{L}$ injection loop was used. Sample dilutions were necessary throughout the course of the experiment to 
ensure that samples concentrations fell within the linear range of the calibration curves.

An initial $100 \mu \mathrm{g} / \mathrm{L}$ calibration check standard diluted from a different $1,000 \mathrm{mg} / \mathrm{L}$ stock standard solution prepared by the HRC staff was analyzed for the first calibration performed. The results were within 10 percent of the predicted results with the exception of iodide. As a result, a NIST traceable high purity iodide standard was used to confirm that the IT standard was prepared properly.

A $100 \mu \mathrm{g} / \mathrm{L}$ mid-range calibration check standard was analyzed at a minimum frequency of 1 in every 20 samples. In most instances, the measured concentration of the check standard was within 10 percent of the true value. If the value differed by a little more than 10 percent, professional judgement was used to determine if the preparation of a new calibration curve was warranted.

A duplicate sample was analyzed at a frequency of 1 in 20 samples. In most instances, the measured concentration of the duplicate was within 20 percent of the true value. If the value differed by a little more than 20 percent, professional judgement was used to determine if the preparation of a new calibration curve was warranted.

\subsubsection{Microsphere Field Screening}

Field-screening for semi-quantitative determination of microspheres involved vacuum filtration of a water sample through a 0.2 micrometer $(\mu \mathrm{m})$ polycarbonate membrane (Poretics) and microscopic examination of the surface for microspheres. Dilution of the sample in varying proportions was necessary once detection of the microspheres occurred at the well. The vol ume of sample filtered, dilute or not, was $100 \mathrm{~mL}$. Ultraviolet microscopic examination of the membranes involved counting the number of microspheres in six fields-of-view per sample and averaging the results. This method was discontinued since the results were not consistent between observers.

In addition to field-screening, unfiltered $40 \mathrm{~mL}$ water samples were sent to LANL for microsphere quantitation using flow cytometry methods.

\subsubsection{Tracer-Data Time}

Due to the substantial depths of the wells and the lengthy plumbing arrangement used for sampling, there is a significant time delay from the time groundwater leaves the formation and enters the well bore to the time when the sample is collected for analysis. Since the tracer data analysis accounts for the time between injection and arrival at the 
well location, this time delay must be subtracted from the time of sample collection to calculate the actual transport time. Based on the volumetric capacities of the various parts of the well and plumbing system, and typical pumping rates for Wells ER-20-6 \#1 and \#2 of 28.35 $\mathrm{m}^{3} / \mathrm{d}(5.2 \mathrm{gpm})$, the delay from the midpoint of the well screens to the sampling ports is about 164 minutes, or 0.116 days.

\subsubsection{Tracer Concentration Plots}

Figures 3-7 through 3-12 contain plots of tracer concentration versus time for each well. Figures 3-7 through 3-9 show the solute tracer concentration plots for Wells ER-20-6 \#1, \#2, and \#3 respectively; and Figures 3-10 through 3-12 show the microsphere concentration plots for those wells. The solute tracers and the microsphere tracers are shown on separate plots because of the different scales. Figure 3-7 (for Well ER-20-6 \#1) shows only the decay curve of tracer concentrations for the tracers injected into that well. Figure 3-8 (for Well ER-20-6 \#2) shows both the concentrations of the tracers injected into Well ER-20-6 \#2 and the concentrations of tracers arriving from Well ER-20-6 \#1. Table 3-9 shows the concentrations of tracers arriving from both Wells ER-20-6 $\# 1$ and \#2.

Figures 3-10 through 3-12 show the same for microspheres. A noteworthy feature of the microsphere breakthroughs is the second peak in the plots for both Well ER-20-6 \#2 and \#3 arriving coincidently. This feature will be discussed in Section 7.0.

Figures 3-13 through 3-16 show the chemical tracer concentrations in the upper and lower completion zones of Wells E R-20-6 \#1 and \#2, respectively. These plots are based on analyses of samples taken from those zones using a discrete bailer. The plots show that the tracer concentrations were consistent for both the zones.

All of these plots show the measured concentrations for each tracer. The analysis of tracer breakthroughs is presented in Section 7.0, and is presented in terms of normalized concentrations. The tracer concentrations were normalized by dividing by the initial injectate concentration.

\subsubsection{Tracer Recoveries}

Table 3-9 Shows the computed tracer recoveries for each well and the total recovery of each tracer. Recoveries were low, which correlates with the fact that observed concentrations were an order of magnitude or more lower than expected. Some of the nonrecovered tracer mass would be recovered with further pumping, which is evident from the persistent tails of the tracer concentration curves. However, this 
probably cannot account for all of the nonrecovered tracer mass. This question will be dealt with in the analysis of the experiment presented in Section 7.0.

Table 3-9

Tracer Recoveries

\begin{tabular}{||c|c|c|c|c|c|}
\hline Tracer & Format & Well \#3 & Well \#2 & Well \#1 & Total Recovery \\
\hline \hline lodide & Mass Recovery (kg) & 3.58 & 0.23 & 0.90 & 4.70 \\
\hline lodide & \% Recovery & 7.40 & 0.47 & 1.85 & 9.73 \\
\hline 2,6 DFBA & Mass Recovery $(\mathrm{kg})$ & 4.80 & 0.28 & 0.98 & 6.07 \\
\hline 2,6 DFBA & \% Recovery & 8.43 & 0.50 & 1.72 & 10.65 \\
\hline PFBA & Mass Recovery (kg) & 13.97 & 3.69 & & 17.66 \\
\hline PFBA & \% Recovery & 24.51 & 6.47 & & 30.98 \\
\hline Red microspheres & Mass Recovery $(\#)$ & $8.20 \mathrm{E}+12$ & $3.75 \mathrm{E}+12$ & $2.96 \mathrm{E}+13$ & $4.15 \mathrm{E}+13$ \\
\hline Red microspheres & \% Recovery & 0.52 & 0.24 & 1.88 & 2.84 \\
\hline Yellow microspheres & Mass Recovery $(\#)$ & $1.99 \mathrm{E}+13$ & $1.32 \mathrm{E}+14$ & $1.13 \mathrm{E}+11$ & $1.52 \mathrm{E}+14$ \\
\hline Yellow microspheres & \% Recovery & 1.18 & 7.87 & 0.01 & 10.28 \\
\hline
\end{tabular}

2,6 DFBA - 2,6 Difluorobenzoic acid

PFBA - Pentafluorobenzoic acid 


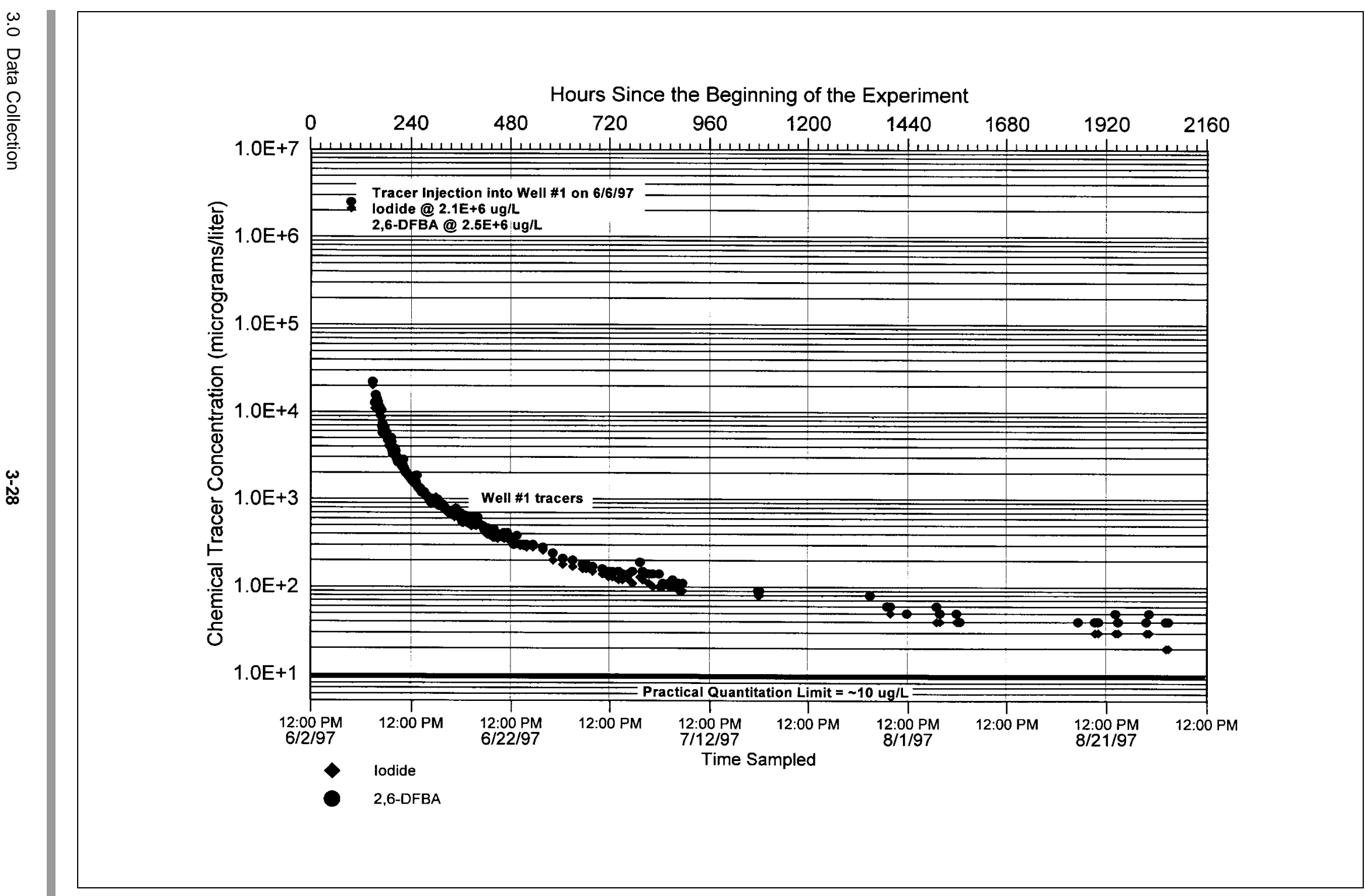

Figure 3-7

Tracer Concentrations in Well ER-20-6 \#1 


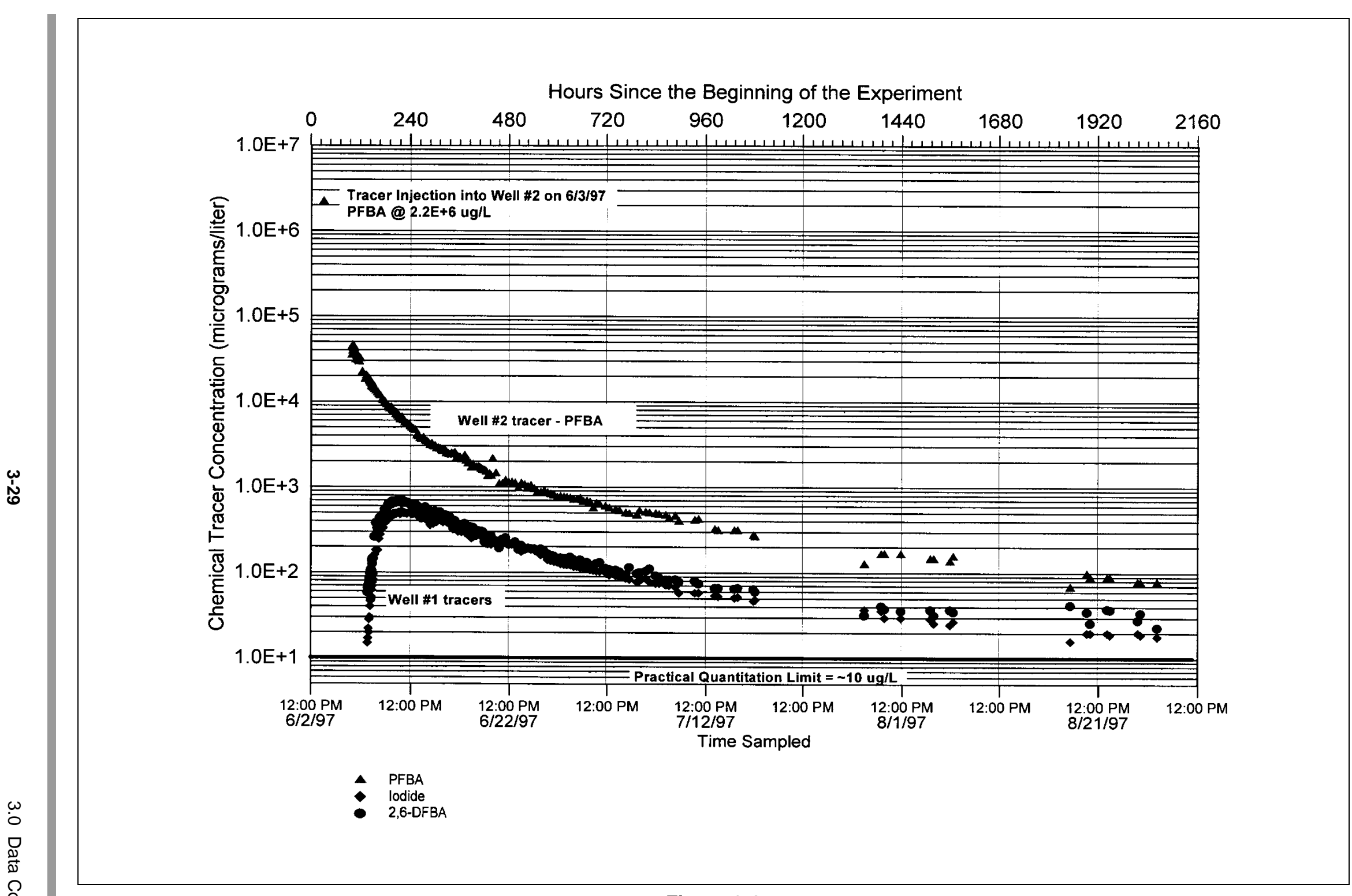

Figure 3-8

Tracer Concentrations in Well ER-20-6 \#2 


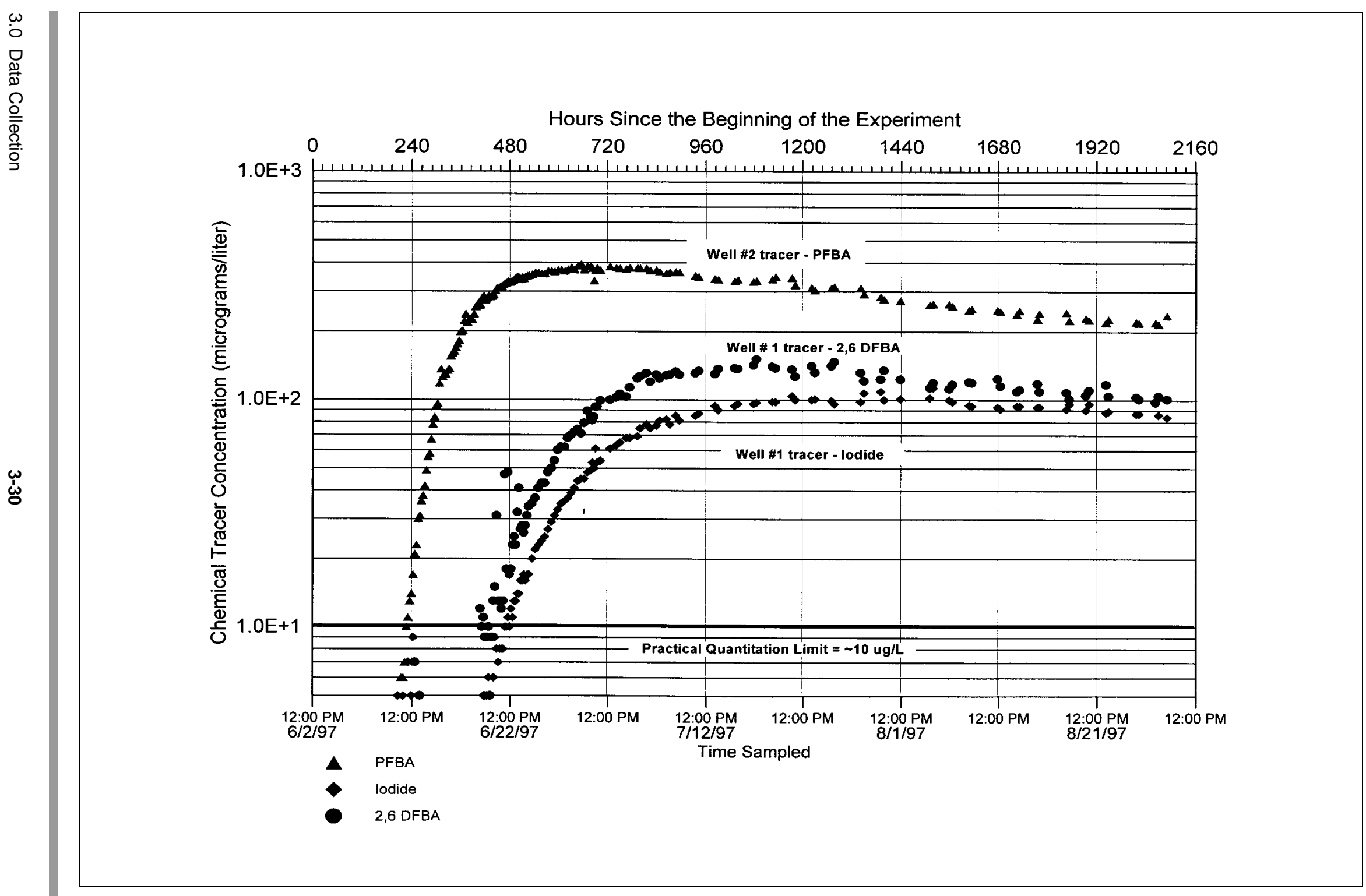

Figure 3-9

Tracer Concentrations in Well ER-20-6 \#3 


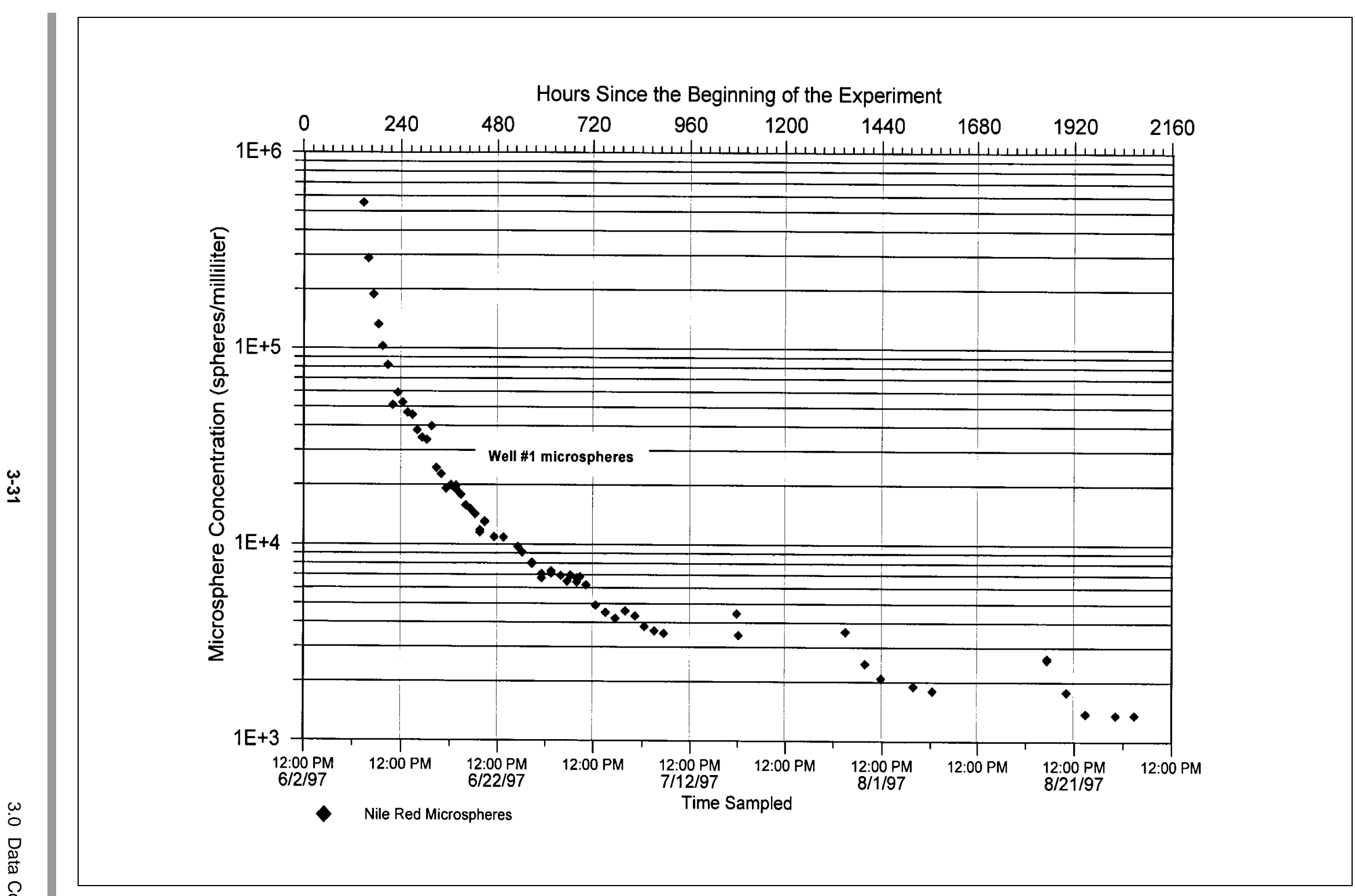

Figure 3-10

Microsphere Concentrations in Well ER-20-6 \#1 


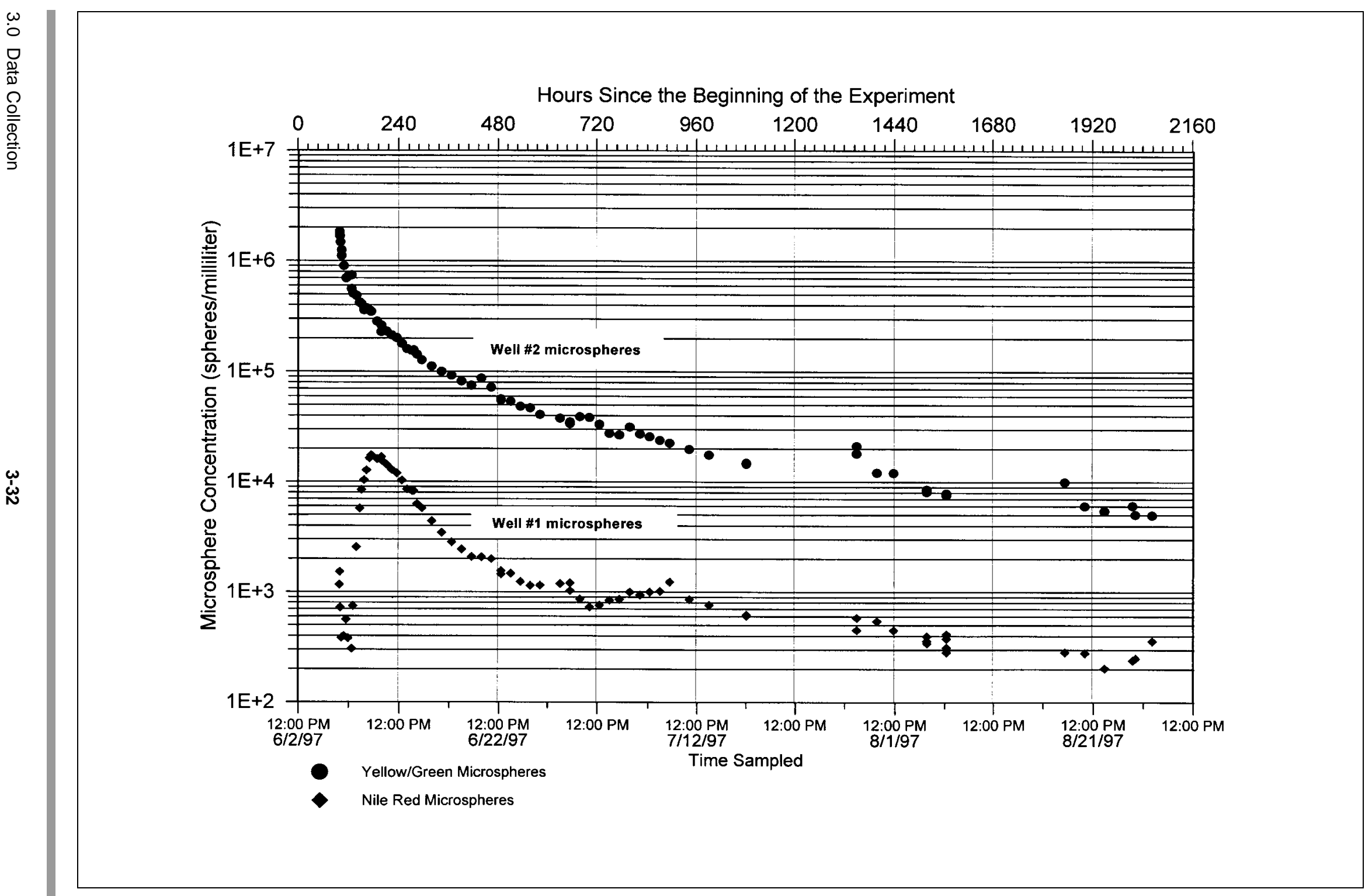

Figure 3-11

Microsphere Concentrations in Well ER-20-6 \#2 
Hours Since the Beginning of the Experiment

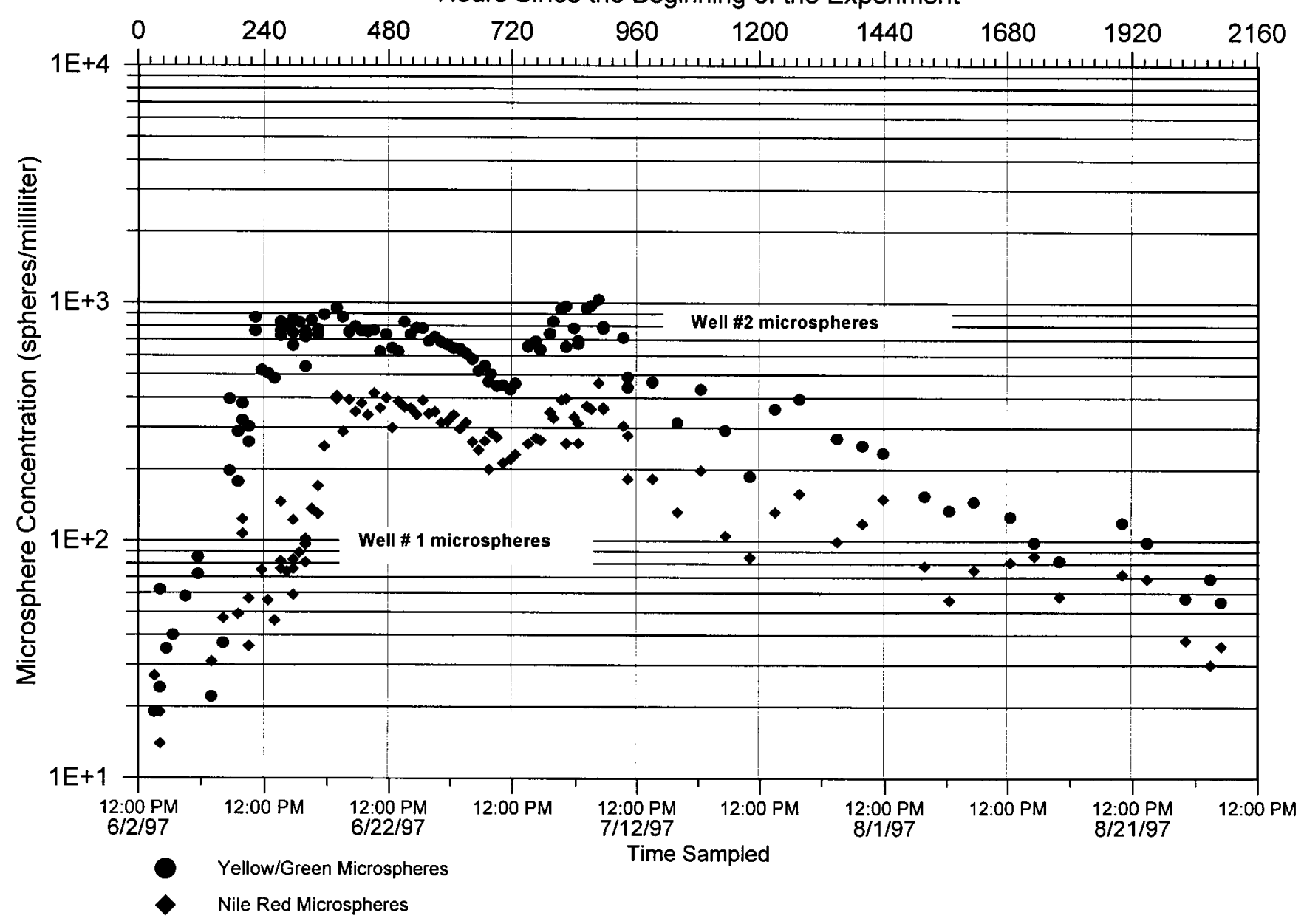

Figure 3-12

Microsphere Concentrations in Well ER-20-6 \#3 


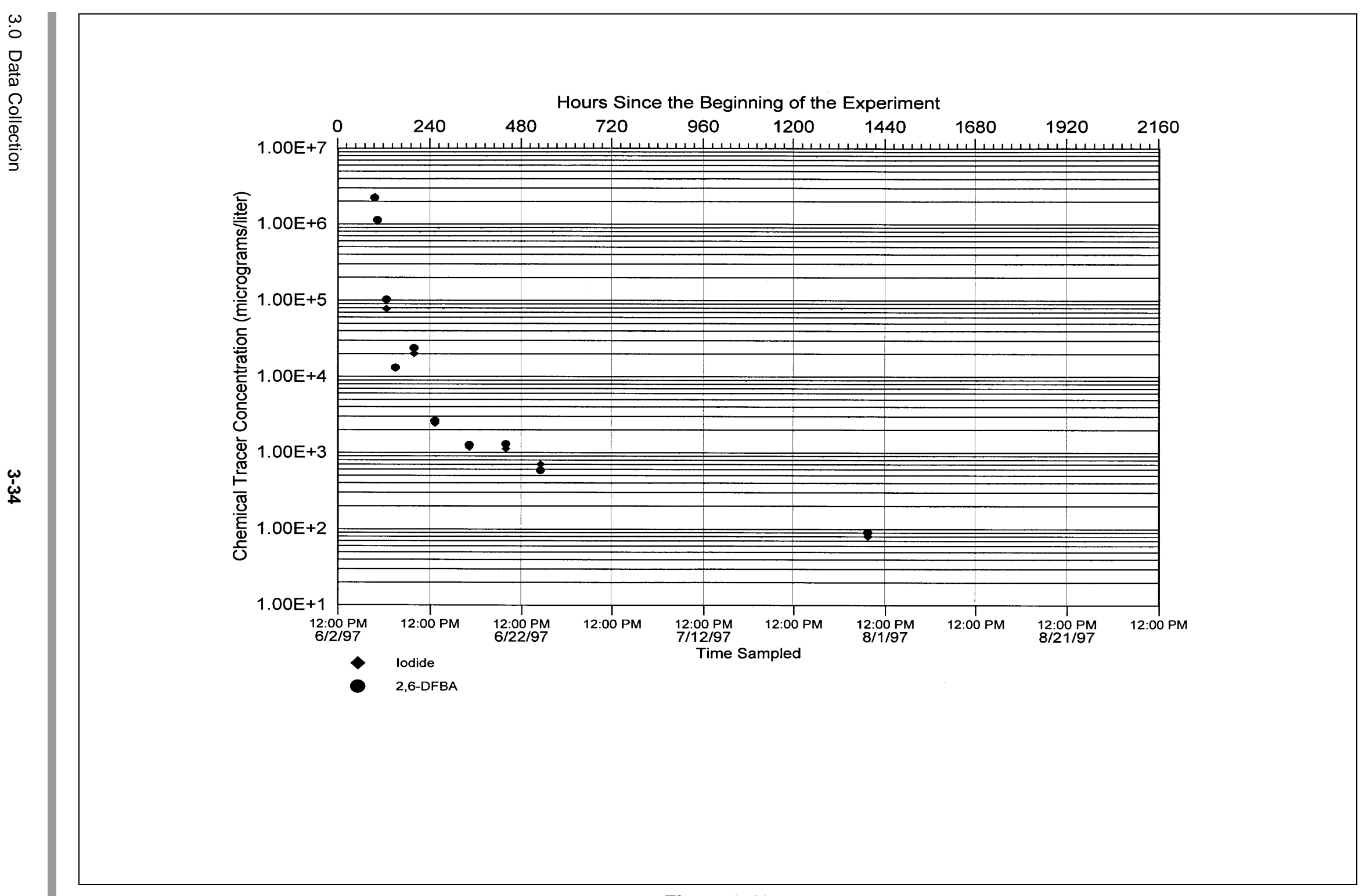

Figure 3-13

lodide and 2,6-DFBA Concentrations in Well ER-20-6 \#1, Upper Zone 


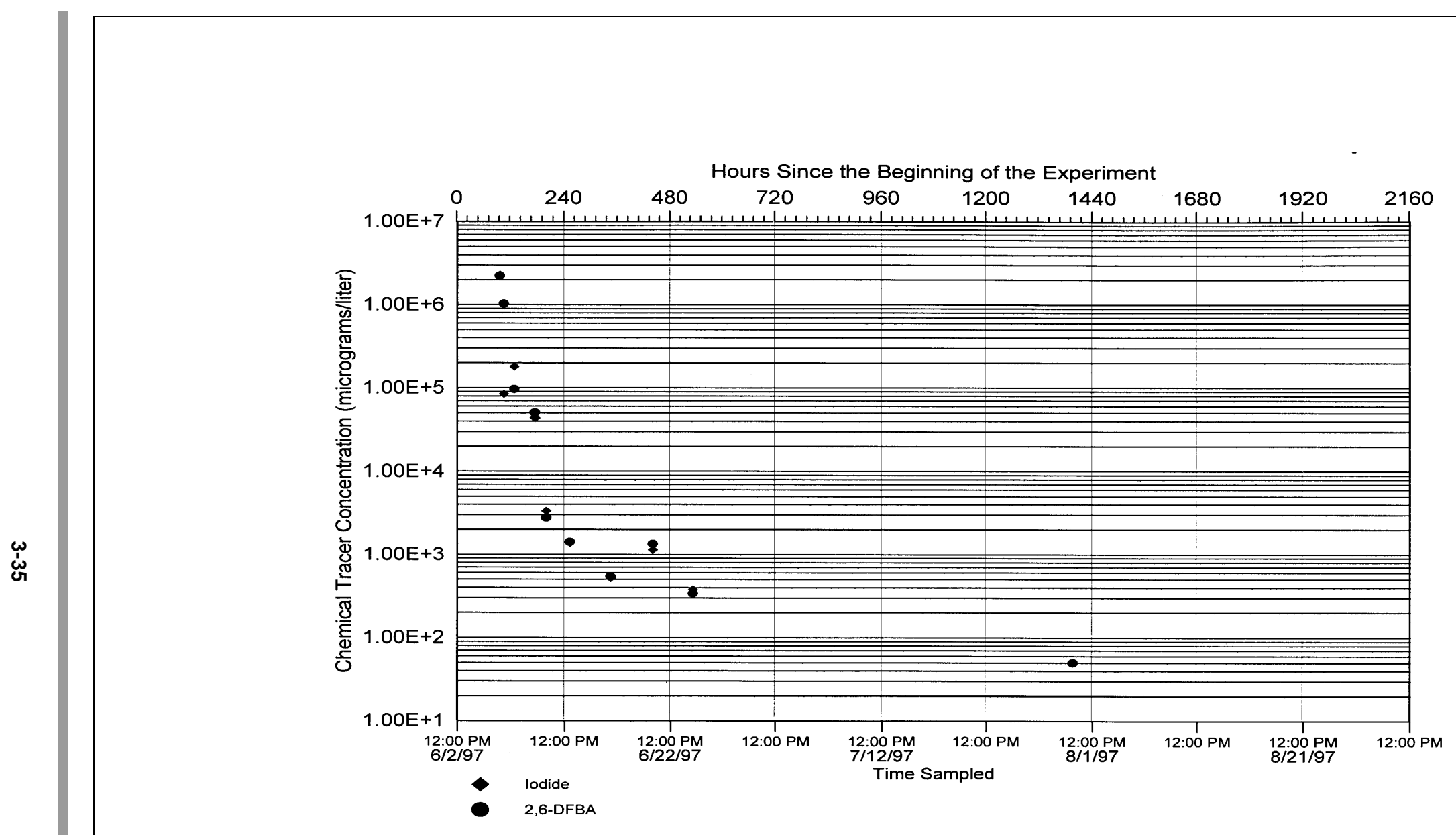

Figure 3-14

lodide and 2,6-DFBA Concentrations in Well ER-20-6 \#1, Lower Zone

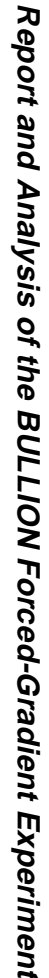




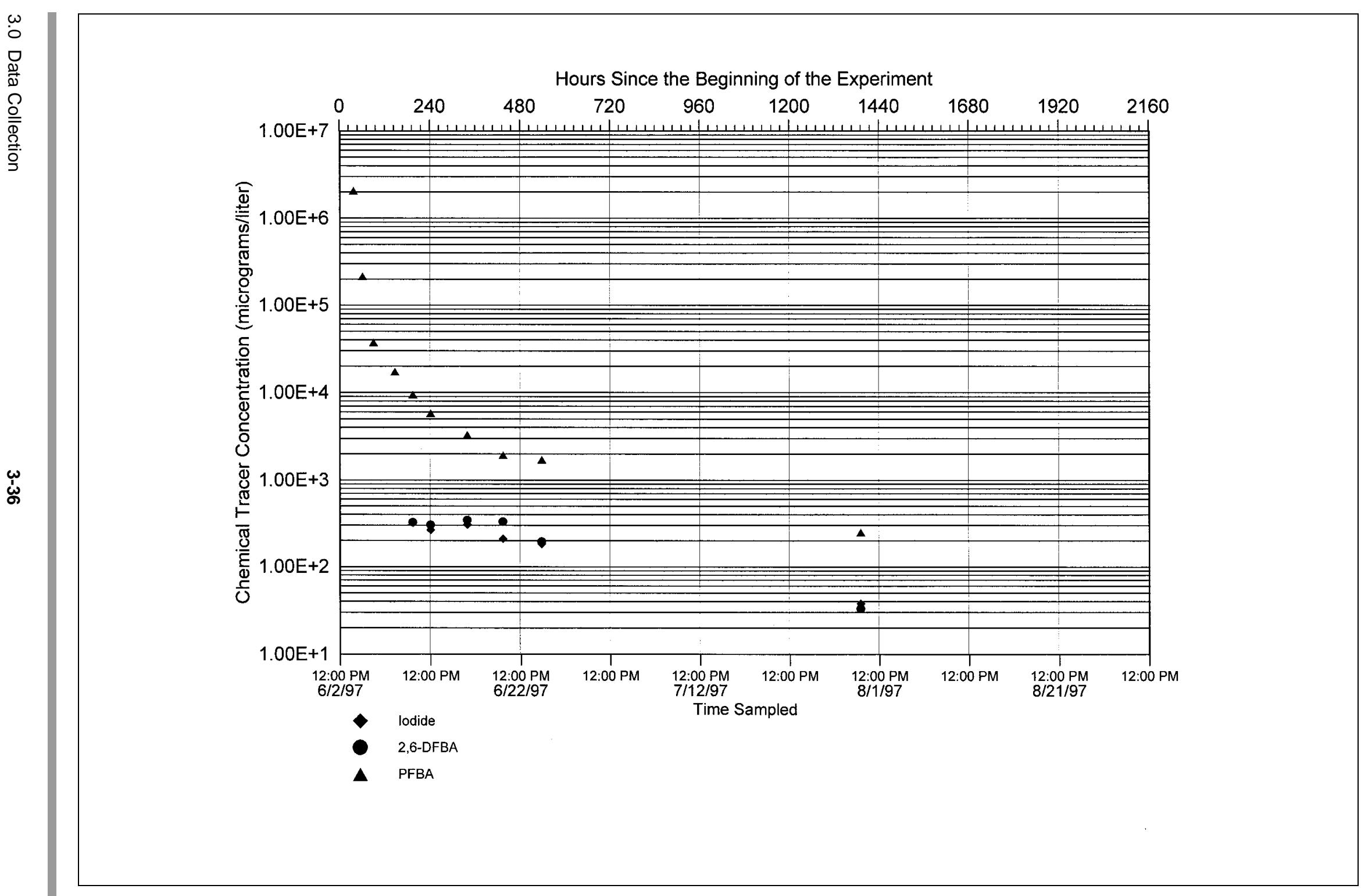

Figure 3-15

PFBA, lodide and 2,6-DFBA Concentrations in Well ER-20-6 \#2, Upper Zone 


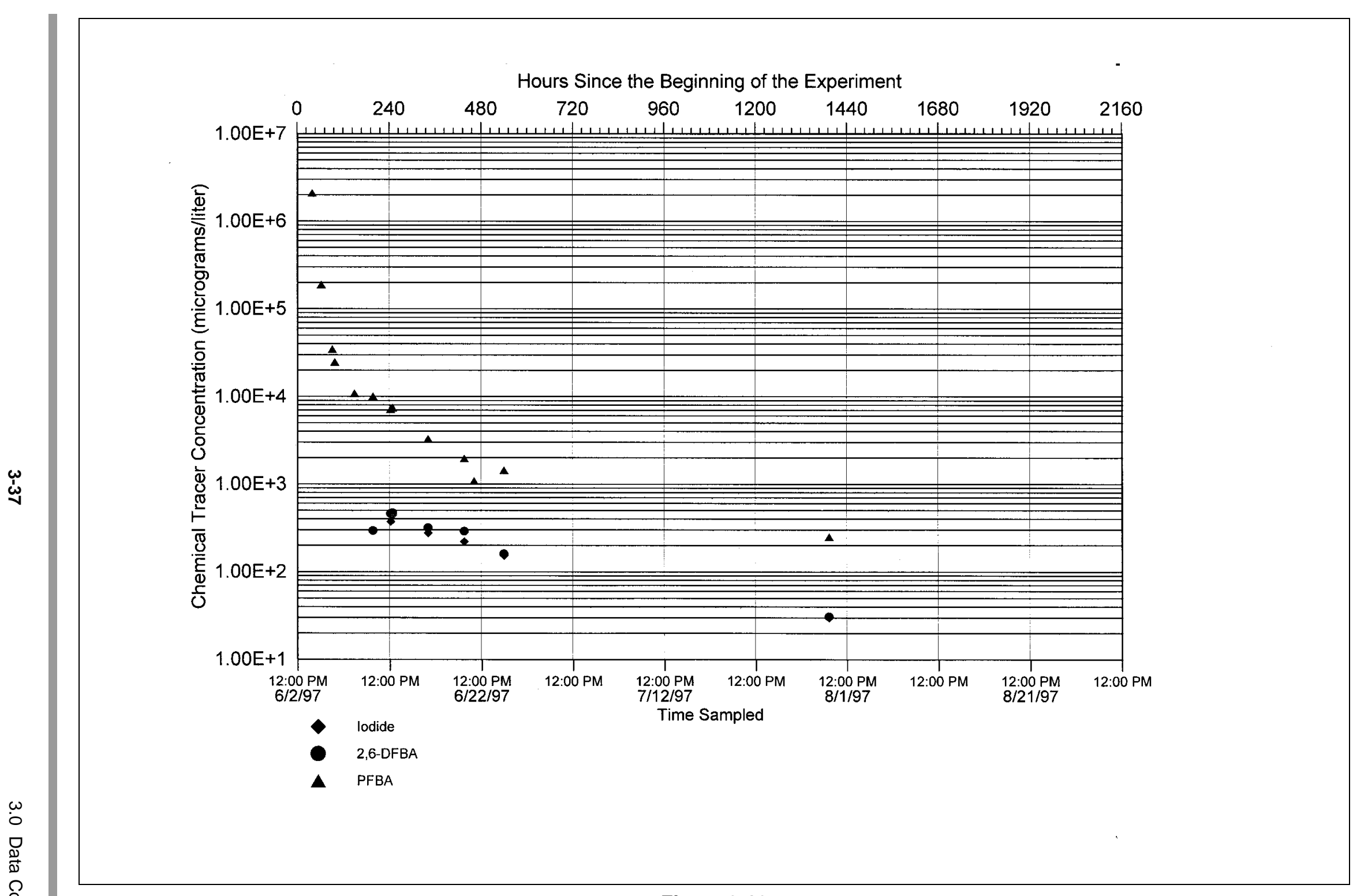

Figure 3-16

PFBA, lodide and 2,6-DFBA Concentrations in Well ER-20-6 \#2, Lower Zone 
This Page Intentionally Left Blank 


\subsection{Analysis of Hydraulic Response}

The drawdown response of the test formation was complicated due to the superposition of pumping responses for all three wells, with their individual on/off schedules and rate changes. Figures 3-4, 3-5, and 3-6 show the complete records for Wells ER-20-6 \#3, \#1, and \#2 respectively.

The records for Wells ER-20-6 \#1 and \#2 show clear responses to pumping in Well \#3 before pumping in those wells started, shown in Figures 4-1 and 4-2. These responses are suitable for analysis to determine aquifer parameters (i.e., transmissivity [T] squared meters per day [ $\mathrm{m}^{2} /$ day]) and storage coefficient (S). Wells ER-20-6 \#1 and \#2 both initially drew down very quickly to a quasi-equilibrium level, discounting the apparent gradual long-term downward trends for the remainder of the experiment. However, beyond these early portions of the records noise in the data masks detail of the small responses; consequently, the records are not amenable to analysis beyond the first 10 hours of record. The long-term drawdown trends of Wells \#1 and \#2 during the latter part of the experiment is discounted as measurement drift. This interpretation is based in part on the head recovery in these wells when pumping was stopped at the end of the experiment. All three wells show the same pattern of recovery, but the recoveries of Wells \#1 and \#2 do not approach zero drawdown as closely as Well \#3, contrary to reasonable expectation. Coincidentally, the amount of drawdown for each well during the period of long-term dedine in question is the same magnitude as the apparent discrepancy in recovery.

The drawdown in Well ER-20-6 \#3 reached a maximum in just under 0.2 days of about $11.0 \mathrm{~m}$, and then recovered stepwise to a quasi-equilibrium of $7.0 \mathrm{~m}$ by 36 days. The step-recoveries were associated with stop/starts of pumping in Well \#3 (i.e., drawdown re-established equilibrium at a lesser amount after pumping resumed). This behavior could be explained by suddenly improved well efficiency. It is thought that the check valves in Well \#3 did not hold, and that the screen/gravel pack/well bore may have been backflushed when pumping periodically stopped, improving hydraulic performance. It was noted that clays were present in the discharge, and it may also be speculated that clay in the local fracture system was being removed due to the high vel ocities resulting from pumping, increasing the formation hydraulic conductivity around the well. For the remainder of the experiment the drawdown of Well \#3 exhibited a very slight, gradual 


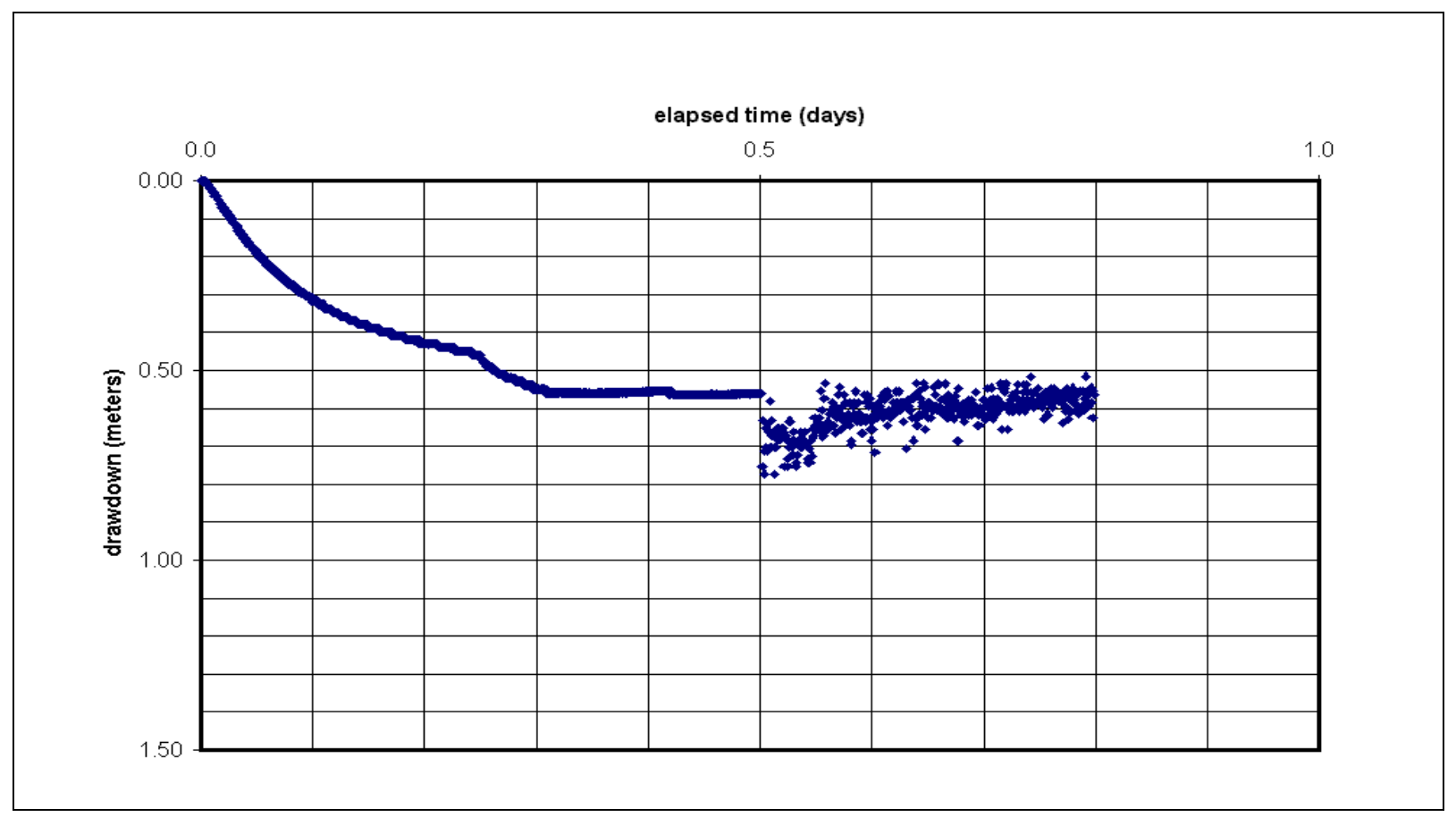

Figure 4-1

Well \#1 Drawdown Record

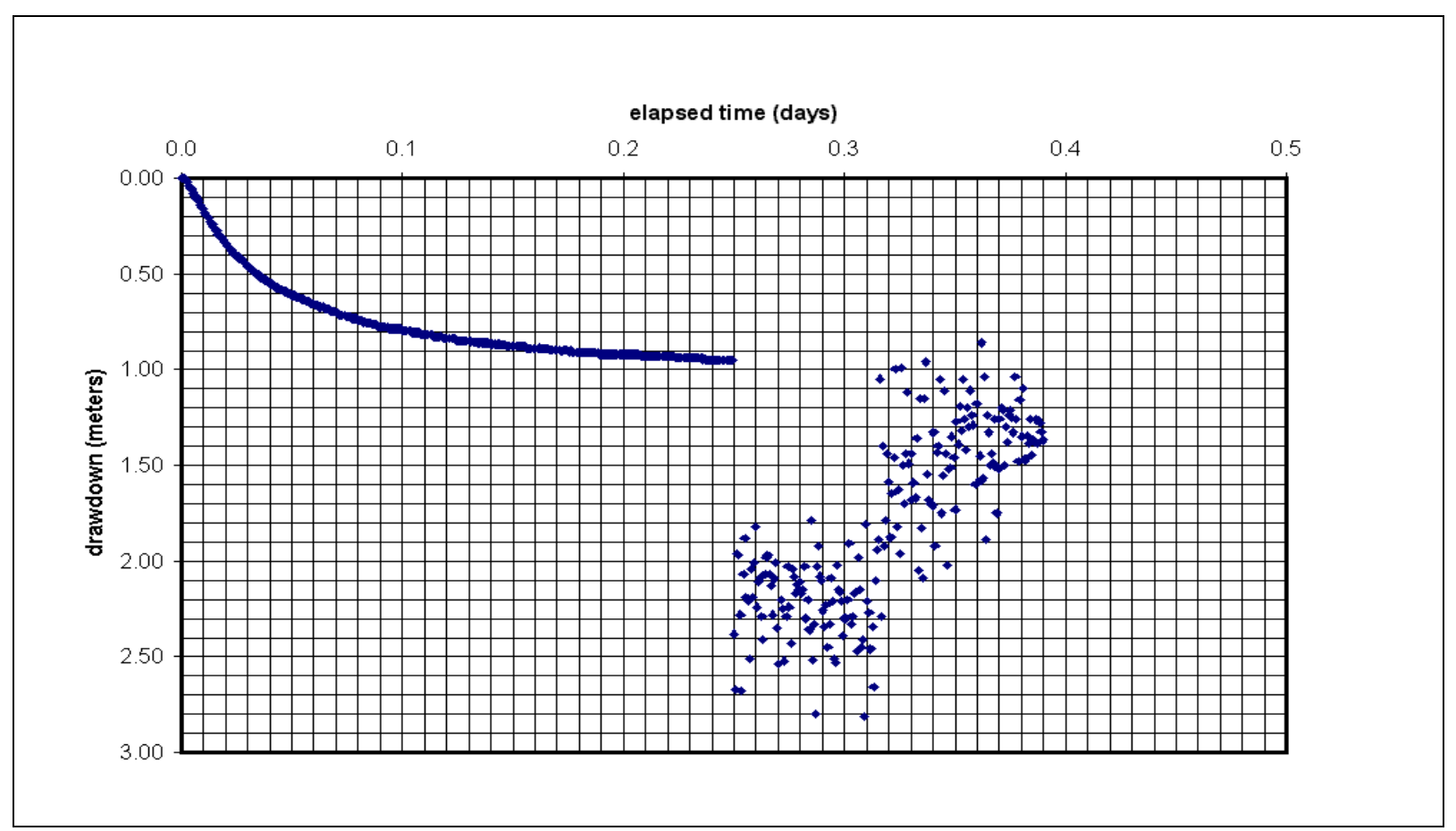

Figure 4-2

Well \#2 Drawdown Record 
upward trend. The long-term behavior of Well \#3 indicates that the drawdown response of this well was significantly affected by wellbore conditions, and it was decided that there was little value in analysis of the response beyond the first few hours. The effects of pumping in Wells \#1 and \#2 cannot be distinguished in the Well \#3 response.

The drawdown response of individual observation wells to pumping in another well was analyzed using the Theis equation for a confined aquifer and also using a dual-porosity model for fractured formations. These analyses were done using the commercial software package AQTESOLV (Geraghty and Miller, Inc., 1991). Only the data from the first 8 to 10 hours were used in the analyses. These early data were the least subject to outside effects such as pump shut downs and boundary conditions. Table 4-1 shows both the parameter values that had previously been determined for the planning model (BULLION Forced-Gradient Experiment Implementation PIan [IT, 1997]) and gives the results of the various analysis methods for the hydraulic responses. Aquifer thicknesses were estimated from the cross section developed for the site, shown in Figure 6-1. Leaky confined-aquifer analysis solutions did not provide any substantial improvement in fitting the drawdown curves.

Table 4-1

ER-20-6 Hydraulic Parameter Values

\begin{tabular}{|c|c|c|c|c|c|c|}
\hline \multirow{2}{*}{$\begin{array}{c}\text { Well } \\
\text { Record }\end{array}$} & \multirow[b]{2}{*}{ Response } & \multirow{2}{*}{$\begin{array}{l}\text { Analysis } \\
\text { Method }\end{array}$} & \multicolumn{2}{|c|}{ Planning Model } & \multicolumn{2}{|c|}{ Experiment Results } \\
\hline & & & $\begin{array}{c}\text { Transmissivity } \\
\mathbf{m}^{2} / \text { day }^{\star}\end{array}$ & $\begin{array}{l}\text { Storage } \\
\text { Coefficient }\end{array}$ & $\begin{array}{l}\text { Transmissivity } \\
\text { m²/day* }^{2}\end{array}$ & $\begin{array}{c}\text { Storage } \\
\text { Coefficient }\end{array}$ \\
\hline \multirow{5}{*}{$\begin{array}{c}\text { ER-20-6 } \\
\# 1\end{array}$} & \multirow{3}{*}{$\begin{array}{l}\text { Observation, } \\
\text { \#3 Pumping }\end{array}$} & Theis & 307 & $8.0 e-4$ & 237 & $7.6 \mathrm{e}-4$ \\
\hline & & $\begin{array}{l}\text { Dual } \\
\text { Porosity }\end{array}$ & 195 & $8.0 e-4$ & 352 & $3.7 e-4$ \\
\hline & & $\begin{array}{c}\text { Theis } \\
\text { Recovery }\end{array}$ & --- & --- & 314 & NA \\
\hline & \multirow{2}{*}{$\begin{array}{l}\text { Observation, } \\
\text { \#2 Pumping }\end{array}$} & Theis & --- & --- & 280 & $1.5 \mathrm{e}-3$ \\
\hline & & $\begin{array}{l}\text { Dual } \\
\text { Porosity }\end{array}$ & --- & --- & 236 & $3.9 e-4$ \\
\hline \multirow{3}{*}{$\begin{array}{c}\text { ER-20-6 } \\
\# 2\end{array}$} & \multirow{3}{*}{$\begin{array}{l}\text { Observation, } \\
\text { \#3 Pumping }\end{array}$} & Theis & 187 & $3.0 e-4$ & 148 & $3.3 e-4$ \\
\hline & & $\begin{array}{l}\text { Dual } \\
\text { Porosity }\end{array}$ & 218 & $3.0 \mathrm{e}-4$ & 218 & $9.5 e-5$ \\
\hline & & $\begin{array}{c}\text { Theis } \\
\text { Recovery }\end{array}$ & & & 209 & NA \\
\hline \multirow{2}{*}{$\begin{array}{c}\text { ER-20-6 } \\
\# 3\end{array}$} & \multirow[b]{2}{*}{ \#3 Pumping } & Theis & 47 & NA & --- & --- \\
\hline & & $\begin{array}{l}\text { Dual } \\
\text { Porosity }\end{array}$ & 69 & NA & --- & --- \\
\hline
\end{tabular}

${ }^{*} \mathrm{~m}^{2} /$ day - Squared meters per day 


\subsection{Theis Analysis}

The Theis equation was used to analyze the drawdown response of Wells ER-20-6 \#1 and \#2 to pumping in Well \#3 at the start of the experiment before the pumps in Wells \#1 and \#2 were started. The best curve-match fit for Well \#1 is illustrated in Figure 4-3, and the best fit for Well ER-20-6 \#2 in Figure 4-4. The curve-match fits do not match the drawdown data earlier than about 20 minutes for Well \#1 and earlier than about 10 minutes for Well \#2. This is addressed in the next section. At later times, about 0.1 day (144 minutes), the response curves for Wells \#1 and \#2 start to approach an equilibrium more rapidly than the Theis curve. This is thought to indicate that drawdown intercepted a source of recharge, and will be discussed further in Section 4.3. This analysis was also applied to the response of Well \#1 to pumping in Well \#2, illustrated in Figures 4-5, 4-6, and 4-7 show the analysis of the recovery data for Wells \#1 and \#2.

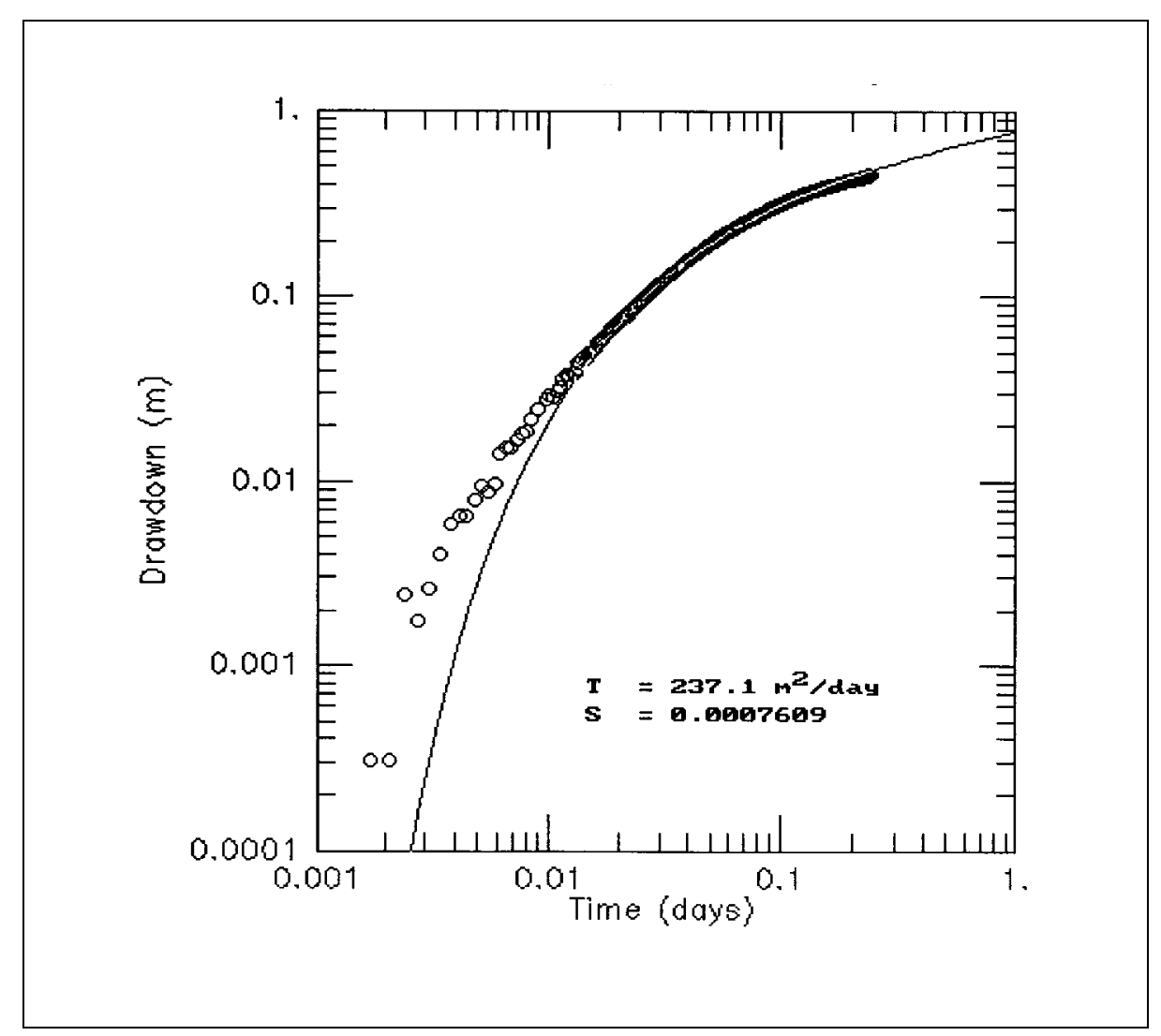

Figure 4-3

Well ER-20-6 \#1 Theis Analysis 


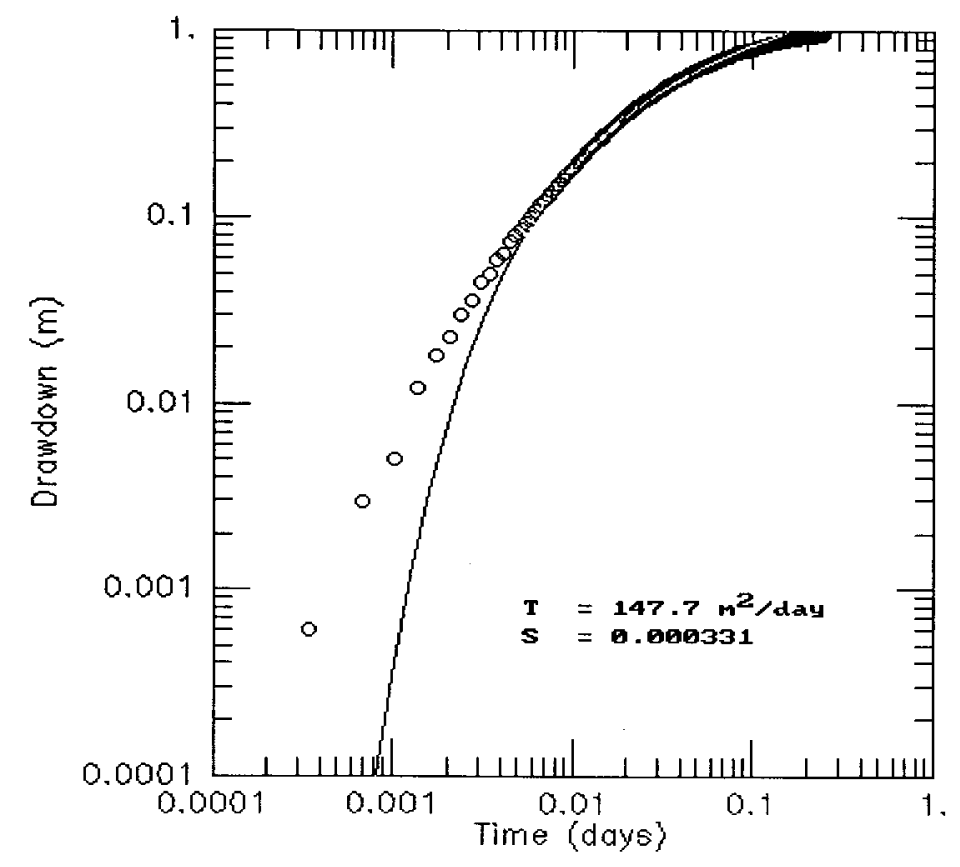

Figure 4-4

ER-20-6 \#2 Theis Analysis

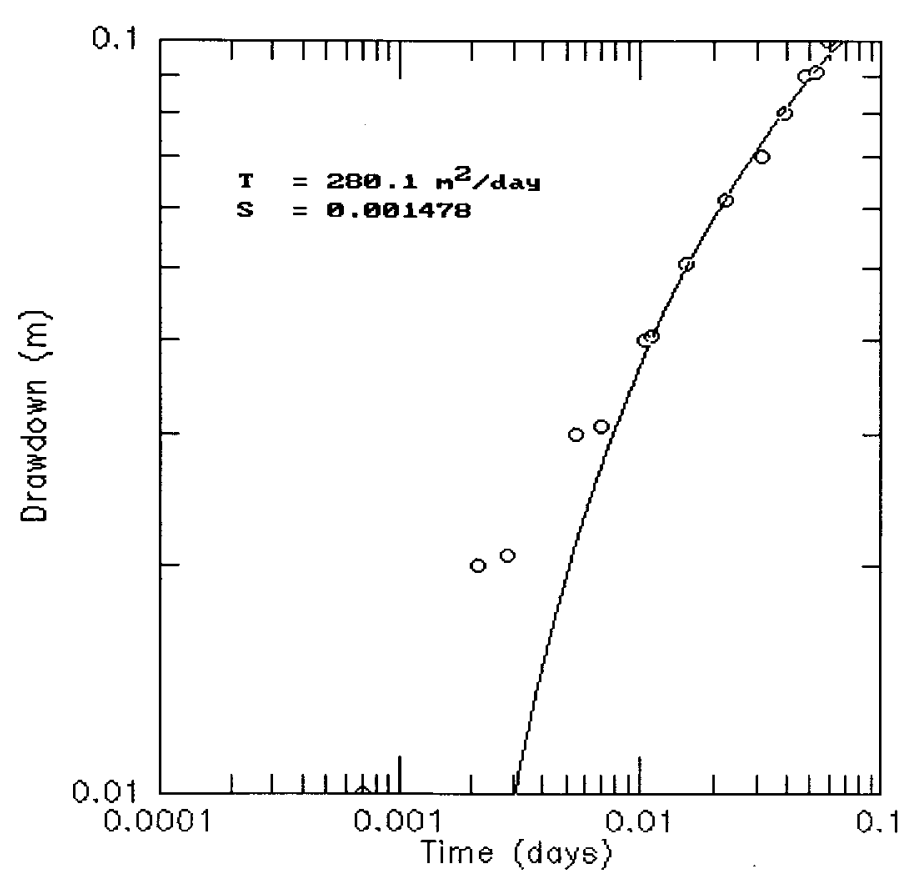

Figure 4-5

ER-20-6 \#1 to \#2 Theis Analysis 


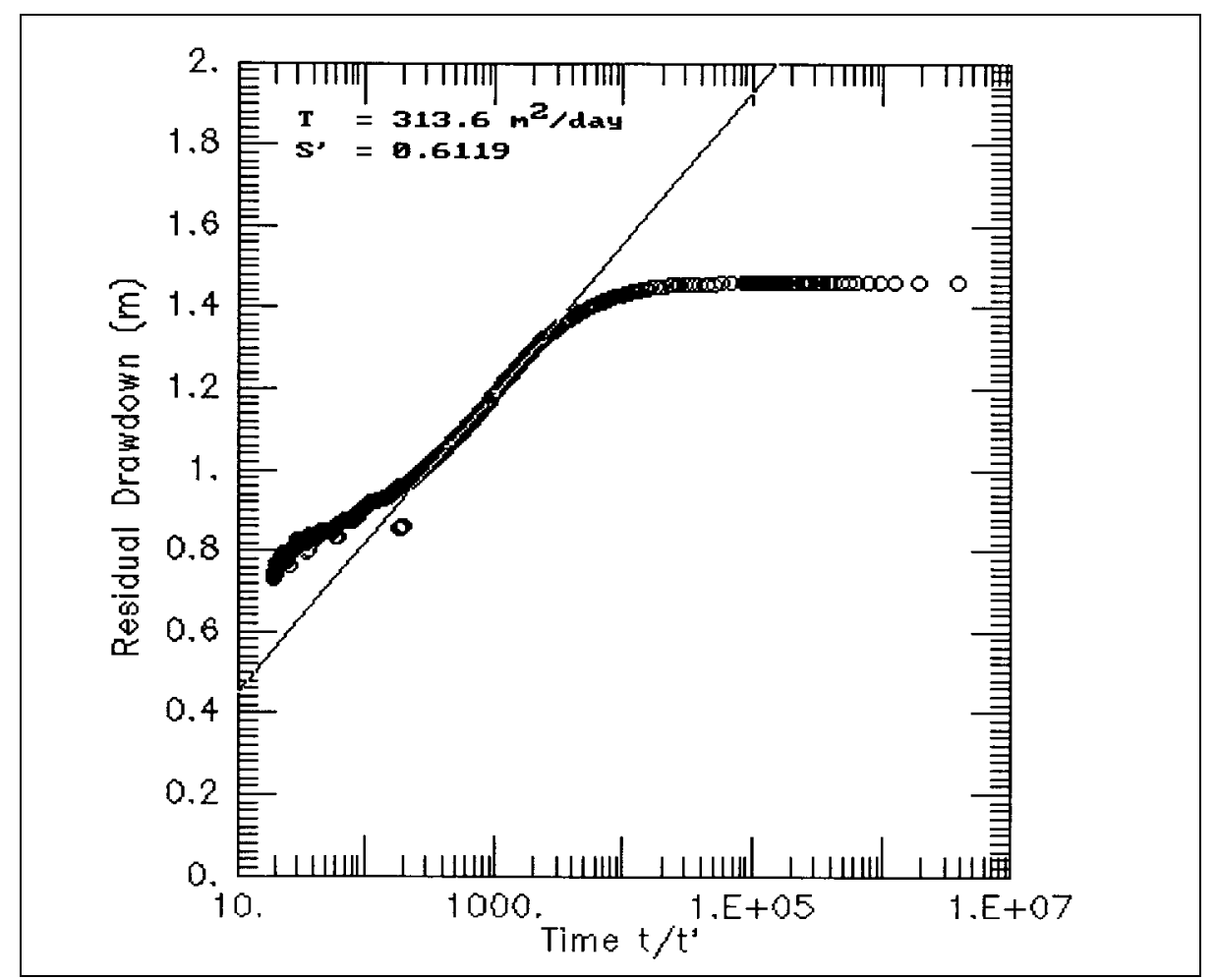

Figure 4-6

ER-20-6 \#1 Recovery Analysis

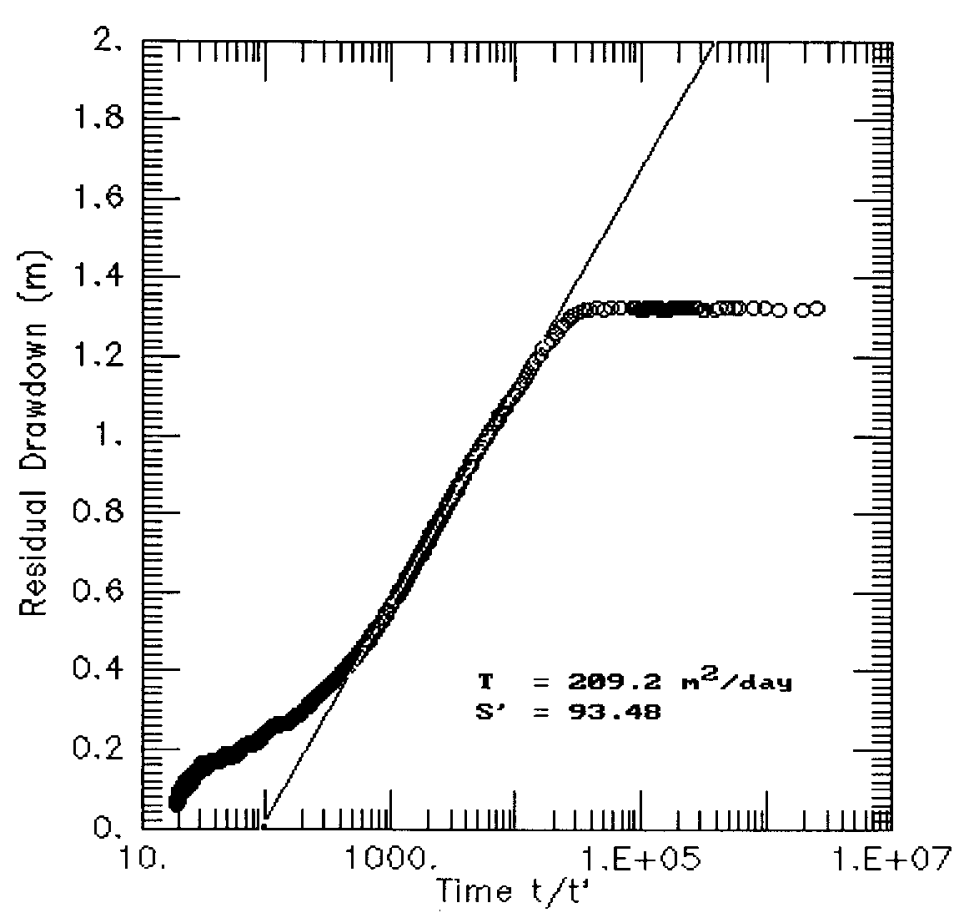

Figure 4-7

ER-20-6 \#2 Recovery Analysis 


\subsection{Dual-Porosity Analysis}

Dual-porosity analysis provides much improved curve fits for the very early-time data. The parameters returned by this analysis include separate fracture ( $K$, meters per day) and matrix ( $K^{\prime}$, meters per day) conductivity values, and apportionment of the storage into fracture (Ss, one per meter) and matrix (Ss', one per meter) components. This analysis was also done using the AQTESOLV software, which implements a dual porosity model included in M oench (1984). The best fit for the Well ER-20-6 \#1 response is illustrated in Figure 4-8, for the Well ER-20-6 \#2 response in Figure 4-9, and for the Well ER-20-6 \#1 to \#2 response in Figure 4-10. The cal culated transmissivities are similar to the Theis-analysis values for transmissivity, and the matrix conductivities are much lower than the fracture conductivities, supporting the expectation that fracture flow dominates groundwater movement. The sum of the storage coefficients for fractures and matrix are similar to the storage coefficient from the Theis solution, as would be expected. In later time, the dual-porosity solution curves merge with the Theis solution curves.

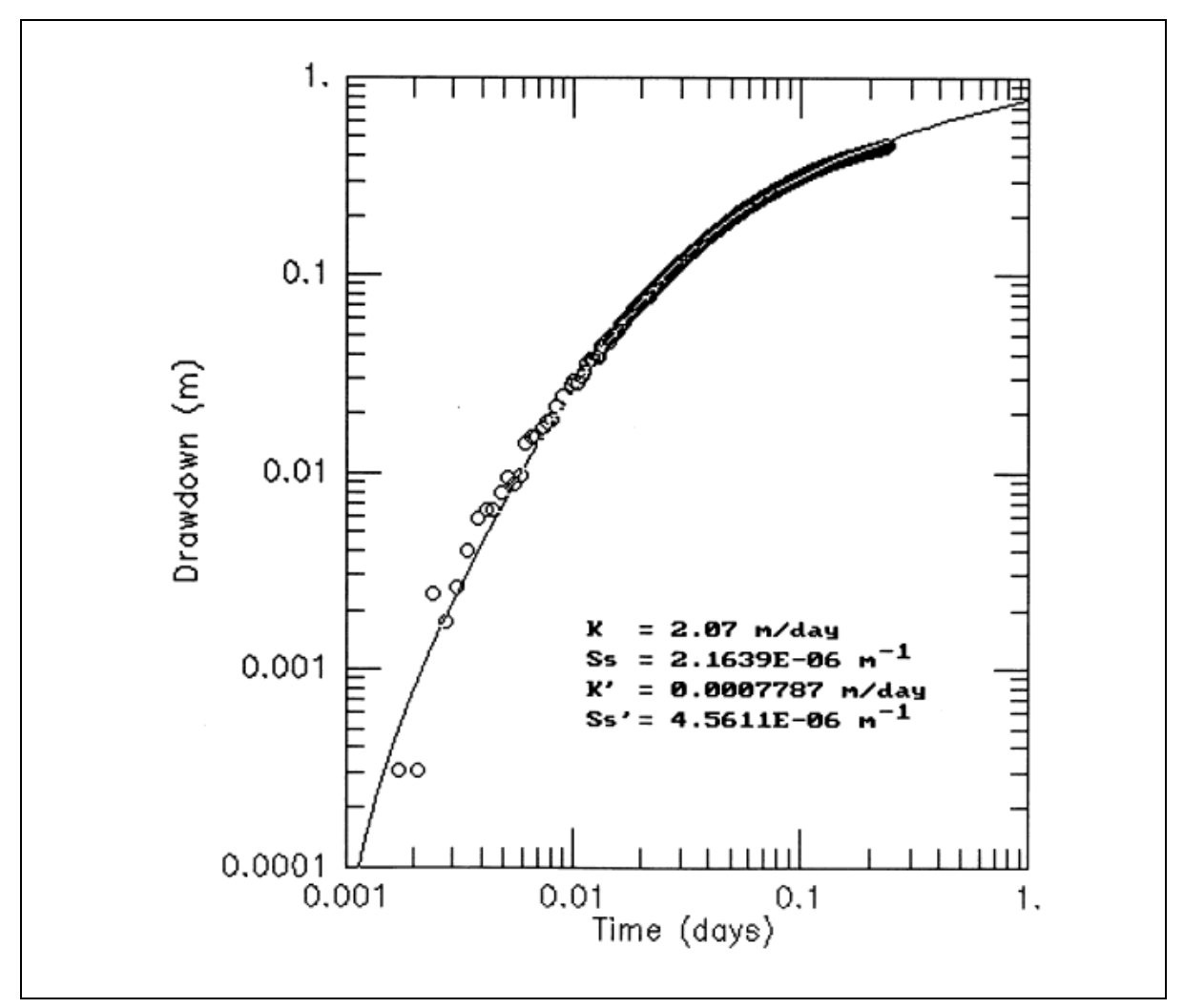

Figure 4-8

ER-20-6 \#1 Dual Porosity Analysis 


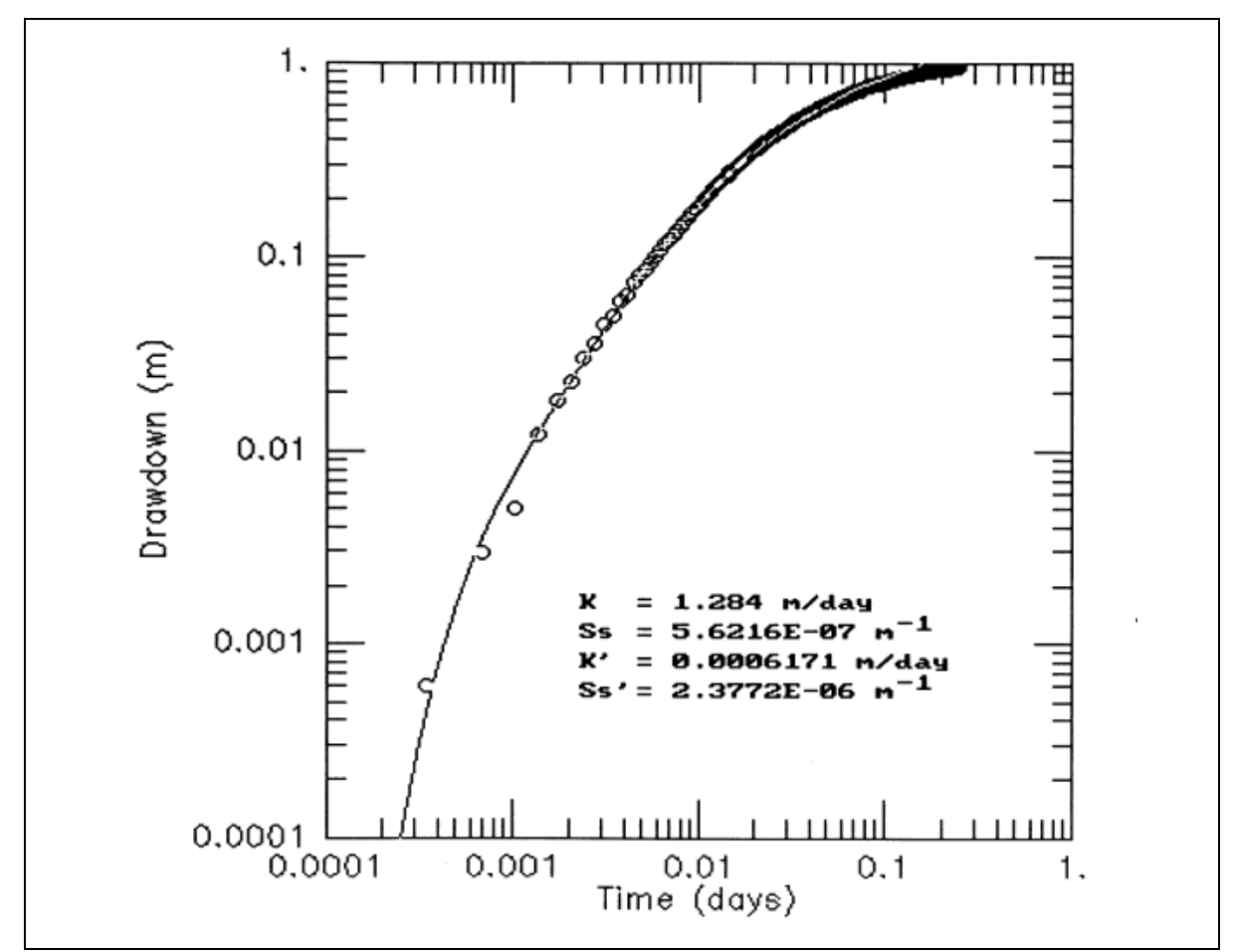

Figure 4-9

ER-20-6 \#2 Dual Porosity Analysis

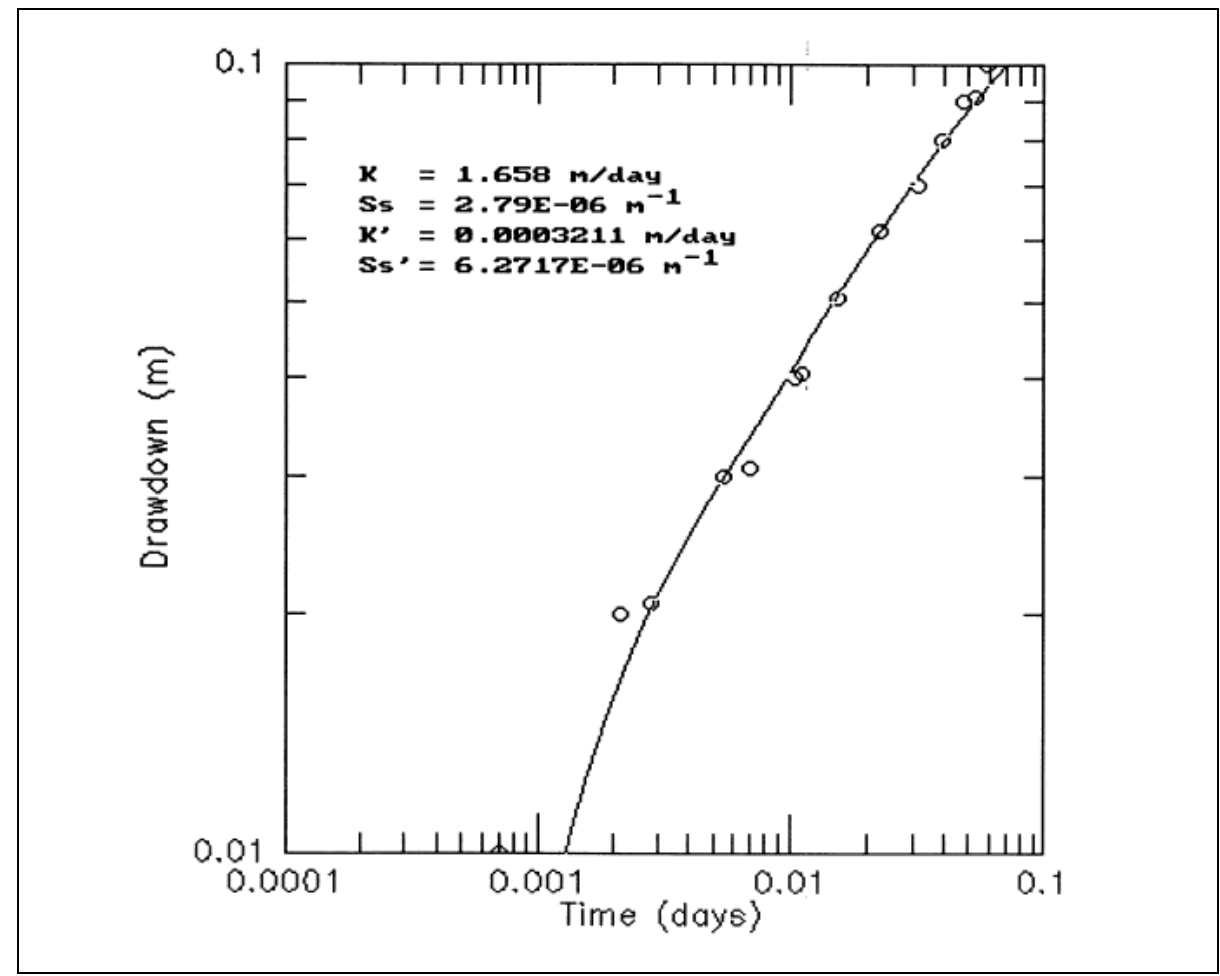

Figure 4-10

ER-20-6 \#1 to \#2 Dual Porosity Analysis 


\subsection{Distance-Drawdown Analysis}

The hydraulic response of the test formation can be represented as a graph of log distance versus drawdown ( acob method) at any particular time, using drawdown information from all three wells. Figure 4-11 shows the distance-drawdown relationship at 0.25 days, at which time Well \#3 drawdown reached quasi-equilibrium. Both the measured drawdown for Well \#3 at 0.25 days and the later equilibrium drawdown are included to show the uncertainty in this plot. The zero drawdown intercept for the plot indicates that the drawdown extended approximately $200 \mathrm{~m}$ from Well \#3. While the distance-drawdown data do not fit the straight line model very well, this analysis provides a useful indication of the approximate distance to the recharge boundary. Graphs of distance-drawdown for later times throughout the experiment show the intercept point for zero drawdown moving out to $400 \mathrm{~m}$.

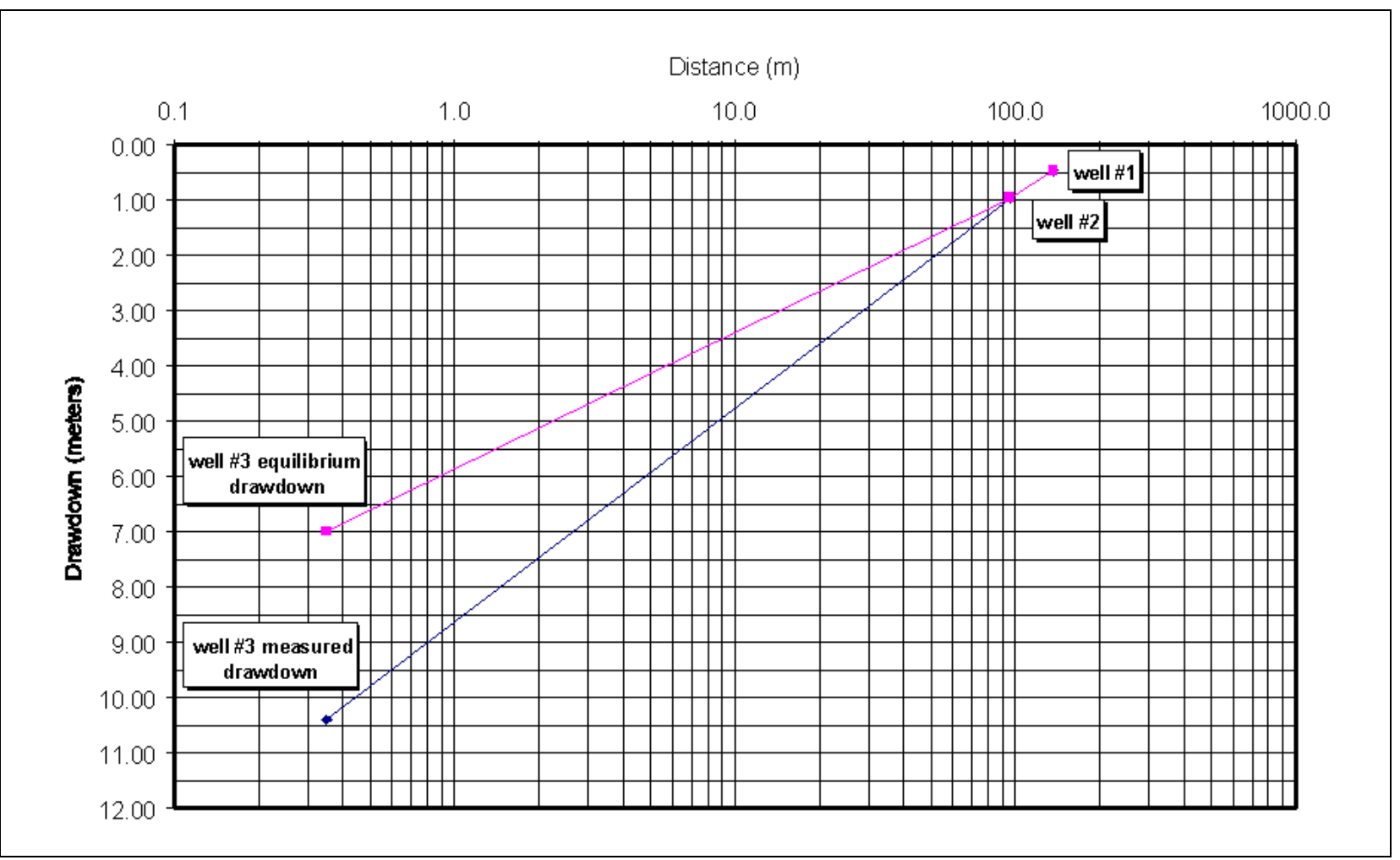

Figure 4-11

Distance-Drawdown at 0.25 Days

\subsection{Anisotropy}

A simple approach was used to evaluate the anisotropy of hydraulic conductivity of the test formation in the horizontal plane. The value of hydraulic conductivity is considered to vary directionally in the 
formation as described by the equation of an ellipse. It was assumed that the greater hydraulic conductivity value, derived from the Well \#1 response to pumping in Well \#3, was the maximum value for the formation (the major axis of the ellipse). This is thought to be approximately correct since this well pair is well aligned with the dominant fracture system. The hydraulic conductivity from the Well \#2 response to pumping in Well \#3 was used as a second point on the ellipse to calculate the equation of the ellipse, and determine the minimum value (minor axis). This calculation was made for the results of all three methods of analysis used for these wells, using both hydraulic conductivity and transmissivity values directly. The ratio of minimum to maximum anisotropy ranged from 7.3 to 8.5 , with an average value of 8 . While this is not an exact analysis, it provides useful information for calibrating the flow model.

\subsection{Summary of Hydraulic Analyses}

A summary of the results of hydraulic analysis was presented in Table 4-1. These values are a guide for determining parameter values used in modeling. As the table shows, the different analysis methods did not produce close agreement, but are reasonably consistent. The analysis methods are based on porous media theory (Theis analysis) or homogeneity (Dual Porosity) and cannot necessarily represent the behavior of a fractured, heterogeneous media, depending on the nature of the fracture system. However, the results indicate that this formation in general can be reasonably represented by modeling as a porous media. As is evident from Table 4-1, the analysis of the hydraulic response during the experiment did not produce substantially different results from the original analysis done for the planning model. 


\subsection{Analytical Solutions to Tracer Transport}

The interpretation of the tracer breakthrough curves was carried out in two steps. The first step, covered in this section, included two analytic-based methods: a simple analytic equation for tracer breakthrough and a semi-analytical model to estimate the transport parameters. The former method estimates effective porosity using only peak arrival times. The latter method is a more refined model that simulated the breakthrough of the tracers at Wells ER-20-6 \#2 and \#3, including the effects of matrix diffusion and colloid transport. The second step for interpretation was the development and application of a three-dimensional numerical model that was also used to interpret drawdown response. This analysis is presented in Sections 6.0 (flow) and 7.0 (transport). The assumptions required to utilize analytic models are typically more restrictive than for the numerical modeling, as described bel ow. Therefore, the parameter values obtained from the analytical models are taken to be approximate, but are useful for bounding the true parameter values.

\subsection{Peak-Arrival Time}

Welty and Gelhar (1989) presented a number of analytical solutions for transport in radial and doublet flow systems. Their radial convergent solution represents the flow configuration of the BULLION test. The solutions of Welty and Gelhar (1989) do not indude matrix diffusion effects and will not be used to match breakthrough curves. However, they do provide an expression of the average travel time from the injection well to the pumped well in terms of the pumping rate and the aquifer geometry.

The average travel time from the injection well to the pumped well is given by the expression:

$$
t_{m}=n b \pi r^{2} /(Q)
$$


where $t_{m}$ is the average groundwater travel time $(\mathrm{L}), \mathrm{Q}$ is the discharge $\left(L^{3} / T\right), r$ is the distance between the pumped well and injection well $(L)$, $\mathrm{n}$ is the effective porosity, and $\mathrm{b}$ is the aquifer thickness $(\mathrm{L})$. This equation is based on an assumption of purely radial flow to a well pumping at a constant rate in a homogeneous and isotropic aquifer. By rearranging the equation, the effective porosity can be estimated from the breakthrough curves. F or the purposes of this analysis, the average groundwater travel time is approximated as the time to peak concentration. Table 5-1 contains the parameter values and the calculated effective porosity values for the transport of the two organic acids from the injections wells to the pumped well. This simplified analysis produces an estimate of effective porosity between 0.005 and 0.007 . It should be noted that the average travel time values are approximate, and were determined as the time to the peak concentration. If the time to peak is less than the average travel time, then the cal culated effective porosity estimates are too small. However, these values provided an initial estimate of the fracture, or effective porosity that hel ped guide the numerical modeling described later in this section.

Table 5-1

Estimates of Effective Porosity Based on Time to Peak Concentration in Well \#3 of PFBA from Well \#2 and DFBA from Well \#1

\begin{tabular}{||l|c|c|}
\hline \multicolumn{1}{|c|}{ Parameter } & $\begin{array}{c}\text { Transport from Well \#1 } \\
\text { to Well \#3 }\end{array}$ & $\begin{array}{c}\text { Transport from Well \#2 } \\
\text { to Well \#3 }\end{array}$ \\
\hline \hline Average Travel Time (days) & 41 & 26 \\
\hline Discharge Rate $\left(\mathrm{m}^{3} /\right.$ day $)$ & 652.7 & 652.7 \\
\hline Aquifer Thickness $(\mathrm{m})$ & 100 & 100 \\
\hline Radial Distance $(\mathrm{m})$ & 131.5 & 89.16 \\
\hline Effective Porosity & 0.0068 & 0.0049 \\
\hline
\end{tabular}

\subsection{LANL Semi-Analytical Method}

The second method, described in detail in Preliminary Analysis of Tracer Responses in the BULLION Forced-Gradient Experiment (Reimus and Haga, 1998), used a more sophisticated dual-porosity, semi-analytical model, RELAP. This model was used to simulate the observed breakthrough curves at Wells \#2 and \#3. The RELAP code has several options including radial versus linear flow, infinite versus finite matrix blocks, and equilibrium versus rate-limited sorption. The sorption capabilities of the code were not used because the tracers were all treated as nonreactive. The filtration of microspheres is modeled as a first-order decay process.

The breakthrough curves were matched by adjusting model parameters. The parameters adjusted were (1) the mass fraction, $f$; (2) the mean fluid residence time, $\mathrm{T}$; (3) the Pecl et number, $\mathrm{Pe}=\mathrm{L} / \alpha$, 
where $L$ is the distance between wells and $\alpha$ is the longitudinal dispersivity; and (4) the matrix diffusion coefficient, Dm, which, when combined with $\phi / b$ ( $\phi$ is the matrix porosity and $b$ is one-half the fracture aperture), yields an effective mass transfer coefficient for diffusion into the matrix. The mass fraction is used to adjust the height of the peak and adjusts for the apparent amount of mass measured in the well. The mean fluid residence time controls, in part, the peak arrival time and is a function of the groundwater flux and the effective porosity. The Peclet number is adjusted to control the rate of spreading via the longitudinal dispersivity. Finally, the matrix diffusion coefficient is adjusted to provide separation between breakthrough curves of two tracers with differing diffusion characteristics. For the microspheres, the filtration rate constant was estimated from the relation $k_{f}=\lambda V$, where $k_{f}$ is the filtration rate constant $[1 / t], \lambda$ is the filtration coefficient $[1 / l]$, and $V$ is the average linear velocity $[\mathrm{l} / \mathrm{t}]$. The parameters obtained from fitting the model equations to the measured breakthrough curves are given in Table 5-2. As part of an evaluation of the sensitivity of the model to different assumptions, Reimus and Haga (1998) looked at both a linear flow model and a radial flow model. They believed that because of heterogeneities and anisotropy, the true flow system may lie somewhere between the linear and radial cases.

The effective porosity values from this analytical analysis differ slightly from the values determined in Section 5.1. The radial case effective porosity values increased to 0.007 and 0.013 for transport from Wells \#1 to Well \#3 and from Well \#2 to Well \#3, respectively. Some of the other parameters obtained from the curve fitting are consistent with other measurements. For example, the Peclet numbers imply longitudinal dispersivities in the range of 22 to $25 \mathrm{~m}$ for the radial flow case. These values are larger than average, but are within the range of measured values at comparable scales as summarized by Gelhar et al. (1992) and Neuman (1990). The one parameter that is somewhat questionable is the mass fraction. The mass fraction represents a multiplier that was used to reduce the amount of mass that was assumed to have made its way from the injection well to the pumped well. For the flow from Well \#1 to Well \#3, only 20 percent of the mass injected into Well \#1 was accounted for in Well \#3. For the flow from Well \#2 to Well \#3, the mass fraction increases to about 50 to 60 percent. Again a substantial amount of the mass is not accounted for in the solution. As will be noted later, a mass loss mechanism was employed in the numerical model calibration. Ther efore, it appears that some portion of the injected tracer mass did not follow a path from the injection wells to the pumped well.

Several features of the test are not addressed in the analytical solutions. First, heterogeneities such as regions of higher or lower hydraulic conductivity or porosity are not included. Additionally, complexities of the flow system including nearby boundaries are not included in the analysis. Nonetheless, these analytical results are 
useful to help bound the range of parameter values and provide starting points for the numerical modeling.

Table 5-2

Parameters for the Application of the Semi-Analytical Method of Reimus and Haga (1998)

\begin{tabular}{|c|c|c|c|c|}
\hline Parameter & Well 1- Well 3 & Well 1- Well 2 & $\begin{array}{c}\text { Well 2- Well } 3 \\
\text { (a) }\end{array}$ & $\begin{array}{c}\text { Well 2- Well } 3 \\
\text { (b) }\end{array}$ \\
\hline Mass Fraction & 0.2 & 0.005 & 0.47 & 0.6 \\
\hline $\begin{array}{l}\text { Linear residence } \\
\text { time, hrs }\end{array}$ & 2150 & 290 & 2100 & 1850 \\
\hline Linear Peclet \# & 4.0 & 3.0 & 2.25 & 2.5 \\
\hline $\begin{array}{l}\text { Radial residence } \\
\text { time, hrs }\end{array}$ & 1650 & 210 & 1450 & 1300 \\
\hline Radial Peclet \# & 6.0 & 4.75 & 3.5 & 4.0 \\
\hline $\begin{array}{l}\text { Linear effective } \\
\text { porosity }\end{array}$ & 0.009 & $\begin{array}{l}0.0005(0.0023) \\
\text { (c) }\end{array}$ & 0.019 & 0.017 \\
\hline $\begin{array}{l}\text { Radial effective } \\
\text { porosity }\end{array}$ & 0.007 & $\begin{array}{l}0.0004(0.0016) \\
\text { (c) }\end{array}$ & 0.013 & 0.012 \\
\hline$\Phi / \mathrm{b}, \mathrm{cm}^{-1}(\mathrm{~d})$ & 2.0 & 2.0 & 2.0 & 2.0 \\
\hline $\begin{array}{l}\text { lodide } \mathrm{Dm} \text {, } \\
\mathrm{cm}^{2} / \mathrm{sec}\end{array}$ & $1.0 \times 10^{-8}$ & $8.0 \times 10^{-8}$ & --- & --- \\
\hline FBA Dm, $\mathrm{cm}^{2} / \mathrm{sec}$ & $0.333 \times 10^{-8}$ & $2.67 \times 10^{-8}$ & $0.333 \times 10^{-8}$ & $2.67 \times 10^{-8}$ \\
\hline Sphere kf, hr-1 (e) & 0.0038 & 0.0047 & 0.0060 & 0.0071 \\
\hline Sphere $\lambda, \mathrm{cm}^{-1}(\mathrm{e})$ & 0.00063 & 0.00033 & 0.0014 & 0.0015 \\
\hline
\end{tabular}

(a) Assumes Dm for PFBA is equal to Dm for 2,6-DFBA between Wells \#1 and \#3.

(b) Assumes Dm for PFBA is equal to Dm for 2,6-DFBA between Wells \#1 and \#2.

(c) First value assumes that tracer movement between Wells \#1 and \#2 was due to pumping Well \#2; value in parentheses assumes tracer movement due to pumping Well \#3.

(d) $\varphi / b$ is an assumed value, not a fitted parameter

(e) Relationship between $\mathrm{kf}$ and $\lambda$ is $\mathrm{kf}=\lambda \mathrm{V}$, where $\mathrm{V}$ is the average linear velocity.

FBA - Fluorobenzoic acid (includes both 2,6 DFBA and PFBA) 


\subsection{Numerical Modeling - Flow Calibration}

The analytical solutions presented in Section 5.0 provide useful initial values for the parameters of interest, but have some limitations. Generally, one or more assumptions required to implement an analytical model may be questionable. Often times the questions regarding the assumption of homogeneity, or infinite aquifer extent, are the first to be questioned. One way to include natural complexities such as heterogeneity or nearby boundary conditions is to use a numerical model. The numerical model discretely approximates the governing equations and easily incorporates heterogeneity and boundary condition complexity.

The geol ogic complexity of the BULLION site, coupled with the potential influence of nearby features such as the West Greeley fault, lead to the decision to utilize a three-dimensional groundwater flow and transport model to simulate the tracer experiment. The model needed to account for advection, dispersion, possible adsorption, radioactive (first order) decay, and matrix diffusion. Additionally, it was deemed advantageous to use a model compatible with the MODFLOWT (Duffield et al., 1996) code that was used to plan the tracer test (IT, 1997). A decision was made to add matrix diffusion capability (via a Dual Porosity/Permeability Package) to MODF LOWT, rather than switch to another code which al ready had the needed capabilities. This was done to ensure compatibility with the previous work.

\subsection{MODFLOWT with Dual Porosity}

The dual-permeability/dual-porosity package for MODFLOWT is comprised of three submodules, DPF.FOR, DPT.FOR, and DOBS.FOR. DPF.FOR contains all of the FORTRAN subroutines pertinent to the flow model, DPT.FOR contains all of the FORTRAN subroutines pertinent to the transport model, and DOBS.FOR contains all of the FORTRAN subroutines used to display porous-matrix output for both flow and transport. All of the logic in the submodules is consistent in structure with analogous subroutines from MODFLOW (McDonald and Harbough, 1988) and the original version of MODF LOWT (Duffield et al., 1996).

The dual porosity/dual permeability conceptualization assumes that there are two parallel continua, one for the fractures and one for the 
matrix. Transfer of water and solute mass between the two continua is accomplished via a mass transfer term that links the fracture equation with the corresponding matrix equation. Thus, the numerical model solves a pair of coupled partial differential equations for flow, and a second pair for transport. In each pair, one equation governs the fractures and the other governs the matrix.

The governing equation for advective-dispersive solute transport in the fractures can be expressed as:

$$
\frac{\partial}{\partial x_{i}}\left(D_{i j} \frac{\partial c}{\partial x_{i}}\right)-V_{i} \frac{\partial c}{\partial x_{i}}=R \frac{\partial c}{\partial t}+\lambda c-\frac{q}{\varepsilon}\left(c^{*}-c\right)-\left(\frac{1-\varepsilon}{\varepsilon}\right) \Gamma
$$

where $D_{i j}\left(L^{2} / T\right)$ is the hydrodynamic dispersion tensor, $V_{i}(L / T)$ is the average fracture vel ocity vector, $\lambda\left(\mathrm{T}^{-1}\right)$ is the first-or der decay coefficient, $q$ is the volumetric fluid-flow rate from injection wells, $\Gamma$ is the matrix mass transfer coefficient defined as the rate of solute transport from the matrix block to the fracture per unit volume of the matrix block, $R$ is the fracture retardation coefficient, and $\varepsilon$ is the fracture porosity defined as:

$$
\varepsilon=\frac{b}{B+b}
$$

where $b$ is the fracture aperture and $B$ is the matrix-block width. The matrix mass transfer coefficient has two definitions depending on the assumed geometry of the matrix blocks. If the blocks are assumed planar such that the matrix is conceptualized as a series of slabs separating fractures, then $\Gamma$ is given by:

$$
\Gamma=-\frac{2}{B}\left(\left.D \frac{\partial c^{\prime}}{\partial z^{\prime}}\right|_{z^{\prime}=B / 2}\right)
$$

where $D$ ' is the effective matrix diffusion coefficient in the matrix, and $z$ is the coordinate direction in the matrix block. If the matrix blocks can 
be described as spherical, with an average diameter of $B$, then the expression for $\Gamma$ becomes:

$$
\Gamma=-\frac{6}{B}\left(\left.D^{\prime} \frac{\partial c^{\prime}}{\partial r}\right|_{r=B / 2}\right)
$$

In both formulations for $\Gamma$, the matrix is treated as a storage region for solute mass, but does not contribute to downgradient movement of the solute. The equation governing the solute mass in the matrix, assuming the slab model for matrix blocks, is given by:

$$
\frac{\partial}{\partial z}\left(D^{\prime} \frac{\partial c^{\prime}}{\partial z^{\prime}}\right)=\phi^{\prime} R^{\prime} \frac{\partial c^{\prime}}{\partial t}+\lambda \phi^{\prime} R^{\prime} c^{\prime}
$$

where $\phi^{\prime}$ is the matrix-block porosity, and $\mathrm{R}^{\prime}$ is the matrix-block retardation coefficient. The governing equation for the spherical block approximation can be expressed in the form:

$$
\frac{1}{r^{2}} \frac{\partial}{\partial r^{2}}\left(D^{\prime} r^{2} \frac{\partial c^{\prime}}{\partial r}\right)=\phi^{\prime} R^{\prime} \frac{\partial c^{\prime}}{\partial t}+\lambda \phi^{\prime} R^{\prime} c^{\prime}
$$

where $r$ is the radius of the sphere. These coupled equations were solved numerically to yield the solute mass in the fractures as a function of time and space. The coupling is accomplished through the matrix mass transfer coefficient, $\Gamma$, in equation 6-1. In each of equations $6-3$ or $6-4, \Gamma$ is defined by a diffusive mass flux term, which is the product of the matrix diffusion coefficient and the concentration gradient in the matrix. That same diffusive flux term occurs in equation 6-5, the governing equation of transport in the matrix 


\subsection{Geologic Model}

The first step in the devel opment of the numerical model of the BULLION tracer test was the creation of the underlying geologic model. The geologic model defines the location of hydrostratigraphic units (HSUs) in space, which correspond to layers in the flow and transport model. Six HSUs were identified at the BULLION site and are described in the BULLION Forced-Gradient Experiment Implementation PIan (IT, 1997). The location of the HSU s are defined by a series of structure contour maps of the top of each of the layers. The top layer of the geologic model for this analysis, in which the water table occurs, coincides with the top of the mafic-poor Calico Hills Formation (Tacp). This unit was mapped as part of the Pahute Mesa geologic model (Drellack and Prothro, 1997), and this mapping was used as the base for the geologic model. Figure 6-1 shows these layers in cross-section. The geologic interpretation was taken from the Completion Report for Well Cluster ER-20-6 (DOE/NV, 1998). The stratigraphic nomenclature for the units shown on this cross section is listed in Table 6-1.

The top of the uppermost HSU (uppermost lava-flow aquifer and bedded tuff: [HSU 1]) corresponds to the top of the mafic-poor Calico Hills Formation (Tacp) of the Volcanics of Area 20 (Ta). This HSU contains both bedded tuff and lava. The lava was penetrated by Well \#3, and a flow breccia stratigraphically related to it was penetrated by Well \#2. However, bedded tuff, not lava was present in Well \#1 at this stratigraphic horizon. The lava and flow breccia in the uppermost HSU will be collectively referred to as the upper lava. The lava in HSU 1 was defined within the model as a separate zone from the bedded tuff, and it is present in the model only at the BULLION FGE site.

The next lower HSU (HSU 2) has been previously defined in the Completion Report for Well Cluster ER-20-6 (DOE/NV, 1998) as the "upper zeolitic bedded tuff," and it is part of the same bedded tuff that is present in HSU 1. It is differentiated from HSU 1 within the model to incorporate the bedded tuff that underlies the upper lava. HSU 2 is underlain by a lava-flow aquifer, the upper part of which is zeolitized. The zeolitized section has been designated as HSU 3, the "altered middle lava."

The fourth HSU (HSU 4), the "middle lava-flow aquifer," produced more water during drilling than the upper lava and was encountered by all three wells. Tritium concentrations were also lower. During drilling, concentrations within this HSU declined as a result of dilution as water production increased. This trend of decreasing tritium concentrations continued during most of the forced-gradient experiment. This lava is projected to have been intercepted by the BULLION cavity. It is underlain by the 15- to 30-m thick "lower-permeability lava zone" (HSU 5) and the "lower lava-flow 


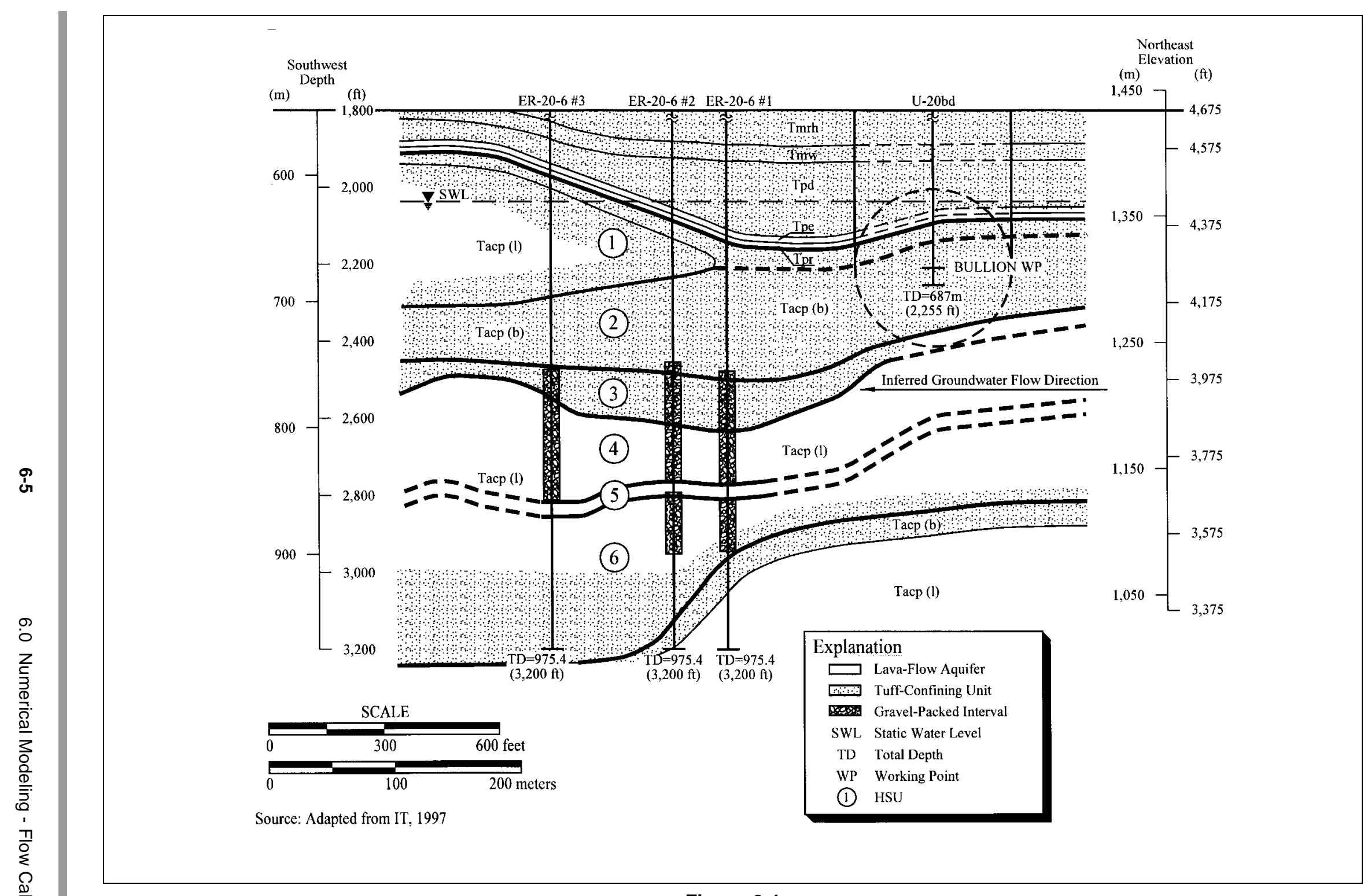

Figure 6-1

Geologic Cross Section through the BULLION FGE Site 
Table 6-1

Stratigraphic, Lithologic, and Hydrogeologic Units for the ER-20-6

Cross Section*

\begin{tabular}{|c|c|c|c|c|}
\hline $\begin{array}{l}\text { Stratigraphic } \\
\text { Group }\end{array}$ & Stratigraphic Unit & Symbol & Typical Lithology & $\begin{array}{c}\text { Hydrogeologic } \\
\text { Unit }\end{array}$ \\
\hline \multirow{2}{*}{$\begin{array}{l}\text { Timber Mountain } \\
\text { Group (Tm) }\end{array}$} & $\begin{array}{l}\text { tuff of Holmes } \\
\text { Road }\end{array}$ & Tmrh & \multirow{2}{*}{$\begin{array}{l}\text { Bedded Tuffd, } \\
\text { zeolitized }\end{array}$} & \multirow{2}{*}{$\begin{array}{c}\text { Tuff-confining unit } \\
\text { (unsaturated at this } \\
\text { location) }\end{array}$} \\
\hline & $\begin{array}{l}\text { rhyolite of Windy } \\
\text { Wash }\end{array}$ & Tmw & & \\
\hline \multirow{3}{*}{$\begin{array}{c}\text { Paintbrush Group } \\
(T p)\end{array}$} & $\begin{array}{c}\text { rhyolite of Delirium } \\
\text { Canyon }\end{array}$ & Tpd & \multirow{3}{*}{$\begin{array}{l}\text { Bedded Tuffs, } \\
\text { zeolitized }\end{array}$} & \multirow{3}{*}{$\begin{array}{l}\text { Tuff-confining uni } \\
\text { (saturated) }\end{array}$} \\
\hline & $\begin{array}{c}\text { rhyolite of Echo } \\
\text { Peak }\end{array}$ & Tpe & & \\
\hline & $\begin{array}{l}\text { rhyolite of Silent } \\
\text { Canyon }\end{array}$ & Tpr & & \\
\hline \multirow{2}{*}{$\begin{array}{c}\text { Volcanics of Area } \\
20(\mathrm{Ta})\end{array}$} & \multirow{2}{*}{$\begin{array}{l}\text { mafic-poor Calico } \\
\text { Hills Formation }\end{array}$} & $\operatorname{Tacp}(b)$ & $\begin{array}{l}\text { Bedded tuff, } \\
\text { zeolitized }\end{array}$ & \multirow{2}{*}{$\begin{array}{c}\text { Lava-flow aquifer } \\
\text { (saturated) }\end{array}$} \\
\hline & & $\operatorname{Tacp}(\mathrm{L})$ & Rhyolite lava flow & \\
\hline
\end{tabular}

* Excerpted from DOE/NV,1998

aquifer" (HSU 6). These lower two HSU s were penetrated by all three wells. Wells \#1 and \#2 also encountered an underlying bedded tuff and the upper part of a deeper lava; however, these deeper units are not considered in the model. The middle lava-flow aquifer, although projected to intercept the cavity, probably did not do so. The lack of tritium in the Well \#l samples during the experiment suggests that radionuclides were not entering the aquifer in large quantities during the test.

HSU 5 was identified on the basis of geophysical log signatures and was set off by blank casing during well completion based on the interpretation that it was a less permeable zone. Core from the lower portion of HSU 5 (depths greater than $853 \mathrm{~m}$ ) from Well \#1 was examined (Prothro et al., 1997), and the degree of fracturing in this interval was less than in the adjoining HSUs. However, core from the greater portion of HSU 5, above a depth of $853 \mathrm{~m}$, was not collected. Therefore, the nature of HSU 5 as a whole is somewhat uncertain.

\subsubsection{Construction of the Geologic Layers}

The areal extent of the geologic model is shown in Figure 6-2. It extends from the West Greeley fault on the east to the Boxcar fault on the west. The northern and southern boundaries were chosen to be a sufficient distance away from the tracer test location to avoid boundary influences in the modeling. The geologic model created for this analysis is a refinement of a previous geologic model built as part of predictive modeling described in the BULLION Forced-Gradient 


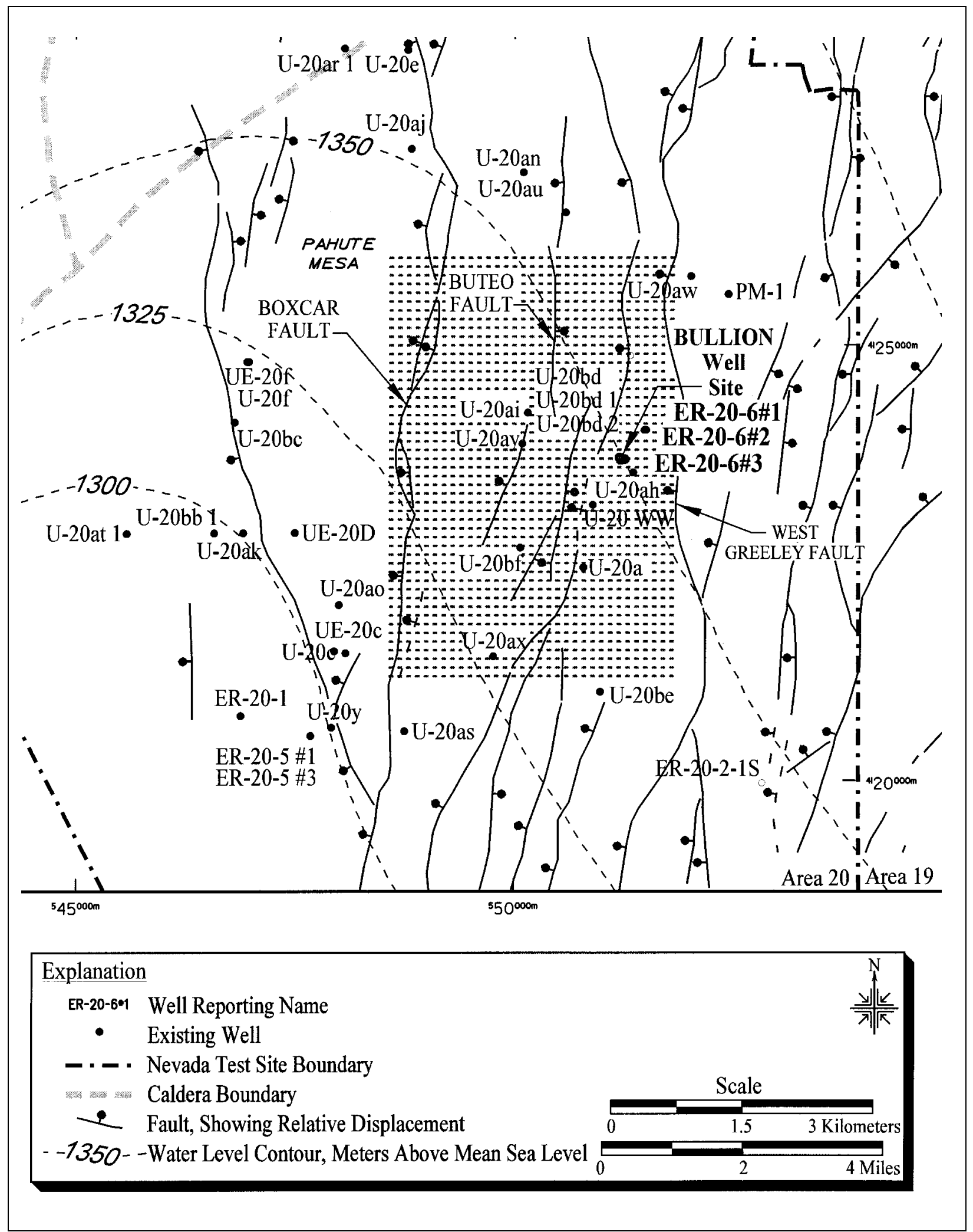

Figure 6-2

Areal Extent of the FGE Geologic Model 
Experiment I mplementation Plan (IT, 1997). Two refinements were implemented: (1) the top of the model was updated with the most recent information, and (2) the location of the West Greeley fault at depth was better represented. The top of both geologic models corresponds to the top of the mafic-poor Calico Hills Formation. Drellack and Prothro (1997) revised the structural contour map on top of that unit as part of their geologic investigation of the Pahute Mesa Corrective Action Unit. The HSU topped by the mafic-poor Calico Hills Formation is called the Calico Hills Zeolitized Composite U nit. Additionally, the subsurface location of faults is better approximated in the recent Pahute Mesa geologic model.

The top of the new BULLION geologic model, as taken from Drellack and Prothro (1997), is shown in Figure 6-3. The total thickness of the BULLION geologic model is defined as the thickness from the top of layer 1 to the bottom of layer 6 . The total thickness at each node in the new geologic model is the same as was previously defined in the BULLION Forced-Gradient Experiment I mplementation Plan (IT, 1997). In addition, the thickness of each of the six HSU s is also the same as defined in IT (1997). The elevation of each of the six HSU s was calculated by subtracting the thickness of the overlying HSU from the elevation of the top of the overlying HSU. F or example, the elevation of the top of HSU 1 is the same as the top of the mafic-poor Calico Hills Formation. The el evation of the top of HSU 2 is the elevation of HSU 1 minus the thickness of HSU 1 . The same process is followed until the bottom of HSU 6 is reached. This process created a geologic model that honored the HSU thicknesses from the Implementation Plan while also honoring the most recent information regarding the top of the mafic-poor Calico Hills Formation.

\subsubsection{Adjustments to the Geologic Model}

After incorporating the listed refinements, some minor adjustments to the HSU top-surface elevations were made near the BULLION FGE site to better match the observed hydrostratigraphy. The final elevation contour maps on the top of each HSU are presented in Appendix A. Several cross sections through the geologic model are also given in Appendix A. Two of those cross sections are shown in Figure 6-4 and Figure 6-5 (corresponding to A-3 and A-6 in Appendix A). The first cross section runs east-west across the geologic model grid just south of the FGE site. N ote the effect of the West Greeley fault bounding the west edge on the structural contours. The second cross section runs through the FGE wells from southwest to northeast. The middle span of the cross section approximately corresponds to Well \#3 on the left and the BULLION test cavity location on the right. This cross section shows how the BULLION geologic model represents the observed stratigraphy at the FGE site, shown in Figure 6-1. 


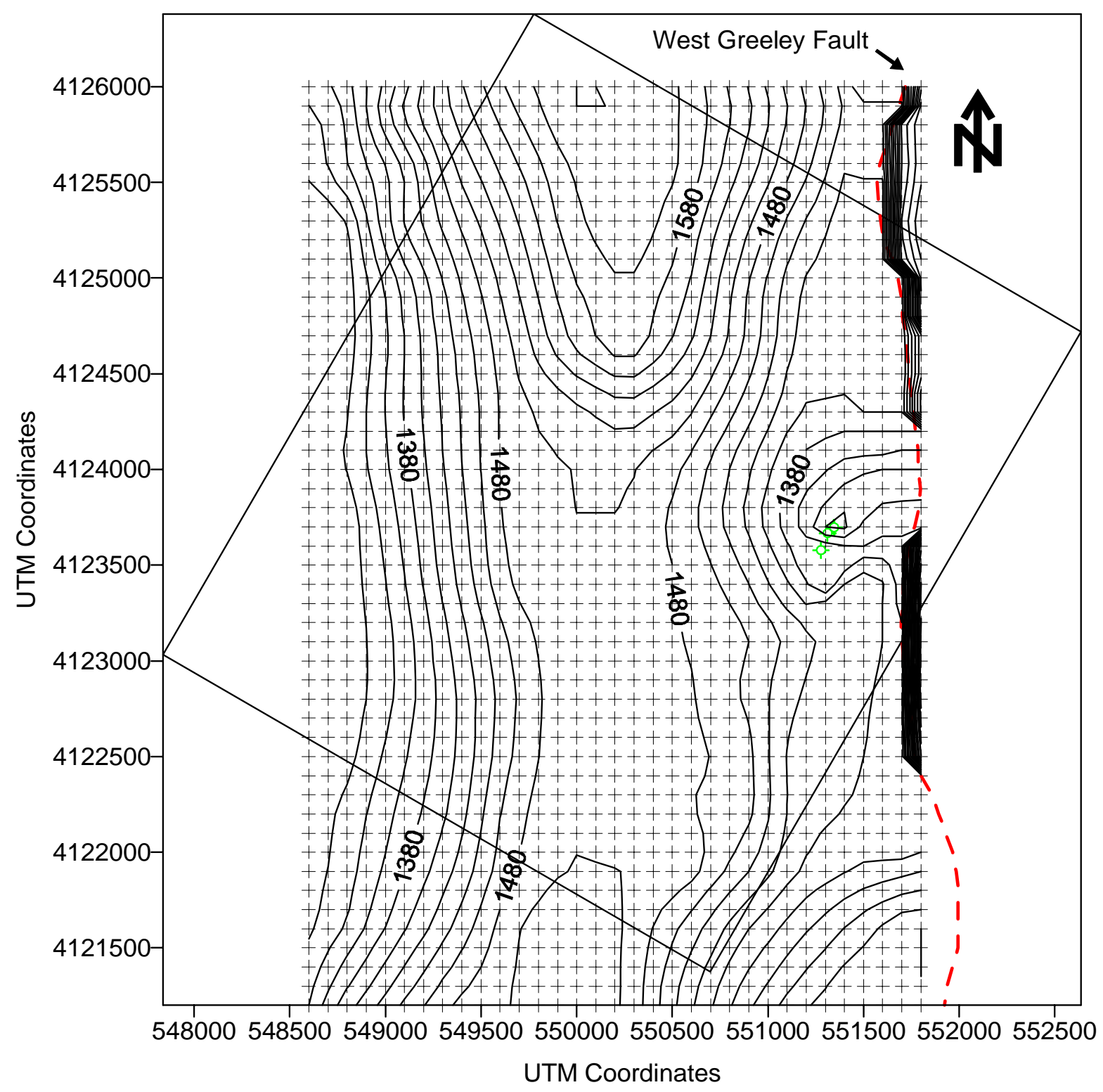

\begin{tabular}{|ll|}
\hline+ & Explanation \\
$+\quad$ & $\begin{array}{l}\text { MULLION Wells Grid Nodes } \\
\text { Elevation Contours, Meters Above Mean Sea Level } \\
\text { UTM Zone 11 Coordinate System }\end{array}$ \\
\hline
\end{tabular}

Figure 6-3

Structure Contour Map of the Top of the Calico Hills Zeolitized Composite Unit 


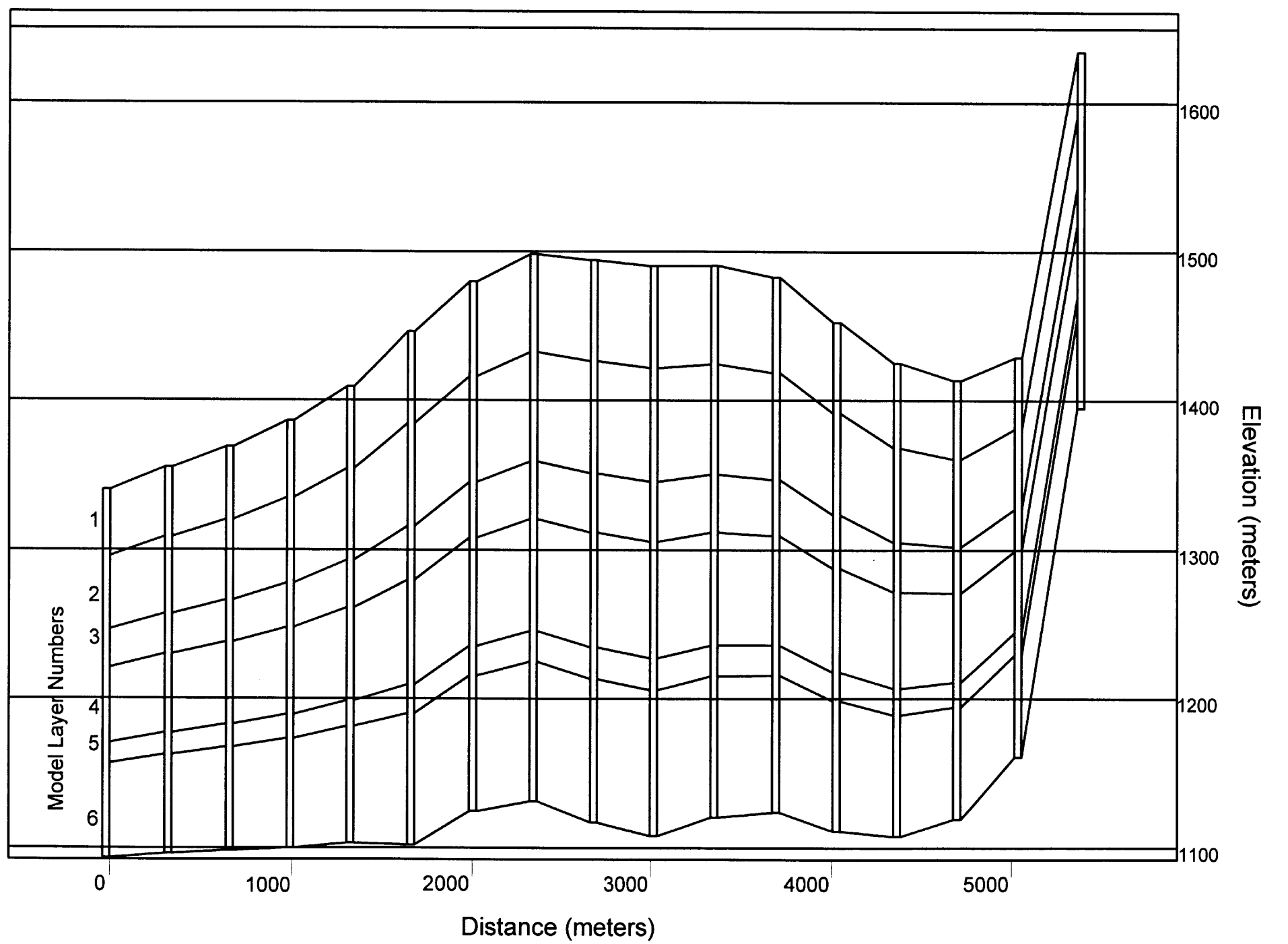

Figure 6-4

East-West Cross Section through the Geologic Model Area 


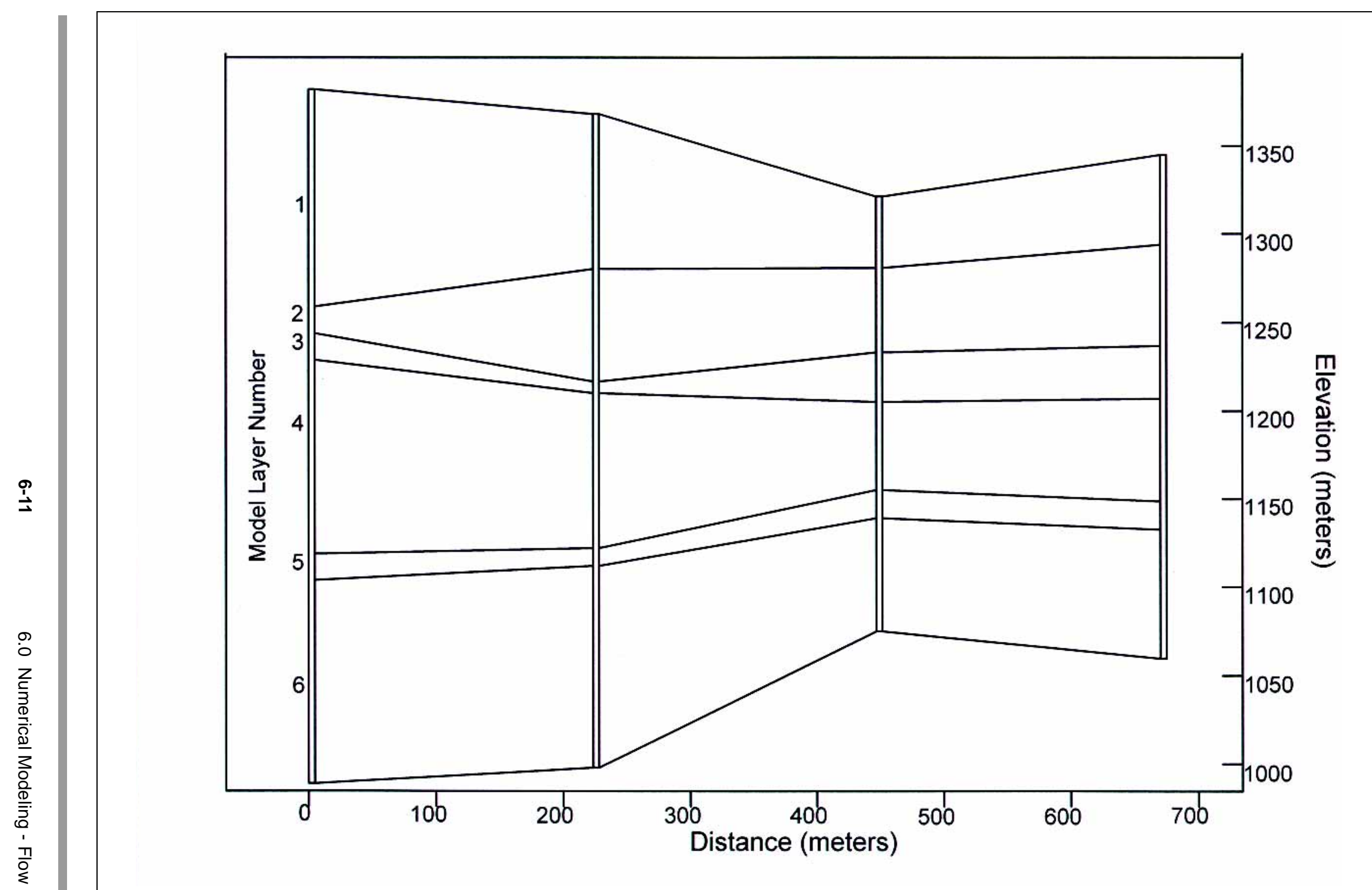

Figure 6-5

Southwest-Northwest Cross Section through the BULLION FGE Site 


\subsection{Model Layering and Grid Layout}

The model grid is presented in Figure 6-6. The grid is rotated 30.1 degrees clockwise to align the y-axis (columns) with the estimated direction of maximum hydraulic conductivity (Section 4.0) which is taken to be aligned with a line drawn between Wells \#1 and \#3. The grid cell dimensions ranged from $1.5 \mathrm{~m}$ near Wells \#1, \#2, and \#3 to $705 \mathrm{~m}$ al ong the western edge of the model. For many of the transport simulations, portions of the grid away from the FGE site were made inactive for transport. This reduced the time required for the transport calculations. The portions of the model grid extending east of the West Greeley fault, west of the Boxcar fault, and the northernmost cell were excluded from the model because they were on the opposite side of a fault or outside of the geologic model area. These excluded areas are shown in Figure 6- 6 by the darkened corners of the model. The three dark bands, two horizontal and one vertical represent areas of very dense grid cells. The density is so great, that at the scale of the map, the grid boundary lines combine to form the three large dark lines.

The flow and transport model has six layers, each of which correspond to the one of the HSU layers. The top layer of the geol ogic model (HSU 1) extends above the estimated water table, shown in Figure 6-7. The projected water table el evation was determined from a hand drawn map based on observed water level data given in O'Hagan and Laczniak (1996). The hand drawn contours are approximate because of the sparse data. A way from the locations of data, the contour locations may be significantly in error. Flow was not allowed in the unsaturated zone above the water table. To simplify the cal culations, all layers were modeled as confined, with the water table serving as the top of the flow system. The assumption of confined layers was deemed reasonable because the primary aquifer units, HSU layers 4 and 6 on Figure 6-1, are confined by the overlying low permeability units. Additionally, the measured storage coefficients are more representative of a confined aquifer than an unconfined one.

The simulated pumping was applied to confined aquifer units separated from the water table by thick confining units, and the aquifer analysis did not indicate substantial vertical leakage. Consequently it was judged that the water table did not have to be handled as unconfined. Prior to simulation, the water table el evation was compared with each HSU elevation at each node in the model. If the bottom of an HSU was above the water table, that cell in the model was made inactive by setting the hydraulic conductivity to zero. If the water table fell within an HSU, the thickness of the HSU was adjusted to reflect the distance between the water table and the bottom of the HSU. This reduction in thickness would then be reflected as a reduction in the transmissivity of that cell in the model. If the top of an HSU was below the water table, no adjustments were necessary. 


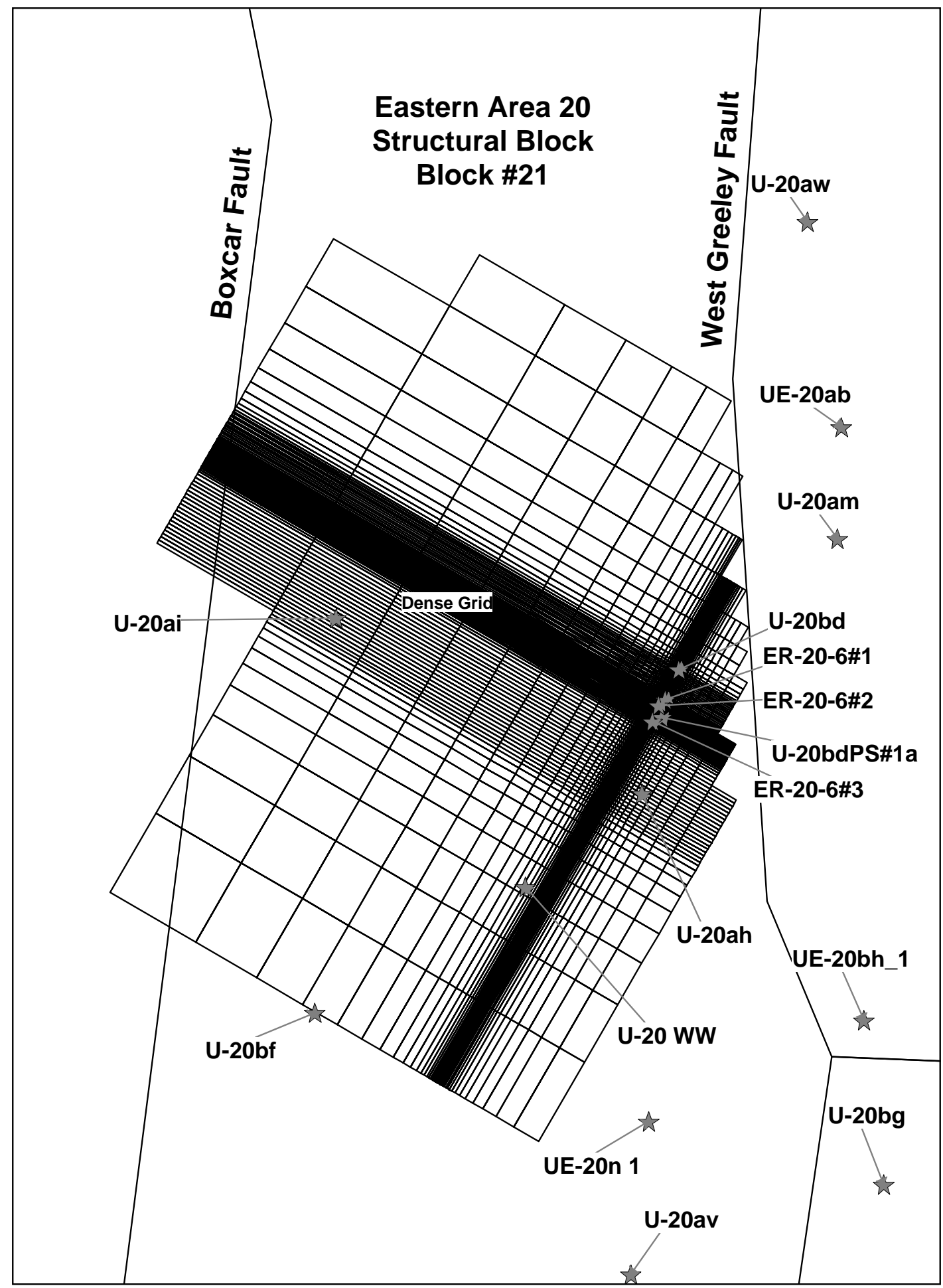

Figure 6-6

BULLION FGE Model Grid 


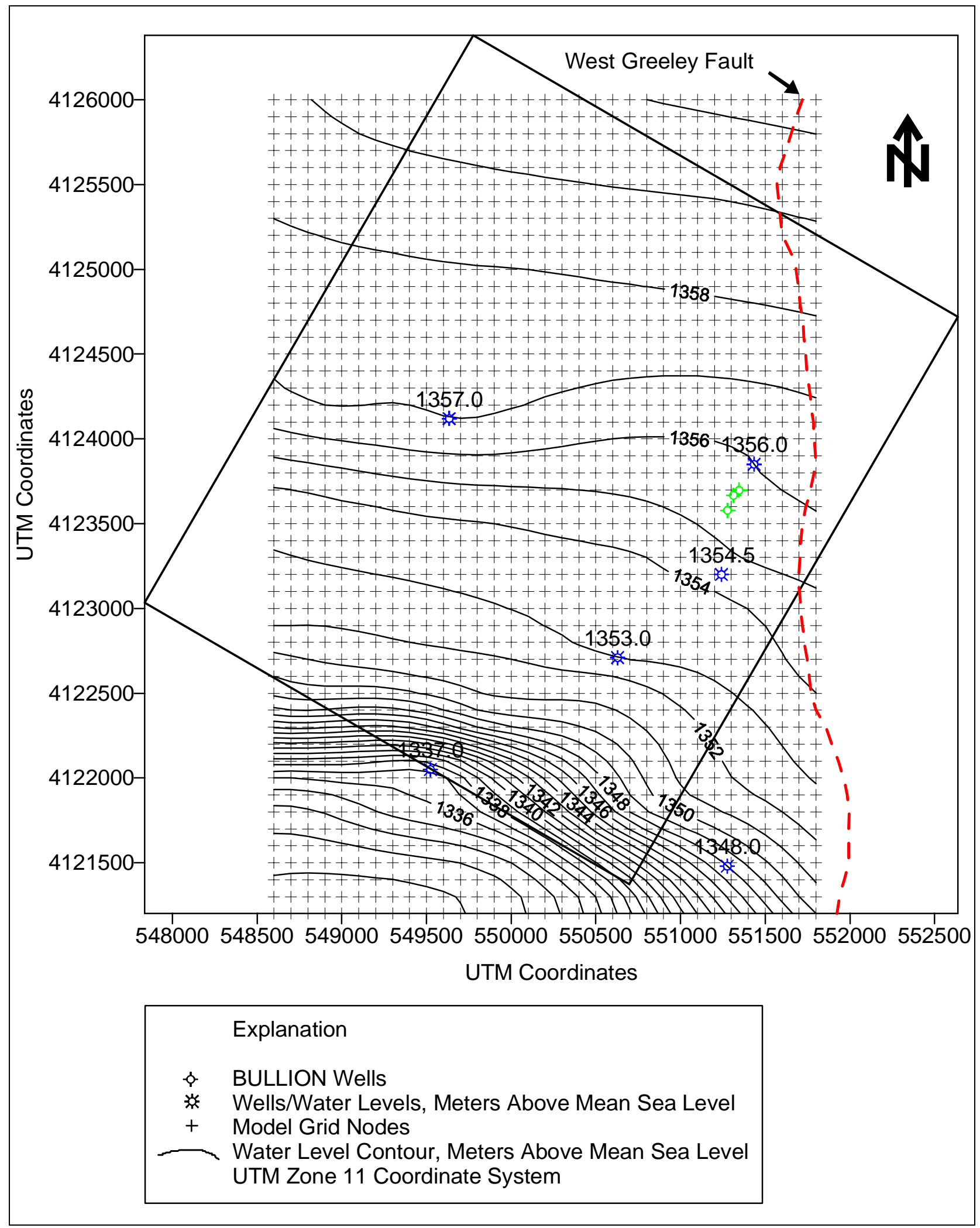

Figure 6-7

Estimated Water-Table Contour Map 


\subsection{Boundary and Initial Conditions}

The boundary and initial conditions of the model reflect the conceptual model of the flow system. The boundary configuration is given in Figure 6-8. All of the boundaries were simulated as general head boundaries in MODF LOWT. A general head boundary allows both head and flux to vary across a boundary. A detailed explanation of the general head boundary is given in M cDonald and Harbaugh (1988). Briefly, a general head boundary is constructed by assigning a constant head value at some distance, $L$, away from the center of the boundary cell. The hydraulic conductivity times the cross sectional area and divided by $L$ is called the conductance. The boundary flow is given by the conductance times the difference in head between the center of the cell and the assigned distant head value. As a result, the flux and head in the boundary cell are not fixed. For the simulations here, the boundary head was assigned at the edge of the cell; therefore, $L$ was one half the cell width. A major change from the previous model is the change of the West Greeley boundary from no flow to a general head boundary. During the FGE, it was observed that water level drawdowns in Well \#3 stabilized after a short time. This was taken as evidence that a source boundary may be present near the FGE site. At the Bullion FGE site, a leaky boundary at the West Greeley fault could also provide such an apparent source of water. This requires the assumption that the fault plane is conductive and transmits water easily. The amount of water that can pass through the West Greeley boundary is controlled by head difference across the boundary and the hydraulic conductance of the boundary. By increasing the conductance, the boundary can be made to act like a constant head source of water. By reducing the conductance, the boundary will act like a no-flow boundary. In this way the impact of a flux of water from the West Greeley fault could be evaluated.

Due to the angle of the model grid, the western boundary of the model was treated as a general head boundary (GHB). This allowed for a small amount of water to flow into the model from the west/northwest. The northern and southern boundaries of the model were modeled as GHBs. In all cases, the conductance at the boundaries was determined from the assigned hydraulic conductivity at cell location. A multiplication factor was added to the preprocessor to allow the conductance to be increased, or decreased independent of the hydraulic conductivity; however, this was used only for the sensitivity analyses.

The hydraulic head value assigned at each GHB along the northern, western, and southern boundaries was determined from the head values in Figure 6-7. Along the West Greeley fault, the head was increased by $0.5 \mathrm{~m}$ to create an inward flux to the model. Along the southeastern GHB, the head was reduced by $0.5 \mathrm{~m}$ to all ow water to exit the model. 


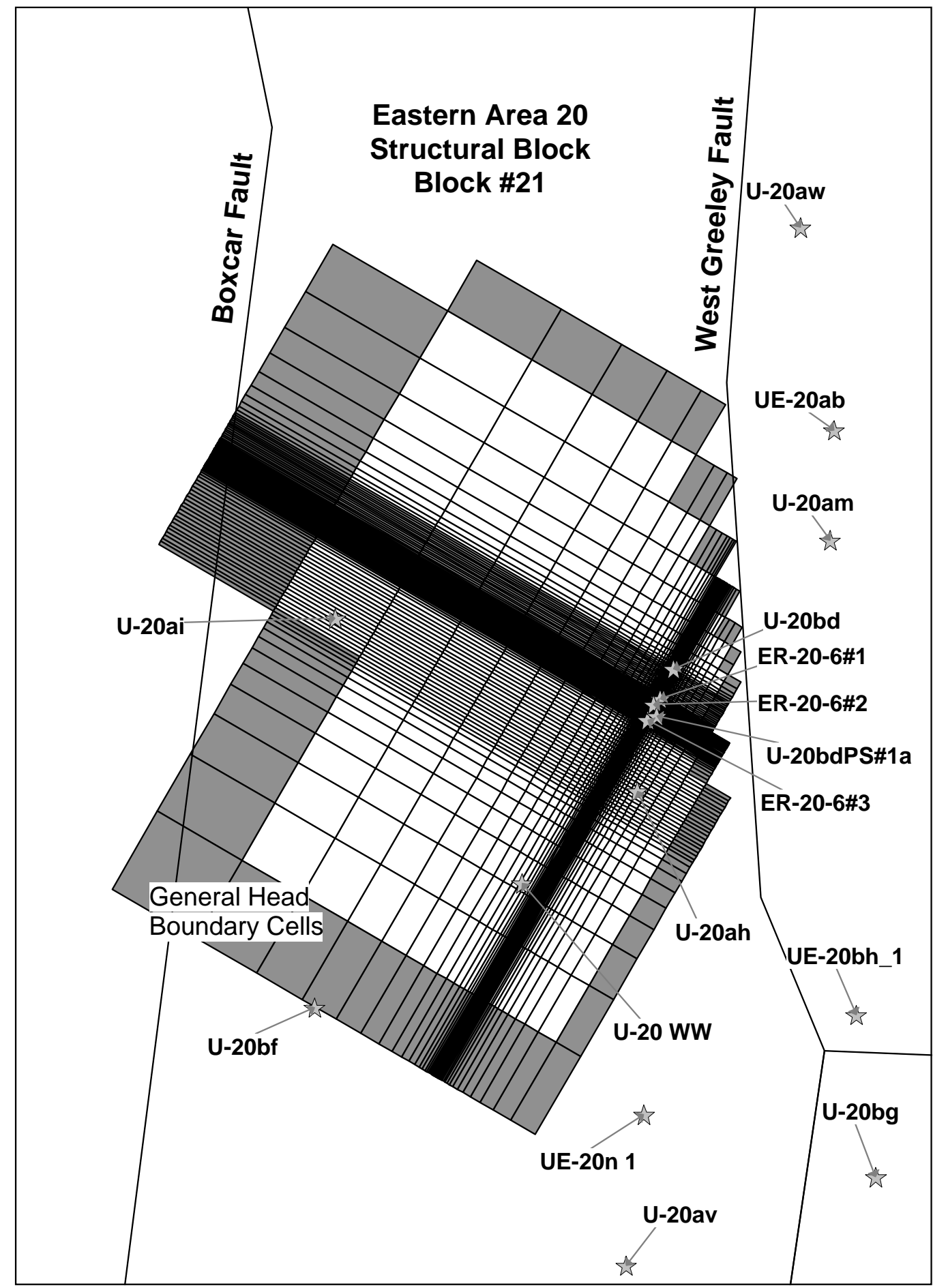

Figure 6-8

BULLION FGE Model Boundary Configuration 
Recharge was added to the top layer of the uppermost active cells in the model, using a value of $1.095 \times 10^{-5}$ meters per day $(\mathrm{m} / \mathrm{d})(4$ millimeters per year $[\mathrm{mm} / \mathrm{yr}])$ derived from the regional flow model (DOE/NV, 1997).

Pumping and injection of water into the aquifer is also specified as a boundary condition for the transient runs. The rates must be specified separately for each model layer that the well penetrates. The pumping rate at a well was divided over the layers weighted according to the transmissivities of the cells and the hydraulic head differences between the different layers. Because the wells deviated from vertical, the cells in which the wells are represented in the model and the land surface location of the wells are not in a vertical column in the model.

However, to simulate the movement of water up or down the well lbore, the cells do need to be in the same vertical column, which was selected at the approximate midpoint of the combined screened interval. The vertical hydraulic conductivity of HSU 5 where Wells \#1 and \#2 are present was set to 100 times the horizontal conductivity of HSU 5 (the lower zeolitic bedded tuff) to approximate the penetration of HSU 5 by the wellbore.

The initial condition for the steady-state simulation was a constant-head value of $1,360 \mathrm{~m}$. During steady-state runs the head at each node was calculated and stored. This calibrated steady-state head was used as the starting head for transient simulations.

\subsection{Hydraulic Calibration}

Hydraulic calibration is the process of adjusting model parameters to match the simulated water levels with the measured water levels. This was carried out in two steps, a steady-state calibration to establish the large scale, pre-test groundwater flow system followed by a transient calibration to match the water-level changes during the experiment. Typically, the hydraulic conductivity and the boundary fluxes are varied during the steady-state calibration. During the transient simulations, some further refinement of hydraulic conductivity and boundary fluxes may be necessary. Additionally, the storage coefficient of the aquifers also becomes important during transient simulations as well as the amount of water withdrawn from each HSU in contact with each well.

\subsubsection{Steady State Flow Calibration}

The steady-state calibration process involved changing the hydraulic conductivity $(\mathrm{K})$ values in each of the layers to reproduce the observed head values and also to be consistent with the hand-drawn 
potenti ometric surface map. The hydraulic conductivity values for each layer and zone are given in Table 6-2.

Table 6-2

Horizontal Hydraulic Conductivity (m/day)

\begin{tabular}{|c|c|c|c|c|c|c|}
\hline & $\begin{array}{c}\text { Upper } \\
\text { Lava-Flow } \\
\text { Aquifer / } \\
\text { Bedded } \\
\text { Tuff } \\
\text { (HSU 1) }\end{array}$ & $\begin{array}{c}\text { Upper } \\
\text { Zeolitic } \\
\text { Bedded } \\
\text { Tuff } \\
\text { (HSU 2) }\end{array}$ & $\begin{array}{c}\text { Altered } \\
\text { Middle } \\
\text { Tuff } \\
\text { (HSU 3) }\end{array}$ & $\begin{array}{c}\text { Middle } \\
\text { Lava Flow } \\
\text { Aquifer } \\
\text { (HSU 4) }\end{array}$ & $\begin{array}{c}\text { Lower } \\
\text { Permeability } \\
\text { Zone in Lava } \\
\text { (HSU 5) }\end{array}$ & $\begin{array}{c}\text { Lower } \\
\text { Lava Flow } \\
\text { Aquifer } \\
\text { (HSU 6) }\end{array}$ \\
\hline Primary Zone & 0.01 & 0.01 & 0.25 & 0.457 & 0.1 & 0.8 \\
\hline $\begin{array}{l}<1 \text { Cavity } \\
\text { Radius, } \\
\text { BULLION }\end{array}$ & 10.0 & 10.0 & 10.0 & 10.0 & & \\
\hline $\begin{array}{c}\text { 1-2 Cavity Radii, } \\
\text { BULLION }\end{array}$ & 1.0 & 1.0 & 1.0 & 10.0 & 0.1 & 10.0 \\
\hline $\begin{array}{c}<1 \text { Cavity } \\
\text { Radius, GIBNE }\end{array}$ & 1.0 & & & & & \\
\hline $\begin{array}{l}\text { Uppermost } \\
\text { Lava Flow }\end{array}$ & 0.8 & & & & & \\
\hline $\begin{array}{l}\text { Bedded Tuff } \\
\text { (southwest) }\end{array}$ & & & & 0.05 & & 0.05 \\
\hline $\begin{array}{c}\text { Overlap of } \\
\text { Upper Lava and } \\
\text { GIBNE } 2 \mathrm{r}\end{array}$ & 0.8 & & & & & \\
\hline $\begin{array}{c}\text { Northern Third, } \\
\text { HSU } 6 \text { - West }\end{array}$ & & & & & 0.1 & 3.0 \\
\hline $\begin{array}{c}\text { Northern Third, } \\
\text { HSU } 6 \text { - East }\end{array}$ & & & & & 0.1 & 10.0 \\
\hline $\begin{array}{l}\text { Wellbore, } \\
\text { HSU } 5\end{array}$ & & & & & 0.1 & \\
\hline $\begin{array}{c}\text { Steep Water } \\
\text { Table Gradient } \\
\text { Area }\end{array}$ & & & & 0.8 & & 0.8 \\
\hline $\begin{array}{l}\text { High K Region } \\
\text { Near Well \#1 }\end{array}$ & & & & 10.0 & & \\
\hline
\end{tabular}

The zones, defined as regions of the model layers with different hydraulic conductivities, are presented in Appendix A, Figures A-15 to A-21. Since the HSUs defined at the BULLION site do not necessarily extend uniformly throughout the model extent, the zonation actually incorporates the additional lateral geologic structure within model layers. This is particularly true of the lava HSUs, since the lavas are not known to be continuous. This is the explanation for the variations in layer descriptions found in Table 6-1.

Bedded tuffs were assigned a horizontal hydraulic conductivity value of $0.01 \mathrm{~m} / \mathrm{d}$ in HSU 1 and a value of $0.05 \mathrm{~m} / \mathrm{d}$ in HSU s 4 and 6 , approximately two orders of magnitude lower than the values used for the lavas. This was set in recognition of the fact that most of the 
permeability of the lavas are due to fractures and that the bedded units are much less fractured than the lavas. It was assumed that the hydraulic conductivity of the BULLION cavity and the other high conductivity regions near the cavity is $10.0 \mathrm{~m} / \mathrm{d}$.

The altered tuff (zeolitized) lava (HSU 3) was estimated to be about one-third to one-half as conductive as the unaltered lava, but may be even less conductive. I ts properties within two cavity radii of the BULLION cavity were estimated to be the same as for the bedded tuffs, using the simplification that the collapse and explosion-induced fracturing would affect all lithologies in a similar manner.

The horizontal hydraulic conductivity value used for the middle lava-flow aquifer was $0.46 \mathrm{~m} / \mathrm{d}$, near the lower end of the range from the interpretation of the hydraulic response of the aquifer to pumping in Well \#3. This value provided better agreement with projected drawdown from the test than did higher values. The lower value in the model resulted from the use of a horizontal ani sotropy factor of 7.0 for the lavas, yiel ding a value of $3.2 \mathrm{~m} / \mathrm{d}$ in the column-direction and $0.46 \mathrm{~m} / \mathrm{d}$ in the row-direction. The upper and lower lavas (HSU 4 and 6) were assigned different values with the lower unit having the greater value. The lower observed gradient in the northern part of the model required increasing hydraulic conductivity of the lower lava from $0.8 \mathrm{~m} / \mathrm{d}$ to $3.0 \mathrm{~m} / \mathrm{d}$. The lower permeability lava zone (HSU 5) was assigned a hydraulic conductivity nearly an order of magnitude less than the unaltered tuffs. This value is uncertain because core from the lower part of HSU 5 appeared to be as fractured as HSU 6. The upper part of HSU 5 was not cored, and therefore could be less fractured and of lower hydraulic conductivity.

The horizontal anisotropy of the lava flow aquifers in HSUs 4 and 6 was given a value of 7.0 except within two cavity radii of the BULLION and GIBNE working points where a value of 1.0 is used. Most of the other units were assigned an anisotropy of 2.0. MODFLOWT uses this factor to multiply the hydraulic conductivity in the column-direction ( $N 30.1$ degrees $\mathrm{E}$ ) while the conductivity in the row-direction is that shown in the table. The value of 7.0 was derived from the analysis of drawdown data in Section 4.0. Within two cavity radii of the working points, the explosion-induced fracturing was assumed to over whel $m$ the regional fracturing, hence a horizontal anisotropy value of 1.0 was used.

The vertical anisotropy factor (the ratio of horizontal to vertical hydraulic conductivity) was assumed to be 1.0, based on the theory that vertical anisotropy is largely due to interlayering of rocks of high and low conductivities, which is already included in the HSU layer differences. Additionally, high-angle fractures are more numerous than low-angle fractures, so the two major principal directions of the conductivity ellipsoid are approximately north-south and nearly 
vertical. Also, a vertical anisotropy of 100 was assigned to the wellbores that penetrated HSU 5 .

Overlying units are largely unsaturated in the northern area so that their properties do not affect the model simulations. In addition, the western part of the middle lava and the southwestern part of the lower lava were replaced by a bedded tuff because the lava is projected to pinch out between the Buteo and Boxcar faults (IT, 1995). To the southeast, the region of steeper hydraulic gradient required a larger hydraulic conductivity for HSU 4 . This was caused by a constriction in the flow system between the bedded tuff to the west and the model boundary to the east. Finally, the region of higher hydraulic conductivity associated with the BULLION cavity was extended southward to include Well \#1. Additionally, a thin zone of higher hydraulic conductivity extending part way from Well \#1 to Well \#3 was added during calibration to better explain the observed tracer behavior at Well \#1. These features will be discussed in more detail under the sensitivity analyses.

The simulated steady-state water table map is given in Figure 6-9. The map is in reasonable agreement with the measured values, including the BULLION site where measured head values are about $1,355 \mathrm{~m}$. The simulated contours do not match the hand drawn contours over the southeastern one-quarter of the model area. The hand drawn contours are based on limited data and may not be accurate except where observed data are available. The model predicted water levels match the observed values at the respective wells. Therefore, lack of conformance between the two sets of contours is not considered problematic. Additionally, north of, and through the FGE site, the two sets of contours are better constrained by data and the two sets of contours are similar.

\subsubsection{Transient Calibration}

The transient calibration matches the hydraulic response of the aquifer to outside stresses such as the injection in Wells \#1 and \#2 and the pumping of all three wells during the BULLION FGE test. The transient simulations begin with the steady state heads as the initial condition and simulate the aquifer response to the injection and pumping. The injection and pumping varied over time with some wells pumping, some off, and occasionally all wells off due to generator failures. A total of 32 stress periods were established to represent all the important changes in well injection of pumping over the $90+$ days of the F GE. Table 6-3 lists the stress periods, their duration, and the amount of pumpage (or injection) for each well.

Both Wells \#1 and \#2 were open to HSU s 4 and 6 . The amount of water injected or withdrawn into HSUs 4 and 6 was apportioned on the basis of transmissivity, likely head differences, and fluid density in the case 


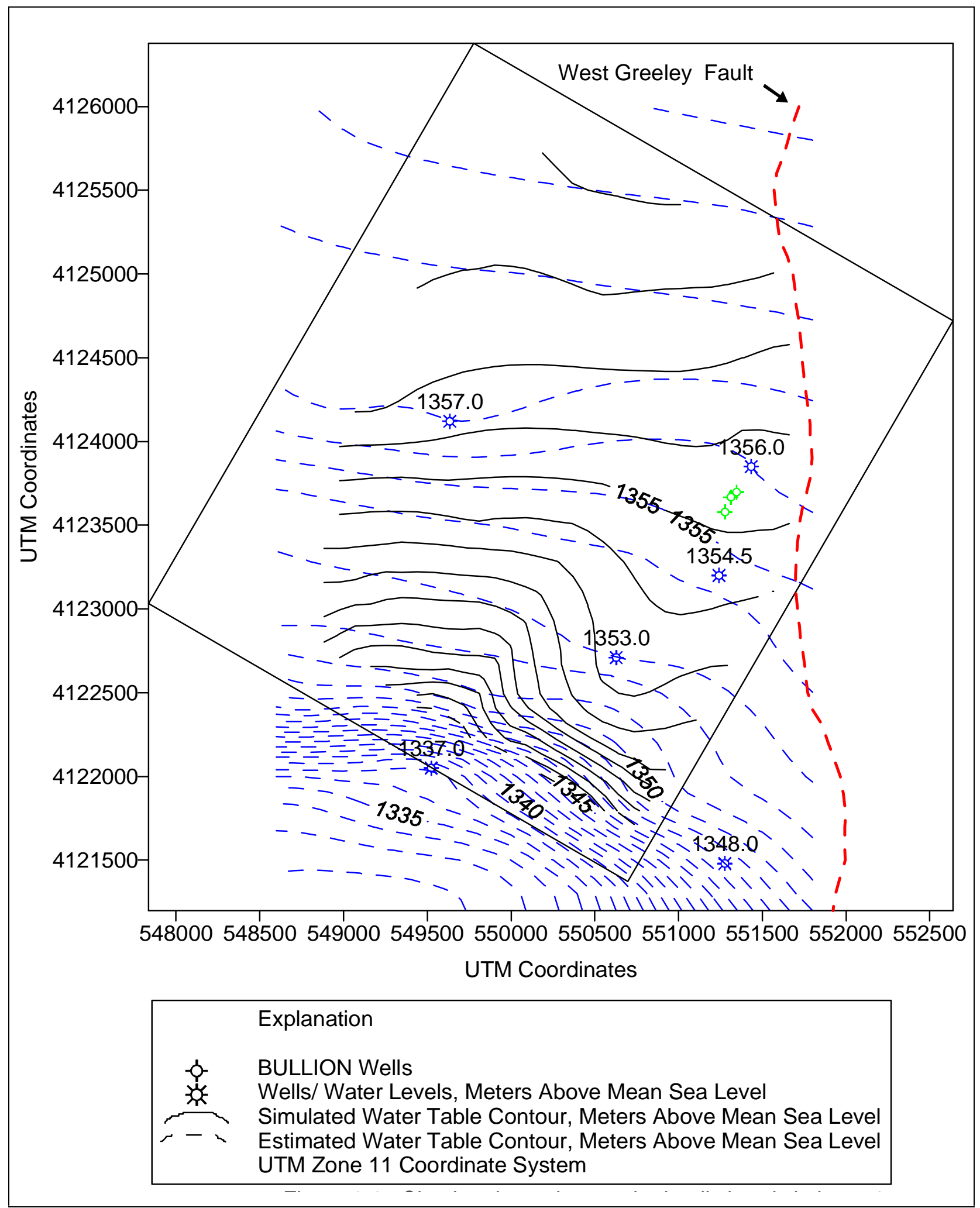

Figure 6-9

Simulated Steady-State Water Table Map 
Table 6-3

Stress Periods Used for Modeling the BULLION FGE

(Page 1 of 2 )

\begin{tabular}{|c|c|c|c|c|c|}
\hline $\begin{array}{l}\text { Elapsed Time } \\
\text { (days) }\end{array}$ & $\begin{array}{c}\text { Stress Period } \\
\#\end{array}$ & $\begin{array}{l}\text { Period } \\
\text { Length } \\
\text { (days) }\end{array}$ & Well \# & $\begin{array}{c}\text { Rate } \\
\left(\mathrm{m}^{3} / \mathrm{day}\right)\end{array}$ & $\begin{array}{c}\text { Withdrawal - } \\
\text { Injection + }\end{array}$ \\
\hline 0.0000 & 1 & 0.2479 & \#3 & 632.32 & - \\
\hline \multirow{2}{*}{0.2479} & \multirow{2}{*}{2} & \multirow{2}{*}{0.0688} & $\# 2$ & 130.82 & - \\
\hline & & & $\# 3$ & 632.32 & - \\
\hline \multirow{2}{*}{0.3167} & \multirow{2}{*}{3} & \multirow{2}{*}{0.1833} & $\# 2$ & 28.35 & - \\
\hline & & & $\# 3$ & 632.32 & - \\
\hline \multirow{3}{*}{0.5000} & \multirow{3}{*}{4} & \multirow{3}{*}{0.0465} & $\# 1$ & 106.29 & - \\
\hline & & & $\# 2$ & 28.35 & - \\
\hline & & & $\# 3$ & 632.32 & - \\
\hline \multirow{3}{*}{0.5465} & \multirow{3}{*}{5} & \multirow{3}{*}{0.1660} & $\# 1$ & 23.44 & - \\
\hline & & & \#2 & 28.35 & - \\
\hline & & & $\# 3$ & 632.32 & - \\
\hline \multirow{2}{*}{0.7125} & \multirow{2}{*}{6} & \multirow{2}{*}{0.2743} & $\# 1$ & 23.44 & - \\
\hline & & & $\# 3$ & 632.32 & - \\
\hline 0.9868 & 7 & 0.2326 & $\# 3$ & 632.32 & - \\
\hline \multirow{2}{*}{1.2194} & \multirow{2}{*}{8} & \multirow{2}{*}{0.2257} & $\# 2$ & 104.66 & + \\
\hline & & & $\# 3$ & 632.32 & - \\
\hline 1.4451 & 9 & 1.3854 & $\# 3$ & 632.32 & - \\
\hline \multirow{2}{*}{2.8306} & \multirow{2}{*}{10} & \multirow{2}{*}{0.2083} & $\# 1$ & 23.98 & - \\
\hline & & & $\# 3$ & 632.32 & - \\
\hline 3.0389 & 11 & 0.9215 & $\# 3$ & 632.32 & - \\
\hline \multirow{2}{*}{3.9604} & \multirow{2}{*}{12} & \multirow{2}{*}{0.0632} & $\# 1$ & 108.47 & + \\
\hline & & & $\# 3$ & 632.32 & - \\
\hline \multirow{3}{*}{4.0236} & \multirow{3}{*}{13} & \multirow{3}{*}{0.1507} & $\# 1$ & 108.47 & + \\
\hline & & & $\# 2$ & 27.25 & - \\
\hline & & & $\# 3$ & 632.32 & - \\
\hline \multirow{2}{*}{4.1743} & 14 & 17931 & $\# 2$ & 27.25 & - \\
\hline & 17 & 1.1001 & $\# 3$ & 632.32 & - \\
\hline & & & $\# 1$ & 23.98 & - \\
\hline 5.9674 & 15 & 0.0563 & $\# 2$ & 27.25 & - \\
\hline & & & $\# 3$ & 632.32 & - \\
\hline 60236 & 16 & 01090 & \#2 & 27.25 & - \\
\hline . & & . & \#3 & 632.32 & - \\
\hline & & & $\# 1$ & 22.89 & - \\
\hline 6.1326 & 17 & 26.0764 & \#2 & 27.25 & - \\
\hline & & & $\# 3$ & 632.32 & - \\
\hline 32.2090 & 18 & 0.2917 & None & NA & NA \\
\hline
\end{tabular}


Table 6-3

Stress Periods Used for Modeling the BULLION FGE

(Page 2 of 2)

\begin{tabular}{|c|c|c|c|c|c|}
\hline $\begin{array}{l}\text { Elapsed Time } \\
\text { (days) }\end{array}$ & $\begin{array}{c}\text { Stress Period } \\
\#\end{array}$ & $\begin{array}{l}\text { Period } \\
\text { Length } \\
\text { (days) }\end{array}$ & Well \# & $\begin{array}{c}\text { Rate } \\
\left(\mathrm{m}^{3} / \mathrm{day}\right)\end{array}$ & $\begin{array}{l}\text { Withdrawal - } \\
\text { Injection + }\end{array}$ \\
\hline \multirow{3}{*}{32.5007} & \multirow{3}{*}{19} & \multirow{3}{*}{5.4681} & $\# 1$ & 28.35 & - \\
\hline & & & $\# 2$ & 28.89 & - \\
\hline & & & \#3 & 632.32 & - \\
\hline \multirow{2}{*}{37.9688} & \multirow{2}{*}{20} & \multirow{2}{*}{6.0979} & \#2 & 28.89 & - \\
\hline & & & \#3 & 632.32 & - \\
\hline \multirow{3}{*}{44.0667} & \multirow{3}{*}{21} & \multirow{3}{*}{0.9896} & $\# 1$ & 28.35 & - \\
\hline & & & $\# 2$ & 28.89 & - \\
\hline & & & $\# 3$ & 632.32 & - \\
\hline 45.0563 & 22 & 4.7049 & $\# 3$ & 632.32 & - \\
\hline 49.7611 & 23 & 0.0833 & None & NA & NA \\
\hline 49.8444 & 24 & 0.5278 & $\# 3$ & 632.32 & - \\
\hline 50.3722 & 25 & 0.1285 & None & NA & NA \\
\hline 50.5007 & 26 & 5.4271 & $\# 3$ & 632.32 & - \\
\hline \multirow{3}{*}{55.9278} & \multirow{3}{*}{27} & \multirow{3}{*}{9.9861} & $\# 1$ & 28.35 & - \\
\hline & & & $\# 2$ & 29.44 & - \\
\hline & & & \#3 & 632.32 & - \\
\hline 65.9139 & 28 & 11.0069 & $\# 3$ & 632.32 & - \\
\hline \multirow{3}{*}{76.9208} & \multirow{3}{*}{29} & \multirow{3}{*}{9.0556} & $\# 1$ & 27.80 & - \\
\hline & & & $\# 2$ & 28.35 & - \\
\hline & & & $\# 3$ & 632.32 & - \\
\hline \multirow{2}{*}{85.9764} & \multirow{2}{*}{30} & \multirow{2}{*}{0.1354} & $\# 1$ & 27.80 & - \\
\hline & & & $\# 3$ & 632.32 & - \\
\hline 86.1118 & 31 & 1.0000 & $\# 3$ & 632.32 & - \\
\hline 87.1118 & 32 & 6.002 & None & NA & NA \\
\hline
\end{tabular}

of injection. The amount of water injected, or withdrawn from HSUs 4 and 6 was adjusted during the calibration. At Well \#1 35 percent of injected water was put into HSU 4 and 65 percent was put into HSU 6 . At Well \#2, 75 percent was put into HSU 4 and 25 percent into HSU 6 . For pumping both Wells \#1, and \#2, 100 percent was taken from HSU 4. The rationale for this apportionment is presented in the following paragraphs.

The tracer solution was expected to preferentially sink to the lower aquifer because of density effects. The solution was denser than the groundwater due to the increased dissolved solids content from the tracers (Well \#1 increase approximately 1.005, Well \#2 approximately 1.0025), and colder than ambient temperature (increase of approximately 1.003-1.004 for 20-30 degrees F ahrenheit difference). In 
addition, heat-pulse flowmeter logging (documented in the Completion Report for Well Cluster ER-20-6 [DOE/NV, 1998]) had determined that there was flow from the upper aquifer to the lower aquifer under the natural vertical gradient. From discrete bailer samples taken immediately following injection, it is known that the tracer solution did at least flood the lower completion. In calibrating the transport, it was found that restricting withdrawal to HSU 4 greatly improved the calibration of the model to measured breakthrough curves. There is an argument based on observations that water was not being pumped back from HSU 6. During the experiment, discrete bailer samples from the open intervals across HSU s 4 and 6 gave essentially the same values in both Wells \#1 and \#2. One explanation for the homogeneity of the tracer concentrations along the length of the injection wells is that water from HSU 4 is flowing downward into HSU 6, even while the wells are being pumped. This could occur if the hydraulic head in HSU 6 is lower than in HSU 4, even while pumping. It was mentioned earlier that the low-rate pumping in these wells produced very little drawdown, which may not have exceeded the natural gradient.

Early simulations began with pumpage from both HSUs. In all those early cases, concentrations in HSU 6 were much higher than in HSU 4. This resulted because the pumping of Well \#3 created a larger horizontal gradient in HSU 4, which in turn flushed HSU 4 faster that HSU 6. However, this was not observed during the experiment. With the proposed scenario, the tracer solution that was injected into HSU 6 may be lost from the tracer test.

The predicted hydraulic head response at the three wells is given in Figure 6-10. The observed "asymptotic" drawdown at Wells \#1, \#2, and \#3 are approximately $1.15 \mathrm{~m}, 1.7 \mathrm{~m}$, and $7 \mathrm{~m}$, respectively. The fit to Well \#3 is quitegood throughout the whole simulation period. The fit is as good at Well \#2, where model ed and observed maximum drawdown are both approximately $1.7 \mathrm{~m}$. The maximum drawdown at Well \#1 is about $0.95 \mathrm{~m}$, slightly less than the observed value of $1.15 \mathrm{~m}$. It should be noted that the observed drawdown is somewhat noisy and open to interpretation. An interesting feature of the drawdown in Well \#1 is the apparent subdued response to its own pumpage. This feature was reproduced by the model by increasing the hydraulic conductivity of HSUs 4 and 6 in the vicinity of Well \#1.

The hydraulic conductivities for the six HSUs were given in Table 6-2. The original conductances across the GHBs are determined from the parameter values of the aquifer immediately adjacent to the GHB. The storage coefficient value is 0.0003 , which is in the range of values obtained from the inter pretation of the drawdown response of the wells. These storage coefficient and hydraulic conductivity values are consistent with the interpreted values from Section 4.0. In general, the match between the measured and simulated drawdowns at all three wells is quite good. 


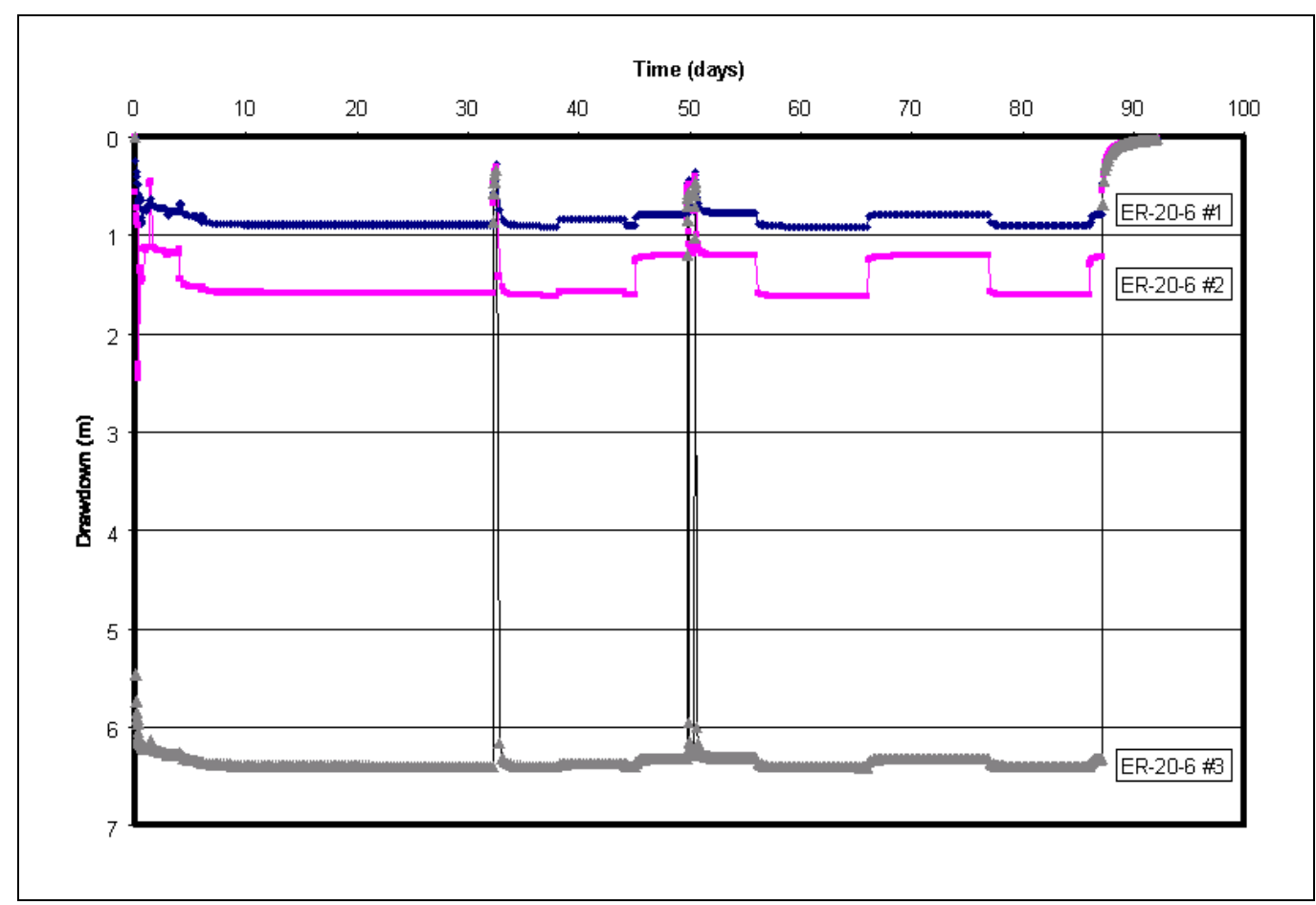

Figure 6-10

Final Calibrated Drawdowns

The impact of the GHB at the West Greeley fault is demonstrated in Figure 6-11 and Figure 6-12, which are time series plots of the drawdown in all three wells for the cases of no flow across the West Greeley, and 10 times the conductance across that boundary. If the fault is treated as a barrier (Figure 6-11), predicted drawdowns would be slightly greater than were obtained with the calibration parameter values. When the conductance of the fault is 10 times greater than the calibration (Figure 6-12) parameter values, the drawdowns are nearly unchanged. It appears that in the vicinity of the BULLION experiment, the West Greel ey fault acts like a leaky boundary that supplies water to the pumped well. However, as will be shown later, the impact on the tracer concentrations is almost negligible. Additionally, an equally valid calibration of the drawdown would have been achievable with no flow across the West Greeley fault. This suggests that the true nature of the fault interaction at BULLION is uncertain, but that it had only a minor effect on the estimation of transport parameters. Refer to Figure 6-10 for the predicted responses using the calibrated parameter values. 


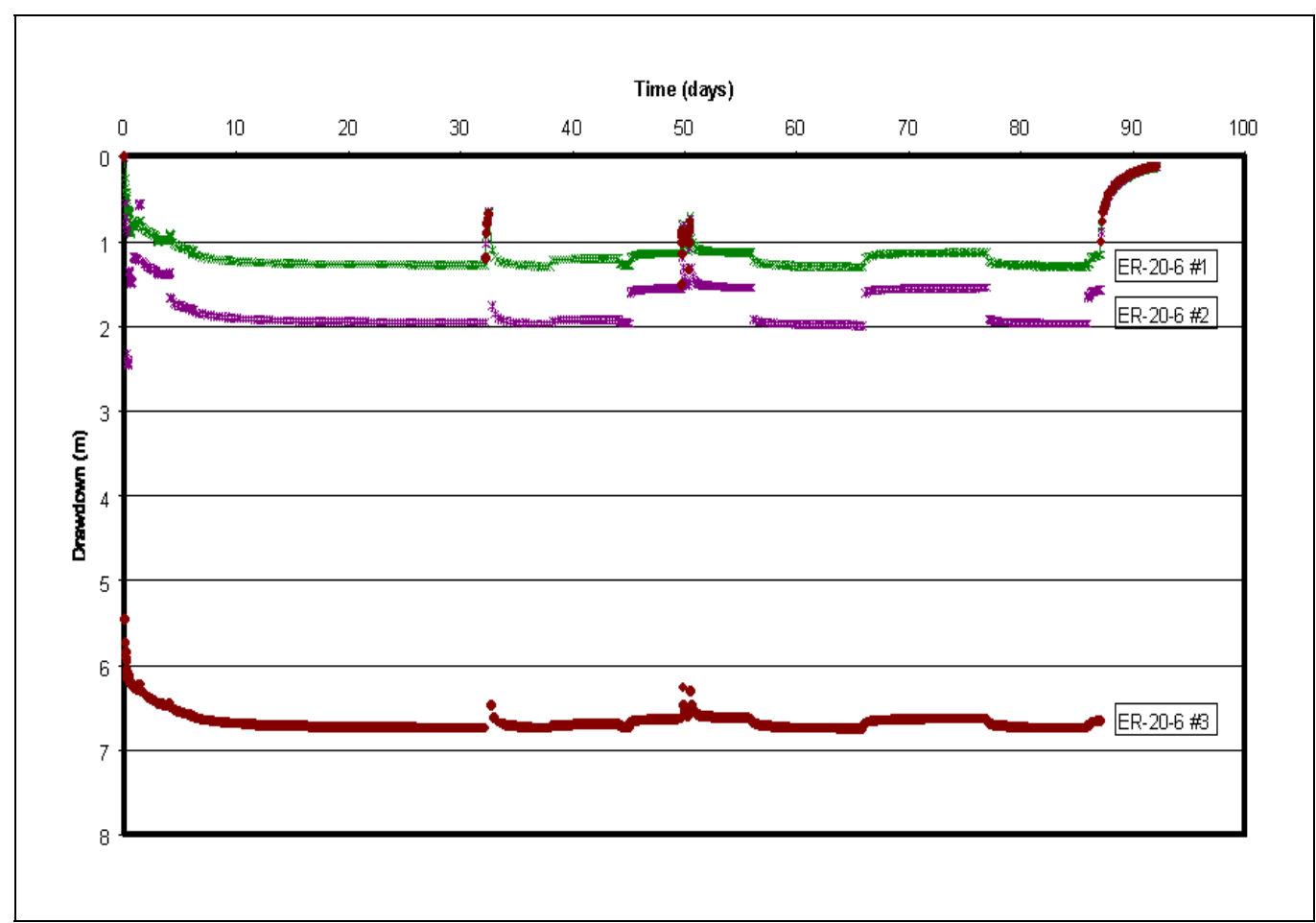

Figure 6-11

Drawdowns with West Greeley Fault Treated as No Flow Boundary

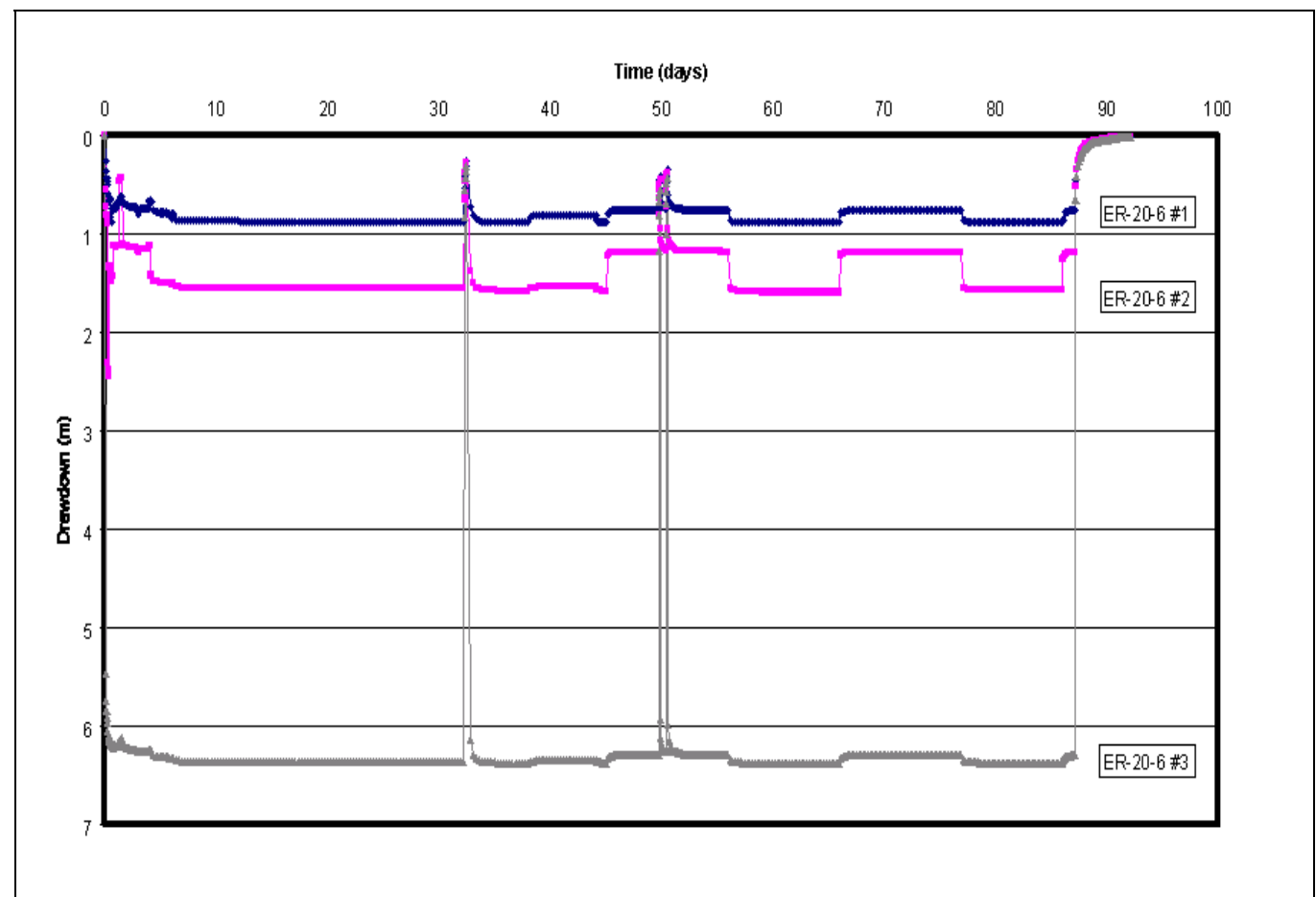

Figure 6-12

Drawdowns with Higher Conductivity for West Greeley Fault Boundary 


\section{Numerical Modeling - Tracer Transport Calibration}

After the steady-state and transient flow calibrations were complete, the task of tracer transport calibration began. The tracer transport calibration is similar to the transient head calibration in that the goal is to match the changes in tracer concentrations observed in the three wells over the length of the experiment. The primary parameters adjusted during calibration were the effective porosity, Iongitudinal dispersivity, matrix porosity, and effective matrix diffusion coefficients. Additionally, the fracture spacing, anisotropy ratios, and amount of water injected into or withdrawn from either HSU 4 or 6 were also varied to obtain a better fit to the observed tracer breakthroughs.

For the calibration of the microsphere data, two important changes were implemented. First, microspheres are assumed to be too large to diffuse into the matrix pores, therefore the matrix diffusion coefficients for the two microspheres were assumed to be equal to zero. Second, the filtration of microspheres was assumed to follow a first or der decay law, as was assumed by Reimus and Haga (1998). The calibration of the microspheres was performed after the other tracer calibrations were completed. This approach assumes that the effective porosity of the organic acid tracers and iodide is the same as for the microspheres. In fact the microspheres might "see" a smaller effective porosity because they may be restricted to the center of fractures in contrast to the dissolved tracers which likely move through nearly the entire cross section area of the fracture.

\subsection{Tracer Calibration Results}

Table 7-1 presents the final calibrated parameter values.

The final calibrated breakthrough curves in Well \#3 for tracers injected into Well \#1 are shown in Figures 7-1 and 7-2. For transport from Well \#1 to Well \#3 (DFBA and iodide), the effective porosity was 0.018 , the longitudinal dispersivity was $10 \mathrm{~m}$, and the proportion of mass injected into HSU 4 was 35 percent. The matrix diffusion coefficients were $1.1 \times 10-6 \mathrm{~m}^{2} / \mathrm{d}$ for DFBA and $1.6 \times 10-6 \mathrm{~m}^{2} / \mathrm{d}$ for iodide. The final calibrated breakthrough curve for PFBA (injected into Well \#2) at Well \#3, is shown in Figure 7-3. The fit to the observed data is equally good, but the parameter values differ slightly for this pathway from the 
Table 7-1

Transport Parameter Values Determined via Calibration of the BULLION FGE Model

\begin{tabular}{||c|c|c|c|}
\hline Parameter & $\begin{array}{c}\text { DFBA transport from } \\
\text { Well \#1 to Well \#3 }\end{array}$ & $\begin{array}{c}\text { lodide transport from } \\
\text { Well \#1 to Well \#2 }\end{array}$ & $\begin{array}{c}\text { PFBA transport from } \\
\text { Well \#2 to Well \#3 }\end{array}$ \\
\hline \hline Fracture Spacing (m) & 0.25 & 0.25 & 0.25 \\
\hline Matrix Porosity & 0.35 & 0.35 & 0.35 \\
\hline $\begin{array}{c}\text { Effective Matrix } \\
\text { Diffusion Coefficient } \\
\text { (m²/day) }\end{array}$ & $1.2 \times 10^{-6}$ & $1.6 \times 10^{-6}$ & $1.35 \times 10^{-6}$ \\
\hline $\begin{array}{c}\text { Dispersivity } \\
\text { (Long./Transverse/ } \\
\text { Vertical) (m) }\end{array}$ & $10 / 3 / 2$ & $10 / 3 / 2$ & $10 / 3 / 2$ \\
\hline $\begin{array}{c}\text { Proportion of Mass } \\
\text { Injected in } \\
\text { HSUs 4 and 6 }\end{array}$ & $35 \% / 65 \%$ & $35 \% / 65 \%$ & $75 \% / 25 \%$ \\
\hline Effective Porosity & 0.018 & 0.018 & 0.023 \\
\hline
\end{tabular}

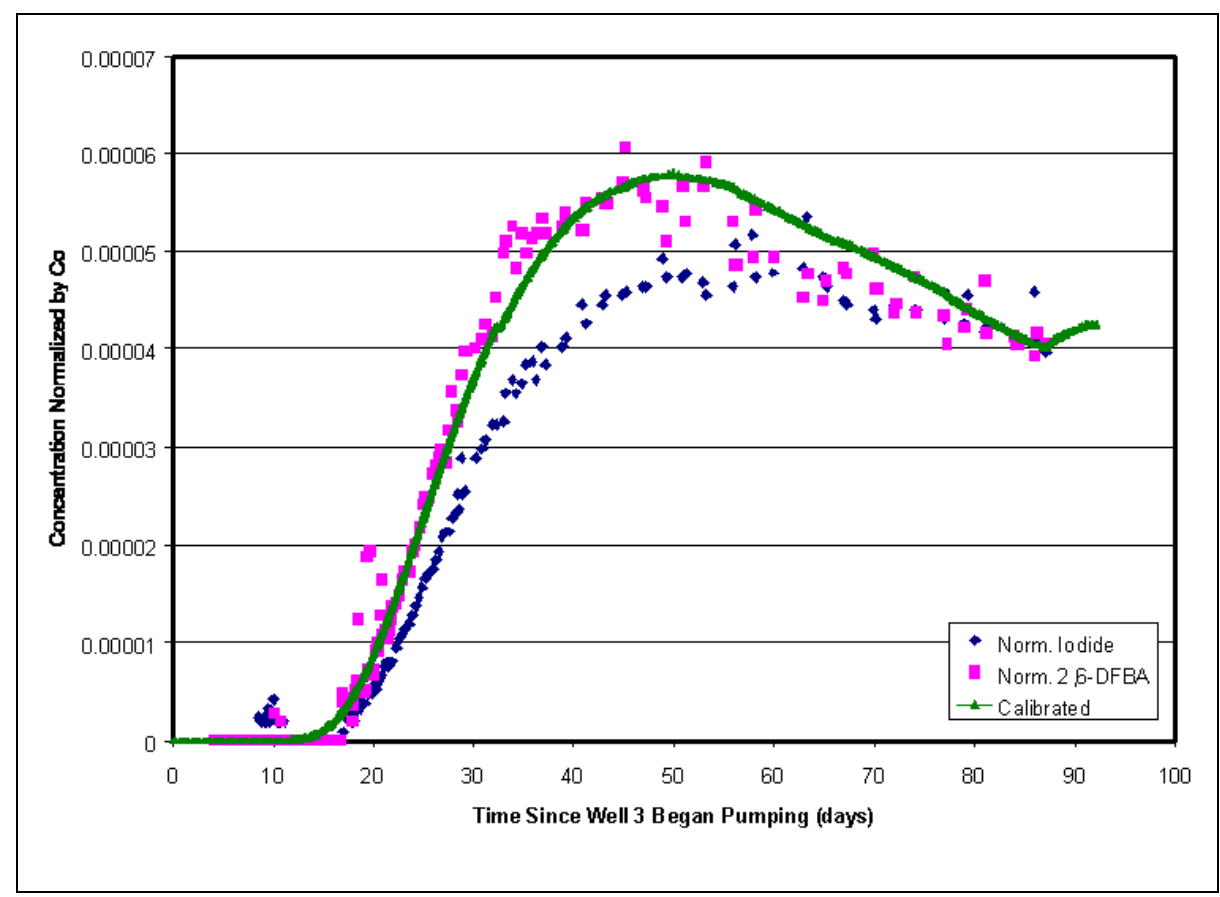

Figure 7-1

Breakthrough Curve at Well \#3 for DFBA

those obtained from the Well \#1 tracers. For the PFBA, the effective porosity was increased to 0.023 , the dispersivity remained at $10 \mathrm{~m}$, the proportion of tracer injected into HSU 4 was 75 percent, and the diffusion coefficient was between the previous two values at $1.35 \times 10^{-6}$ $\mathrm{m}^{2} / \mathrm{d}$. For both injection wells, the transport parameters, effective porosity, and matrix diffusion coefficient values were quite similar. 


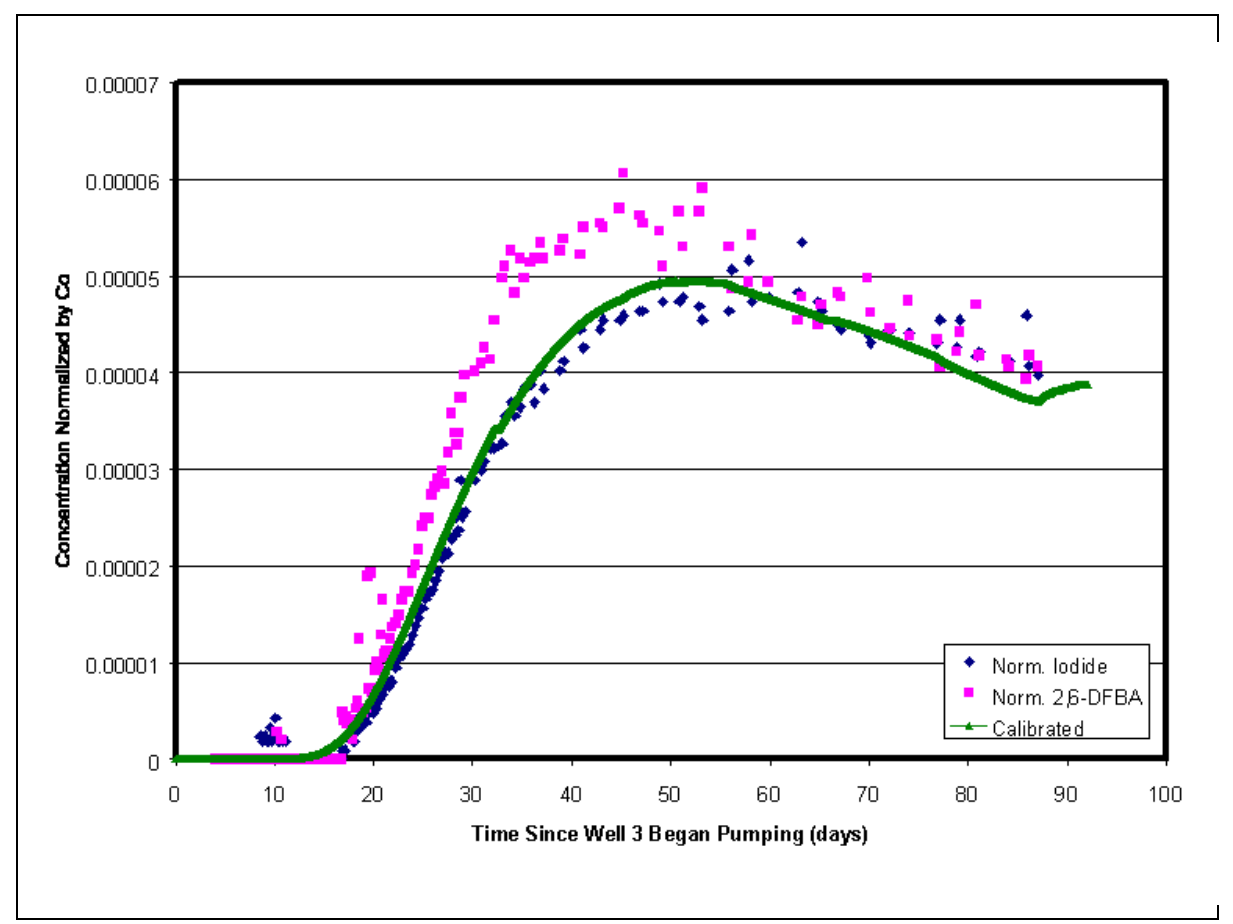

Figure 7-2

Breakthrough Curve at Well \#3 for lodide

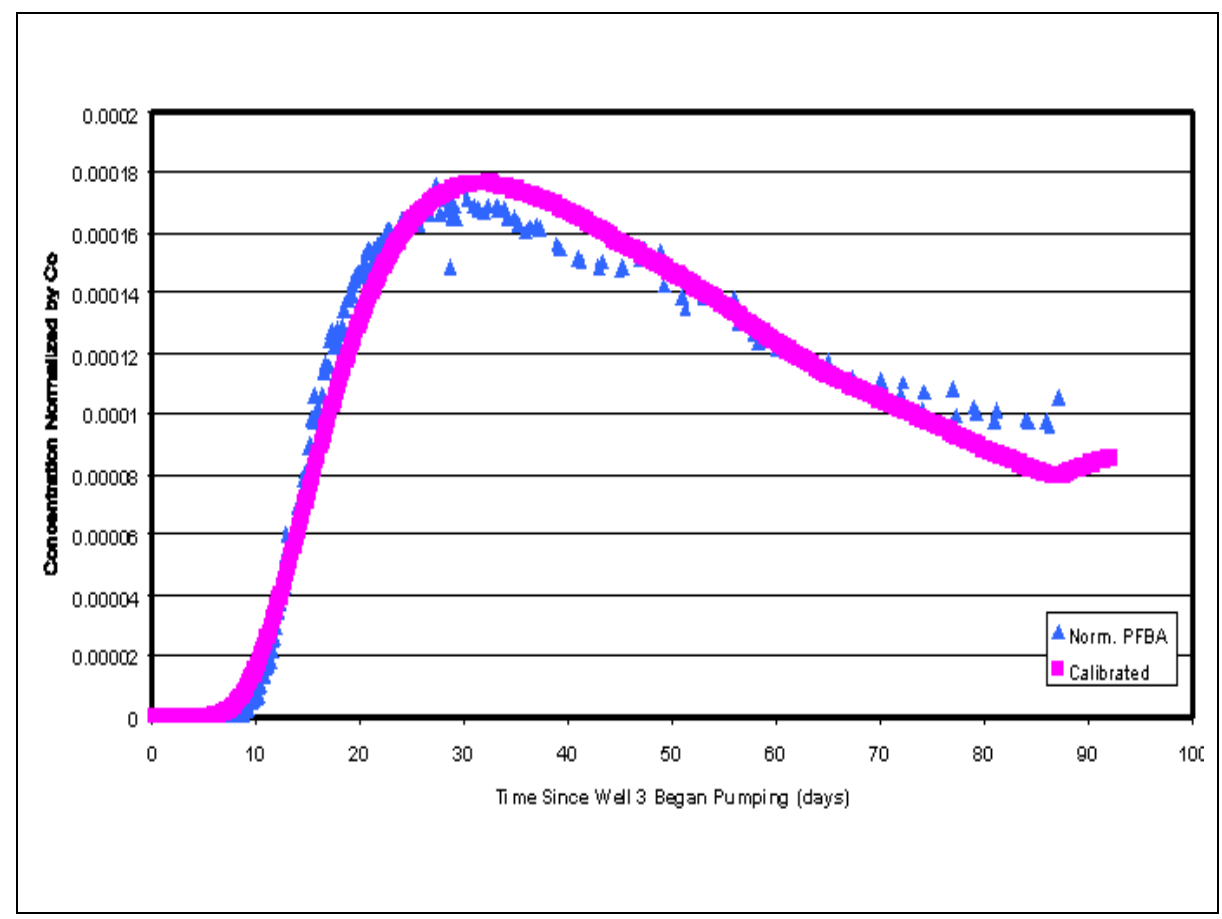

Figure 7-3

Breakthrough Curve at Well \#3 for PFBA 
The biggest difference was the amount of mass injected into HSU 4, or conversely, the amount of tracer lost to HSU 6.

The simulated DFBA and iodide breakthrough curves at Well \#2, resulting from tracers injected into Well \#1, are given in Figure 7-4. Note that only one simulation curveis presented in the next two figures because the curves for the two different tracers overlaid very closely.

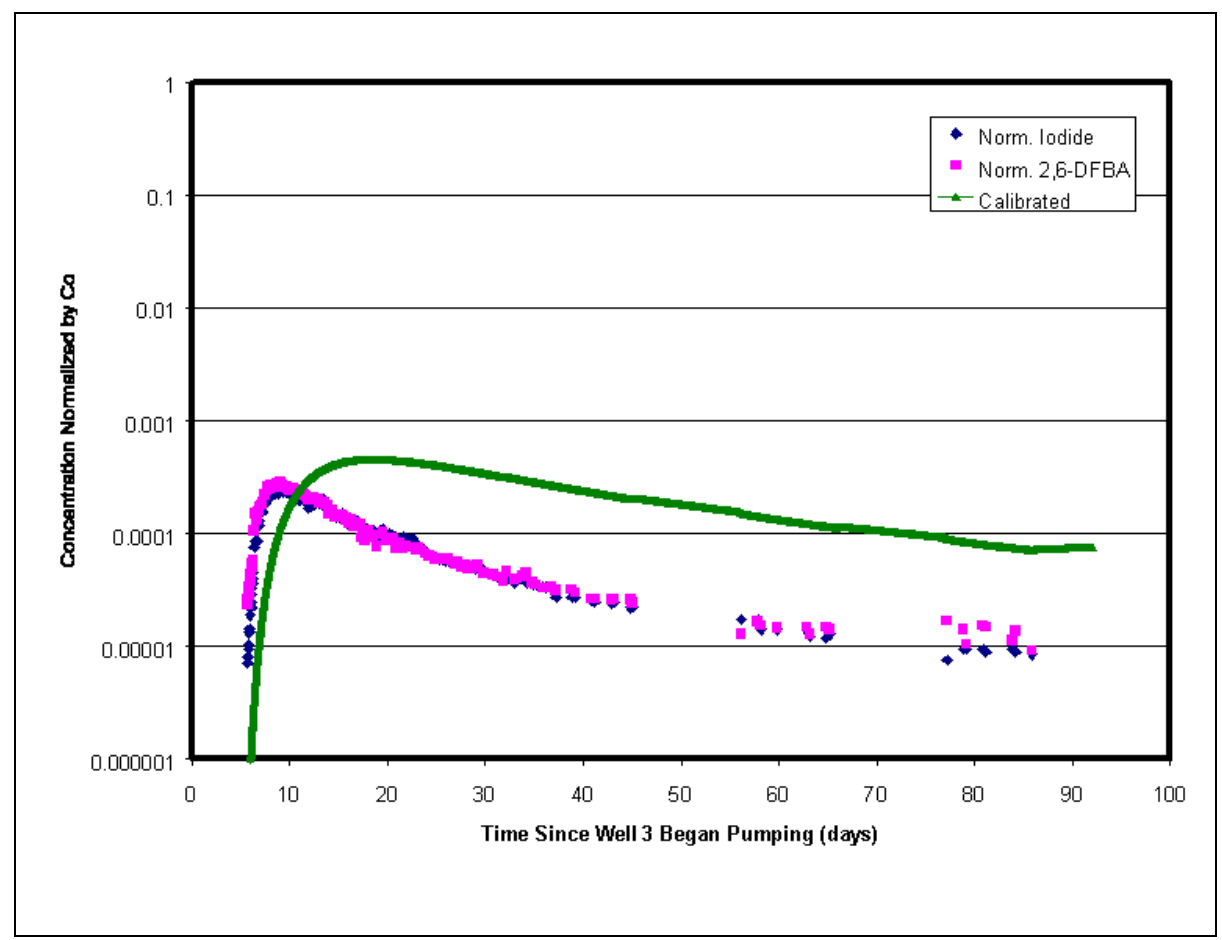

Figure 7-4

Breakthrough Curves at Well \#2 for DFBA and lodide

In this case the breakthrough curve is not a good fit to the data. The observed data has a very steep leading edge, followed by a long tail. The simulation does not reproduce the leading edge well, and overpredicts the concentrations on the tail. Several reasons are proposed for the lack of agreement. First, there are likely local conditions near Wells \#1 and \#2, perhaps related to the BULLION test, that have not been simulated in sufficient detail. Secondly, the rapid breakthrough may be indicative of a fast flow path between the two wells such as a discrete fracture. These detail heterogeneities were not included in the model. A third explanation of the lack of fit may be a limitation of the advective/dispersive, porous media-based MODF LOWT code to simulate fracture-dominated flow at scales as small as the distance between Wells \#1 and \#2. To better fit the breakthrough curve in Well \#2, a more sophisticated fracture modeling approach may be needed. 
The tracer concentration decline (decay) curves for Wells \#1 and \#2 are given in Figures 7-5 and 7-6, respectively. The fits are adequate, with the simulated decline at Well \#2 a slightly better fit than the simulated decline at Well \#1. It should be pointed out that these are log plots, and that the measured values at the end of these curves are between 4 and 5 orders of magnitude bel ow the peak values. It proved to be extremely difficult to improve on these results. One of the reasons for the high $\mathrm{K}$ zone around Well \#1 was to create a faster velocity to more quickly flush the tracer away from the well. The more rapid observed decline may be indicative of fracture dominated local conditions that are not well simulated by the model at very small scales.

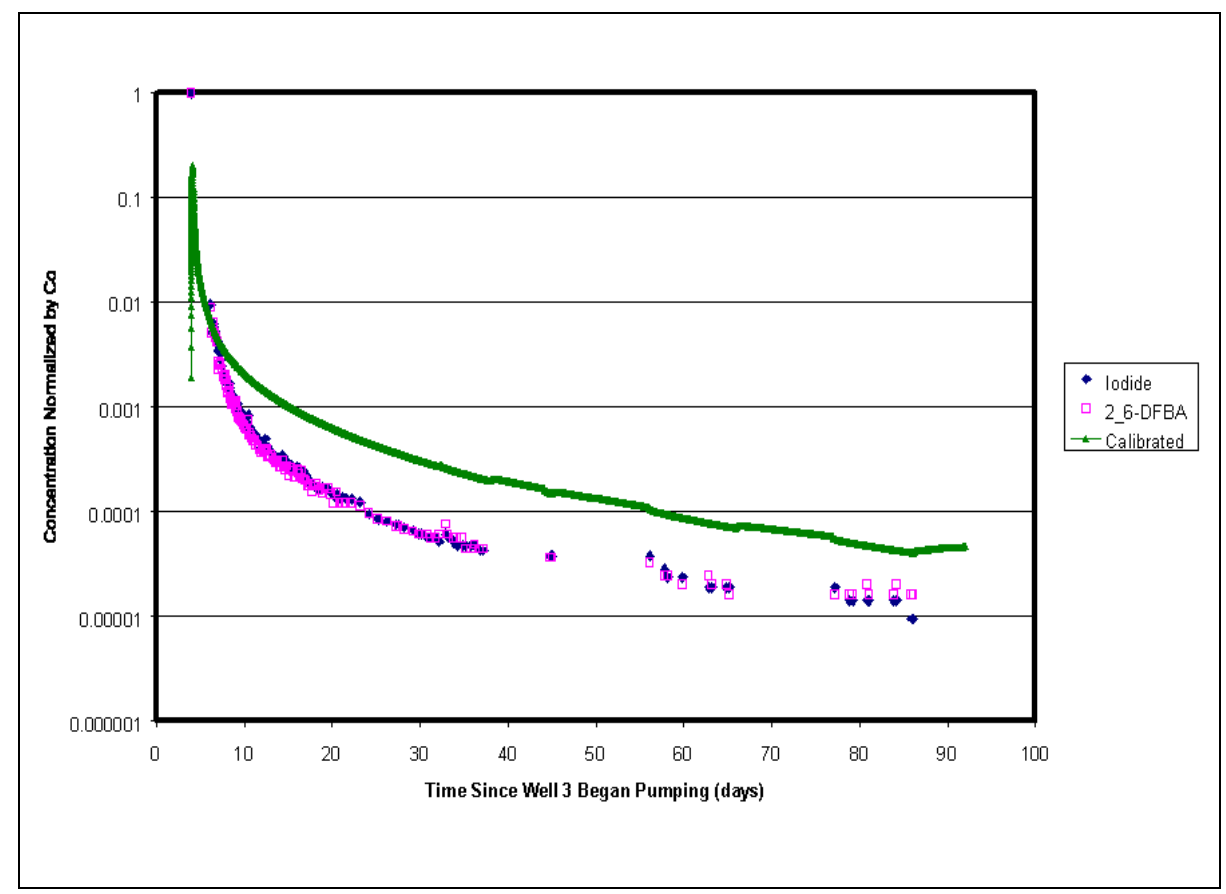

Figure 7-5

DFBA and lodide Concentration Decline in Well \#1

The simulated decline curves did not fit the observed data as well as the breakthrough curves at Well \#3. This is believed to be due to several factors. First, the dispersion coefficients used in the model apply equally in all directions. Recent literature (Gel har et al., 1992) suggests that dispersion coefficients increase with increasing travel distance, yet the longitudinal dispersivity value of $10 \mathrm{~m}$ that was used for transport through the length of the model al so applied to transport near the injection wells. This dispersivity created an upstream dispersive flux that pushed mass upgradient of the injection well. This in turn prevented the simulated tracer from being flushed out from the injection wells as effectively as was observed in the experiment. 


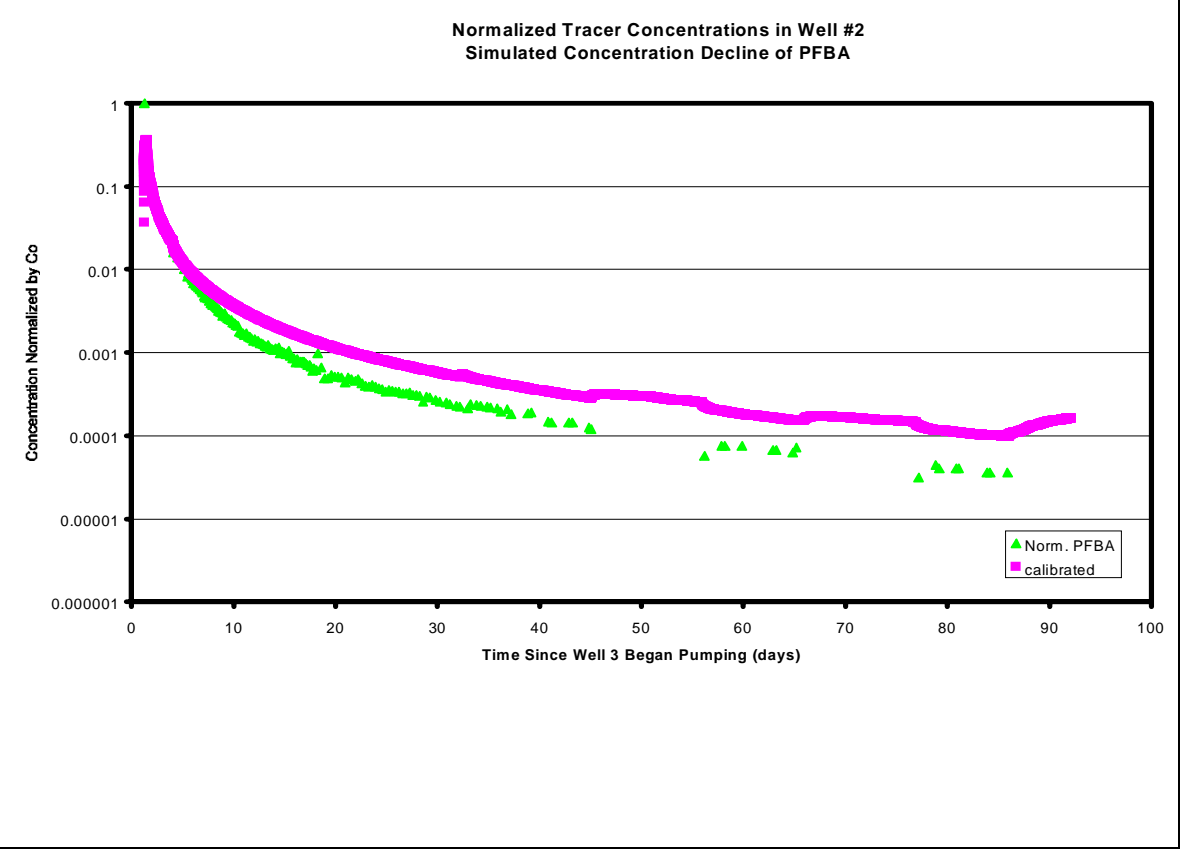

Figure 7-6

PFBA Concentration Decline at Well \#2

The poor correspondence of the predicted breakthroughs of Well \#1 tracers in Well \#2 to that observed is due in part to the large dispersivity used in the model relative to the distance. It is also likely due to a small scale heterogeneity that creates a rapid pathway between the two wells, but only for a small portion of the mass injected into Well \#1. The concentrations of Well \#1 tracers in Wells \#1 and \#2 are nearly identical for times greater than 20 days. Coupled with the very rapid breakthrough times, this indicates that there may be a small conduit, such as a fracture, between the two wells. This could not be simulated well with the current model.

Another view of the tracer decline in Well \#1 is given in Figure 7-7. Here only the first nine days of the breakthrough curves are presented. The discrete bailer-sample early-time measured concentrations are also included. Several features are observed. First, the model simulations and the measure values determined from pumped samples fit very well at the start of Well \#1 pumping between six and seven days. After seven days the two curves begin to separate. Second, the model predicts dilution effects at the end of the injection cycle, at about four days. Third, the discrete bailer sample concentrations are often greater than the pumped sample concentrations, but certainly not in all cases. The bailer samples may have higher concentrations than in the main part of the wellbore because these samples were taken from the access tubes. The access tubes were only perforated at a low rate along every 


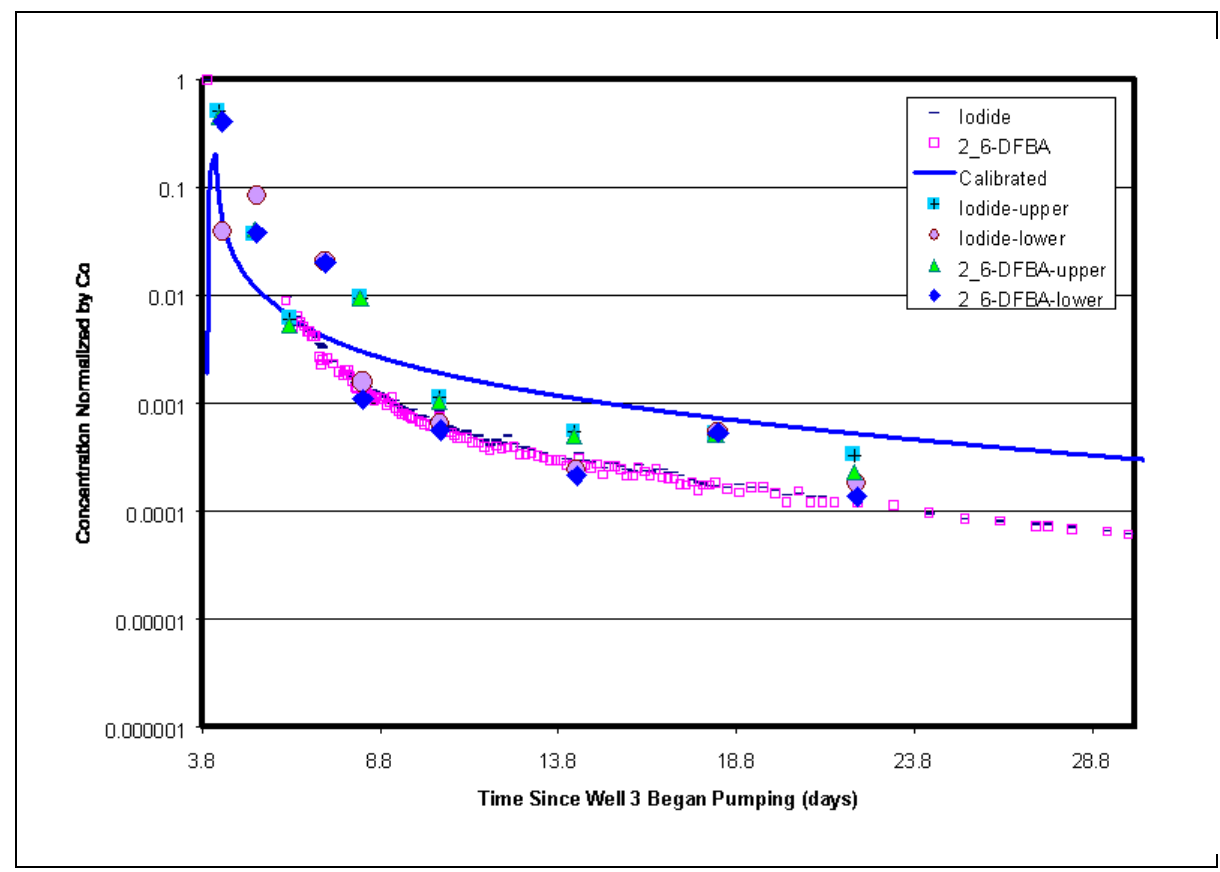

Figure 7-7
Early-Time Tracer Concentration Decline in Well \#1

other joint of pipe, and may not flush as rapidly as the well itself. If the initial bailed samples had higher concentrations than the wellbore, then the model response would match the measured decline curve reasonably well. If the bailed samples are an accurate representation of the decay, then the model predicts too rapid decline at early time. The data available do not provide sufficient information to know if the very early time decline is simulated well by the model or not.

The calibration of the model for microsphere transport concentrated on the initial breakthrough at Well \#3 for the microspheres from Well \#2 (yellow) and Well \#1 (red). The simulated microsphere breakthrough curves for the Well \#2 and Well \#1 tracers in Well \#3 are presented in Figure 7-8. A secondary peak of both microsphere tracers occurred simultaneously at about 35 days. This is speculated to be the result of release of filtered-out microspheres back to the groundwater caused by back flushing of the pumping well and near vicinity fractures following Well \#3 pump shut down. This will be further discussed in Section 7.3. The simulated microsphere breakthrough curves do not fit the observed data as well as the dissolved tracer simulations. This is likely due to the more approximate nature of the first-order decay filtration assumption. This suggests that additional work to better understand colloid transport is necessary. The parameters used to generate the predicted breakthrough were the same as for DFBA and iodide, with the exception that matrix diffusion was zero for the microspheres. As noted earlier, a first order decay process was assumed to represent a filtration mechanism. The decay coefficient that best represented the 


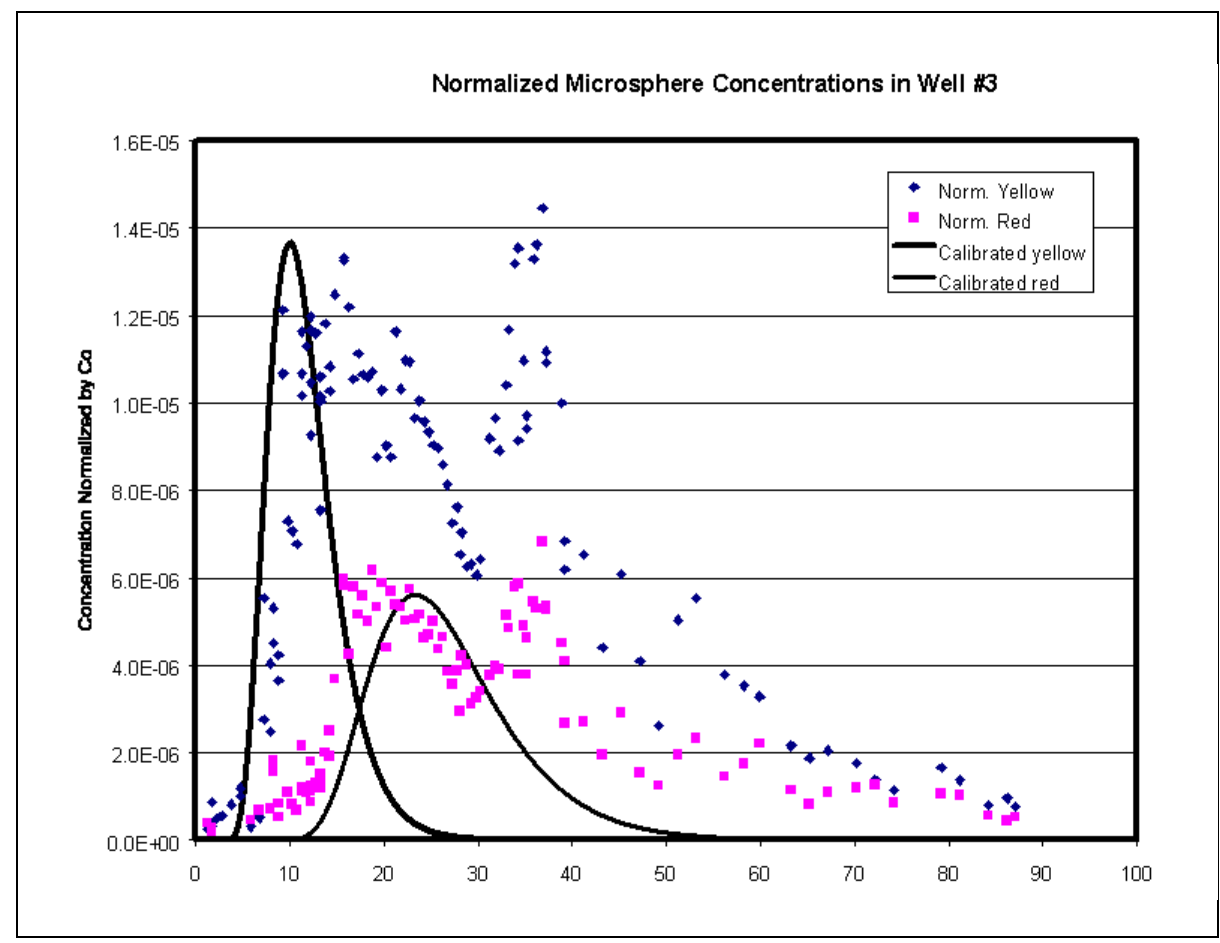

Figure 7-8

Microsphere Breakthrough Curves at Well \#3

peak was 0.35 (1/day) for the yellow spheres and 0.15 (1/day) for the red spheres. The tail of the breakthrough cannot be modeled with the current first order decay assumption. The peaks in both cases did not coincide with the observed peaks. For the yellow spheres a larger porosity would have shifted the peak, but that is not consistent with the idea that the effective porosity for the spheres should be less than for the dissolved species. F or the red spheres, a smaller porosity would shift the predicted peak toward the observed peak. Additionally, it is expected that fracture flow phenomena will be more important in the simulation of colloid transport. It may well be the case that the colloid breakthrough curve is really the sum of a number of discrete pathways. This could explain the apparent early predicted peak for the yellow spheres.

The breakthrough curves as presented above represent the tracer behavior as observed at the three wells. Another interesting presentation of the results is the spatial distribution of the tracers at key times during the experiment. The numerical model provides tracer concentration data at each node and at each time step. Three times were selected for presentation; immediately after injection of tracers into Well \#1, at the start of Well \#1 tracer breakthrough in Well \#3, and at the time of peak concentration of Well \#1 tracers in Well \#3. For each of these times, concentrations of DF BA in both layers 4 and 6 are presented in Figures 7-9 through 7-14. It can be seen that the amount 


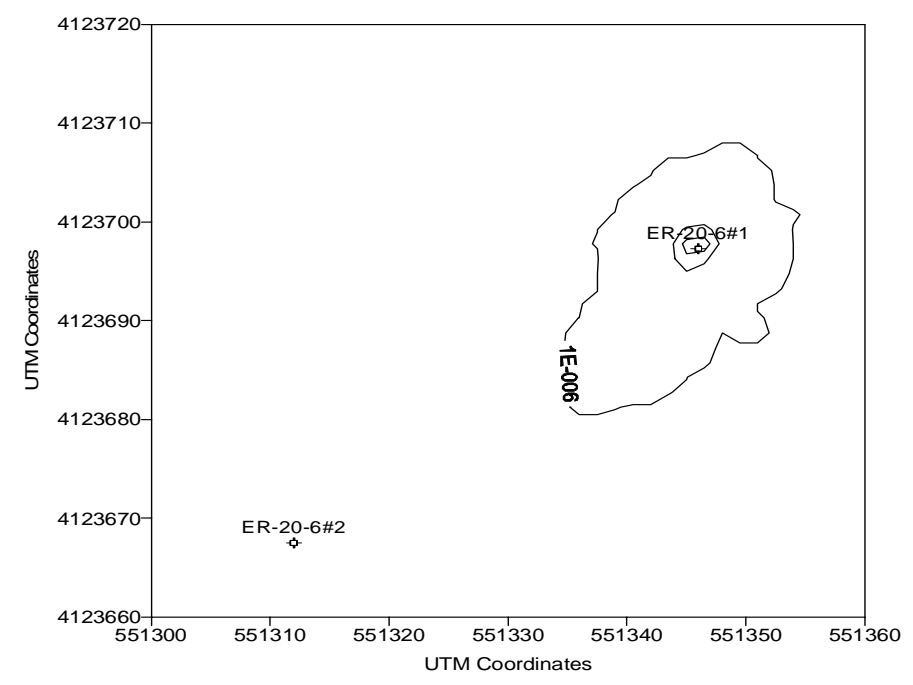

Explanation

\&. BULLION Wells

Contours of Normalized Concentration, Contour Interval 5E-2 UTM Zone 11 Coordinate System

Figure 7-9

HSU 4 DFBA Normalized Concentration Contours at the End of Well \#1 Injection

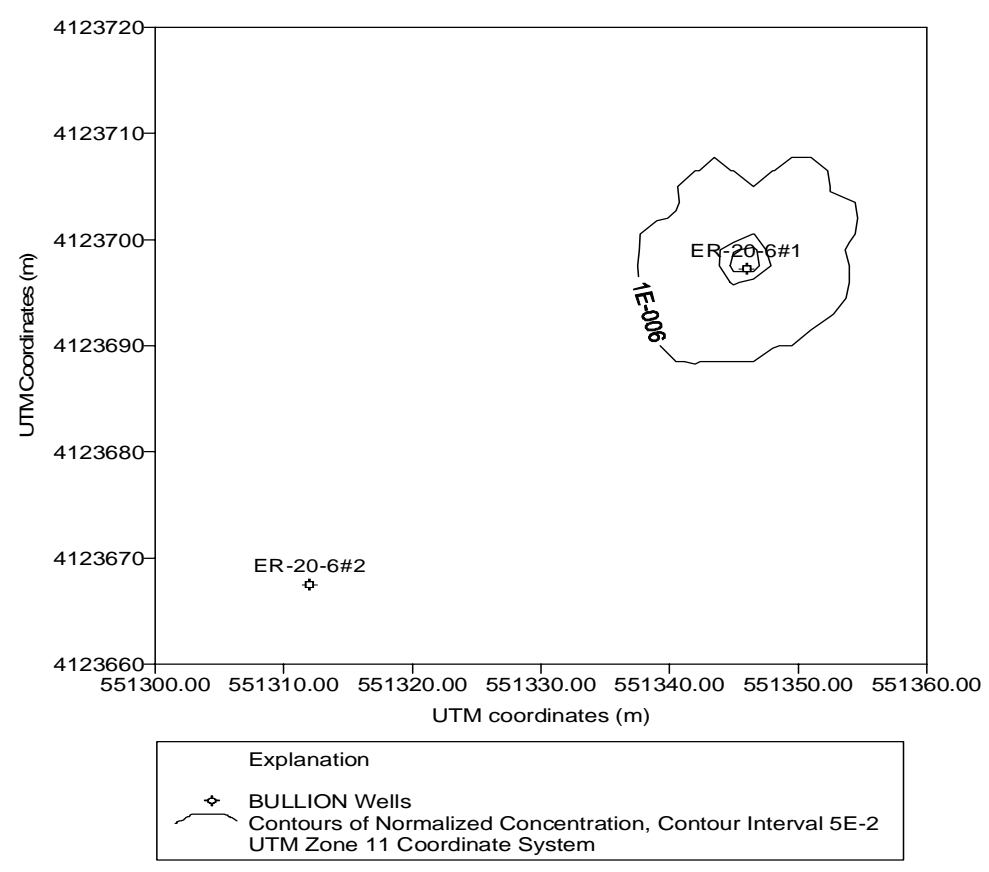

Figure 7-10

HSU 6 DFBA Normalized Concentration Contours at the End of Well \#1 Injection 


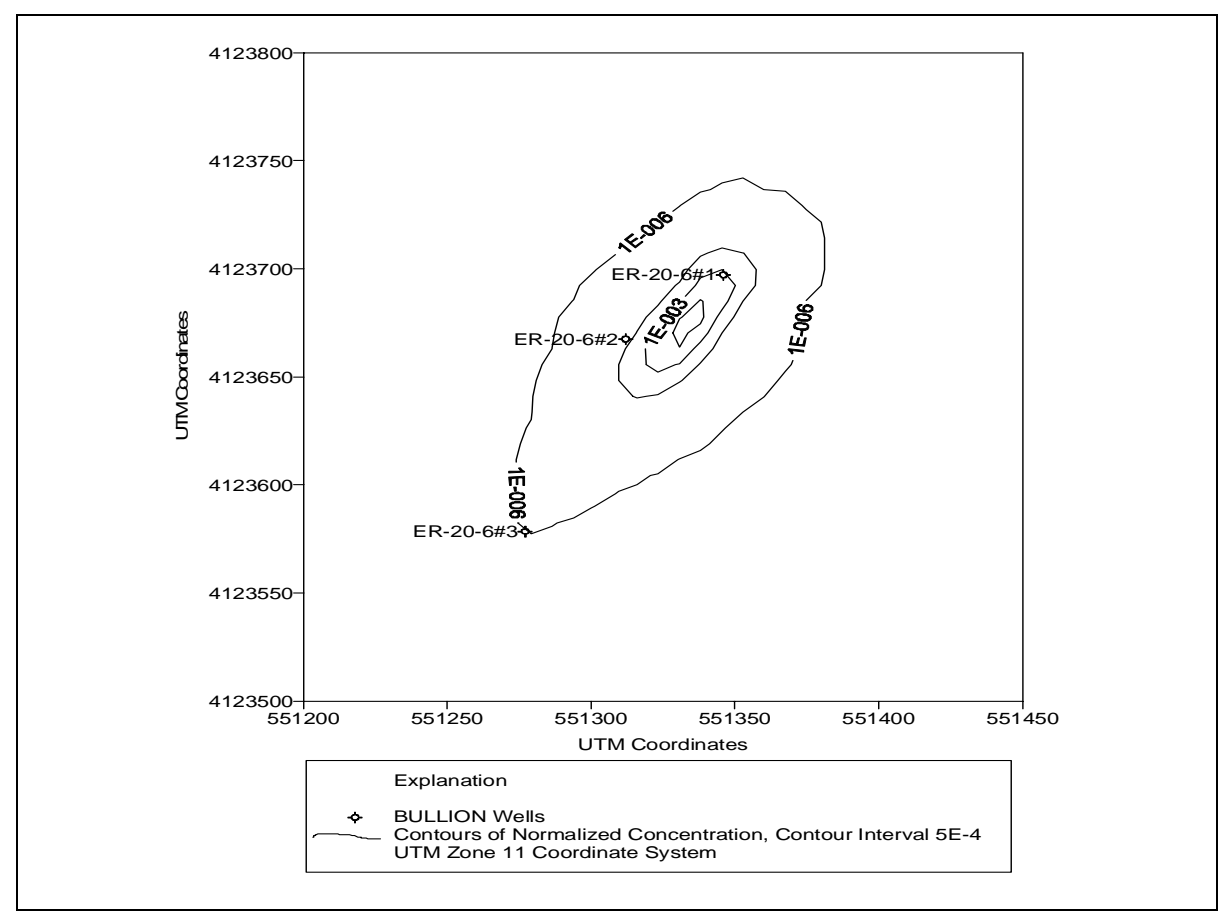

Figure 7-11

HSU 4 DFBA Normalized Concentration Contours at the Start of Breakthrough in Well \#3

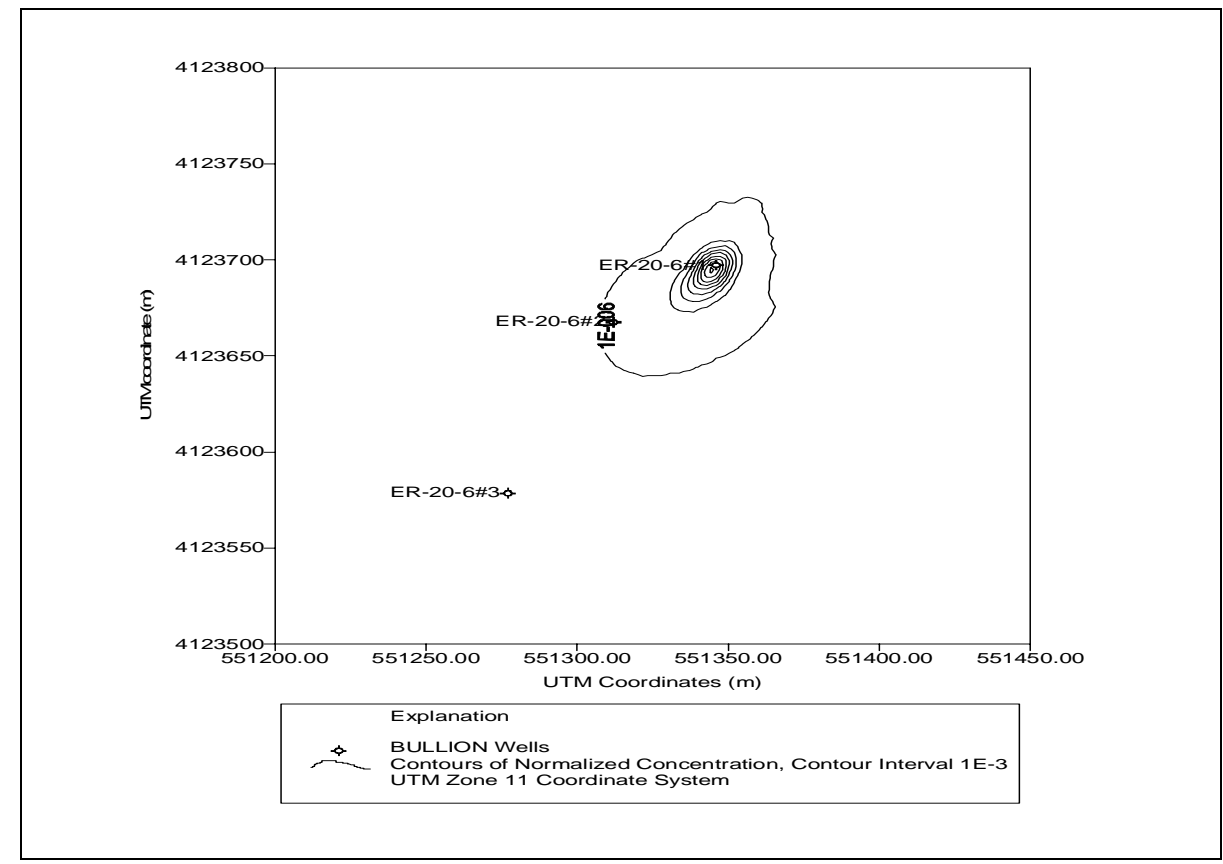

Figure 7-12

HSU 6 DFBA Normalized Concentration Contours at the Start of Breakthrough in Well \#3 


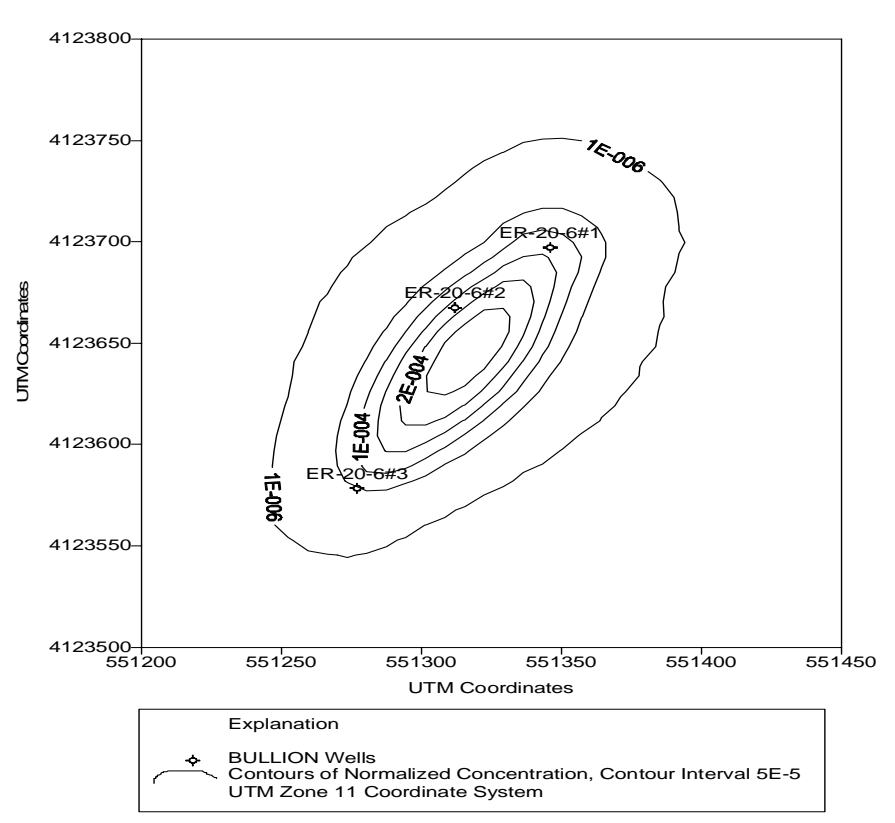

Figure 7-13

HSU 4 DFBA Normalized Concentration Contours at the Time of Peak in Well \#3

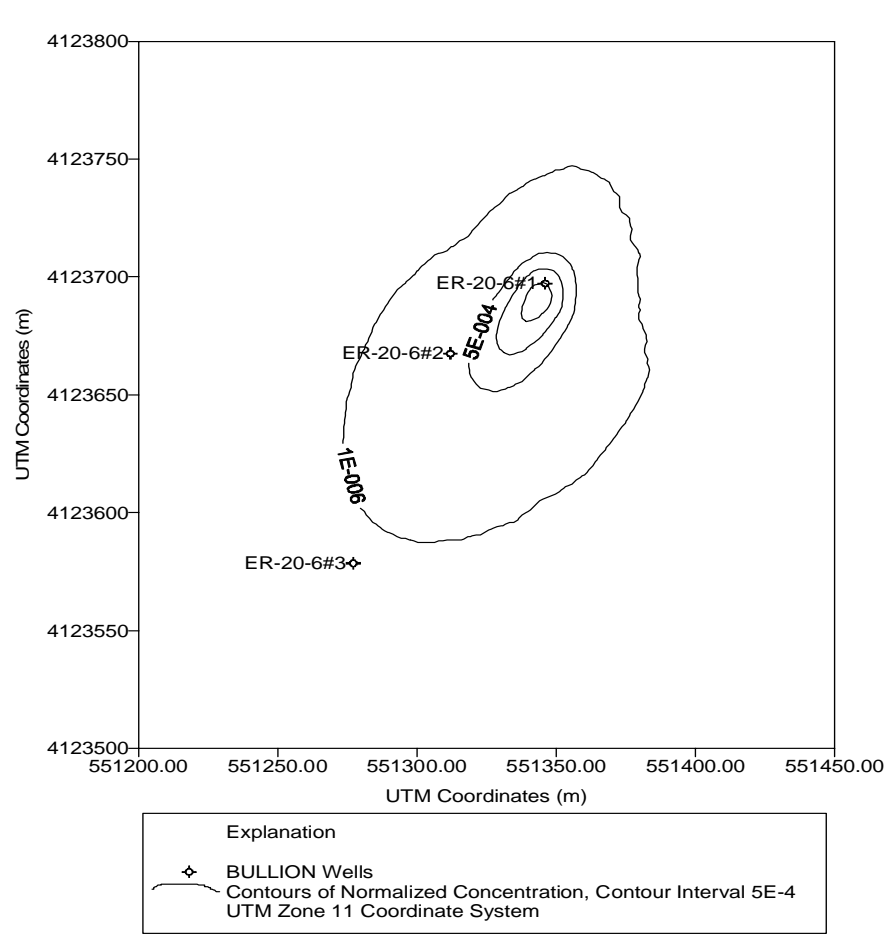

Figure 7-14

HSU 6 DFBA Normalized Concentration Contours at the Time of Peak in Well \#3 
of spreading was greater in HSU 4 than in HSU 6, due largely to the influence of the pumping well.

Figures 7-9 and 7-10 show the relative concentrations of DFBA and PFBA in layers 4 and 6 immediately after the injection of tracers in Well \#1. The tracers have al ready spread a substantial distance from the injection wells, both upgradient and downgradient. The influence of the hydraulic anisotropy is evident. Differences in the two figures represent what has been hypothesized as a tendency of the tracers to preferentially migrate into the lower aquifer (layer 6). The tracer solution was denser than ambient formation fluid due to the increased dissolved solids content from the tracers and al so the temperature of the tracer solution was about 30 degrees $F$ ahrenheit cooler than ambient groundwater temperature. The final simulation injected 65 percent of the tracer mass into the lower aquifer, with 35 percent remaining in the upper aquifer.

After about 15 days of pumping, the Well \#1 tracers began to breakthrough in Well \#3. Figure 7-11 is the tracer concentration in layer 4 at the time of breakthrough. Figure 7-12 is the corresponding map of tracer concentrations in layer 6 . Here it is more evident that tracer migration to the production well (Well \#3) was primarily in layer 4, but that tracer did spread and moved under more ambient conditions in layer 6 . Recall that for simulations of pumping from Wells \#1 and \#2, all water pumped was taken from HSU 4; but the true situation is unknown. To match the observed tracer decay curves at Wells \#1 and \#2, it was assumed that after injection, layer 6 did not produce any water due to a postulated lower head in layer 6 representing a downwards vertical gradient at the site.

The peak concentration of Well \#1 tracers (DFBA) in Well \#3 occurred at about 50 days after pumping began. Figures 7-13 and 7-14 are the corresponding concentration contours in layer 4 and 6, respectively. As can be seen in the figures, tracer was spread over the entire aquifer between the injection wells and the pumped wells. This was due, in part, to the effect of matrix diffusion which stored tracer in the matrix pores and then slowly released it over time. Additionally, the effect of pumpage at Wells \#1 and \#2 contributed to the slow rate of tracer decay at the injection wells. This also contributed to the spreading of the tracers over much of the aquifer between the wells.

The parameter values for these final calibration results were provided earlier. Some of these parameter values differ from the earlier estimates from the analytical solutions. This is a result of the additional constraints placed on the solution that the more comprehensive numerical model imposed. By requiring that both the hydraulic response and the tracer response be matched at all three wells rather than just the breakthrough at the pumped well, a more constrained solution resulted. 
To illustrate the effectiveness of these constraints, a series of sensitivity runs were performed to assess the impact of changing a parameter on the resulting model response.

\subsection{Sensitivity Analysis}

The adequacy of the resulting parameters obtained via the calibration of the flow and transport model to the BULLION FGE cannot be assessed without the accompanying sensitivity analysis. The sensitivity analysis provides a measure of how much a parameter can vary before it begins to significantly disrupt the fit to the observed data. The parameters for the sensitivity analyses are grouped into three categories: (1) those that impact the drawdown response alone, (2) those that impact the tracer response alone, and (3) those that impact both the drawdown and tracer response simultaneously.

Of all the parameters, only the storage coefficient can be considered to influence only the drawdown response. If fact, even storage coefficient has some impact on tracer migration because the storage coefficient controls, in part, the time rate of change in the potentiometric surface, which in turn defines the hydraulic gradient. The hydraulic gradient, along with hydraulic conductivity and effective porosity determine the water velocity and the mean travel velocity of an ideal tracer.

Nonetheless, storage coefficient is treated separately in the sensitivity analyses because it primarily influenced the short-term response of the drawdown to changes in pumping rate. Figure 7-15 is a plot of the drawdown in all three wells for the case of a storage coefficient increase by a factor of 10. It can be seen that the rate of drawdown was slowed relative to the calibrated case (F igure 6-10), but that the effect is short-lived and the overall drawdown remains approximately the same. The corresponding tracer breakthrough curves were indistinguishable from the calibrated case and are not presented here. For the case of a factor of 10 decrease in storage coefficient, the corresponding drawdown curves were indistinguishable from the calibrated case and are not presented.

A number of parameters impacted both the drawdown response and the tracer breakthrough curves. The magnitude of boundary fluxes, hydraulic conductivity differences, and the amount of water withdrawn from HSUs 4 and 6 by Wells \#1 and \#2 all may impact the predicted tracer behavior. For the boundary fluxes, the conductance is calculated from the cell hydraulic conductivity, so increases in horizontal hydraulic conductivity also produce increases in boundary fluxes. The boundary fluxes can also be modified independent of the hydraulic conductivity via a conductance multiplier. For the sensitivity analyses, boundary conductances were increased by a factor of ten along the West Greeley fault and decreased to zero, to make the West Greeley fault impermeable. 


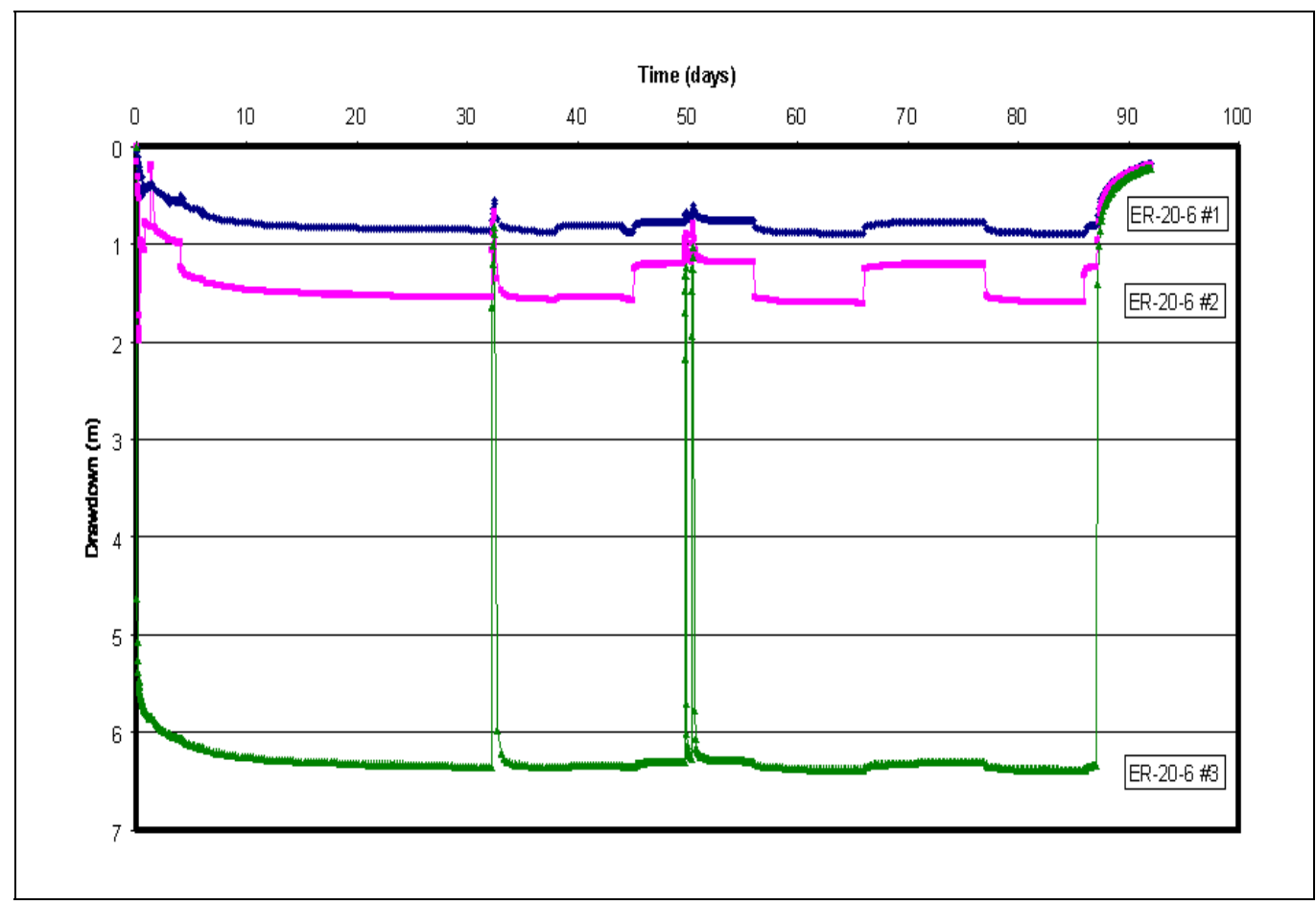

Figure 7-15

Drawdowns in Well \#3 with Increased Storage Coefficient

The response of the breakthrough of DF BA in Well \#3 to a decrease of the West Greeley conductances to zero is given in Figure 7-16. The resulting breakthrough curve is only slightly different from the calibrated case (Figure 7-1). The case of a factor of 10 increase in conductances produced no noticeable departure from the calibrated case and is not presented. As noted earlier in the discussion of the hydraulic response, the effects of possible leakage of water from the West Greeley fault is negligible. This means that the BULLION FGE cannot be used to determine if the West Greeley fault is a conduit or a barrier to flow.

The impact of a factor of two increase or decrease of the hydraulic conductivity of HSU 4 and 6 was also evaluated. The breakthrough curves of DFBA in Well \#3 are given in Figures 7-17 and 7-18 for the factor or two increase and decrease, respectively. From Figure 7-18 it can be seen that the tracer concentrations are more sensitive to decreases in conductivity. The drawdown effects are as expected. For Well \#3, the maximum drawdown was $12.5 \mathrm{~m}$ for a decrease in $\mathrm{K}$, and $3.3 \mathrm{~m}$ for a factor of two increase. These results show the response of the model to average hydraulic conductivity values. Small scale variability is averaged out in these examples. Nonetheless, the average hydraulic conductivity is well constrained by the drawdown response because even a factor of two change in the hydraulic conductivity value 


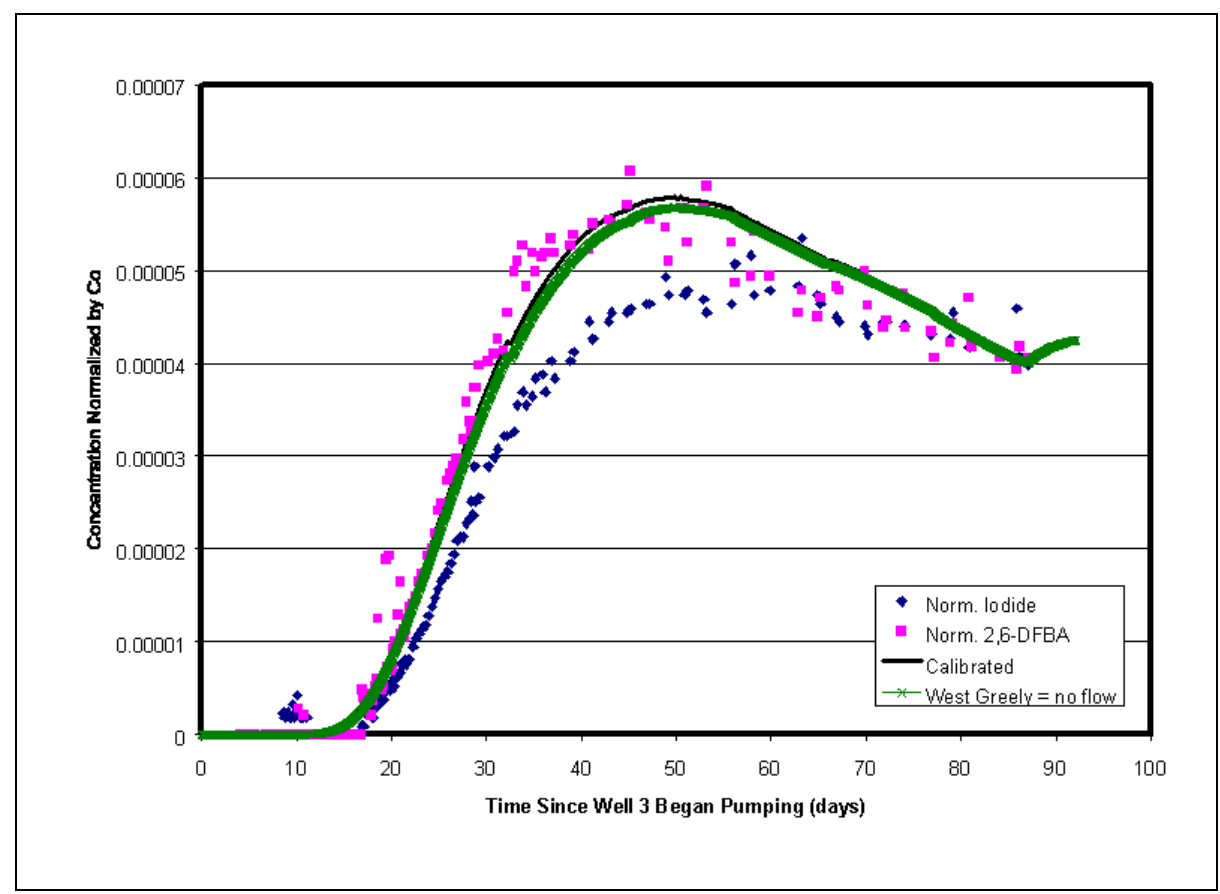

Figure 7-16

DFBA Breakthrough Curve at Well \#3 for the West Greeley Fault as a No-Flow Boundary

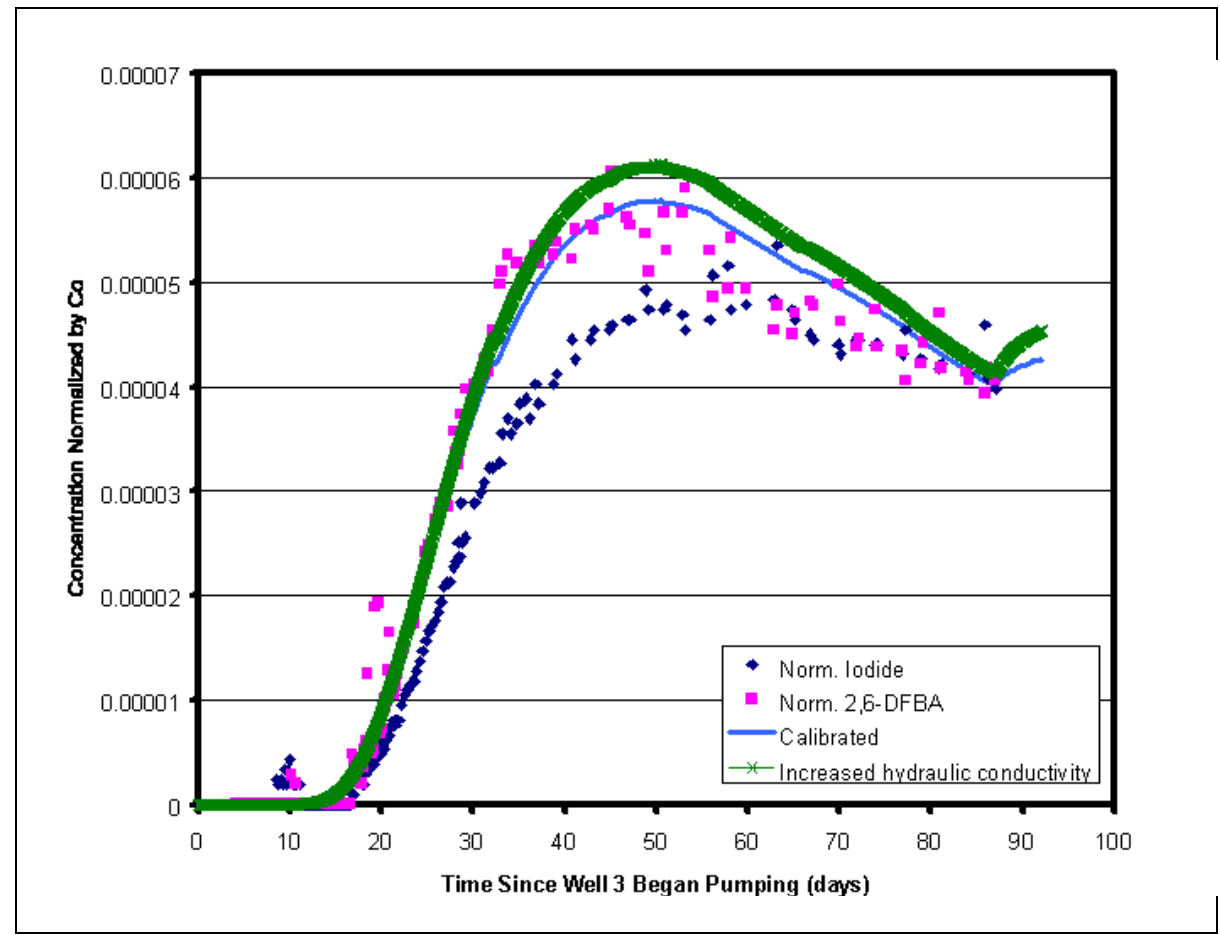

Figure 7-17

DFBA Breakthrough Curve for Well \#3 with Increased Hydraulic Conductivity 


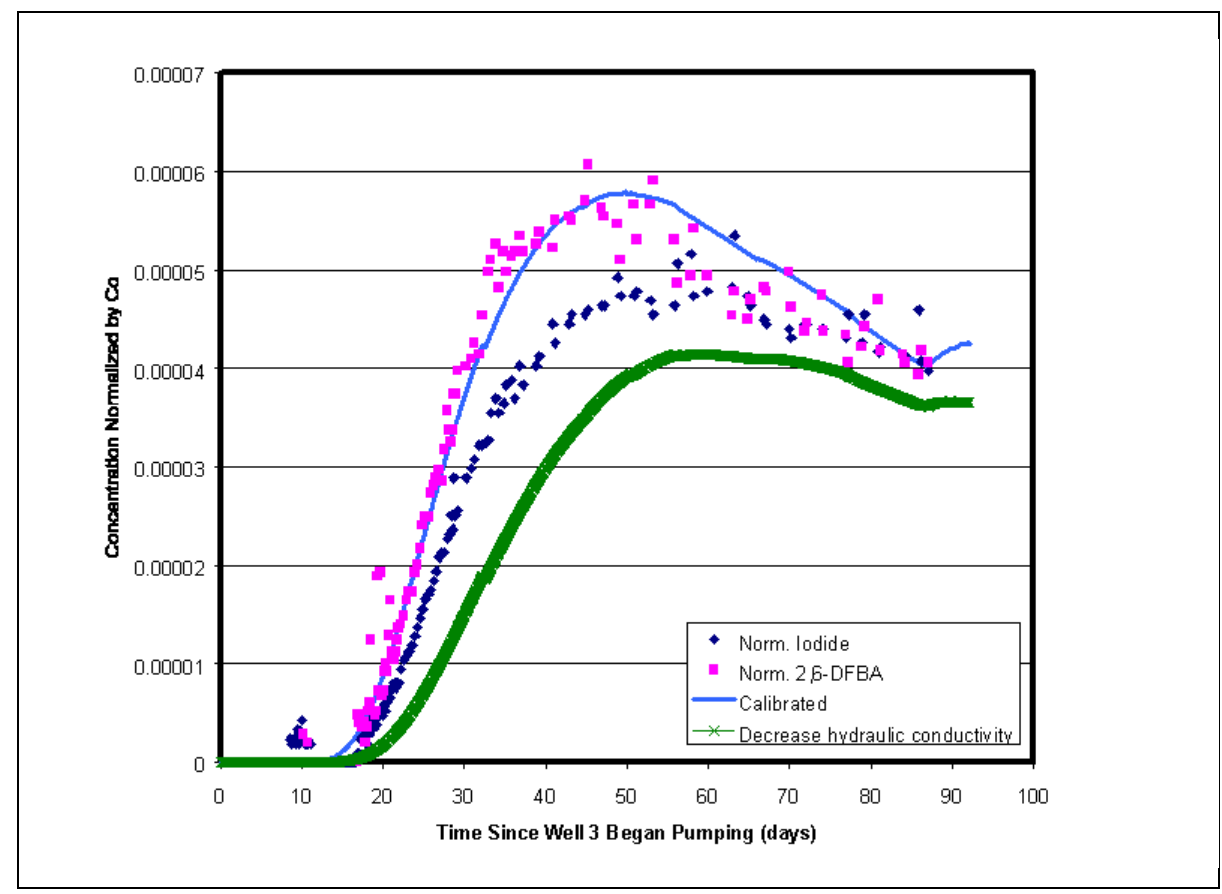

Figure 7-18

DFBA Breakthrough Curve for Well \#3 with Decreased Hydraulic Conductivity

produces maximum drawdowns significantly different from the observed values.

Another sensitivity is the impact of removing the high hydraulic conductivity zone from around Well \#1 (see Section 6.5.1 and Figure A-19 for details). This zone was added for two reasons to enhance the calibration. First, the observed drawdown response at Well \#1 to its own pumping was much smaller than the response of Well \#2 to the Well \#2 pumping. This suggested a region of higher hydraulic conductivity around Well \#1. Secondly, the initial attempts at calibration produced tracer concentrations at Well \#1 that were much too high. The flushing of tracer from Well \#l could have been accomplished by either decreasing the porosity or increasing the flux via the hydraulic conductivity. Because the subdued drawdown response at Well \#1 to its own pumpage was better reproduced with the high $\mathrm{K}$ zone approach. It is informative to examine the impact of this feature on the simulated breakthrough curves. Figures 7-19, 7-20, and 7-21 are the simulated breakthrough and decline curves of DFBA in Wells \#3, \#2, and \#1, respectively, without this high hydraulic conductivity zone. The breakthrough in Well \#3 is delayed in time and decreased in peak concentration. At Well \#2, the same response was observed. The tracer decline curve at Well \#1 (Figure 7-21) shows that predicted concentrations are larger for the case of the high $\mathrm{K}$ region removed. Figure 7-22 shows the drawdown responses for the three 


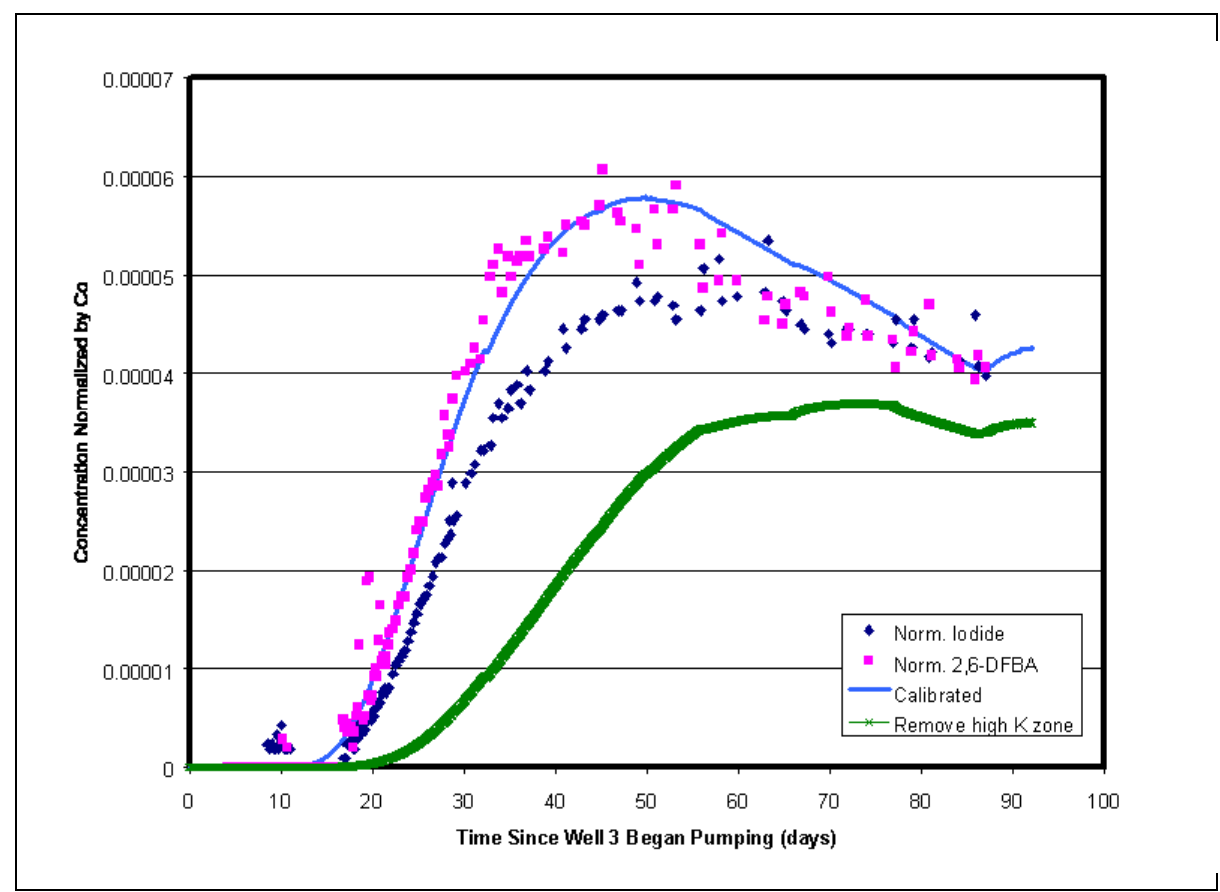

Figure 7-19

Simulated Breakthrough Curve of DFBA for Well \#3 without the High Conductivity Zone

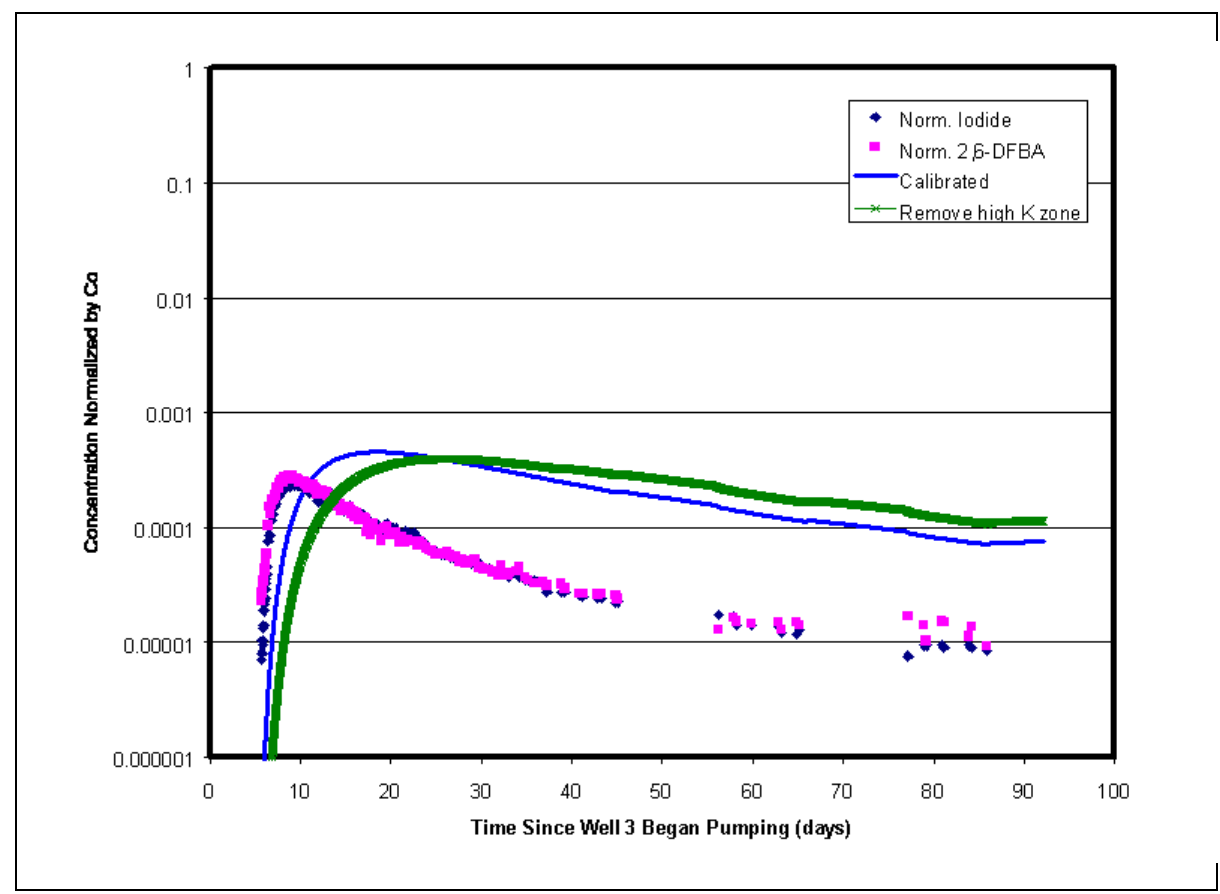

Figure 7-20

Simulated Breakthrough Curve of DFBA for Well \#2 without the High Conductivity Zone 


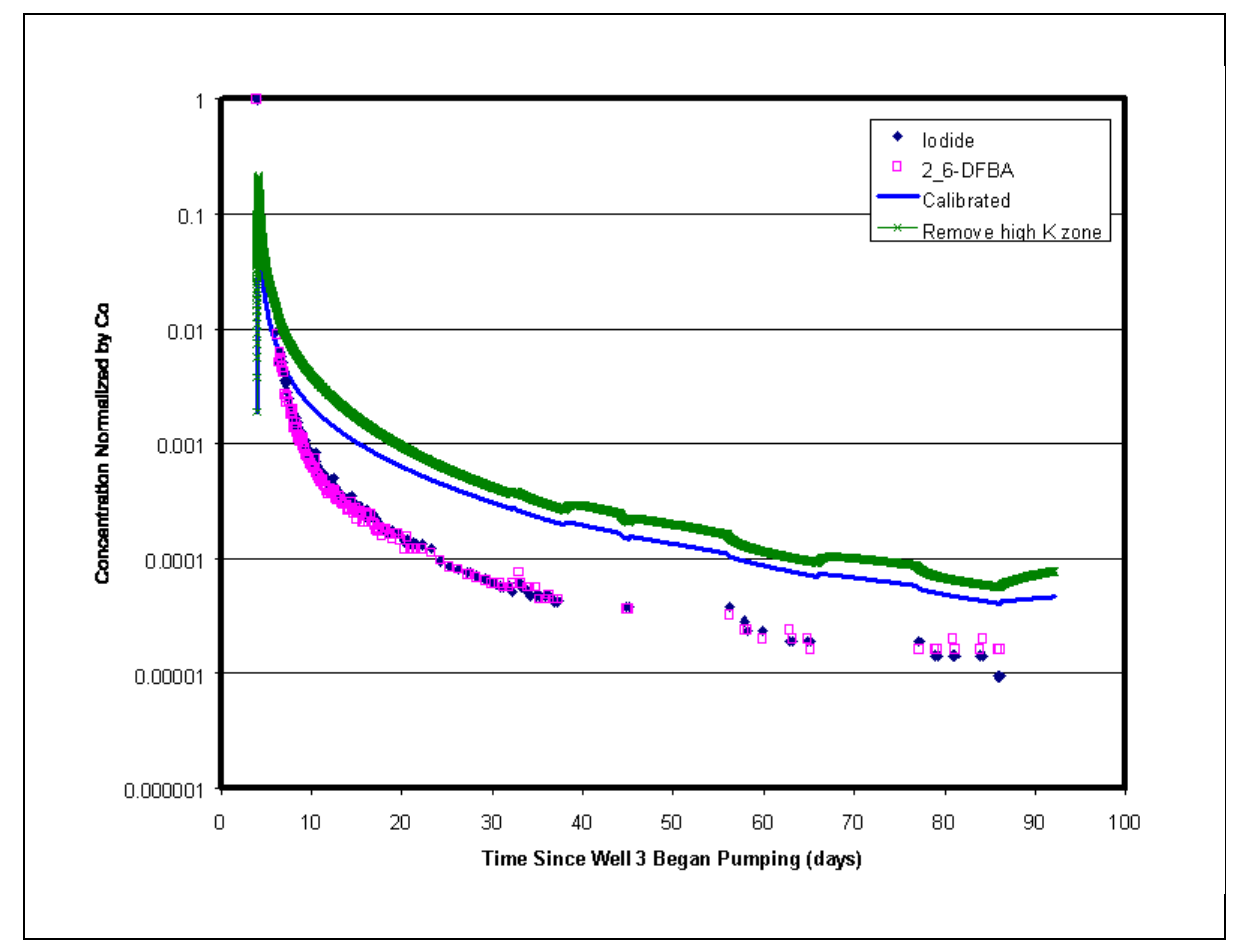

Figure 7-21

Simulated Breakthrough Curve of DFBA for Well \#1 without the High Conductivity Zone

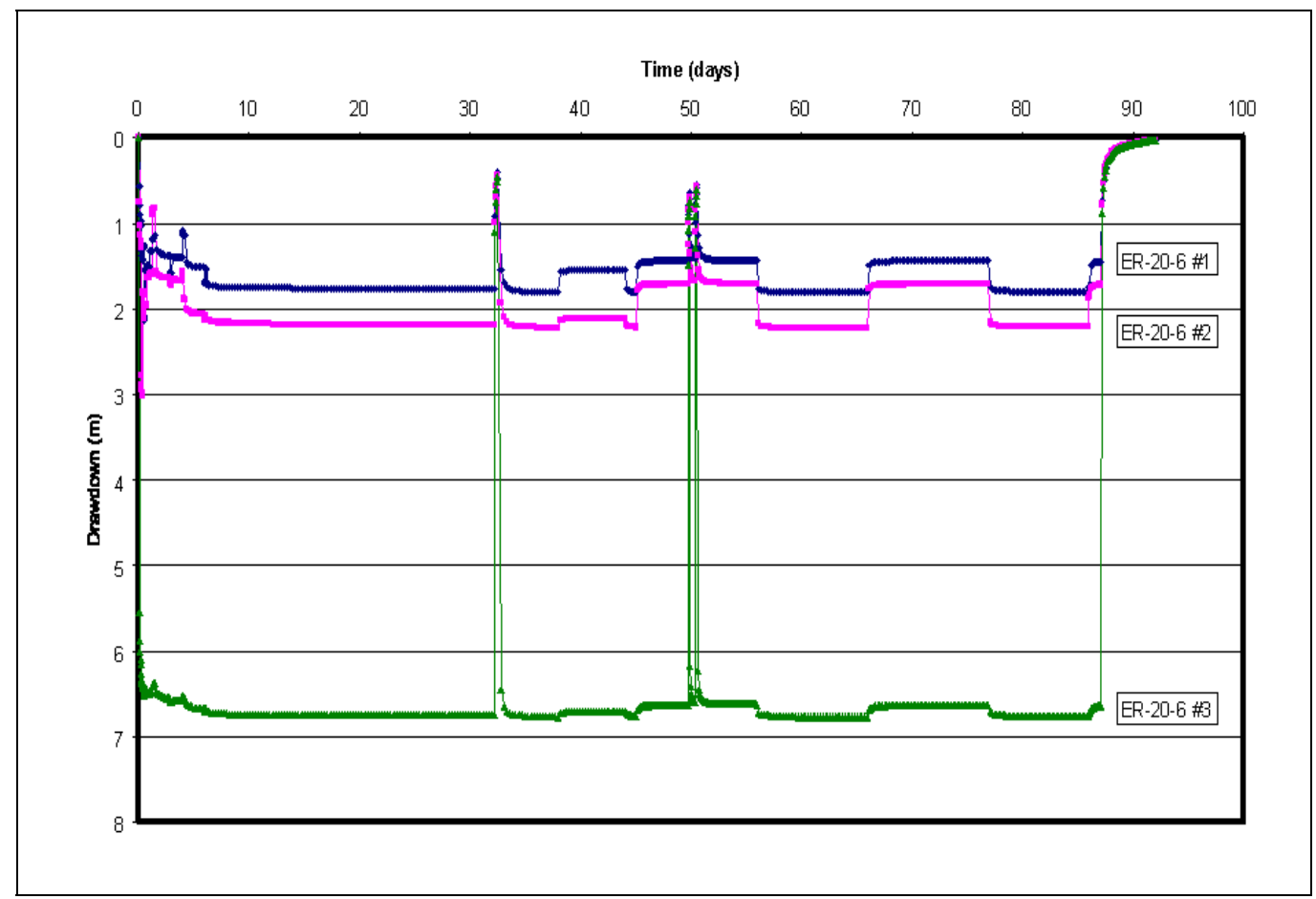

Figure 7-22

Simulated Drawdowns without the High Conductivity Zone 
wells. The drawdown at Well \#3 is not significantly different, but at Wells $\# 2$ and $\# 1$, the maximum drawdowns are measurably increased when the high $\mathrm{K}$ region is removed. An additional feature of the drawdown curves is the response of Well \#1 to its own pumping. When the high $\mathrm{K}$ region is removed, the drawdown responses at Wells \#1 and \#2 are nearly the same for the period of well shut downs from 45 to 85 days. However, the measured drawdown data suggest that the difference in maximum drawdown at Wells \#1 and \#2 between the times when the injections wells were pumped and when they were idle was $0.03 \mathrm{~m}$ at Well \#1 and 0.15 at Well \#2. These measured values have some error associated with them because of the noisiness of the measured data. Nonetheless, it seems likely that the Well \#1 response is much less than the Well $\# 2$ response. If the high $K$ region is removed, then the drawdown responses are not consistent with observed data. If it were not for the drawdown data, it would have been possible to fit the tracer breakthrough curves with another set of parameters such as a reduction in porosity.

The amount of mass that was injected into HSU 4 is directly reflected in the tracer breakthrough curves. Figure 7-23 is the breakthrough of DFBA in Well \#3 assuming the injected mass into HSU 4 was one-half of what was used for the calibrated case The corresponding tracer breakthrough curves in Wells $\# 2$ and $\# 1$ are given in Figures 7-24 and $7-25$, respectively. It is no surprise that the resulting concentrations are about one-half of the calibrated case. Therefore, the model response is linear with respect to input mass.

Another parameter that has a significant influence on the tracer breakthrough curve is the porosity. Figure 7-26 is the DF BA breakthrough curve at Well \#3 for the case of decreased porosity of the lava-flow aquifer by one half, from 0.018 to 0.009 . The porosity of the high conductivity zone surrounding Well \#1 was not changed in this example. The corresponding doubling of porosity to 0.036 is given in Figure 7-27. Decreasing the porosity shifts the curve forward in time, but also increases the peak concentration because of the reduction in time available to matrix diffusion to occur. Increasing the porosity has the opposite effect.

Doubling the longitudinal, transverse, and vertical dispersivities from $10 \mathrm{~m} / 3 \mathrm{~m} / 2 \mathrm{~m}$ to $20 \mathrm{~m} / 6 \mathrm{~m} / 4 \mathrm{~m}$ produced the DFBA breakthrough curves in Figures 7-28, 7-29, and 7-30 for Wells \#3, \#2, and \#1, respectively. At Well \#3 (Figure 7-28) the larger dispersivity decreases the peak concentration, leads to earlier breakthrough, and flattens the tail of the breakthrough curve. At Well \#2 (Figure 7-29), the breakthrough is earlier and the tail is flattened, but peak concentration is unchanged. At Well \#1 (F igure 7-30), the decline curve is flatter than for the calibrated case.

Decreasing the dispersivity to $5 \mathrm{~m} / 1.5 \mathrm{~m} / 1 \mathrm{~m}$ led to the breakthrough curves for DFBA given in Figures 7-31, 7-32, and 7-33 for Wells \#3, \#2, 


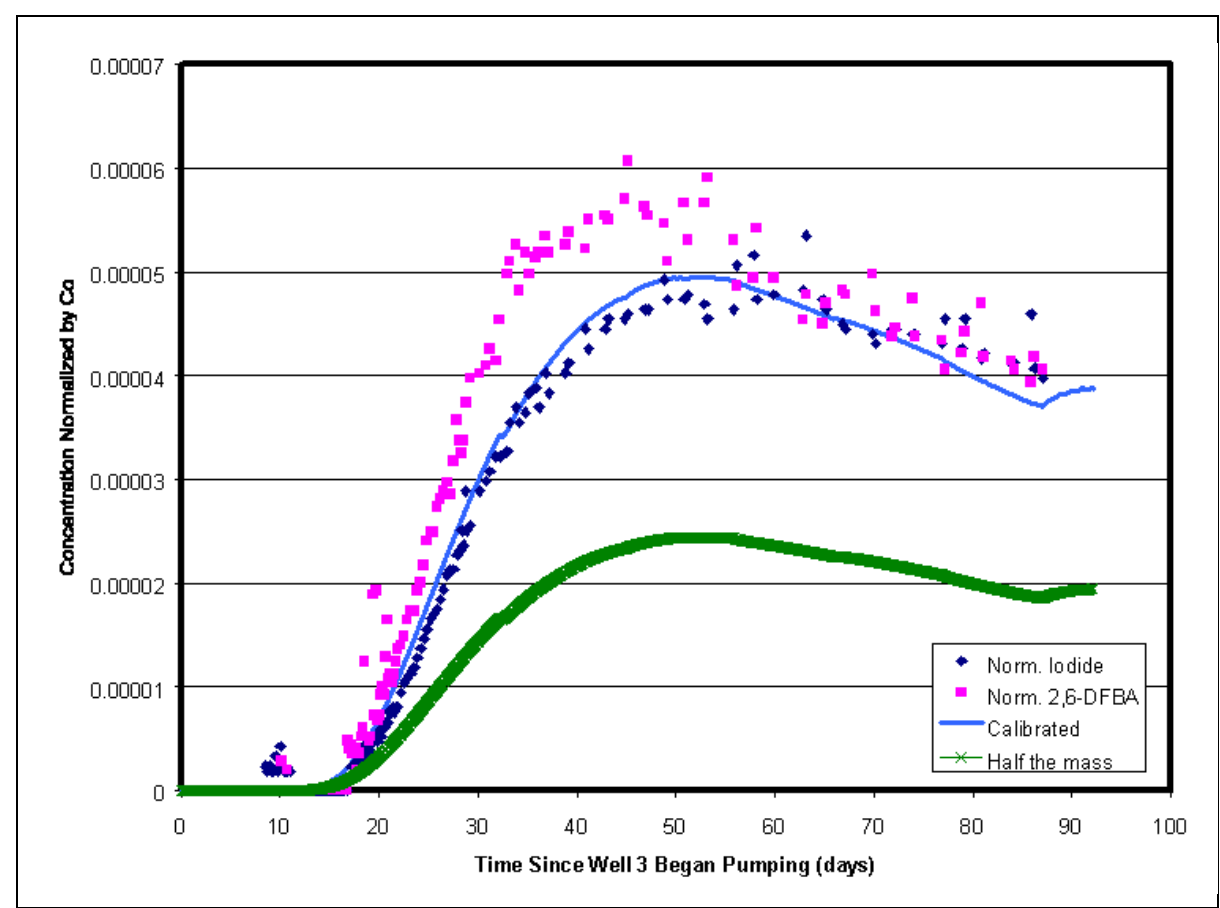

Figure 7-23

Simulated Breakthrough of DFBA for Well \#3

with Reduced Injection Mass in HSU 4

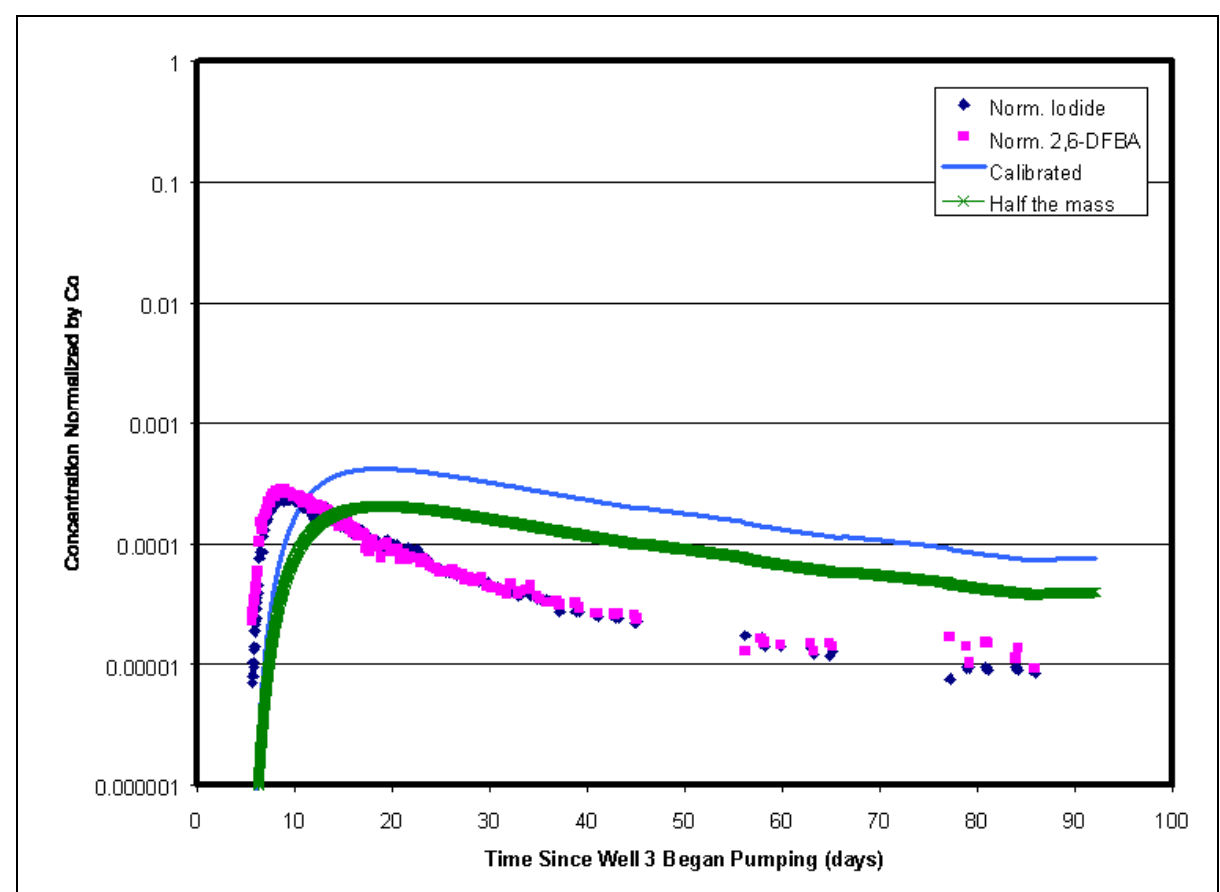

Figure 7-24

Simulated Breakthrough of DFBA for Well \#2

with Reduced Injection Mass in HSU 4 


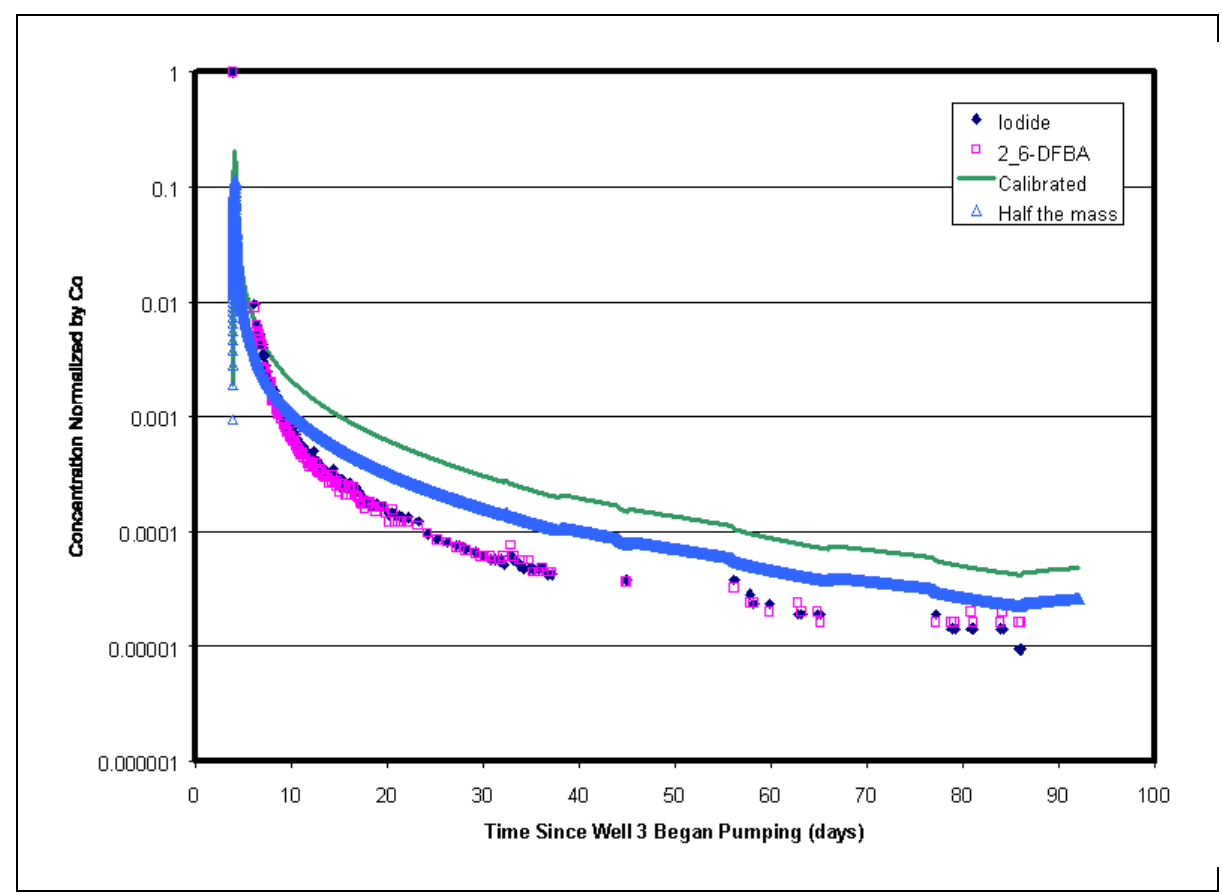

Figure 7-25

Simulated Breakthrough of DFBA for Well \#1 with Reduced Injection Mass in HSU 4

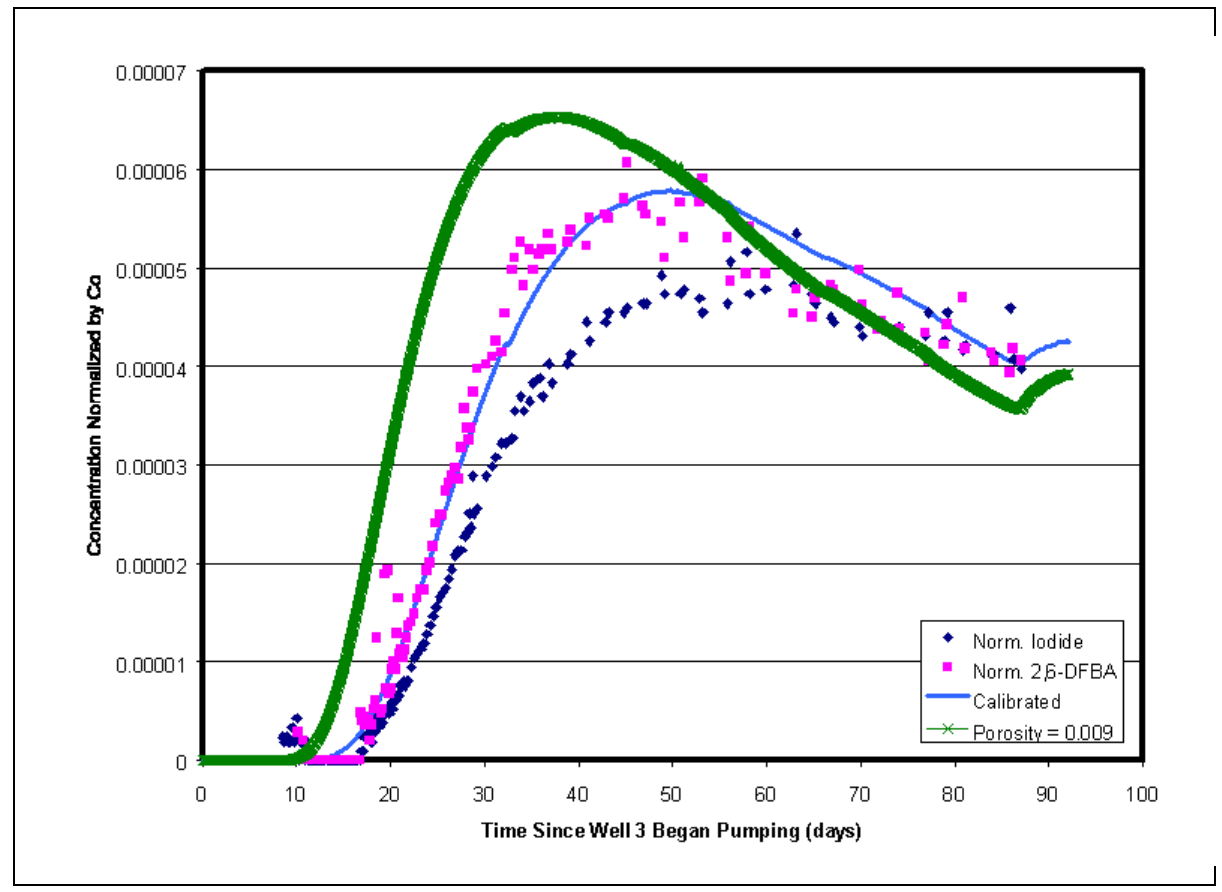

Figure 7-26

Simulated Breakthrough of DFBA for Well \#3 with Decreased Porosity 


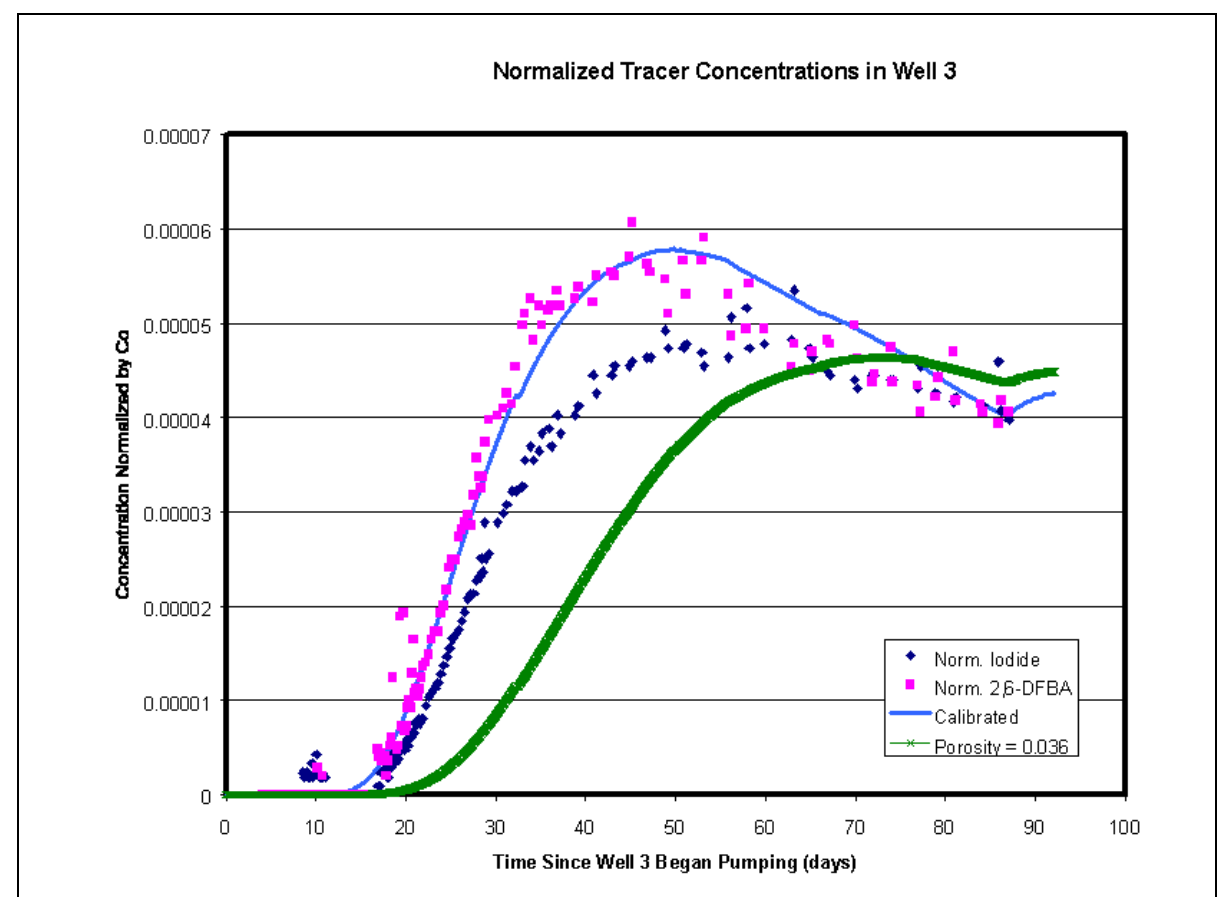

Figure 7-27

Simulated Breakthrough of DFBA for Well \#3 with Increased Porosity

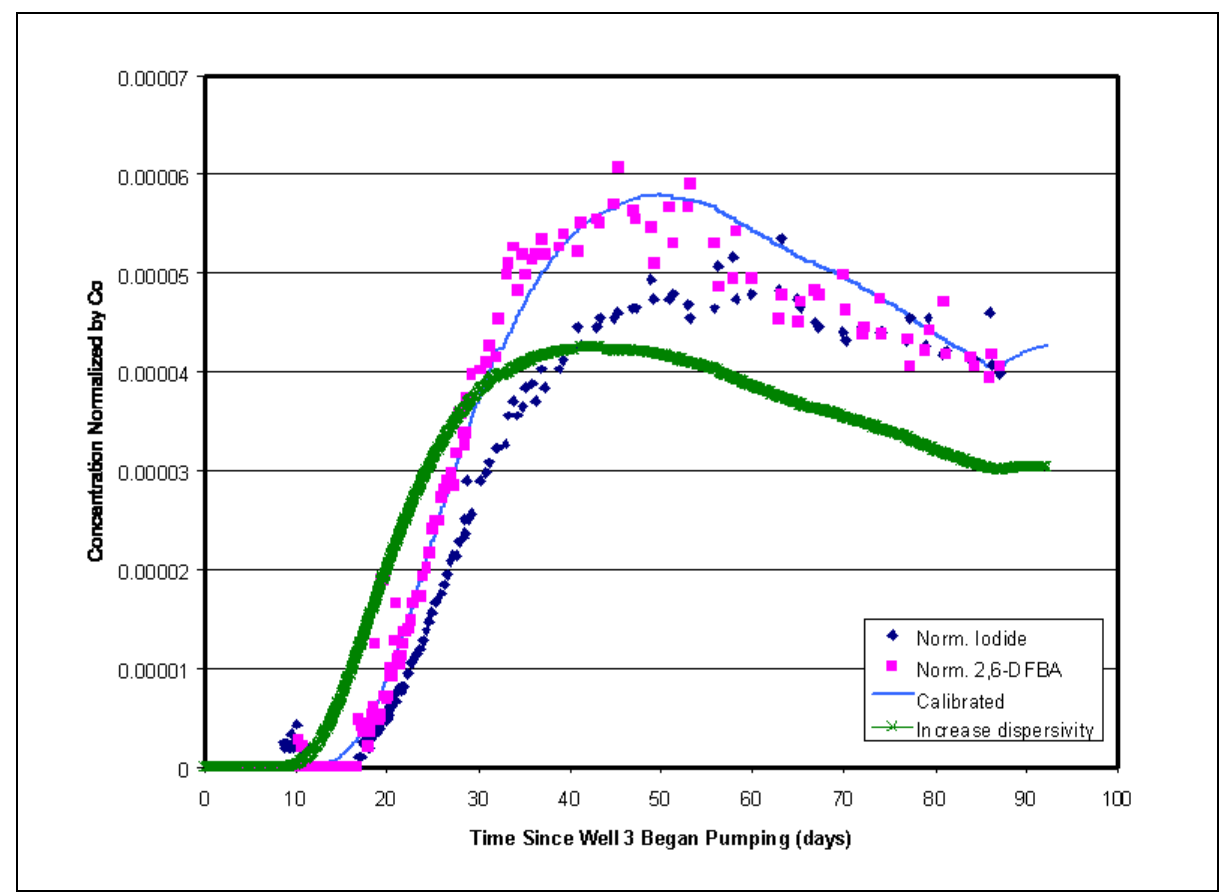

Figure 7-28

Simulated Breakthrough of DFBA for Well \#3 for Increased Dispersivities 


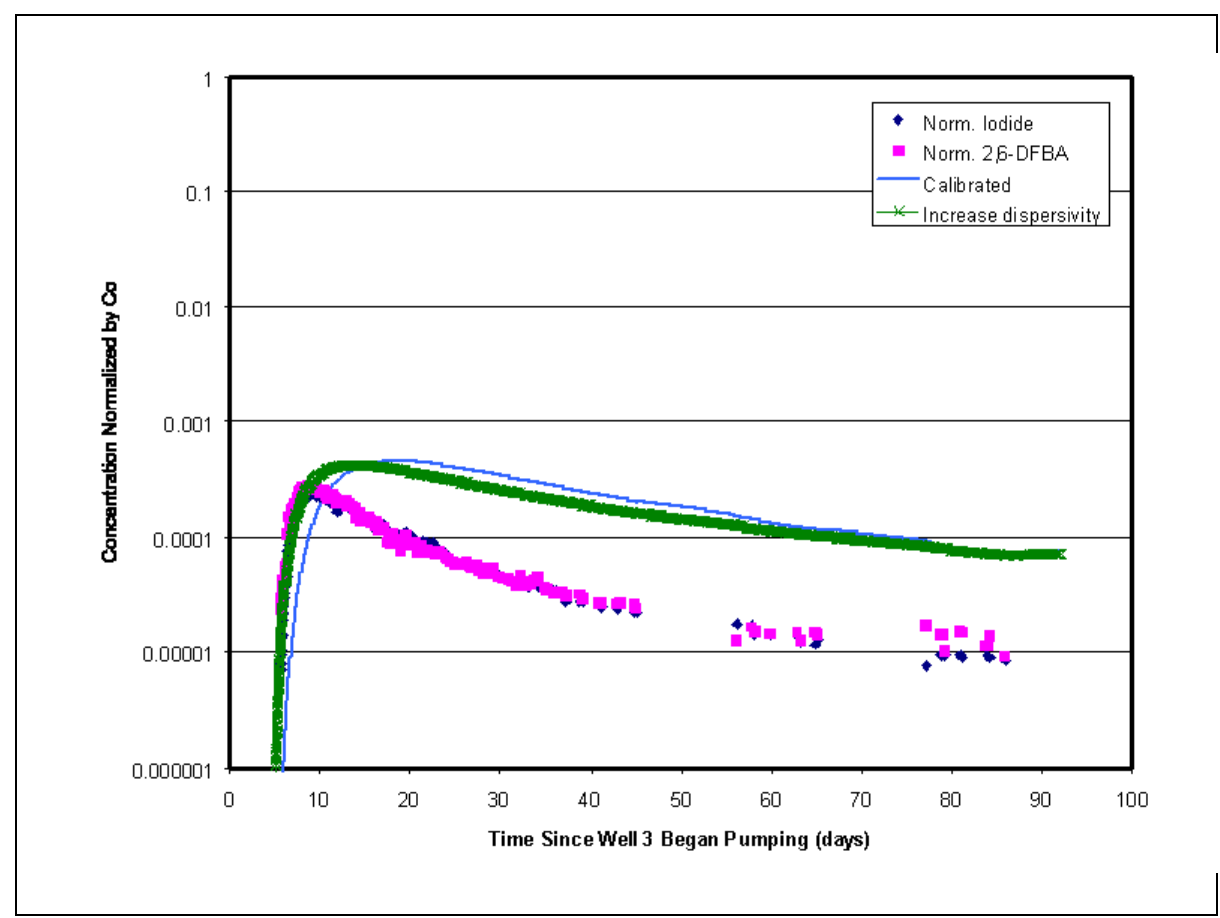

Figure 7-29

Simulated Breakthrough of DFBA for Well \#2 for Increased Dispersivities

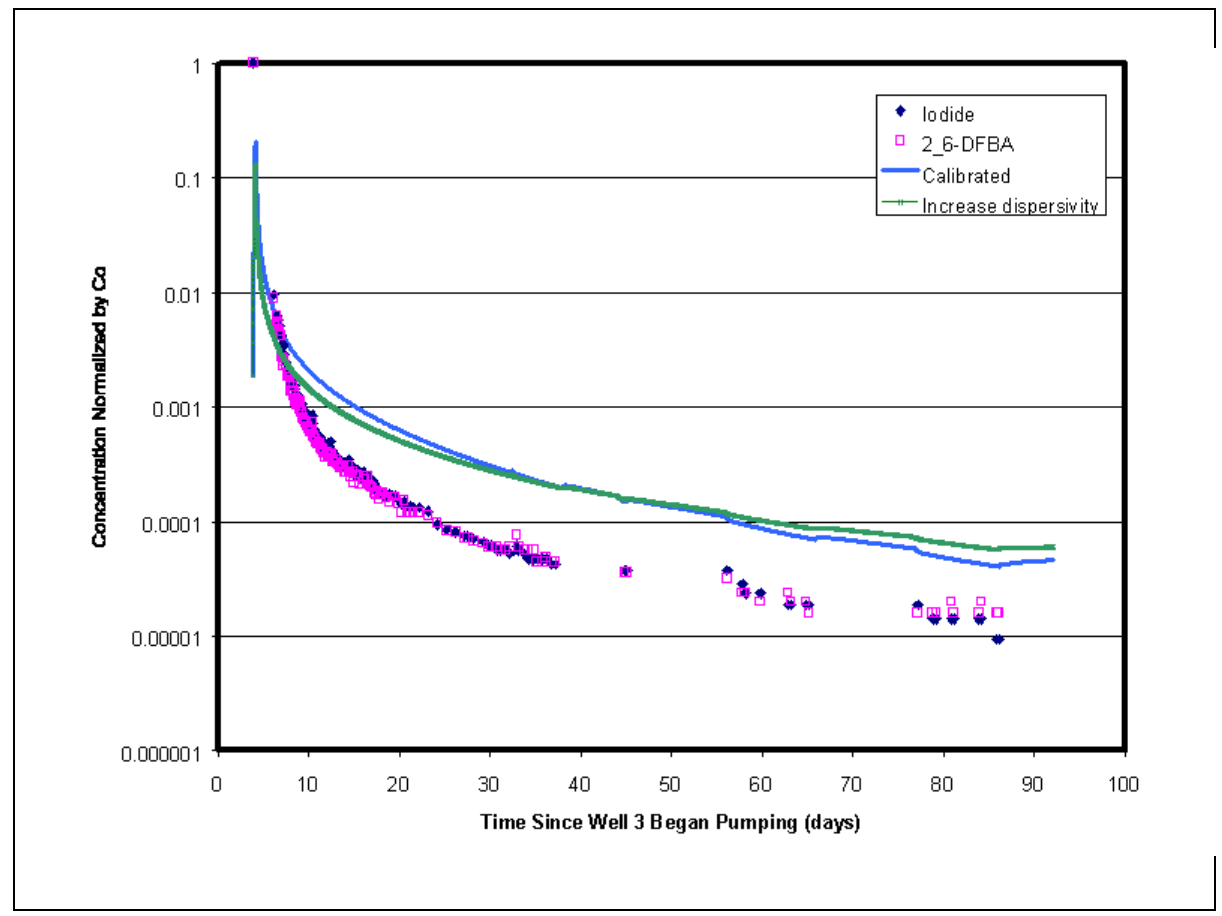

Figure 7-30

Simulated Breakthrough of DFBA for Well \#1 for Increased Dispersivities 


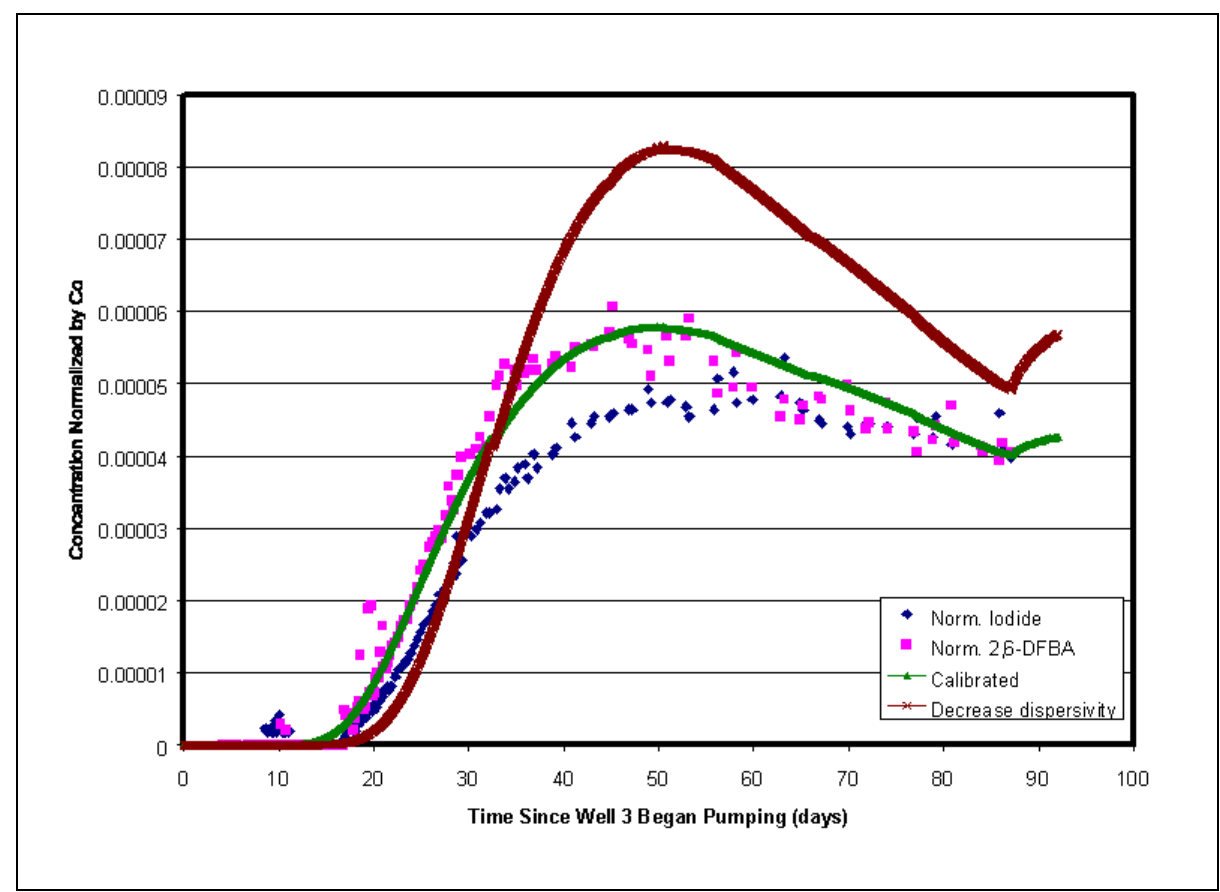

Figure 7-31

Simulated Breakthrough of DFBA for Well \#3 for Decreased Dispersivities

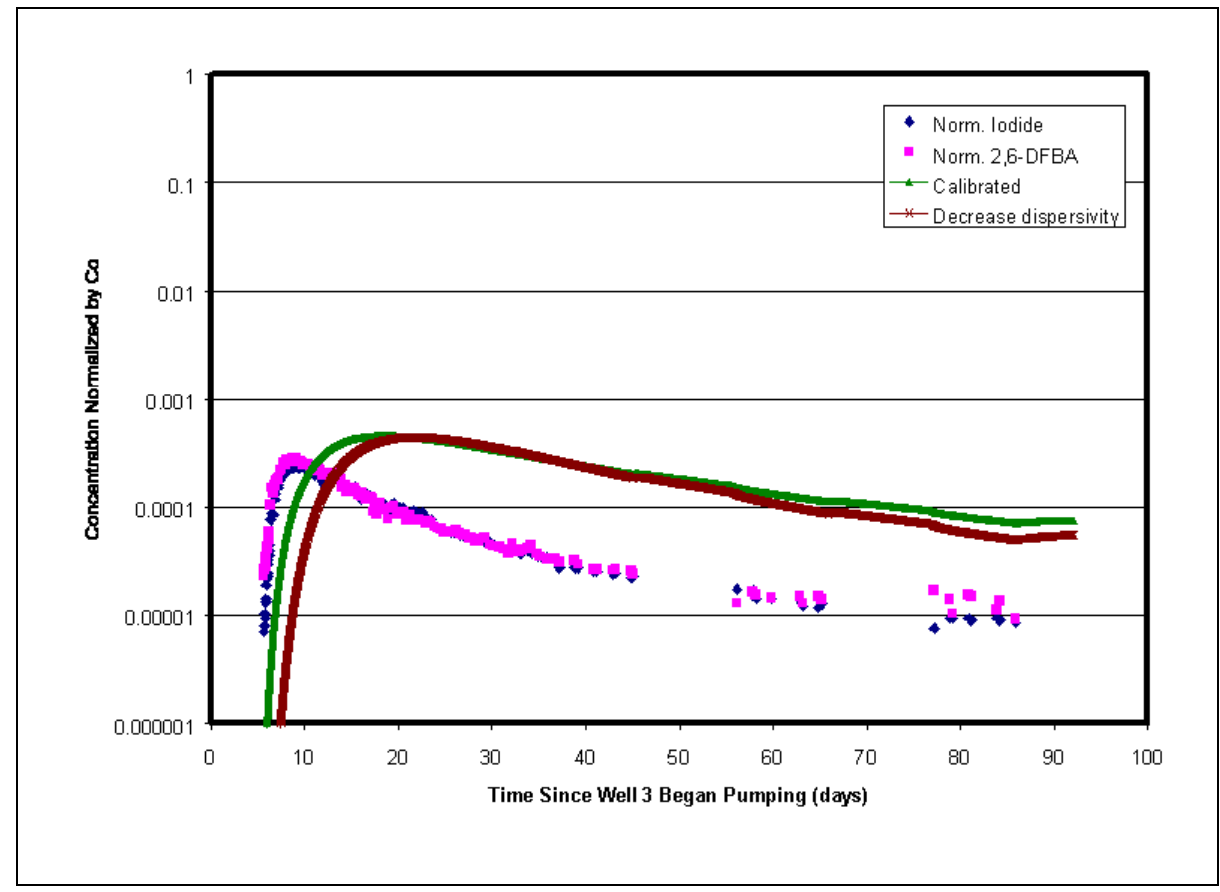

Figure 7-32

Simulated Breakthrough of DFBA for Well \#2 for Decreased Dispersivities 


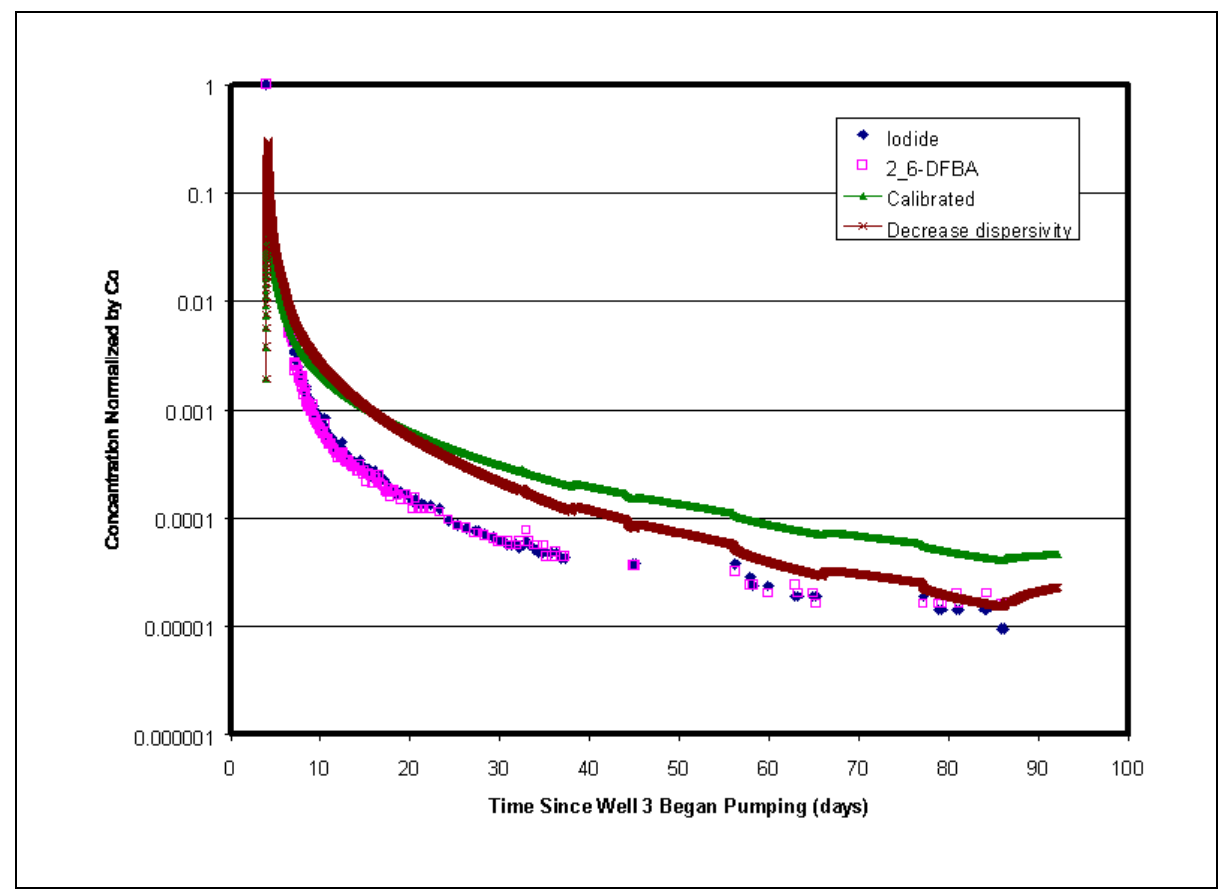

Figure 7-33

Simulated Breakthrough of DFBA for Well \#1 for Decreased Dispersivities

and \#1, respectively. The smaller dispersivity produces a later breakthrough with larger peak concentrations and steepening of the tail at Well \#3 (Figure 7-31). At Well \#1 (Figure 7-33), the tracer decay curves match at the end of the test, near 80 days. This points out one of the limitations of using the advection-dispersion equation to model solute migration over a variety of scales. Near Well \#1, the longitudinal dispersivity is $10 \mathrm{~m}$, just as it is further downgradient in the flow system. This dispersivity produces an upgradient dispersive flux that works in the opposite direction of the water flow. A big part of the difficulty of matching the tracer decay response at Well \#1 is related to this dispersive flux. As observed by Gelhar et al. (1992), the dispersivity increases with the scale of the experiment with a rule-of-thumb being that the longitudinal dispersivity should be about 10 percent of the scale of the test. For the tracer migration to Well \#3, the scale is between 90 and $130 \mathrm{~m}$, so a dispersivity of $10 \mathrm{~m}$ is reasonable. Near the injection well, the scale of the experiment is very small. I deally one would want to use a dispersivity of 10 centimeters (cm) to $100 \mathrm{~cm}$ near the injection wells. Our current modeling did use that approach. Therefore the dispersive fluxes near the injection wells are going to be overestimated by the BULLION FGE model. 


\subsubsection{Alternative Calibrations}

Although the figures above represent the sensitivity of the model response to increases or decreases in various parameter values, a more interesting question is whether the breakthrough curves could have been calibrated with another set of parameter values. Table 7-2 presents the final calibration values for transport parameters and the alternative parameters sets that were evaluated. With the exception of recal ibration 1 and 2 , the hydraulic system was left unchanged because the drawdown response was considered fixed. In recalibrations 1 and 2, the high conductivity zone (Appendix A, Figure A-19) was extended south another 10 rows. This case was assumed to examine the ability of the model to be calibrated to a secondary conceptualization.

Table 7-2

Parameters of the Alternative Calibrations for Transport from Well \#1 and Well \#3

\begin{tabular}{|c|c|c|c|c|c|c|c|c|}
\hline \multicolumn{2}{|c|}{ Parameter } & $\begin{array}{c}\text { Final } \\
\text { Calibrated }\end{array}$ & $\begin{array}{c}\text { Alternative } \\
\text { Calibration } \\
1\end{array}$ & $\begin{array}{c}\text { Alternative } \\
\text { Calibration } \\
\quad 2\end{array}$ & $\begin{array}{c}\text { Alternative } \\
\text { Calibration } \\
3\end{array}$ & $\begin{array}{c}\text { Alternative } \\
\text { Calibration } \\
4\end{array}$ & $\begin{array}{c}\text { Alternative } \\
\text { Calibration } \\
5\end{array}$ & $\begin{array}{c}\text { Alternative } \\
\text { Calibration } \\
6\end{array}$ \\
\hline \multicolumn{2}{|c|}{ Fracture Spacing $(\mathrm{m})$} & 0.25 & 0.25 & 0.25 & 0.25 & 0.25 & 0.15 & 0.25 \\
\hline \multicolumn{2}{|l|}{ Matrix Porosity } & 0.35 & 0.35 & 0.35 & 0.35 & 0.35 & 0.10 & 0.35 \\
\hline \multirow{2}{*}{$\begin{array}{l}\text { Matrix Diffusion } \\
\text { Coefficient } \\
\left(\mathrm{m}^{2} / \text { day }\right)\end{array}$} & DFBA & $1.2 \times 10^{-6}$ & $5.0 \times 10^{-6}$ & $7.0 \times 10^{-6}$ & NA & $3.0 \times 10^{-8}$ & $1.6 \times 10^{-6}$ & $3.2 \times 10^{-6}$ \\
\hline & lodide & $1.6 \times 10^{-6}$ & NA & NA & $3.0 \times 10^{-6}$ & NA & $2.3 \times 10^{-6}$ & $4.0 \times 10^{-6}$ \\
\hline \multicolumn{2}{|l|}{ Dispersivity (m) } & $10 / 3 / 2$ & $10 / 3 / 2$ & $10 / 3 / 2$ & $25 / 7.5 / 5$ & $25 / 7.5 / 5$ & $10 / 3 / 2$ & $5 / 1 / 1$ \\
\hline \multicolumn{2}{|c|}{$\begin{array}{l}\text { Proportion of mass } \\
\text { injected into HSU } 4 / 6\end{array}$} & $35 \% / 65 \%$ & $58 \% / 42 \%$ & $70 \% / 30 \%$ & $80 \% / 20 \%$ & $30 \% / 70 \%$ & $35 \% / 65 \%$ & $40 \% / 60 \%$ \\
\hline \multicolumn{2}{|l|}{ Effective Porosity } & 0.018 & 0.018 & 0.018 & 0.036 & 0.036 & 0.018 & 0.009 \\
\hline
\end{tabular}

The first alternative calibration is shown in Figures 7-34 through 7-36. Figure 7-34 is the breakthrough curve of DFBA in Well \#3, recalibrated with the injected mass in HSU 4 increased from 35 percent to 58 percent and the matrix diffusion coefficient increased from $1.1 \times 10^{-6}$ to $5 \times 10^{-6} \mathrm{~m}^{2} /$ day. The initial breakthrough was fit as well, but the tail of the curve is too high due to the increased matrix diffusion. The DFBA breakthrough and decline curves in Wells \#2 and \#1 are given in Figures 7-35 and 7-36. In both of these figures the calibrated curve is a better match than the recalibration.

A second recalibration is given in Figures 7-37 through 7-39. In these runs 70 percent of the mass was injected into HSU 4 and the matrix diffusion coefficient was increased to $7.0 \times 10^{-6} \mathrm{~m}^{2} /$ day. The fit to the DFBA tracer curve for Well \#3 (Figure 7-37) is not as good as in the calibrated case. I nterestingly, if the injected mass were reduced by about 20 percent to the 58 percent level, it is likely the curve would match the breakthrough of iodide instead of DFBA. This ratio of the diffusion coefficients (1.4) is about the same as in the calibrated case (1.33). The corresponding breakthrough and decline curves at Wells \#2 


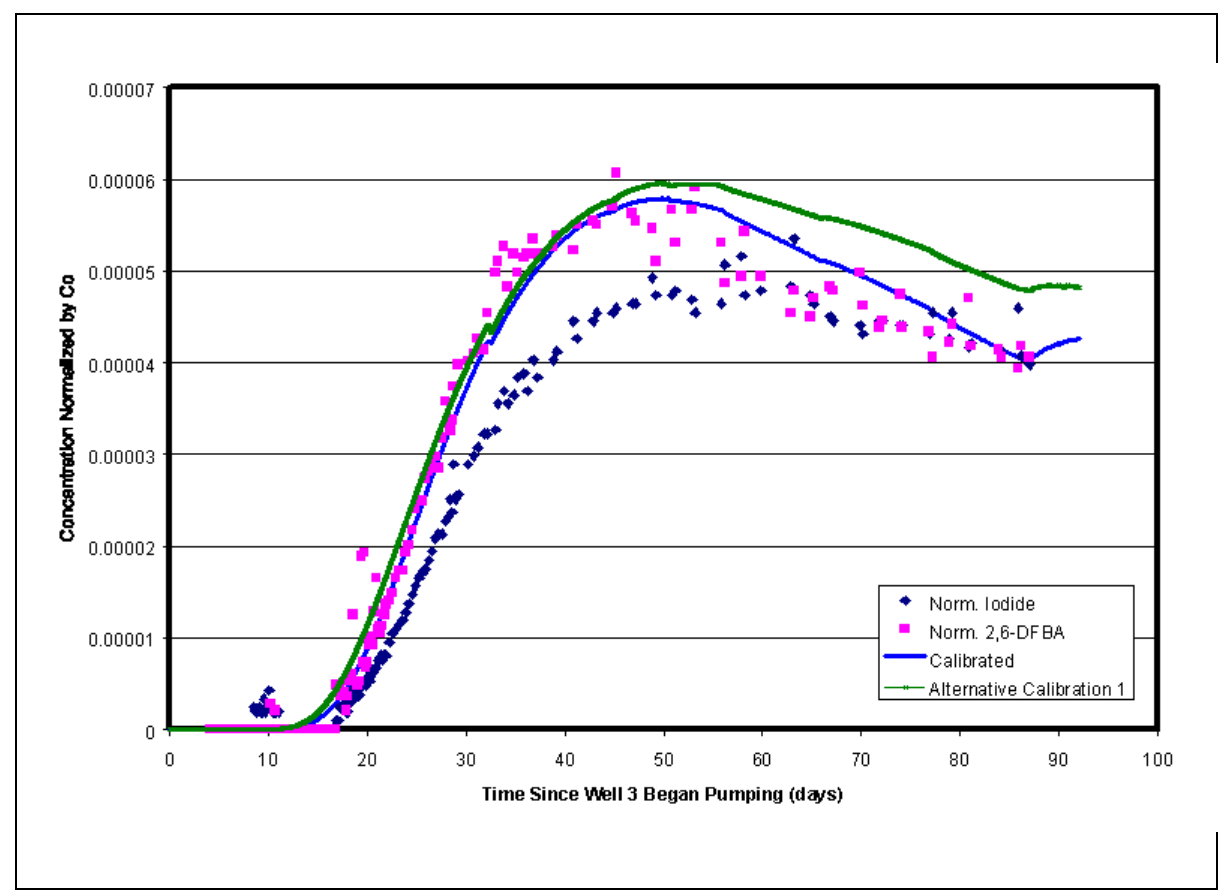

Figure 7-34

Simulated Breakthrough of DFBA for Well \#3 Alternative Calibration 1

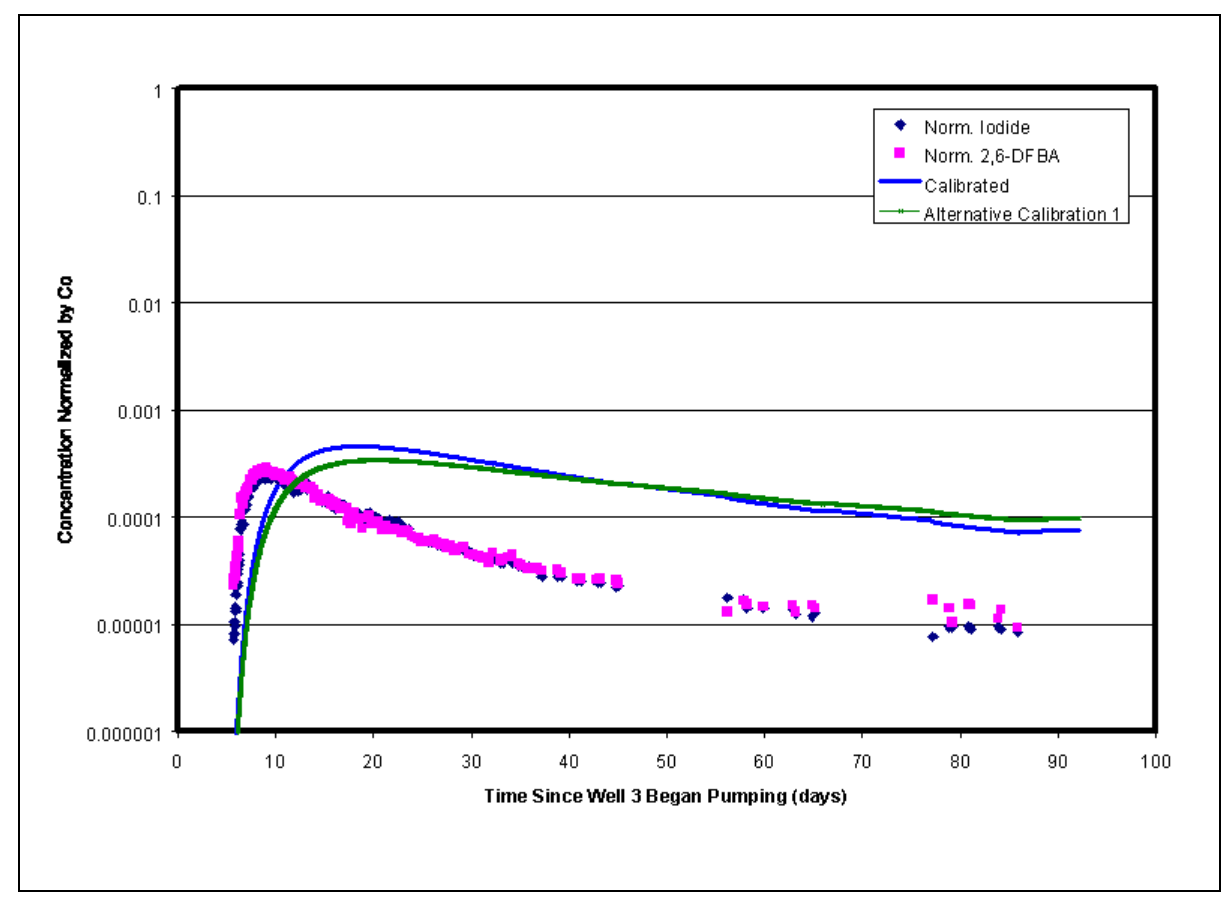

Figure 7-35

Simulated Breakthrough of DFBA for Well \#2 Alternative Calibration 1 


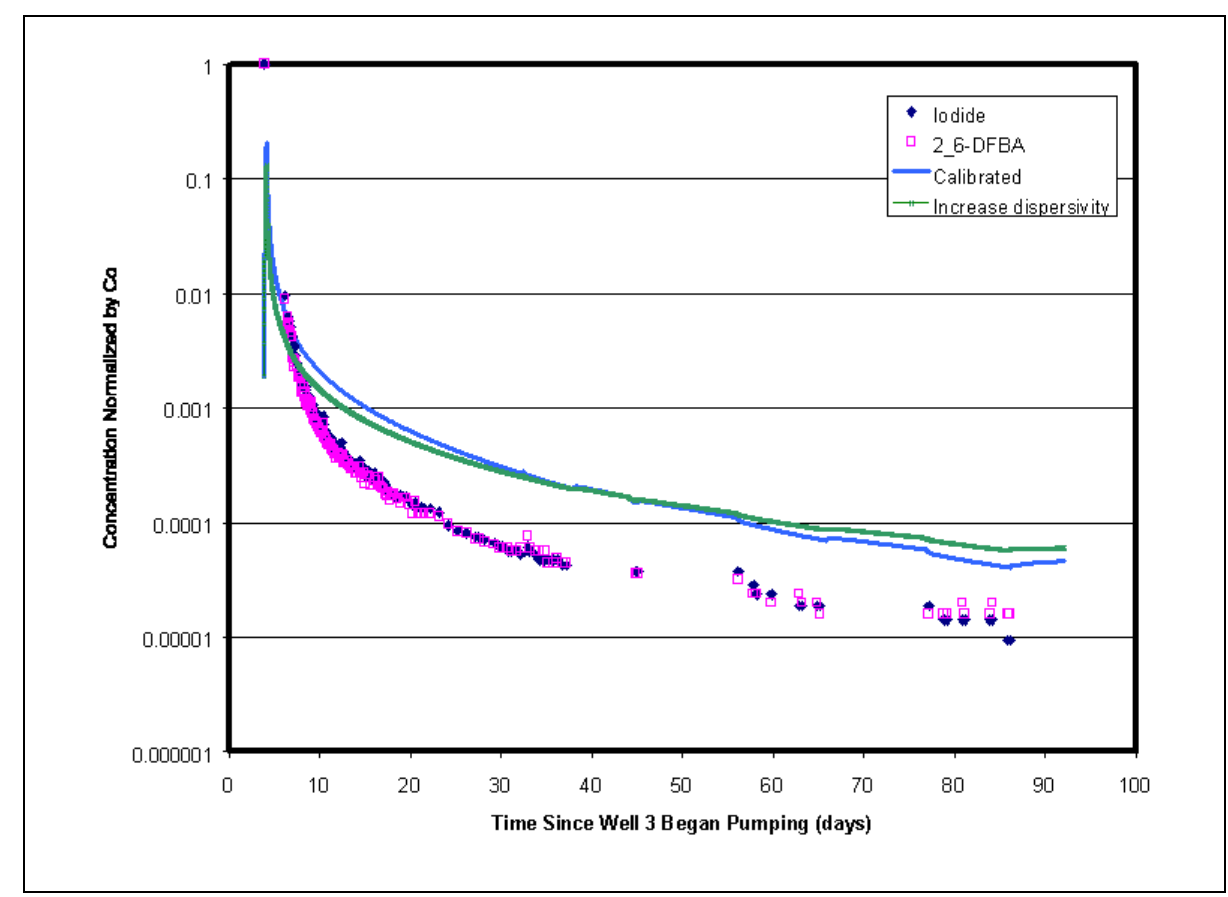

Figure 7-36

Simulated Breakthrough of DFBA for Well \#1 Alternative Calibration 1

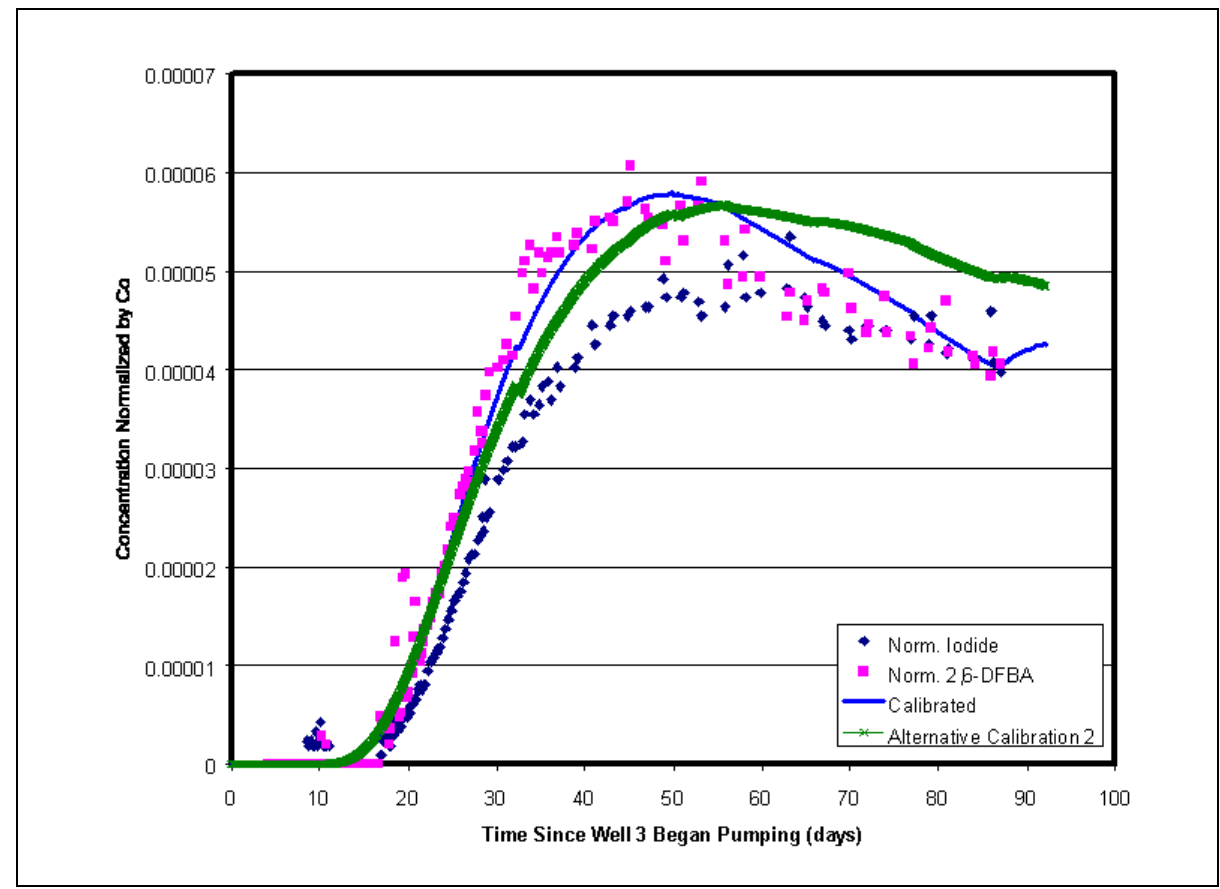

Figure 7-37

Simulated Breakthrough of DFBA for Well \#3 Alternative Calibration 2 


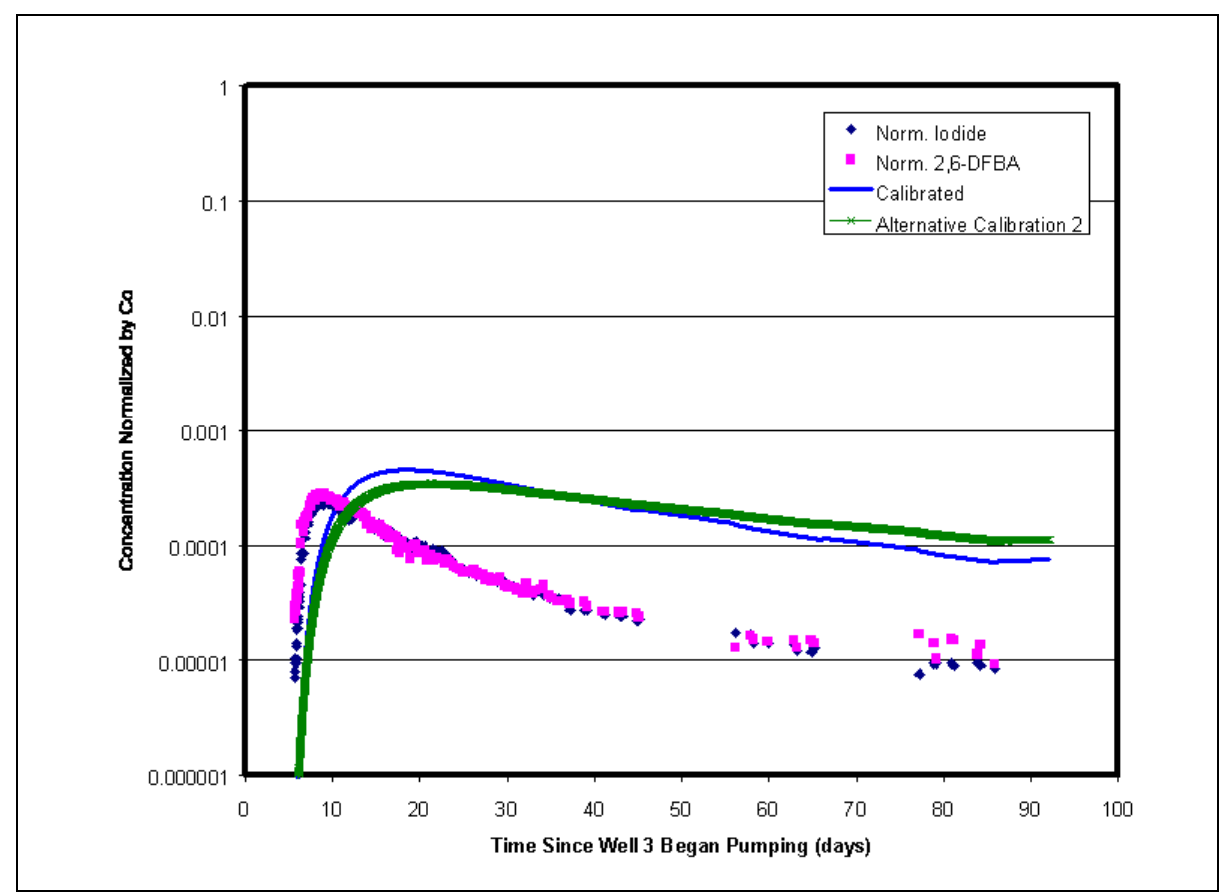

Figure 7-38

Simulated Breakthrough of DFBA for Well \#2 Alternative Calibration 2

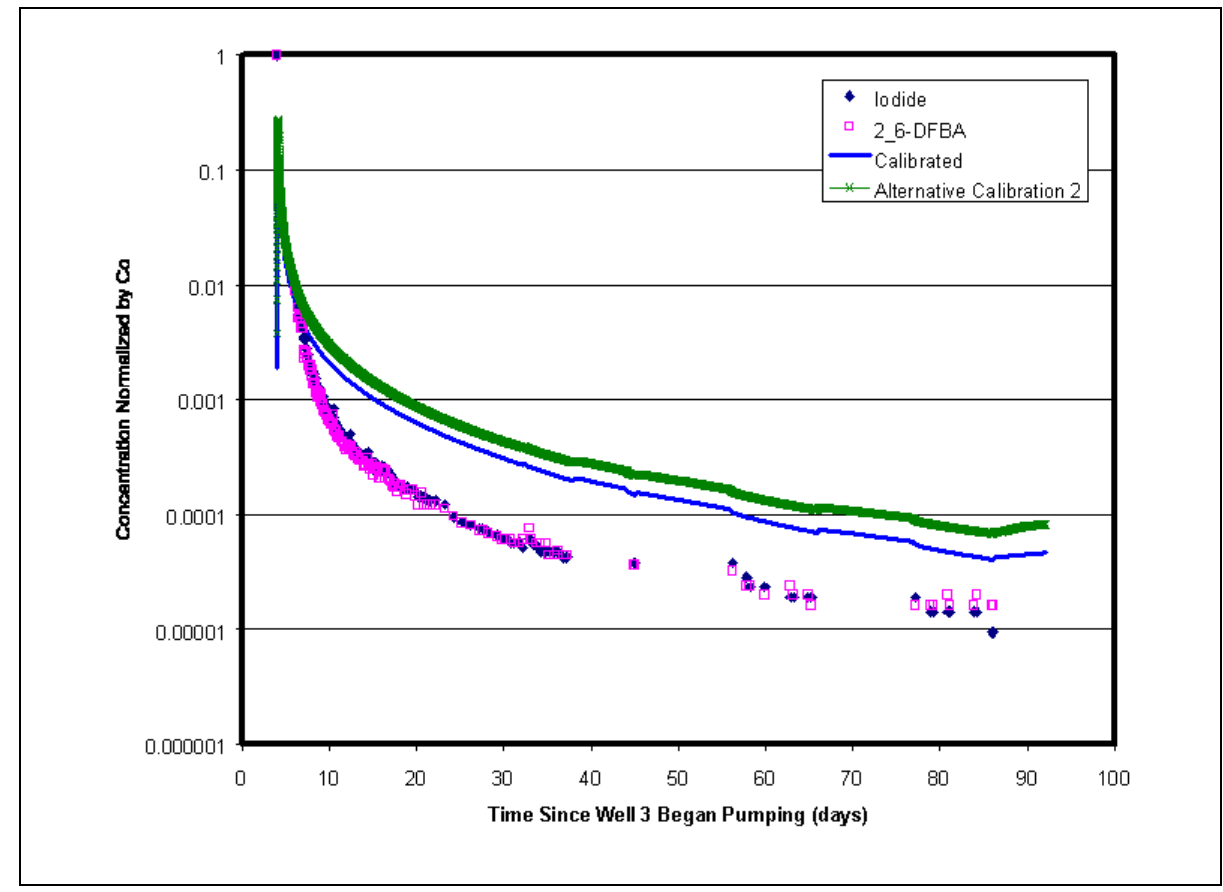

Figure 7-39

Simulated Breakthrough of DFBA for Well \#1 Alternative Calibration 2 
and \#1 are given in Figures 7-38 and 7-39. These fits are also not as good as in the calibrated case.

Alternative calibration 3 expanded the number of parameters varied, increasing the effective porosity, the dispersivities, and the proportion of mass injected into layer 4 . The resulting breakthrough curve for Well \#3, Figure 7-40, is a good match to the iodide breakthrough curve. The curves for Well \#2 and \#1 are shown in Figures 7-41 and 7-42, respectively. For both these wells, the recalibration is not as good as the final calibration.

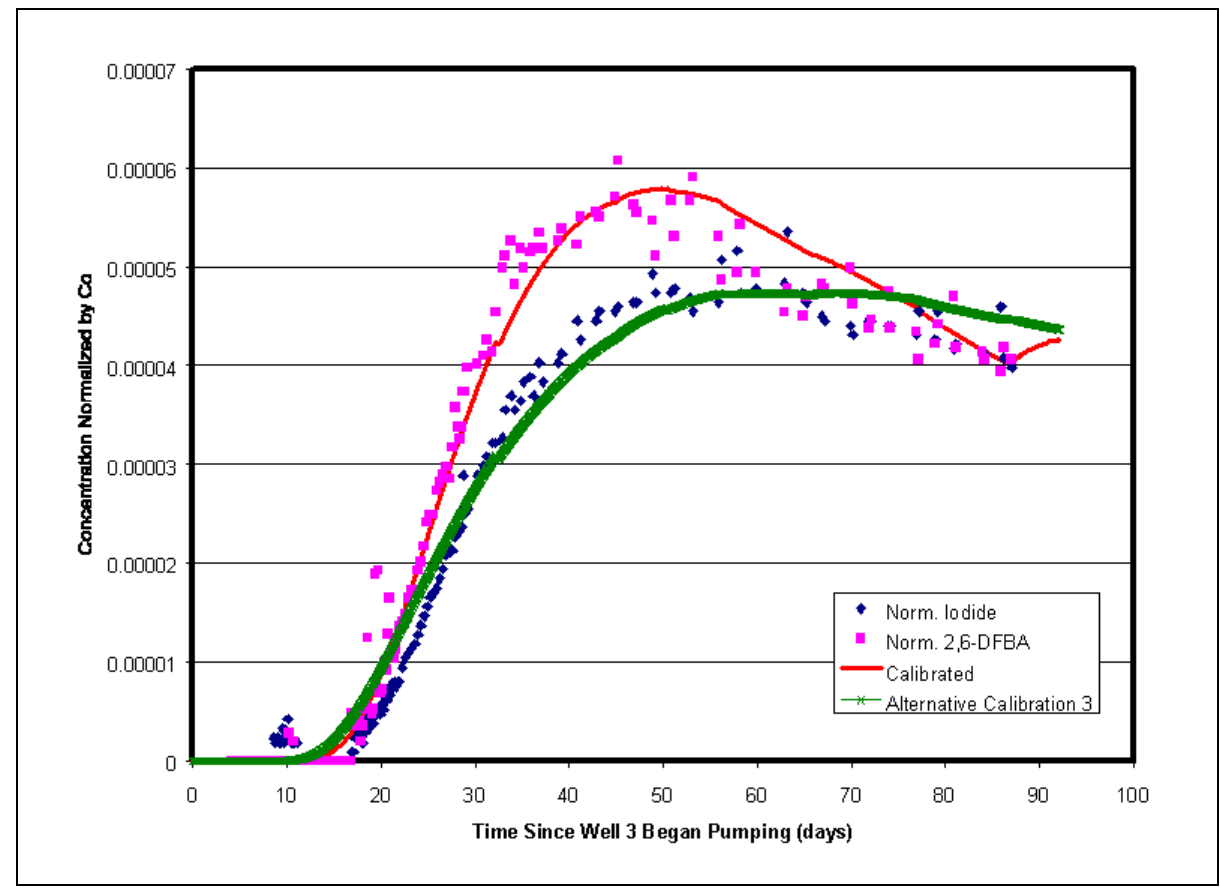

Figure 7-40

Simulated Breakthrough of DFBA for Well \#3 Alternative Calibration 3

The fourth alternative calibration is given in Figures 7-43, 7-44, and 7-45. In this recalibration, the dispersivity and porosity were kept at the larger values, but the injected mass and matrix diffusion coefficients were substantially reduced. In this case the result most dosely matches the DFBA curve. It is very interesting to note that the matrix diffusion value is about a factor of 100 smaller than in the final calibrated case. It is also notable that when the matrix diffusion coefficient is this small, a factor of three difference between iodide and DFBA could readily be achieved. Alternative calibration 4 represents all three breakthrough curves nearly as well as the final calibration. In addition it does so with the matrix diffusion in a range that is less sensitive and affords a greater difference between iodide and DFBA. 


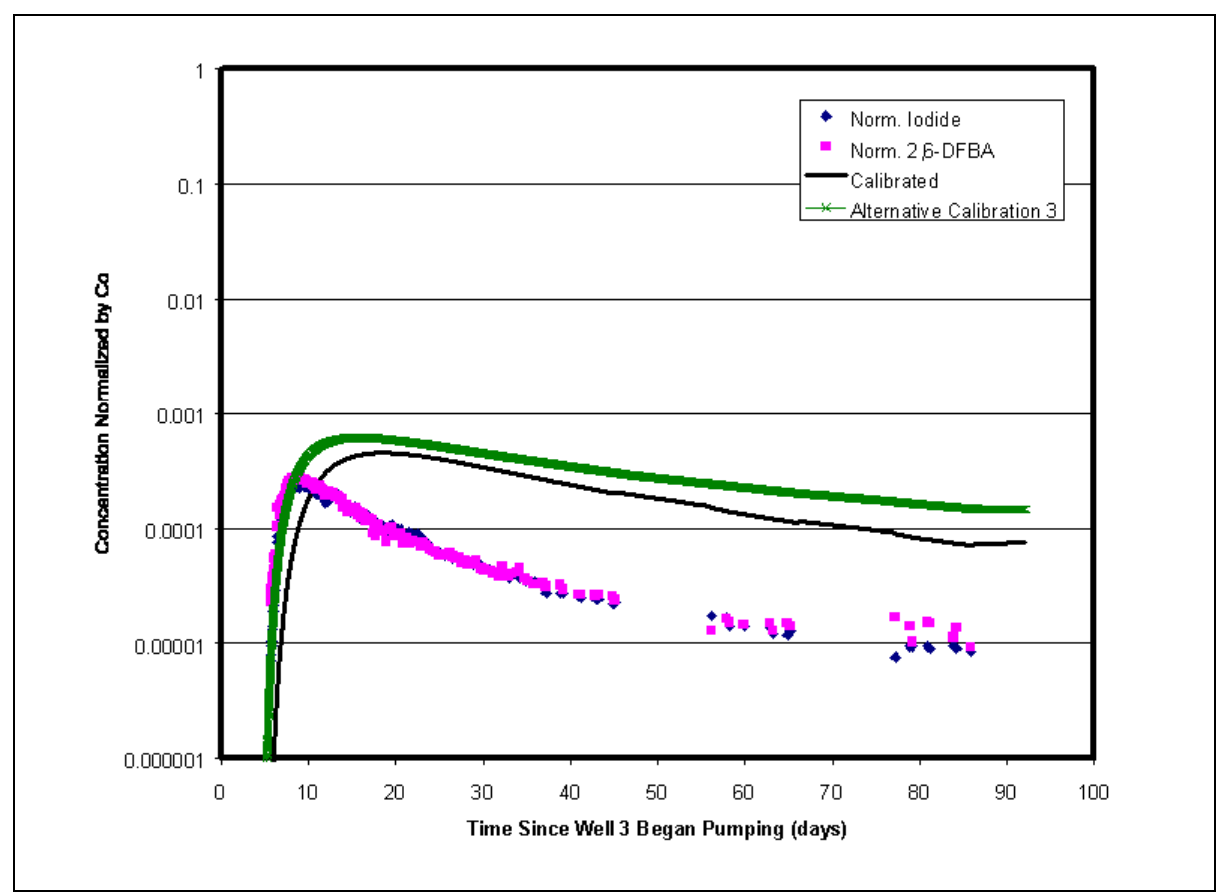

Figure 7-41

Simulated Breakthrough of DFBA for Well \#2 Alternative Calibration 3

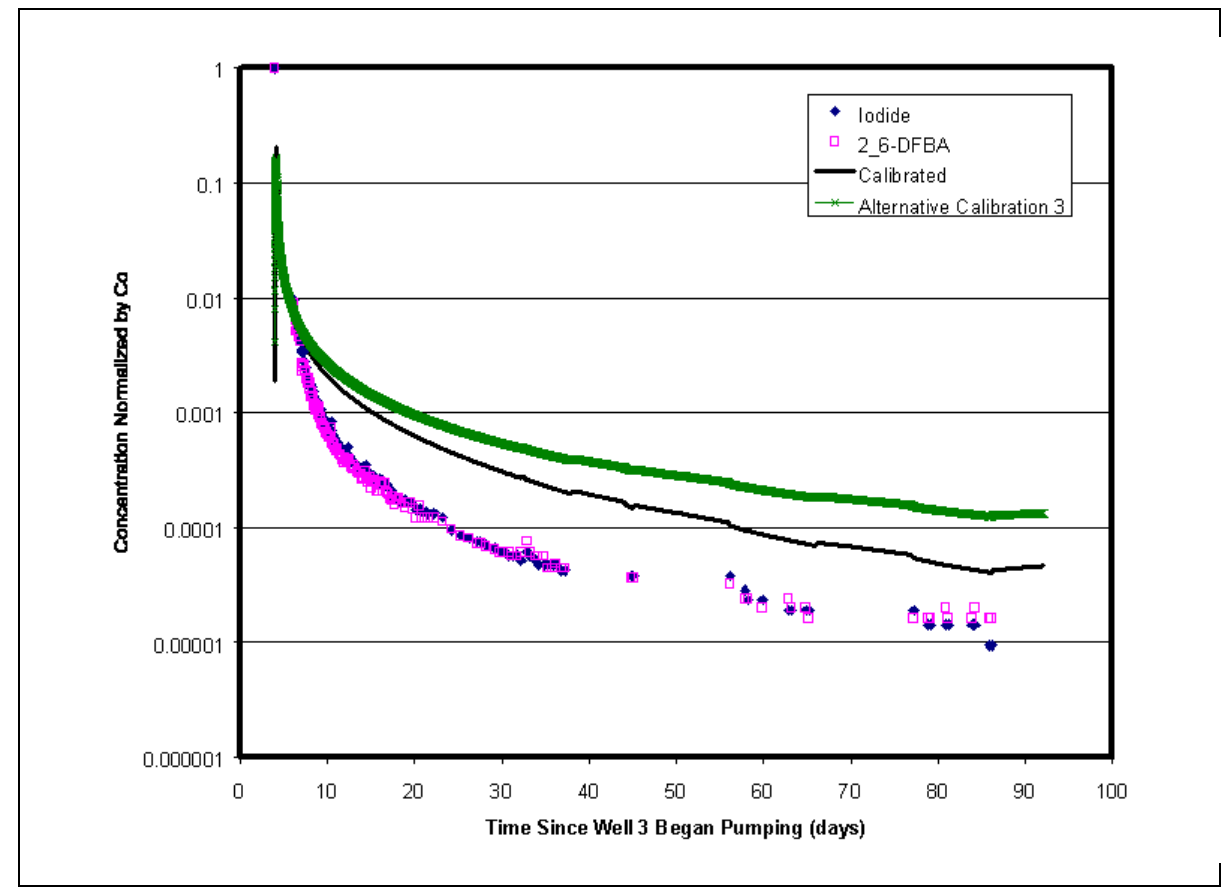

Figure 7-42

Simulated Breakthrough of DFBA for Well \#1 Alternative Calibration 3 


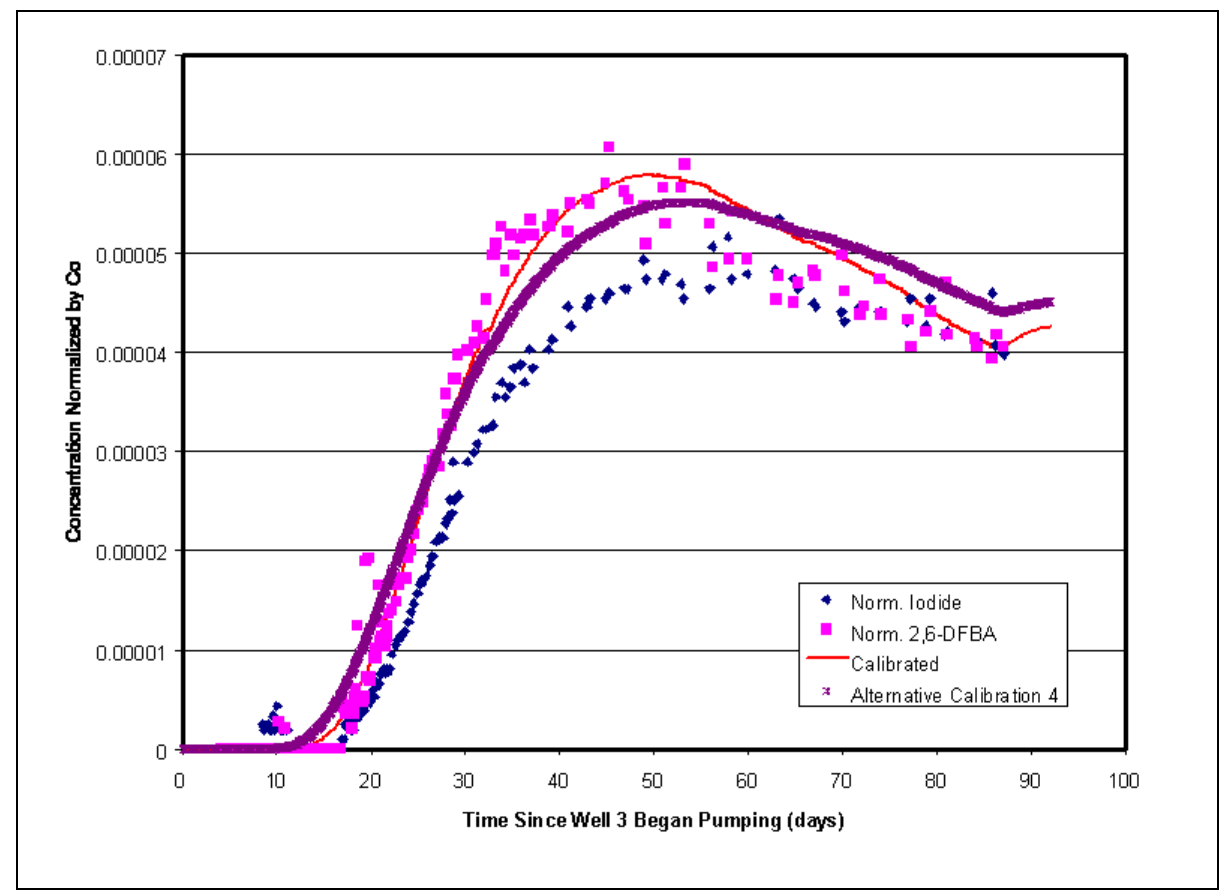

Figure 7-43

Simulated Breakthrough of DFBA for Well \#3 Alternative Calibration 4

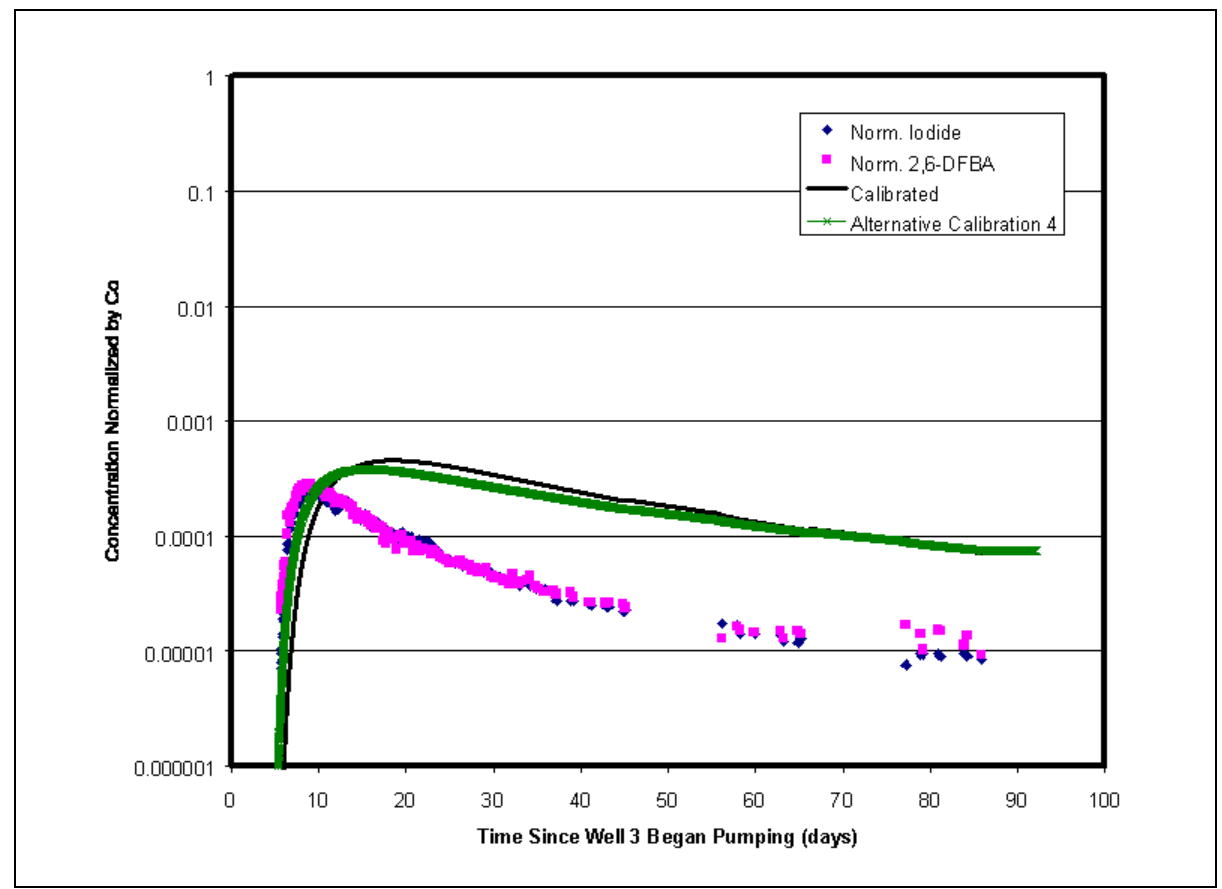

Figure 7-44

Simulated Breakthrough of DFBA for Well \#2 Alternative Calibration 4 


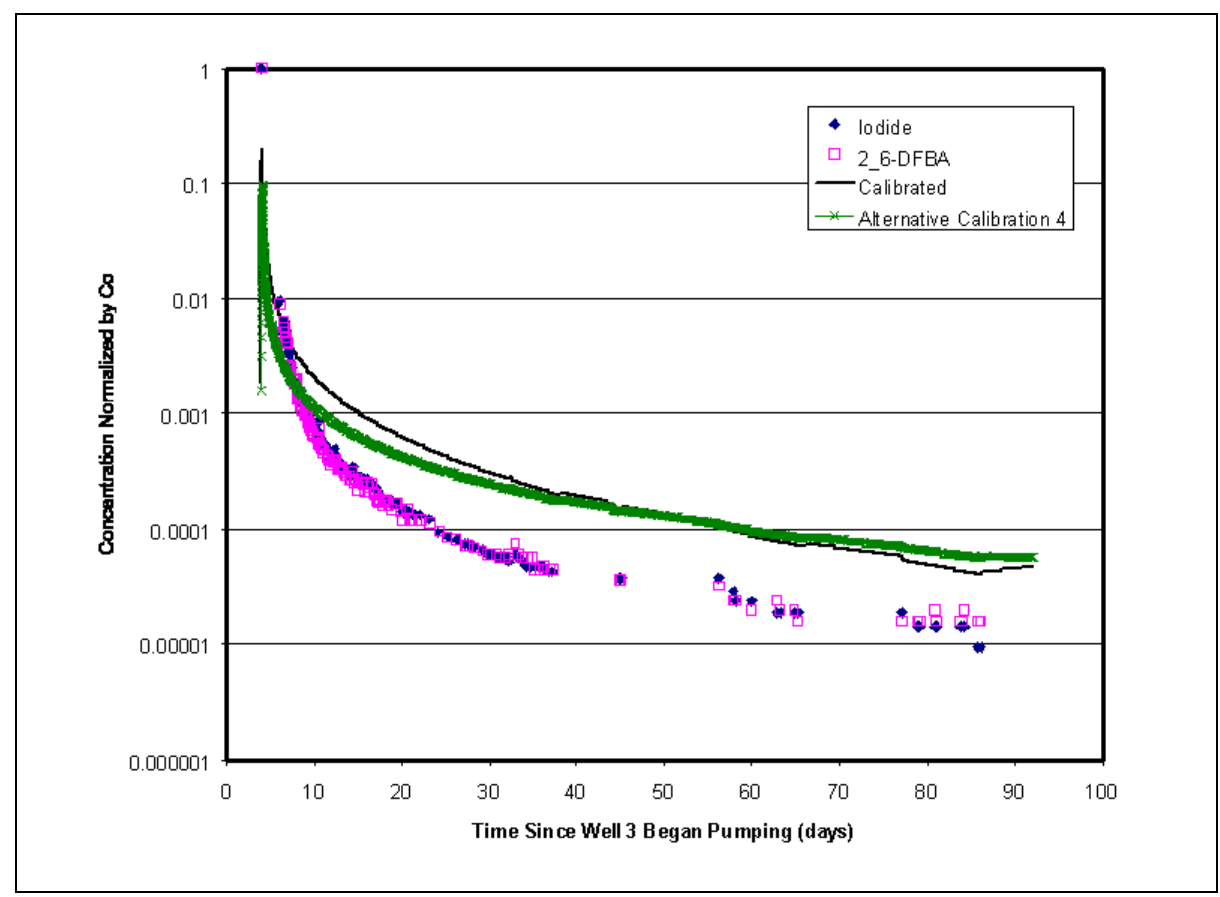

Figure 7-45

Simulated Breakthrough of DFBA for Well \#1 Alternative Calibration 4

The only drawback to alternative 4 is the large dispersion coefficients relative to the scale of the test.

Alternative calibration 5 was performed to assess the impact of changing several of the diffusion-related parameters such as the fracture spacing and the matrix porosity. Figure 7-46 is the resulting breakthrough curve for Well \#3 with a reduction in both the fracture spacing and the matrix porosity. The resulting diffusion coefficients are very similar to the final calibrated case.

The final alternative calibration, number 6 , has reduced fracture porosity and dispersivities. The tracer mass and the matrix diffusion coefficients are similar to the final calibrated values. The resulting breakthrough curves are given in Figures 7-47, 7-48, and 7-49. The fits to the observed data are about as good as the final calibration.

These alternative calibrations provide evidence that the calibration is not unique and that the parameters from the experiment have an associated error, or uncertainty. Based on these results, the following uncertainties are proposed. The hydraulic conductivity is uncertain by less than a factor of two because of the large sensitivity of the head response in the wells to the pumpage. The effective porosity is uncertain to about a factor of two. If the values differ more than a factor of 2, the calibration would be extremely difficult. The 


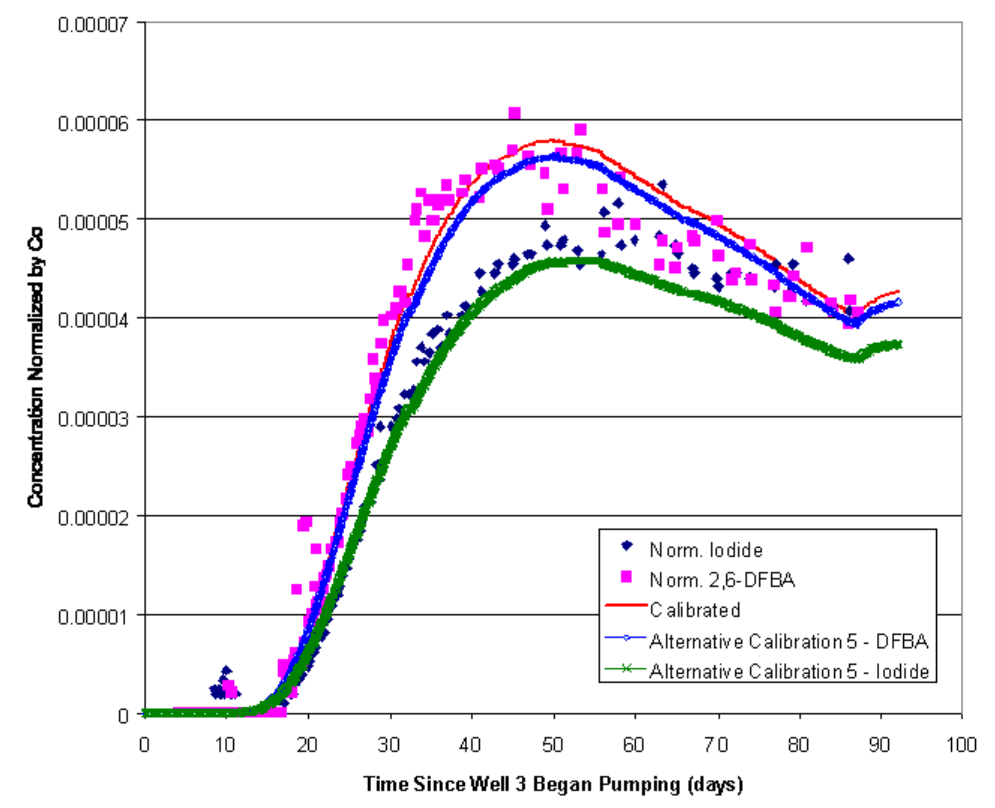

Figure 7-46

Simulated Breakthrough of DFBA for Well \#3 Alternative Calibration 5

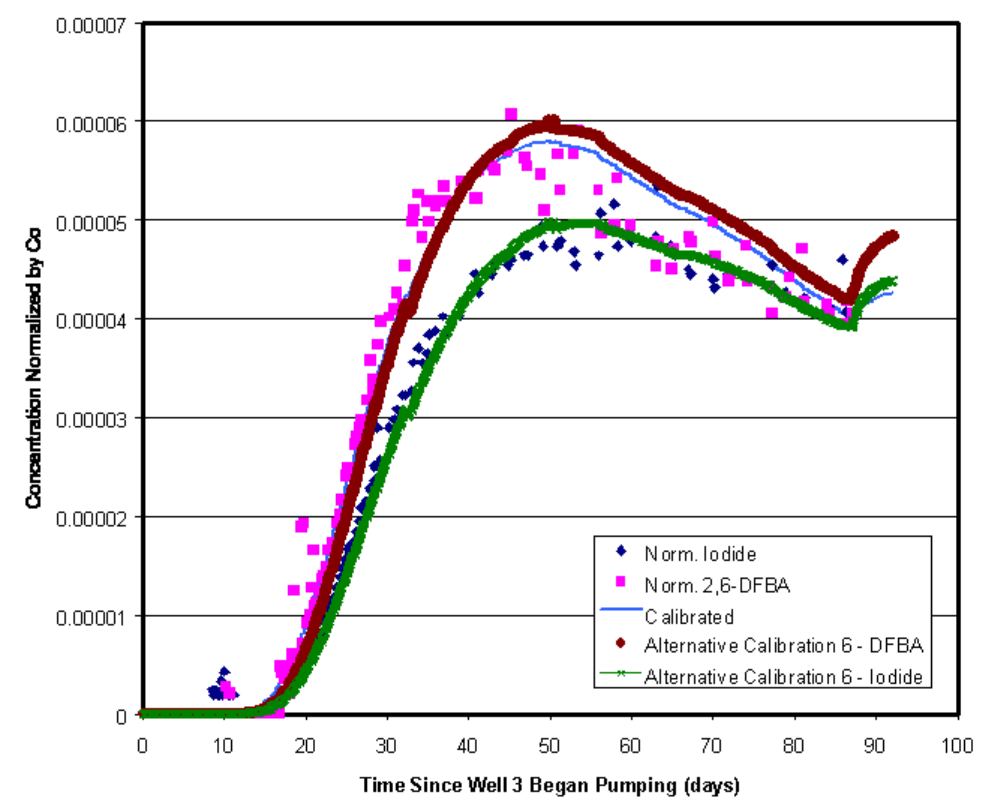

Figure 7-47

Simulated Breakthrough of DFBA for Well \#3 Alternative Calibration 6 


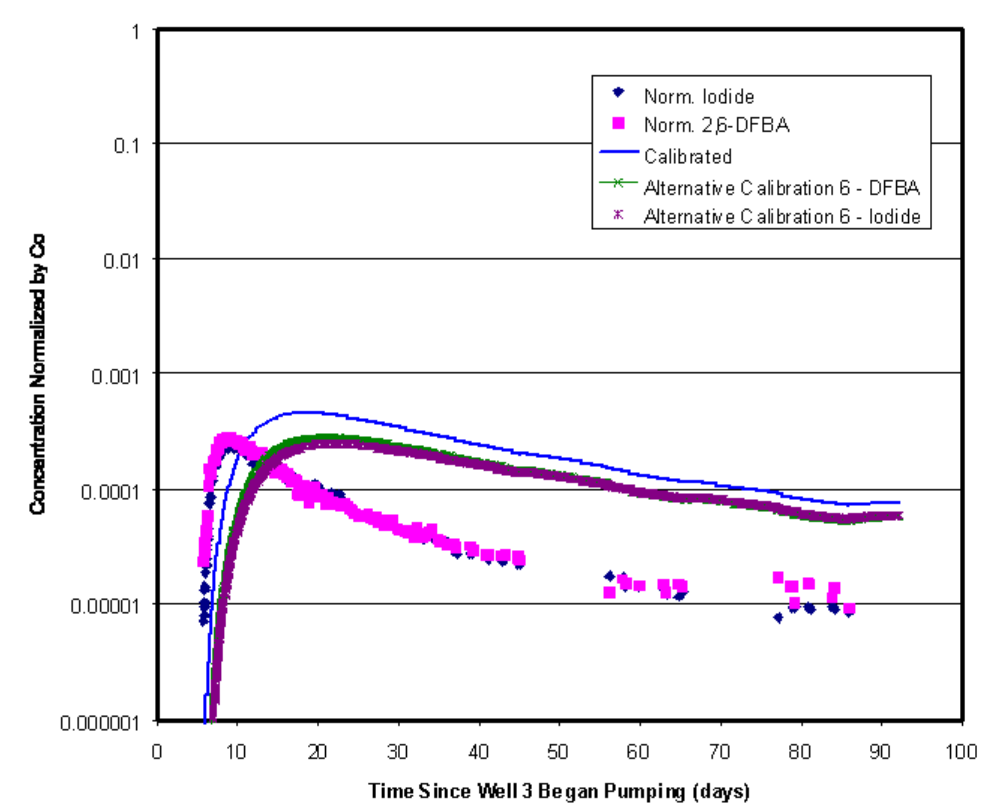

Figure 7-48

Simulated Breakthrough of DFBA for Well \#2 Alternative Calibration 6

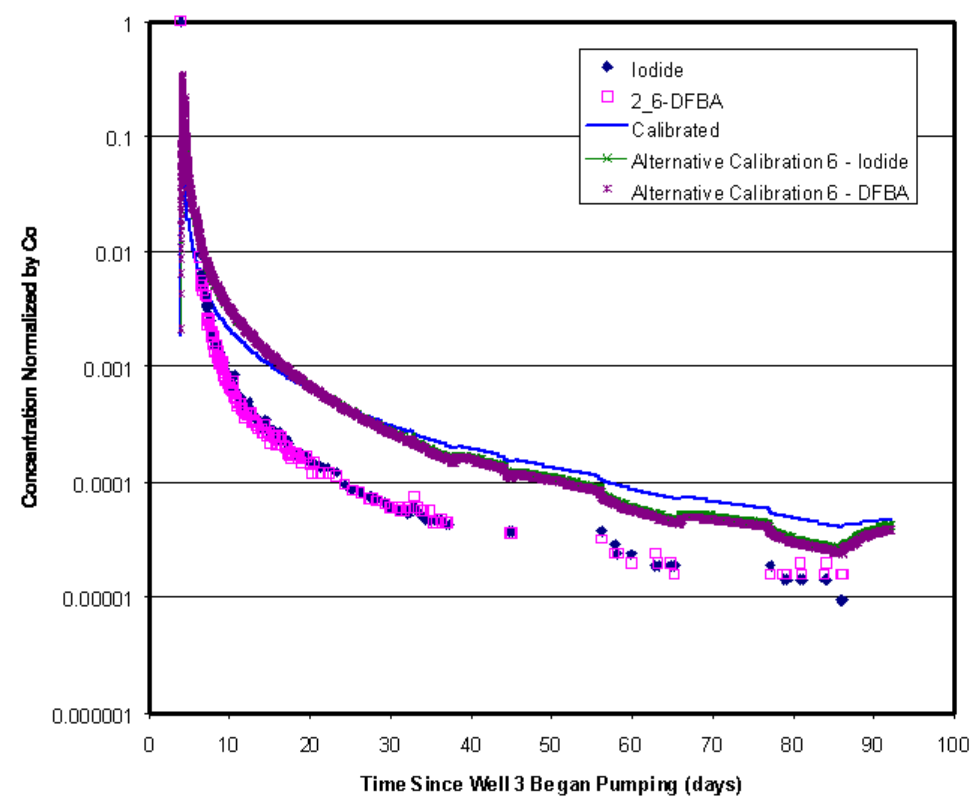

Figure 7-49

Simulated Breakthrough of DFBA for Well \#1 Alternative Calibration 6 
dispersivity is known within a factor of 5. Finally, the matrix diffusion coefficient has an uncertainty of at least one order of magnitude. These uncertainties are just for the parameter values obtained from the experiment, and likely underestimate the errors of extrapolating the test results to all of Pahute Mesa.

\subsection{Second Microsphere Peaks}

As noted in Section 3.5.10 the microsphere breakthrough curves for Well ER-20-6 \#3 had two peaks for each color microsphere. This phenomenon did not occur in the microsphere breakthrough in Well \#2. The rise to the second peak from the decline curve of the first peak in each case began at the same time, at 30 days elapsed time. The second peaks also occurred at the same time, at 37 days elapsed time. There is no clear reason for either the second peak or the coincident timing. One possible reason for the second peaks are alternate, longer (and consequently slower) flowpaths, resulting in second breakthrough curves superimposed on the first. However, this explanation does not readily account for the coincidence in the timing. The two colors of microspheres were injected in different wells at different times, and presumably would have taken somewhat different flowpaths to Well \#3. It seems unlikely that these separate factors would have combined in such a way as to produce such a close coincidence without some single, controlling factor.

Another speculative explanation is that the second peaks resulted from the release of filtered-out microspheres, triggered by some event. The event is presumed to have been some hydraulic change in the flow field that could physically affect the microspheres in the aquifer away from the wells. Examination of the production and drawdown records for Well \#3 finds that there was a stoppage of pumping at 30 days that coincided with the beginning of the rise to the second peaks.

Figure 7-50 shows the pumping record and the drawdown record for Well \#3 overlaid on the same time scale.

Note that the drawdown after resumption of pumping is approximately three meters less than before the stoppage. It has been speculated that this reduction in drawdown represents development of the well or the formation, possibly due to backflushing of the pump column into the well. This kind of before/after stoppage and drawdown change also occurred several times earlier in the experiment (at 15 and at 21 days), but this instance had the greatest associated drawdown change. Either the backflushing or changes in flow conditions associated with the decreased drawdown may have caused the resuspension of filtered-out microspheres.

That the microsphere concentrations began to increase immediately following the resumption of pumping suggests that resuspension must have occurred nearby the well. Figures 7-51 and 7-52 show the 


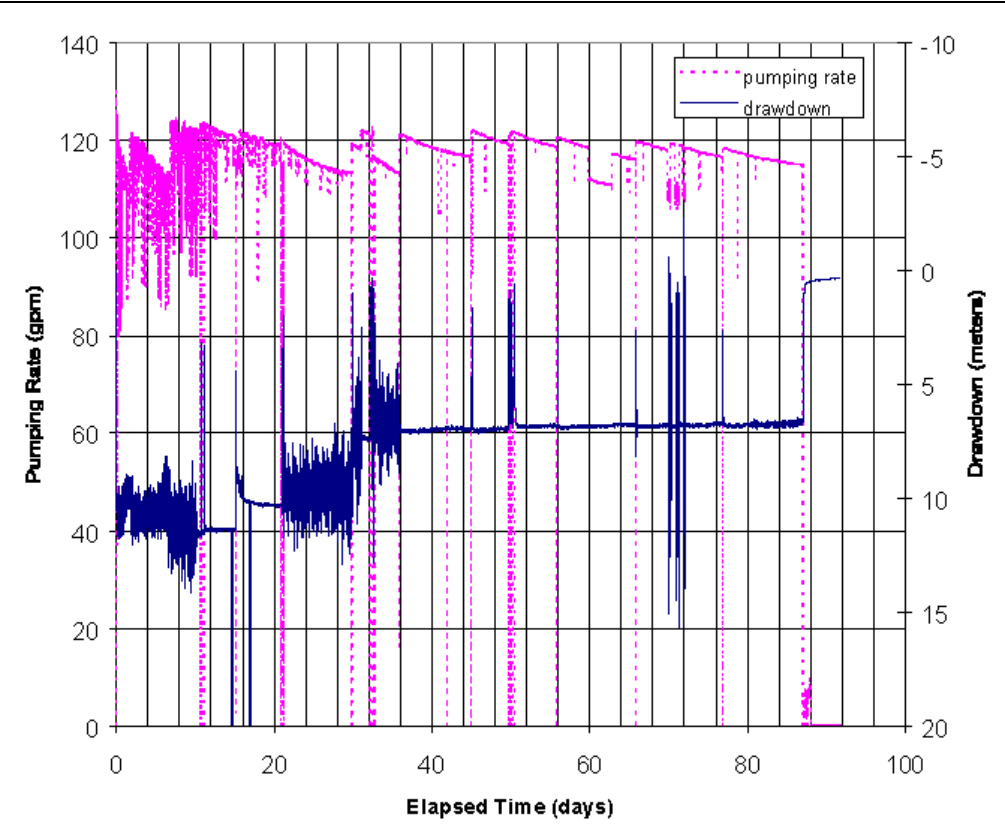

Figure 7-50

Pumping and Drawdown Records for Well \#3

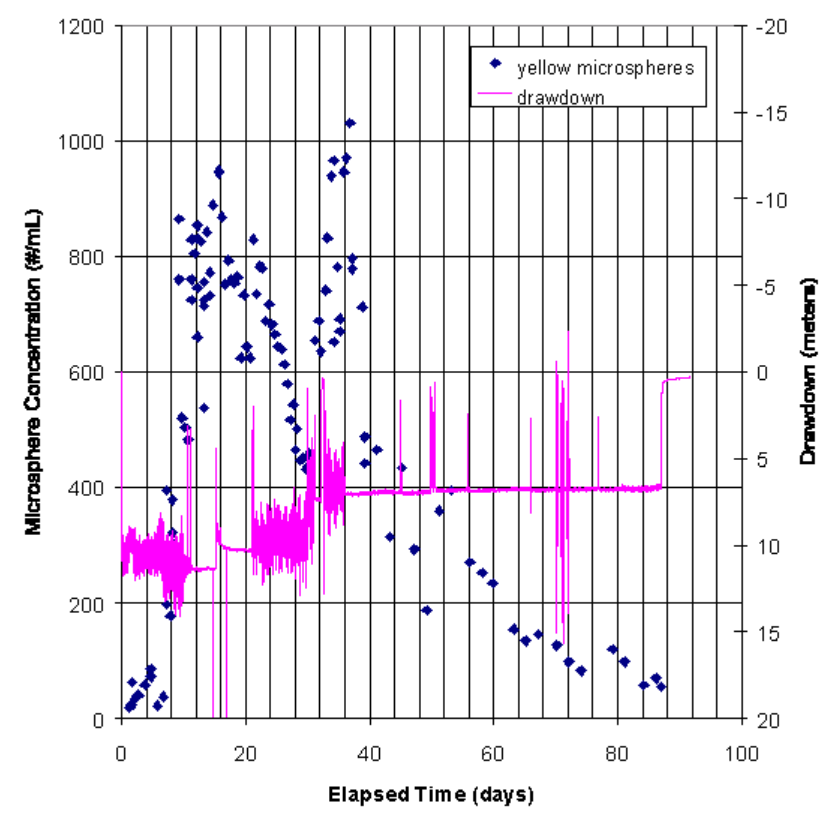

Figure 7-51

Yellow Microsphere Concentrations for Well \#3 Versus the Drawdown Record 


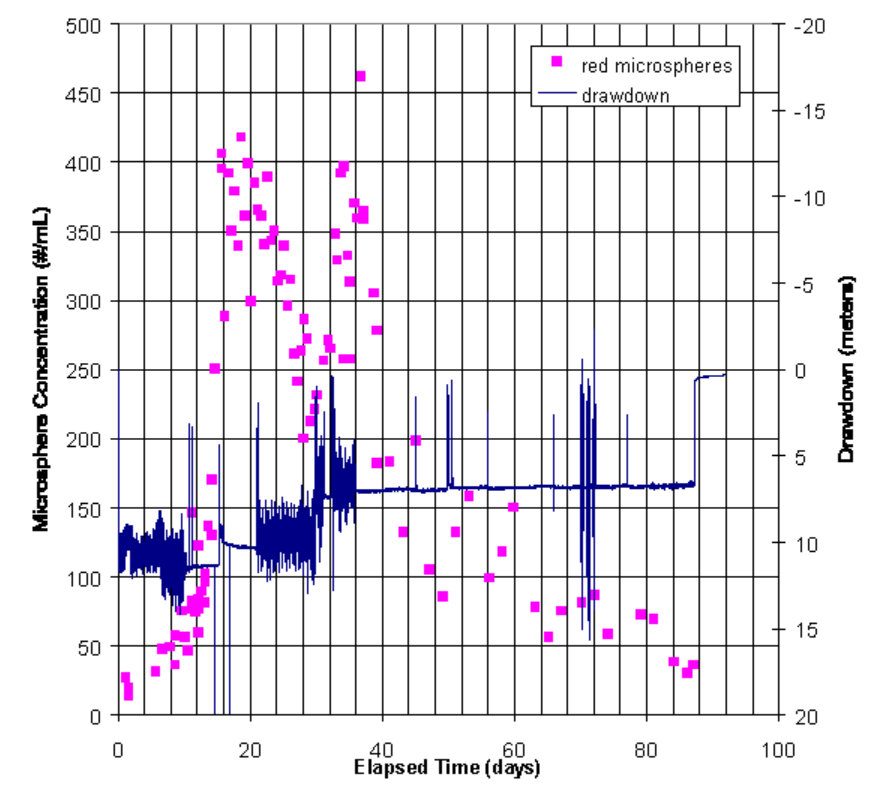

Figure 7-52

Red Microsphere Concentrations for Well \#3 Versus the Drawdown Record

microsphere concentrations in Well \#3 plotted against the drawdown record. The coincidence of the mi crosphere concentration curves with the pumping stoppage/reduced drawdown, and the coincidence of both microsphere curves are evident. That the second peaks took seven days to devel op suggests that resuspension occurred throughout a large area around the well rather than at one narrowly defined distance from the well.

The question may be asked why earlier instances of pump stoppage with drawdown reduction did not produce additional microsphere peaks. The answer may be that earlier instances occurred when the first microsphere peak was still developing. The microspheres would have just been arriving in the vicinity of the well and not yet have been filtered out en-mass. Also, the microsphere breakthrough curve was rising at this time, and any concentration increase resulting from resuspension would have been masked in the rising curve. The red microsphere breakthrough curve for Well \#3 does show a slope increase starting at 15 days that could be interpreted as this same phenomenon. The drawdown reduction for this instance was almost as large as at 30 days.

Neither of these explanations is offered as the definitive answer, but as speculations to foster further thinking. 


\subsection{Summary and Conclusions}

\subsection{Summary of Flow and Transport Model Results}

The drawdown response at the three BULLION FGE wells to pumping during the experiment was calibrated using the flow modules of the groundwater flow and transport code, MODFLOWT. The tracer breakthrough curves for the two organic acid tracers (DFBA and PFBA) and iodide were simulated for each of the three wells. The process began with calibration of the boundary fluxes of the model to reproduce the steady-state hydraulic head field. This process was hindered by a lack of hydraulic head data that made the location of specific contour lines somewhat difficult. General head boundaries were defined all around the BULLION FGE model and were adjusted to approximate the estimated water table contours. As was observed in the sensitivity analysis, the boundary fluxes had very little impact on the tracer breakthrough curves and a small impact on water levels when compared with some of the other parameters. The influence of the steady-state calibration on the tracer test results was very small. This means that errors in the steady-state fluxes do not negatively impact the tracer interpretation, but it also means that the tracer interpretation does not provide much insight into the hydraulic characteristics of the faults zones, particularly the West Greeley fault system.

The transient flow calibration involved the adjustment of the storage coefficient and hydraulic conductivity distribution to match the observed drawdown at each of the wells. The storage coefficient was set at the average of the three values obtained from the dual porosity analysis. Further refinement via calibration was not attempted. As was noted in the sensitivity analyses, the deviations from the 0.0003 value had only a minor effect on the calibrated breakthrough curves.

The hydraulic conductivity went through a greater number of adjustments before the final hydraulic conductivity distribution was attained. The average transmissivity from the interpretation of the drawdown response was about $250 \mathrm{~m}^{2} /$ day. Taking the saturated thickness to be about $100 \mathrm{~m}$, the mean hydraulic conductivity is about $2.5 \mathrm{~m} /$ day. From the interpretation of the drawdown data, the average horizontal anisotropy ratio was about 8 with the maximum value being aligned in the direction of a line between Well \#1 and Well \#3. Taking $2.5 \mathrm{~m} /$ day as the hydraulic conductivity in the major principal 
component direction, the corresponding value in the minor principal component direction is about $0.3 \mathrm{~m} / \mathrm{day}$. The calibrated model ended with an anisotropy ratio of 7 and values of $0.46 \mathrm{~m} /$ day and $3.2 \mathrm{~m} /$ day in the minor and major principal component directions, respectively. The direction of the major component axis, and the flow model grid were aligned with Wells \#1 to \#3, in agreement with the interpretation of the drawdown analysis. The calibrated model values are larger than the values derived from analysis of the drawdown responses, as given in Table 4-1 by a factor of 1.3 to 1.5. These differences are quite small and may result from the differences in time frame. The interpretation of the drawdown data came from the first 8 to 10 hours of the drawdown response whereas the calibrated model simulated flow and transport out to 92 days. In addition, the final calibrated drawdowns were slightly smaller than observed in Wells \#1 and \#3, so the calibrated hydraulic conductivity could have been reduced slightly.

An additional component of the calibration was the addition of the high hydraulic conductivity zone in the vicinity of Well \#1. This was added for two reasons. First, the observed drawdown response at Well \#1 to its own pumping was much smaller than the response of Well \#2 to the Well $\# 2$ pumping. This suggested a region of higher hydraulic conductivity around Well \#1. Secondly, the initial attempts at calibration produced tracer concentrations at Well \#1 that were much too high. The flushing of tracer from Well \#1 could have been accomplished by either decreasing the porosity or increasing the flux via the hydraulic conductivity. Because the subdued drawdown response at Well \#1 to its own pumpage was better reproduced with the high $\mathrm{K}$ zone approach, that is what was used in the final calibrated simulations.

The sensitivity analyses indicated that the flow simulation was sensitive to reductions in hydraulic conductivity, so only a very small change (much less than a factor of two) would have been needed to match the observed drawdowns. Removal of the high $\mathrm{K}$ region also produced tracer breakthroughs that were inconsistent with observed data. It is believed, then, that the calibrated hydraulic conductivity values are well constrained by the observed data.

The transport parameters from the calibration of the transport model are summarized in Table 8-1 (same as Table 7-1).

Three parameters control the diffusion of tracer into the matrix. The rate of tracer diffusion is controlled by the matrix diffusion coefficient in the one-dimensional diffusion equation for the matrix. The distance of tracer migration into the matrix is a function of both the diffusion coefficient and the matrix porosity. For the simulation of the BULLION FGE, the tracer diffused only a few centimeters into the matrix, so the infinite matrix assumption could have been used as well. The mass of tracer diffused into the matrix is also a function of the fracture spacing. The smaller the spacing, the greater surface area 
Table 8-1

Transport Parameter Values Determined via Calibration of the BULLION FGE Model

\begin{tabular}{|c|c|c|c|}
\hline Parameter & $\begin{array}{c}\text { DFBA transport from } \\
\text { Well \#1 to Well \#3 }\end{array}$ & $\begin{array}{c}\text { lodide transport from } \\
\text { Well \#1 to Well \#2 }\end{array}$ & $\begin{array}{c}\text { PFBA transport from } \\
\text { Well \#2 to Well \#3 }\end{array}$ \\
\hline \hline Fracture Spacing (m) & 0.25 & 0.25 & 0.25 \\
\hline Matrix Porosity & 0.35 & 0.35 & 0.35 \\
\hline $\begin{array}{c}\text { Effective Matrix } \\
\text { Diffusion Coefficient } \\
\text { (m²/day) }\end{array}$ & $1.2 \times 10^{-6}$ & $1.6 \times 10^{-6}$ & $1.35 \times 10^{-6}$ \\
\hline $\begin{array}{c}\text { Dispersivity } \\
\text { (Long./Transverse/ } \\
\text { Vertical) (m) }\end{array}$ & $10 / 3 / 2$ & $10 / 3 / 2$ & $10 / 3 / 2$ \\
\hline $\begin{array}{c}\text { Proportion of Mass } \\
\text { injected in } \\
\text { HSUs 4 and 6 }\end{array}$ & $35 \% / 65 \%$ & $35 \% / 65 \%$ & $75 \% / 25 \%$ \\
\hline Effective Porosity & 0.018 & 0.018 & 0.023 \\
\hline
\end{tabular}

available for diffusion. At the FGE site, a value of $0.25 \mathrm{~m}$ was used for the fracture spacing. Prothro et al. (1997) examined the core from Well \#1 and found the average fracture spacing in the lava and flow breccia units to average 8.5 fractures per meter of core. This equates to a fracture spacing of $0.12 \mathrm{~m}$. Also noted by Prothro et al., the majority of fractures dip at greater than 30 degrees. Therefore, the $0.12 \mathrm{~m}$ value could be consi dered a maximum value. The value of $0.25 \mathrm{~m}$ used in the model is more in line with the average fracture spacing from other core in similar rock on Pahute Mesa where the value of $2.2 \mathrm{~m}$ per vertical meter was more typical. This equates to a $0.45 \mathrm{~m}$ fracture spacing, again uncorrected to fracture dip. Drellack et al. (1997) presents a survey of available information on volcanic cores for Pahute Mesa. Because the core in Well \#1 is likely influenced by the nearby BULLION test, the rock is expected to be more fractured than native rock further away from the test itself. Overall, the true fracture spacing is unknown and could vary from values as small as $0.05 \mathrm{~m}$ (corrected for dip) to as much as $0.5 \mathrm{~m}$. The value of 0.25 is near the center of this range. The matrix porosity may be larger than what would be expected for a lava or flow breccia. In alternative calibration 5 , the fracture spacing was reduced to $0.15 \mathrm{~m}$ at the same time matrix porosity was reduced to 0.10 . The matrix diffusion coefficients, $1.6 \times 10^{-6}$ and $2.3 \times 10^{-6} \mathrm{~m}^{2} /$ day for I odide and DFBA, respectively, were slightly larger than in the calibrated case. In total, it should be noted than changes in any of the three parameters (i.e., fracture spacing, matrix porosity, and matrix diffusion coefficient) will change the amount of tracer mass diffused into the matrix. Therefore, the values of the matrix diffusion coefficient should be viewed as being very uncertain as exemplified by alternative calibration 4 where the diffusion coefficient was reduced nearly 2 orders of magnitude while increasing effective porosity and dispersivities. 
The ratio of the diffusion coefficients for the DFBA and iodide injected at Well \#1 is about 1.3, much smaller than the ratio of 3 given by Reimus and Haga (1998) for Yucca Mountain tuffs. During calibration, numerous attempts were made to obtain a ratio of 3 , but without success, except for alternative calibration 4 where a much smaller diffusion coefficient was used. There is a trade-off between fitting the ratio of diffusion coefficients and the magnitude of the diffusion coefficient. The magnitude of the calibrated diffusion coefficients are in the range of values measured at other sites and at other locations on the Nevada Test Site. The ratio is determined from laboratory measurements on freshly cut surfaces and may not be representative of in situ conditions. As additional data are collected regarding matrix diffusion on Pahute Mesa, the parameter sets can be updated. Until then, it has been assumed in this work that the ratios may not be representative of in situ conditions and that the magnitude of the diffusion coefficient needed to attain a ratio of 3 is too small compared with measurements. As additional data become available, the diffusion parameters can be updated.

The longitudinal dispersivity value of $10 \mathrm{~m}$ is in the range of measured values summarized by Gelhar et al., 1992 for tests at scales of about $100 \mathrm{~m}$. The horizontal transverse value of $3 \mathrm{~m}$ is also in the range of other observations. The vertical dispersivity of $1 \mathrm{~m}$ may be too large, but it probably had almost no effect on the simulations because each of the HSU s was equivalent to a model layer and of significant thickness. The tracer concentration was averaged over each layer, so there was no vertical concentration gradient within each layer. The layer (HSU 5) between the model aquifer units was of low permeability and it is expected that there is only minor interaction between HSUs 4 and 6 .

The longitudinal dispersivity may still be too large to simulate the movement and spreading of Well \#1 tracers at Well \#2. This was evident in the sensitivity analyses of dispersivity where it appears that the relatively large dispersive flux was causing tracer migration upgradient from Well \#l against the direction of groundwater flow in the simulation (Figures 7-9 through 7-14). This situation is physically unrealistic and points out a limitation of the application of the advection/dispersion equation.

The effective porosity of almost two percent is larger than was used in the regional groundwater transport model (DOE/NV, 1997), but is consistent with the greater observed fracturing at the FGE site. Even at two percent, the effective porosity is more representative of a fractured aquifer than porous media. During the sensitivity analysis, it was clear a factor of two change in its value produced a significantly different result. However, as observed in alternative calibrations 3, 4, and 6 , a factor of two change in porosity can be compensated by adjustment to other parameters such as dispersivity or the portion of mass in layer 4. 
The final parameter was the amount of mass injected into HSU 4. This proportion varied significantly from Well \#1 to Well \#2. During the calibration it was determined that some of the tracer mass was injected into the lower aquifer (HSU 6) while the remainder entered HSU 4. A combination of greater dissolved solids and a colder temperature means that the tracer fluid was of greater density than the ambient groundwater. Evidence of downward vertical flow after drilling suggests that the hydraulic head in HSU 6 is less than in HSU 4. This would also lead to some of the tracer flowing into HSU 6. Upon pumping, the lower head in HSU 6 would limit the amount of water withdrawn. The discrete bailer samples from Wells \#1 and \#2 provide evidence that the tracer concentration in the upper and lower sections of the injection wells were essentially the same during pumping, but with the concentration in the upper section slightly higher than in the lower section. One explanation for the similar concentration in the upper and lower portions of the well is that water continued to move downward into HSU 6, even during pumping. Unfortunately, individual head measurements are not available in the two aquifers.

The alternative calibrations in which multiple parameters were varied provides insights into the amount of certainty that can be attributed to each parameter. In alternative 1, the amount of mass injected into HSU 4 was nearly doubled at the same time the diffusion coefficient was increased by a factor of about 4 . In alternative 2 both parameters were again increased and similar calibration was achieved. Changes of a factor of two to the porosity and dispersion coefficients could be compensated for by adjusting other parameters as shown in alternatives 3,4 , and 6 . There are too many inter depencies of parameters for a single unique calibration to have been achieved. Nonetheless, the approximate uncertainty in the parameter values have been estimated and conclusions regarding the experiment have been drawn.

\subsection{Conclusions}

A variety of conclusions can be drawn from the BULLION Forced-Gradient Experiment pertaining to the site of the experiment, transport processes, and transport parameter values. These will be discussed in the following sections.

\subsubsection{Groundwater Chemistry}

Groundwater from each well was sampled a total of four times. The chemistry of the samples is similar both between wells, and among the sampling events. The chemistry is typical of waters from a volcanic environment and similar to other Pahute Mesa locations. The water is an oxygenated, sodium bicarbonate type water, with low total dissolved 
solids content and an alkaline $\mathrm{pH}$. Dissolved trace metal

concentrations are low and bel ow levels of regulatory concern.

\subsubsection{Geology and Aquifer Hydraulics}

Two lava-flow units of the mafic-poor unit of the Calico Hills were tested as part of the BULLION FGE. These units are quite variable, both laterally and vertically. The flow through the aquifers is fracture dominated as evidenced by the dual porosity drawdown solution, the relatively large horizontal anisotropy ratio, and the relatively small effective porosity. At the scale of this experiment (90 to $130 \mathrm{~m}$ ) a porous media equivalent solution was able to adequately simulate the drawdown response to pumping. For flow simulations, it is safe to conclude that porous media solutions are likely to be acceptable for future flow simulations. However, since the small-scale heterogeneity of the fracture system was not reproduced in the model, exact simulation of the observed responses should not be expected.

The bulk hydraulic conductivity values obtained from the experiment are within the range of values summarized in the regional groundwater model documentation packages. Therefore, the BULLION FGE hydraulic conductivity values provide confidence that the current range of values is reasonable for fractured volcanic aquifers.

The hydrologic effects of faults could not be demonstrated during the calibration. Although the West Greeley fault was treated as a conduit for flow and a source of water, it could just as easily have been treated as impermeable without changing the tracer calibration. The sensitivity analyses showed that the model was not sensitive to changes in the fault properties.

\subsubsection{Radionuclide Transport from the BULLION Cavity}

Tritium concentrations declined from initial, el evated levels in Wells \#1 and $\# 2$ to less than $10,000 \mathrm{pCi} / \mathrm{L}$, and there was no indication of other radionuclides migrating from the test cavity during the course of the experiment. Tritium concentrations in Well \#3 did increase from approximately $1,000 \mathrm{pCi} / \mathrm{L}$ to around $4,000 \mathrm{pCi} / \mathrm{L}$. This result suggests that the original interpretation of the presence of radionuclides in the boreholes, especially tritium, was incorrect. Radionuclides had been observed in the HSU s overlying the lava-flow aquifers during the drilling of the three test wells, and tritium had initially been present at elevated levels in water produced from Wells \#1 and \#2.

The dedine of tritium concentrations and the absence of other radionuclides may be the result of one or more factors. The geologic cross section indicates the cavity intersects the lava-flow aquifer used 
for the experiment. However, there is little direct evidence for this geologic interpretation. The BULLION cavity may not intersect the lava flow aquifer, or the lava flow aquifer may not extend beneath the cavity. Or, if the cavity does intersect the lava flow aquifer, the cavity may be effectively sealed on the bottom by glass and not leak radionuclides into the aquifer. Also, it was mentioned earlier that the planning modeling indicated that transport from the cavity would take much longer than even the extended length of the experiment. The expected breakthrough of radionuclides from the cavity assumed that transport of radionuclides from the cavity had been in progress for some years prior to the start of the experiment. The lack of radionuclides may be a time issue; they may not have transported from the test cavity to the wells during the duration of the experiment. It has been postulated that the presence of radionuclides observed initially may have been due to placement by prompt injection at the time of the test. Regardless of the reason, there was no observation of the migration of radionuclides from the BULLION cavity.

\subsubsection{Tracer and Solute Transport}

Fracture dominated transport was observed at the BULLION FGE site. The low effective porosity (2 percent), the clear evidence of matrix diffusion, and the physical evidence in coreall support the conclusion of fracture dominated transport. At the scale of the experiment (about $130 \mathrm{~m}$ ) the dual continuum approached utilized in MODF LOWT was able to reproducethe tracer breakthrough response in the pumped well. At the injection wells, the model was less able to reproduce the observed tracer breakthrough curves, due in large part to the constant dispersivities used in the model. At the corrective action unit scale, the usage of porous media, or dual porosity approaches should produce acceptable and accurate predictions of radionuclide concentrations. At small scales, where local heterogeneities become more important, fracture flow approaches may be needed.

The effective porosity values are much larger than have been assumed to date for the regional transport simulations. The FGE porosity values fall within the hypothesized ranges of values for the regional simulations, but near the larger end of the range. This may indicate that fracture porosities of the fractured volcanics may be much larger than have been assumed in large scale modeling to date.

The dispersivity values all fall within ranges already observed in the literature. The dispersivity has larger uncertainty than porosity, perhaps as large as a factor of 5 .

The matrix diffusion parameters, particularly the fracture spacing and the diffusion coefficient are less well constrained. Nonetheless, the mechanism of matrix diffusion, was demonstrated to be valid by the experiment. The observed breakthrough curves cannot be explained 
without invoking matrix diffusion. The ratio of the diffusion coefficients of iodide to DFBA was about a factor of 1.3 to 1.4., but would be larger if an alternative calibration using a much smaller diffusion coefficient were used. The calibrated range of effective diffusion coefficients was similar to ranges selected during the value of information study. The only exception to this is alternative calibration 4 for which a much smaller diffusion coefficient was determined. The calibrated ratio is less than was expected based on core studies at Yucca Mountain. At this time, it is not possible to know how applicable the Yucca Mountain studies are to the BULLION FGE site. Therefore, it is best to conclude that the mechanism of matrix diffusion has been shown to exist at the FGE site, but that is it difficult to parameterize the diffusion accurately at this time.

\subsubsection{Microsphere/Colloid Transport}

The microspheres showed a much more erratic behavior than did the dissolved species. The microspheres are influenced by fracture conditions to a greater extent than the dissolved tracers. An initial attempt to simulate microsphere transport with a first order filtration mechanism proved to be a poor fit to the data. The microspheres proved that colloidal size particles move in the fractured lava-flow aquifers over scales of at least $100 \mathrm{~m}$. It is also clear that much more work is needed to better understand the mechanisms that control colloidal size particle transport in the aquifers. For example, a resuspension mechanism is going to be necessary because a resuspension phenomenon was observed in the microsphere data.

\subsection{Implications of the BULLION FGE Results for CAU Scale Modeling}

The BULLION FGE experiment was the first forced-gradient tracer experiment with a controlled source to be successfully conducted on Pahute Mesa. Several key features of the FGE experiment have implications for the CAU modeling of Pahute Mesa. Fractured volcanic aquifer units have relatively high hydraulic conductivities, even when contained within generally bedded and lower permeability units. This is consistent with the results of the regional flow model where more heterogeneous units such as the tuff cones where assigned hydraulic conductivity values similar to the volcanic aquifer units such as the Timber Mountain Aquifer.

The microspheres demonstrated that colloidal size particles will transport within the fractured volcanic units. Unfortunately, the filtration model of colloid movement is over simplified and additional mechanisms, such as mechanic resuspension, are needed to better simulate colloid transport. The movement of natural colloids is more complicated that the microspheres because of surface chemical 
reactions. Nonetheless, the transport of colloids will likely need to be considered during the CAU modeling based on the FGE results.

The application of porous media equivalent models is appropriate for simulations on the scale of the CAU. Matrix diffusion, which is part of many sophisticated models, has been shown to be an important mechanism in the aquifers of Pahute Mesa.

The resulting transport parameters derived from the F GE suggest ambient groundwater velocities and corresponding solute transport at velocities that are smaller than many of the more conservative simulations already performed at the regional scale. For example, the porosity of about 0.02 from the F GE experiment is nearly at the top of the range of porosity values used in the Value of I nformation Analysis (0.0001 to 0.03). The F GE results will allow for a smaller range and larger values for porosity to be used for CAU scale simulations.

The opposite occurs with respect to the matrix diffusion coefficient. The matrix diffusion coefficient, about $2.0 \times 10^{-6} \mathrm{~m}^{2} /$ day determined from FGE is nearly at the bottom of the range used for the $V$ alue of I nformation Analysis $\left(1.7 \times 10^{-6}\right.$ to $2.6 \times 10^{-5} \mathrm{~m}^{2} /$ day). These numbers are not directly comparable, however, because other parameters, particularly the fracture spacing differ significantly. The fracture FGE simulations was $0.25 \mathrm{~m}$, at the bottom of the range of $0.2 \mathrm{~m}$ to $5.8 \mathrm{~m}$ used in the VOI. To maintain the same amount of mass going into the matrix, the diffusion coefficient increases with increases in fracture spacing. The smaller matrix diffusion coefficient values at the FGE site may be reflective of the smaller fracture spacing. Regardless, the results of the FGE experiment will allow for narrower ranges of values during the CAU modeling. 


\section{This Page Intentionally Left Blank}




\subsection{References}

American Society for Testing and Materials. 1985. Standard for Metric Practice, E 380-85. Philadelphia, PA.

ASTM, see American Society for Testing and M aterials.

DOE/NV, see U.S. Department of E nergy, Nevada Operations Office.

Drellack, S.L., J r., and L.B. Prothro. 1997. Descriptive Narrative for the Hydrogeologic Model of Western and Central Pahute Mesa Corrective Action Units. Las Vegas, NV: Bechtel Nevada.

Drellack, S.L., J r., and L.B. Prothro, R.E. Roberson, B.A. Shier, and E.H. Price. 1997. Analysis of Fracture in Volcanic Cores from Pahute Mesa, Nevada Test Site, DOE/NV/117118-160.

Las Vegas, NV: Bechtel Nevada.

Duffield, G.M., J .L. Benegar, and D.S. Ward. 1996. MODF LOWT, A M odular Three-Dimensional Groundwater Flow and Transport Model, User's Manual, Version 1.1., Sterling, VA:

GeoTrans Inc.

Gelhar, L.W., C. Welty, and K.R. Rehfeldt. 1992. “A Critical Review of Data on Field-Scale Dispersion in Aquifers." In Water Resources Research, Vol. 28 (7): 1955-1974.

Washington, DC: American Geophysical Union.

Geraghty and Miller, Inc. 1991. Documentation for AQTESOLV, Aquifer Test Solver, Version 1.00 Documentation. Herndon, VA.

IT, see IT Corporation.

IT Corporation. 1995. Drilling and Completion Criteria for Underground Test Area Operable Unit Well Cluster ER-20-6, DOE/NV/10972-129. Prepared for the U.S. Department of Energy, Nevada Operations Office. Las Vegas, NV.

IT Corporation. 1996. Criteria for theForced-Gradient Experiment at the BULLION Event Location, ITLV/10972-182. Las Vegas, NV.

IT Corporation. 1997. BULLION F orced-Gradient Experiment I mplementation PIan, ITLV/10972-195. Las Vegas, NV.

McDonald, M.G., and A.W. Harbaugh. 1988. "A Modular Three-Dimensional Finite Difference Ground-Water-Flow Model." In U.S. Geological Survey Techniques of Water Resources Investigations, Book 6, Chapter A1. Denver, CO: U.S. Geological Survey. 
Moench, A. F. 1984. "Double-Porosity Models for a Fissured Groundwater Reservoir with Fracture Skin." In Water Resources Research, Vol. 20, (7): 831-846. Washington, DC: American Geophysical Union.

Neuman, S.P. 1990. "Universal Scaling of Hydraulic Conductivities and Dispersivities in Geologic Media." In Water Resources Research, Vol. 26, (8): 1749-1758. Washington, DC: American Geophysical Union.

O'Hagan, M.D., and R.J . Laczniak. 1996. Ground-water Levels Beneath Eastern Pahute Mesa and Vicinity, Nevada Test Site, NyeCounty, Nevada, Water-Resources I nvestigations Report 96-4042. Prepared in cooperation with U.S. Department of Energy under Interagency Agreement DE-AI 08-91NV11040. Carson City, NV: U.S. Geological Survey.

Prothro, L.B., M.J . Townsend, S.L. Drellack, J r., and J .L. Gonzales. 1997. Processing and Geologic Analysis of Conventional Cores from Well ER-20-6 \#1, Nevada Test Site, DOE/NV11718-162. Las Vegas, NV: Bechtel Nevada.

Reimus, P.W., and M.J . Haga. 1998. Preliminary Analysis of Tracer Responses in the BULLION Forced-Gradient Experiment. Los Alamos, NM: Los Alamos National Laboratory.

U.S. Department of Energy, Nevada Operations Office. 1996. Underground Test Area Subproject Waste Management PIan, DOE/NV-343. Prepared by IT Corporation. Las Vegas, NV.

U.S. Department of Energy, Nevada Operations Office. 1997. Regional Groundwater Flow and Tritium Transport Modeling and Risk Assessment of the Underground Test Area, Nevada Test Site, Nevada, DOE/NV-477. Prepared by IT Corporation. Las Vegas, NV.

U.S. Department of Energy, Nevada Operations Office. 1998. Completion Report for Well Cluster ER-20-6, DOE/NV-467. Prepared by IT Corporation. Las Vegas, NV.

Welty, C., and L.W. Gelhar. 1989. Evaluation of Longitudinal Dispersivity from Tracer Test Data, R89-05. Cambridge, MA: Massachusetts I nstitute of Technology. 
Appendix A

Geologic Model for the BULLION FGE Model 


\section{This Page Intentionally Left Blank}




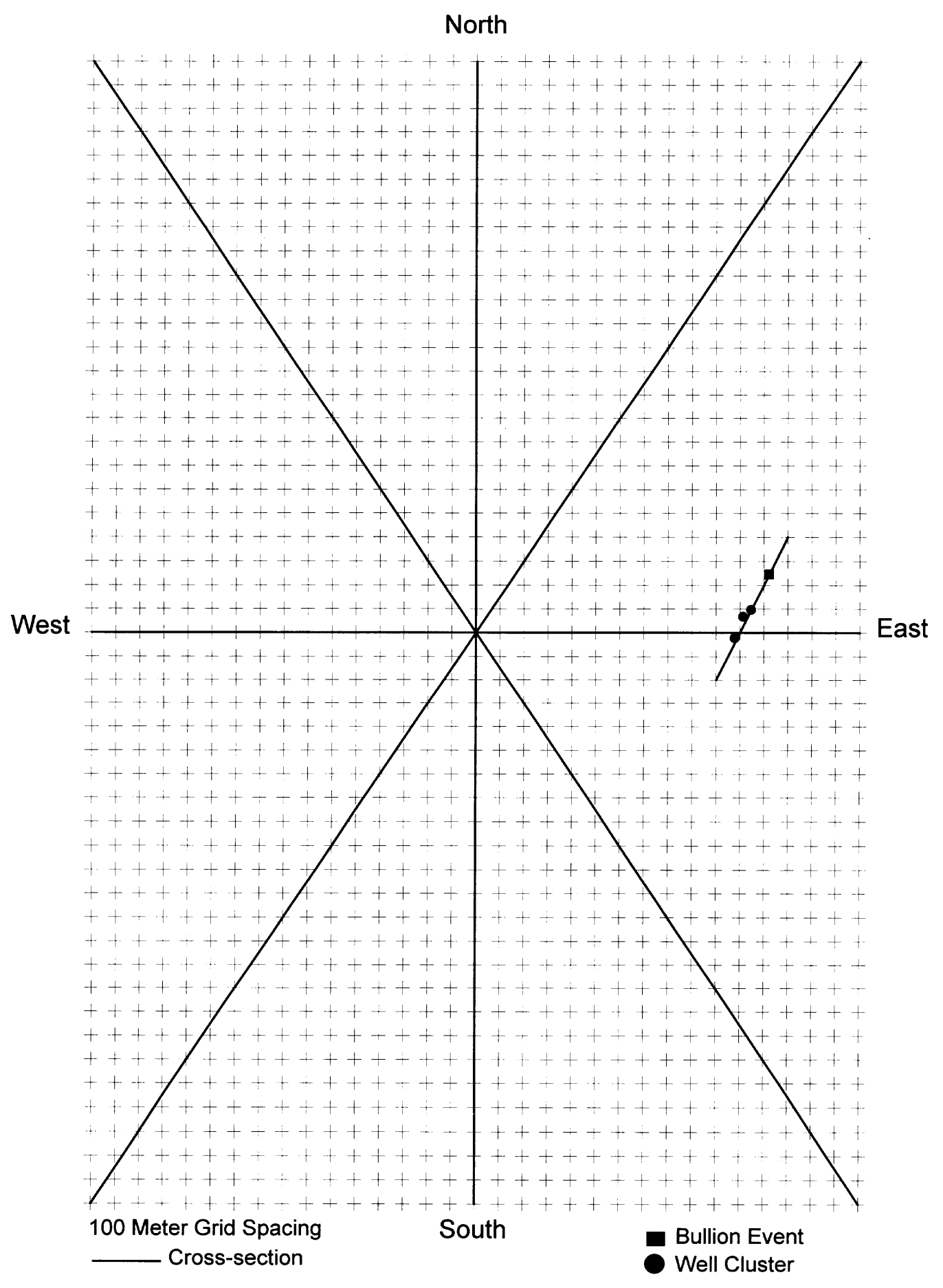

Figure A-1

Location of BULLION Geologic Model Cross Sections 


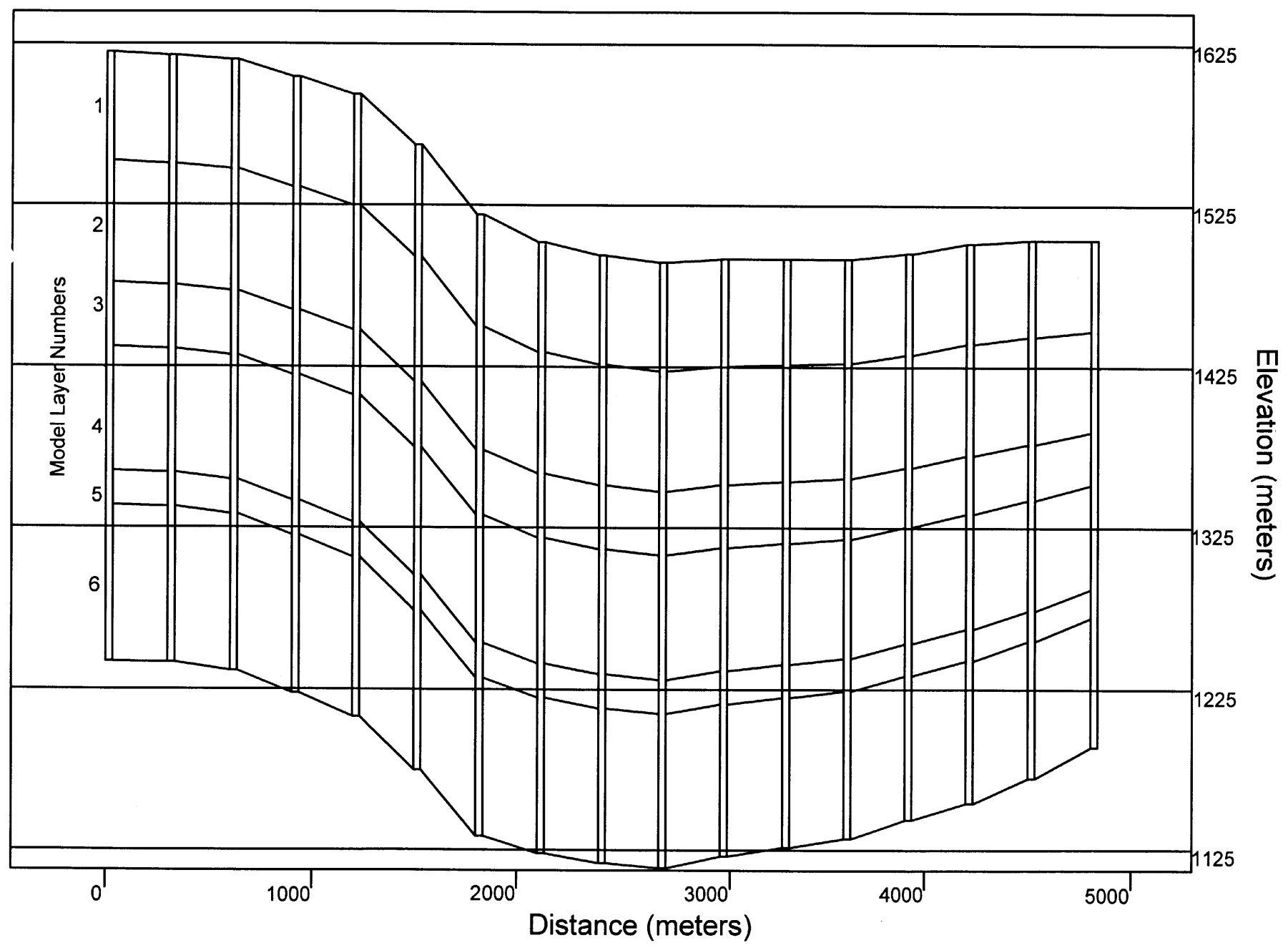

Figure A-2

BULLION Geologic Model Cross-Section, North-South 


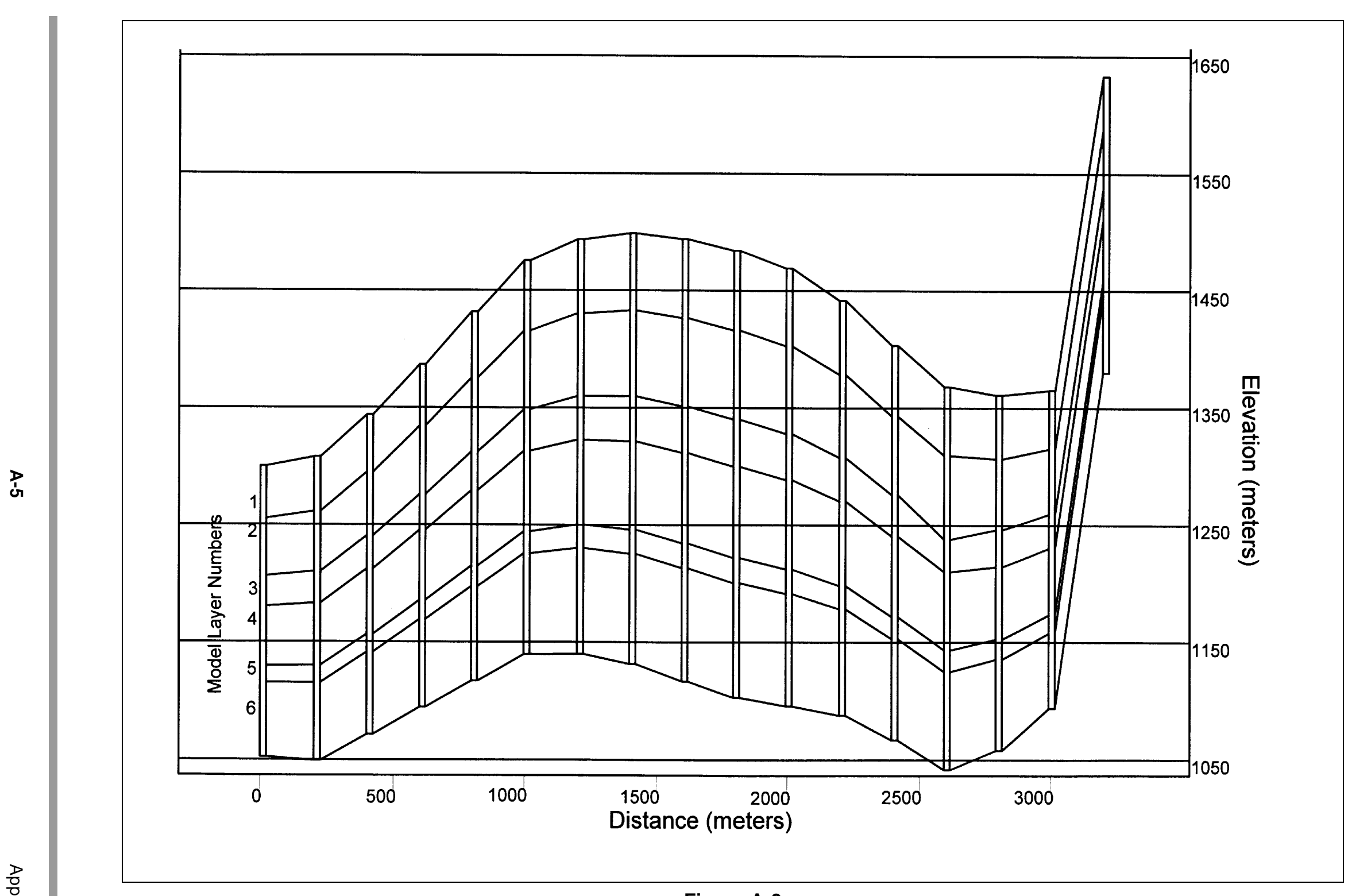

Figure A-3

BULLION Geologic Model Cross-Section, East-West

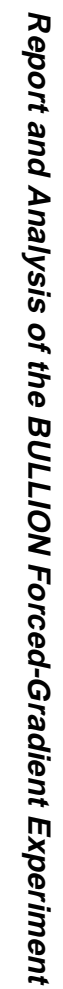




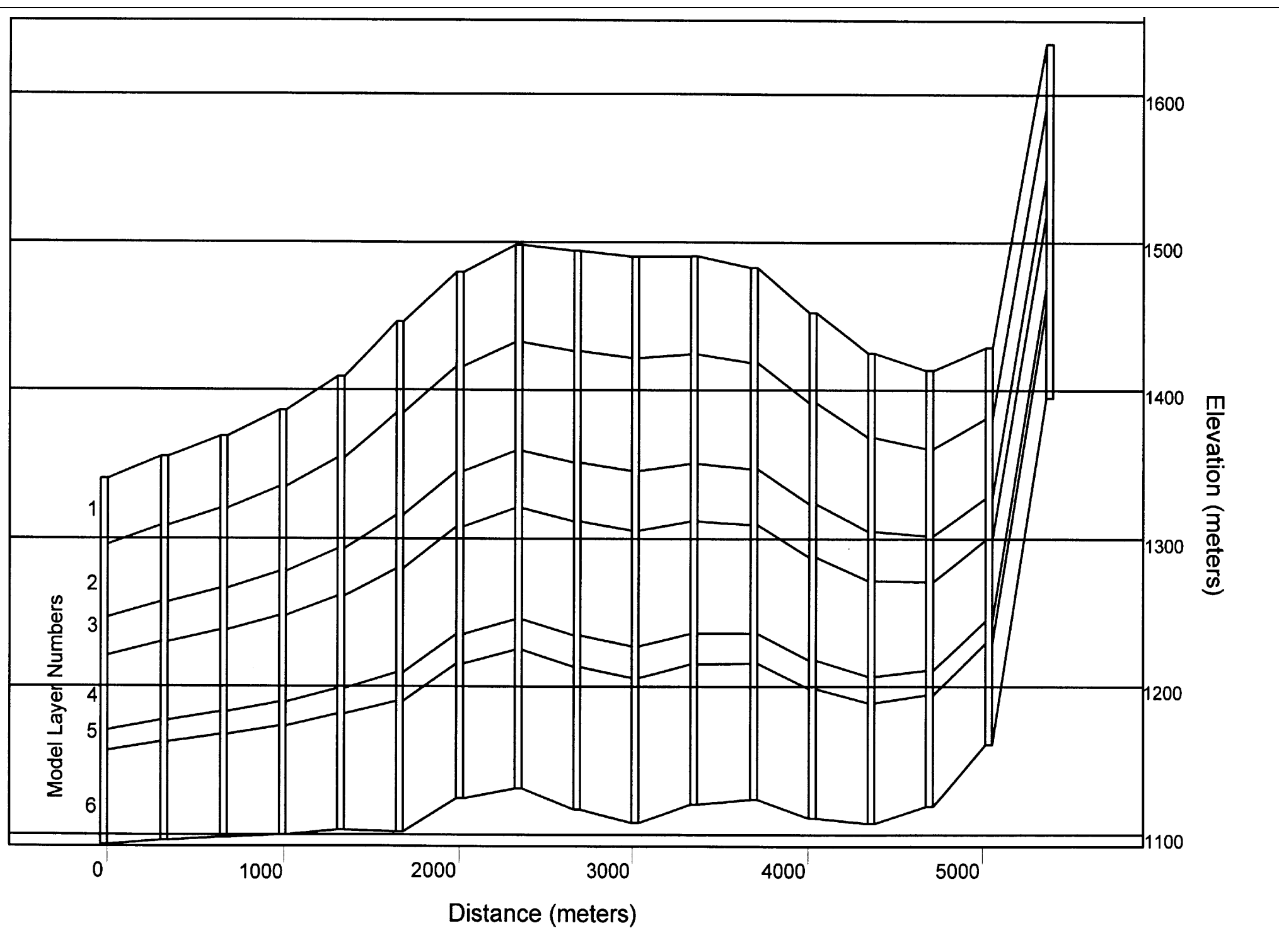

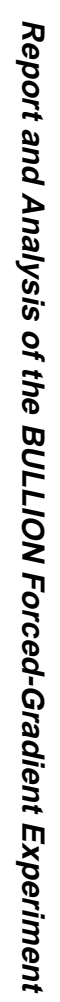

Figure A-4

BULLION Geologic Model Cross-Section, Southwest-Northeast 


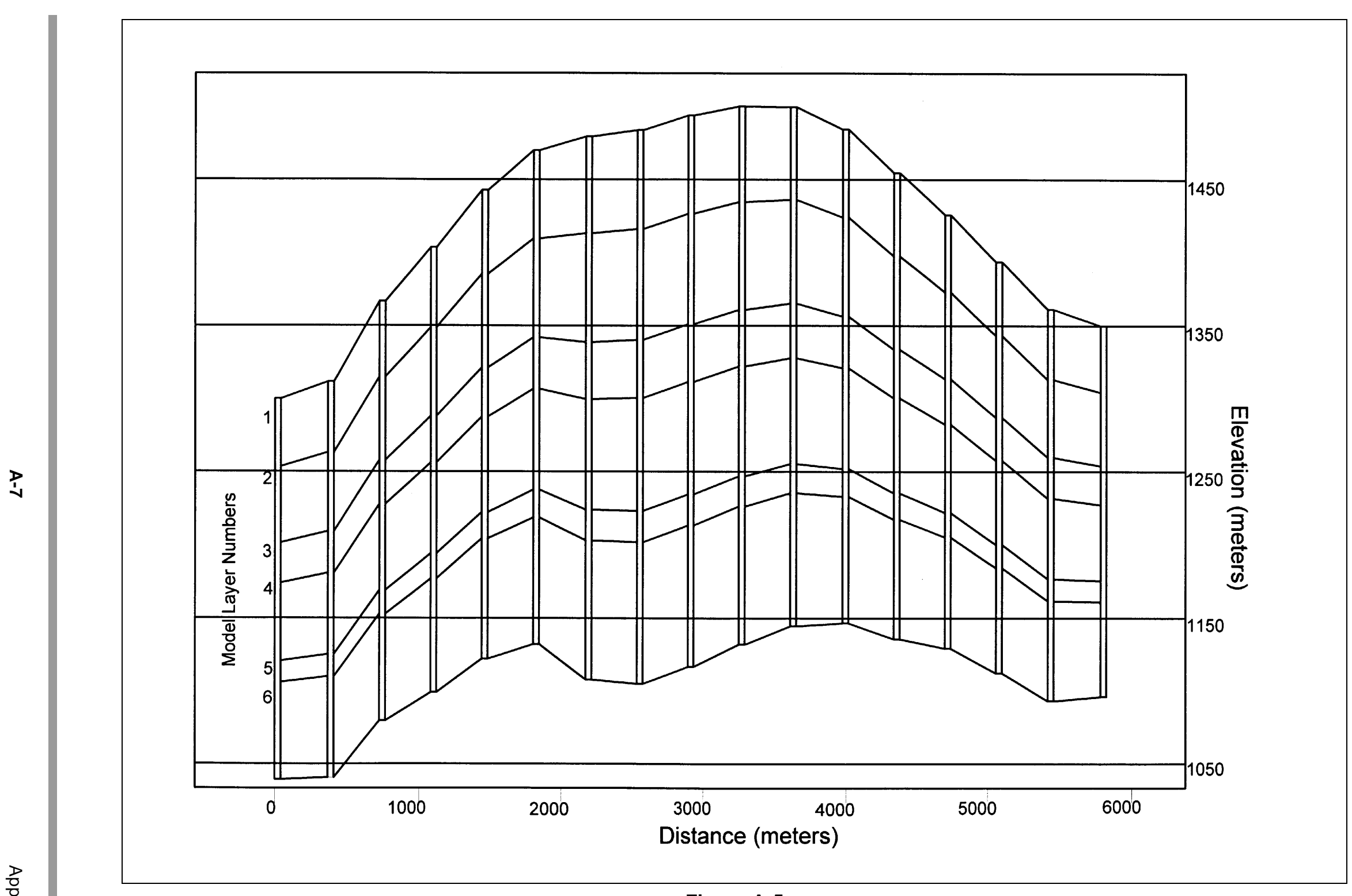

Figure A-5

BULLION Geologic Model Cross-Section, Southeast-Northwest

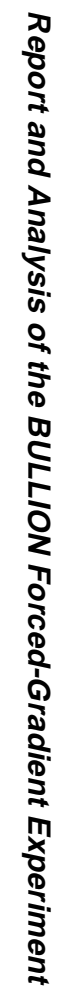




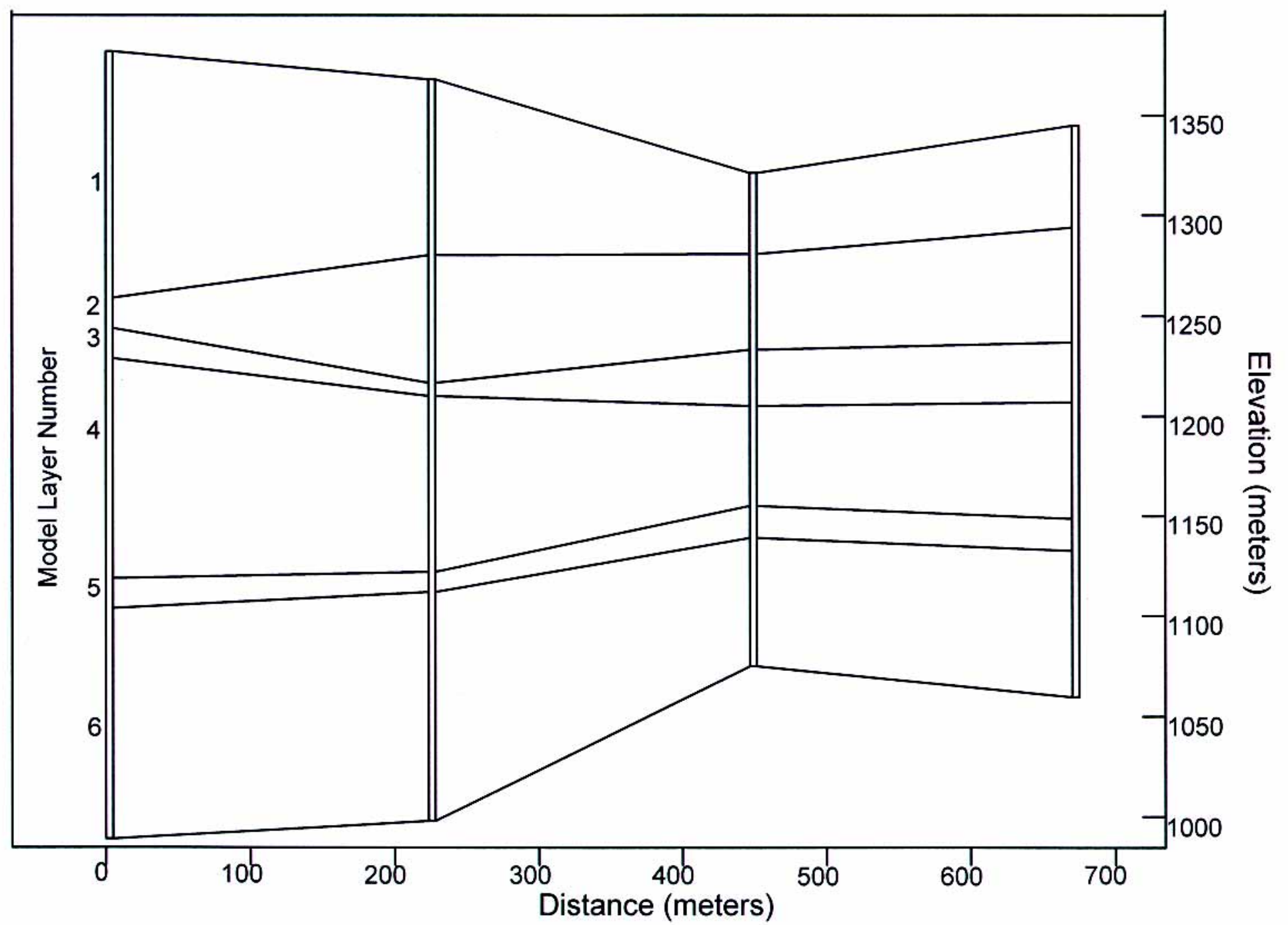

Figure A-6

BULLION Geologic Model Cross-Section, Southwest-Northeast Well Cluster 


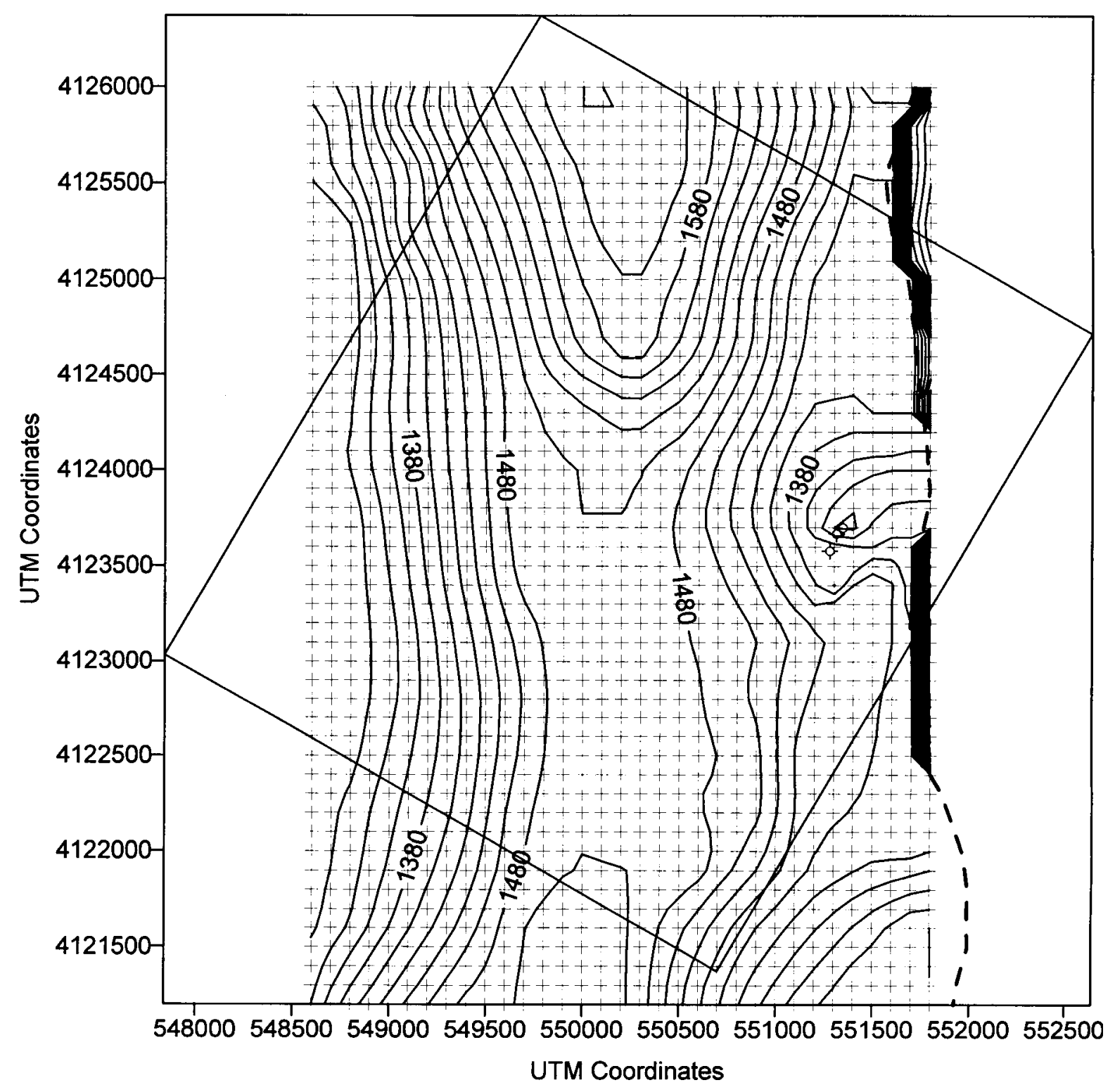

Figure A-7

Top of Layer 1 for BULLION FGE Model 


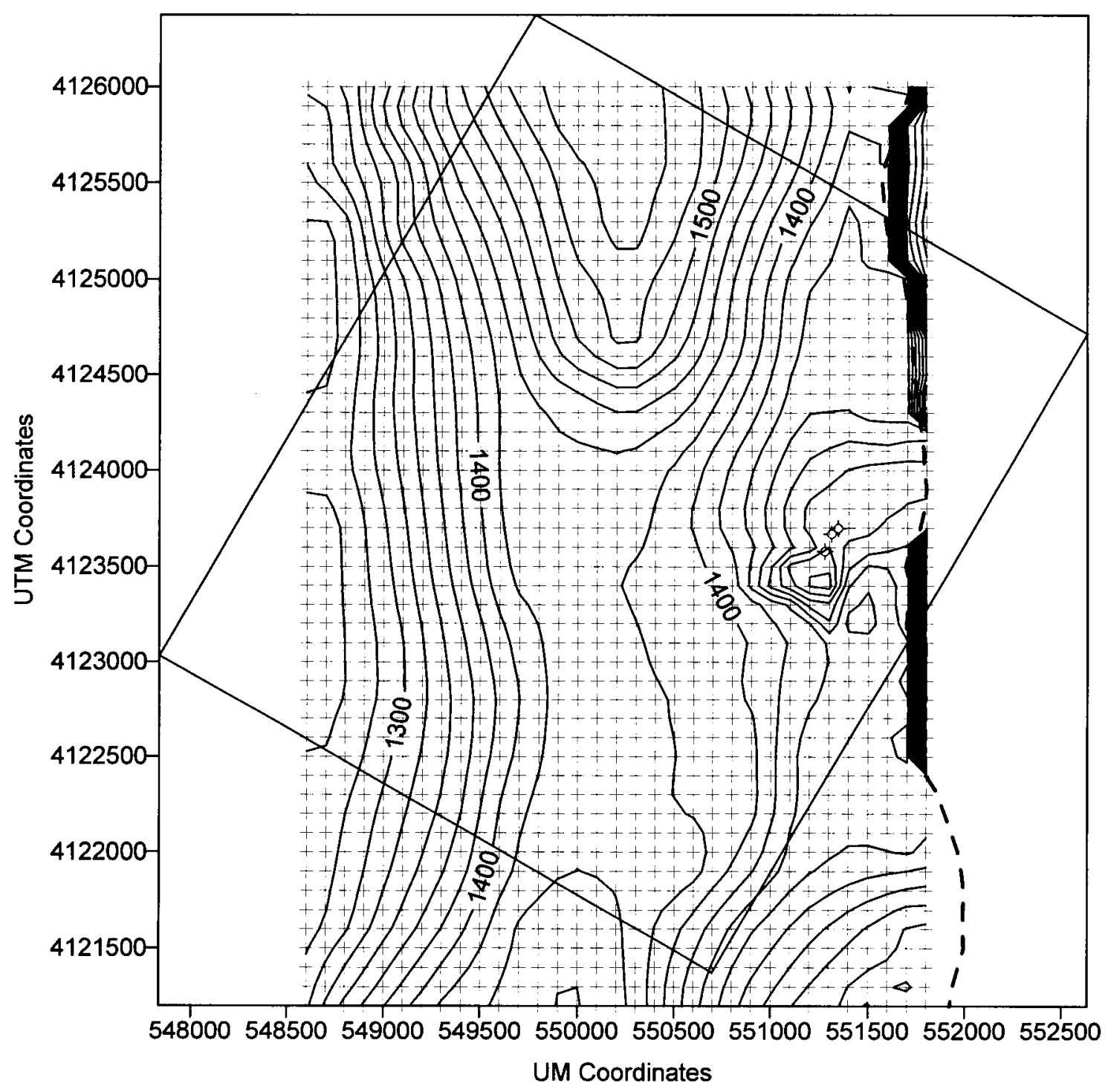

Figure A-8

Top of Layer 2 for BULLION FGE Model 


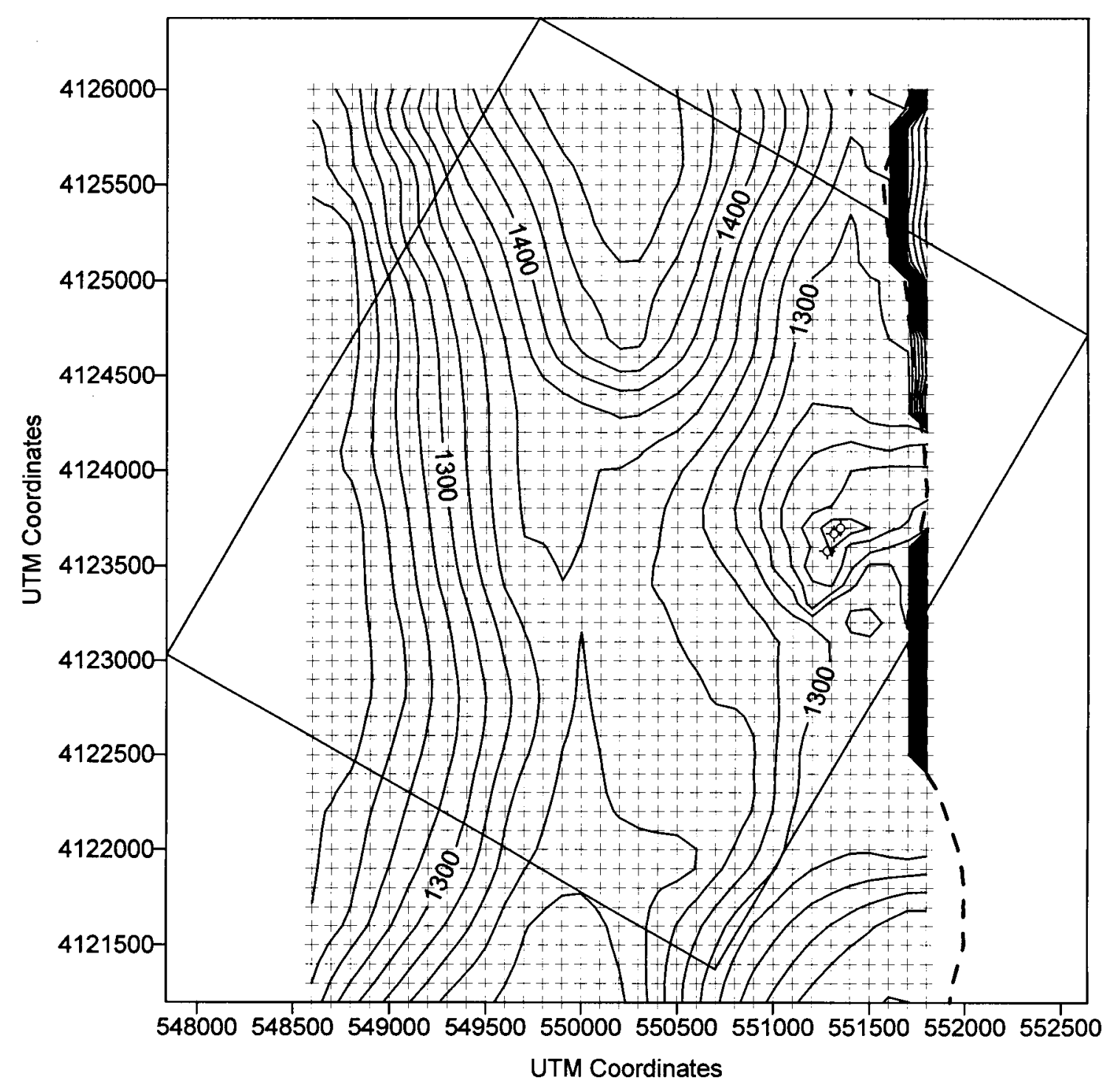

Figure A-9

Top of Layer 3 for BULLION FGE Model 


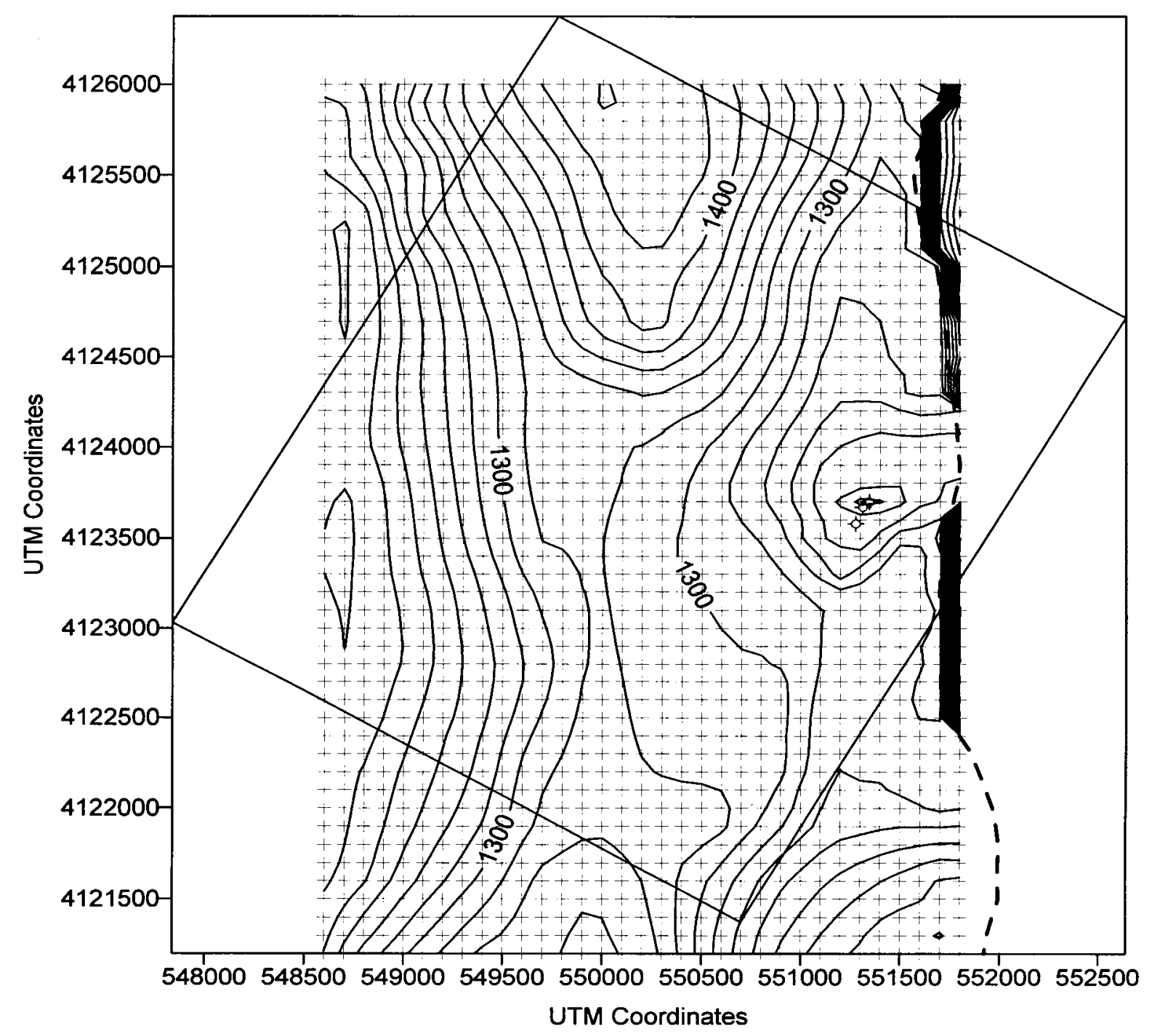

Figure A-10

Top of Layer 4 for BULLION FGE Model 


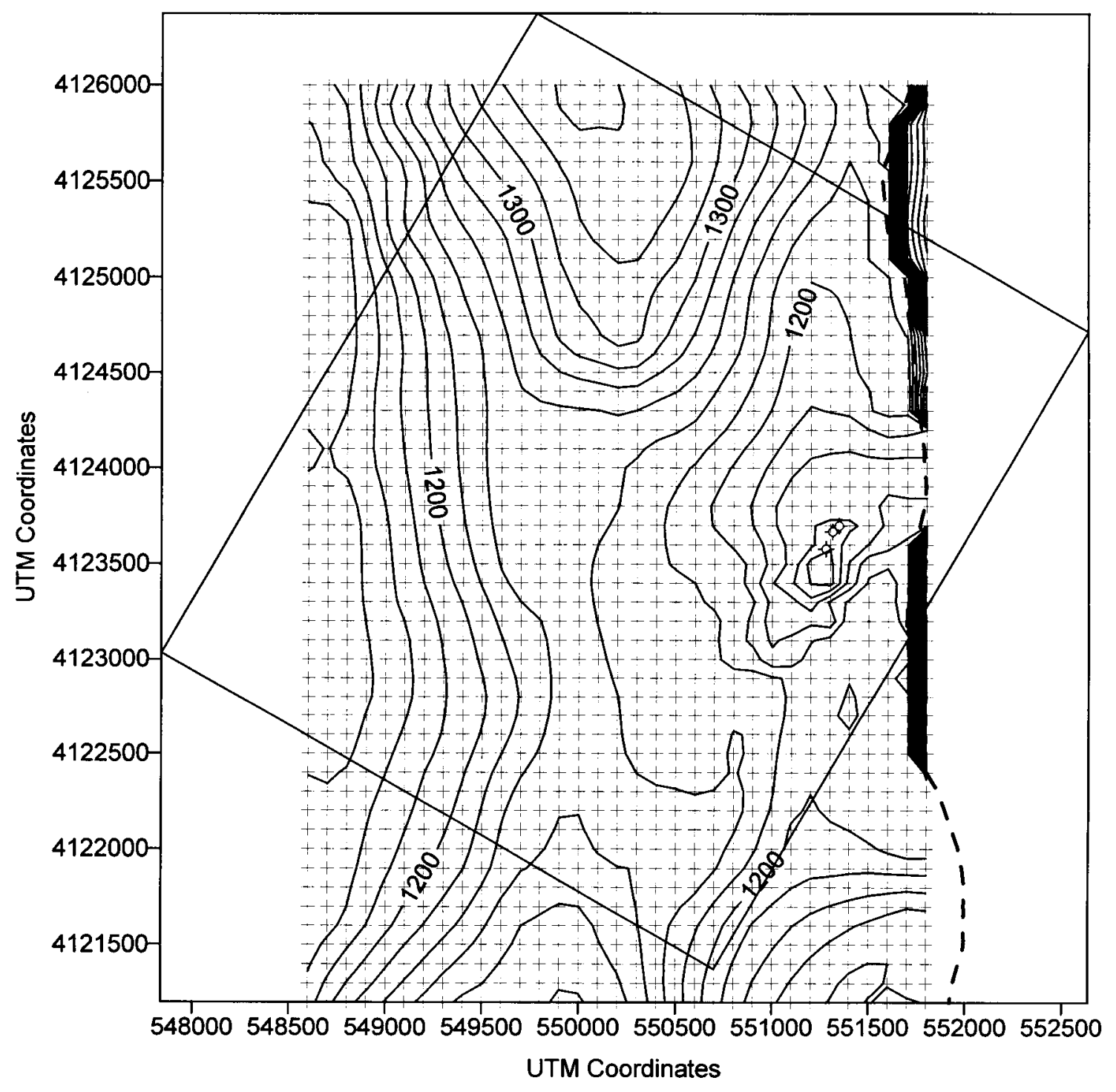

Figure A-11

Top of Layer 5 for BULLION FGE Model 


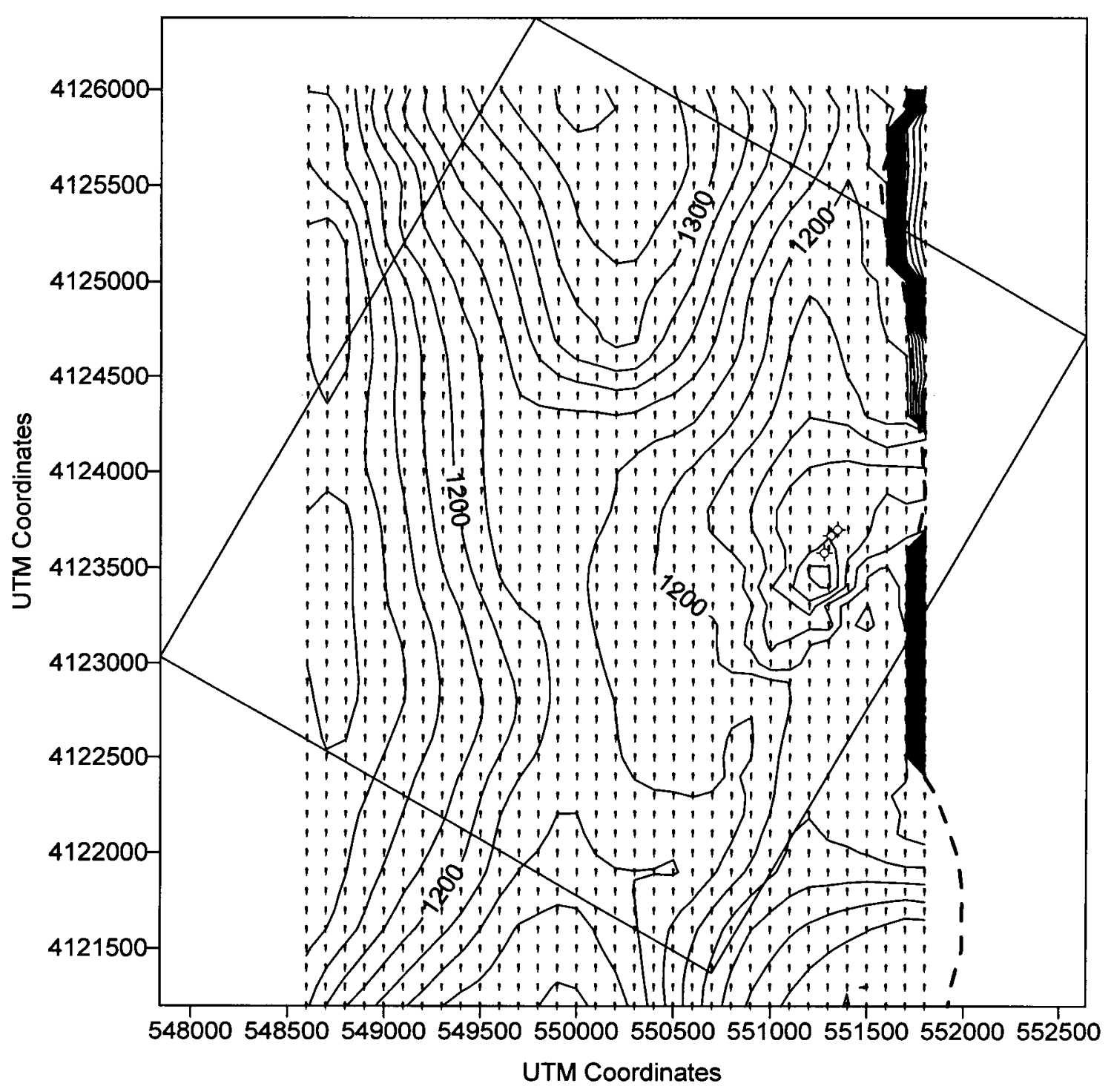

Figure A-12

Top of Layer 6 for BULLION FGE Model 


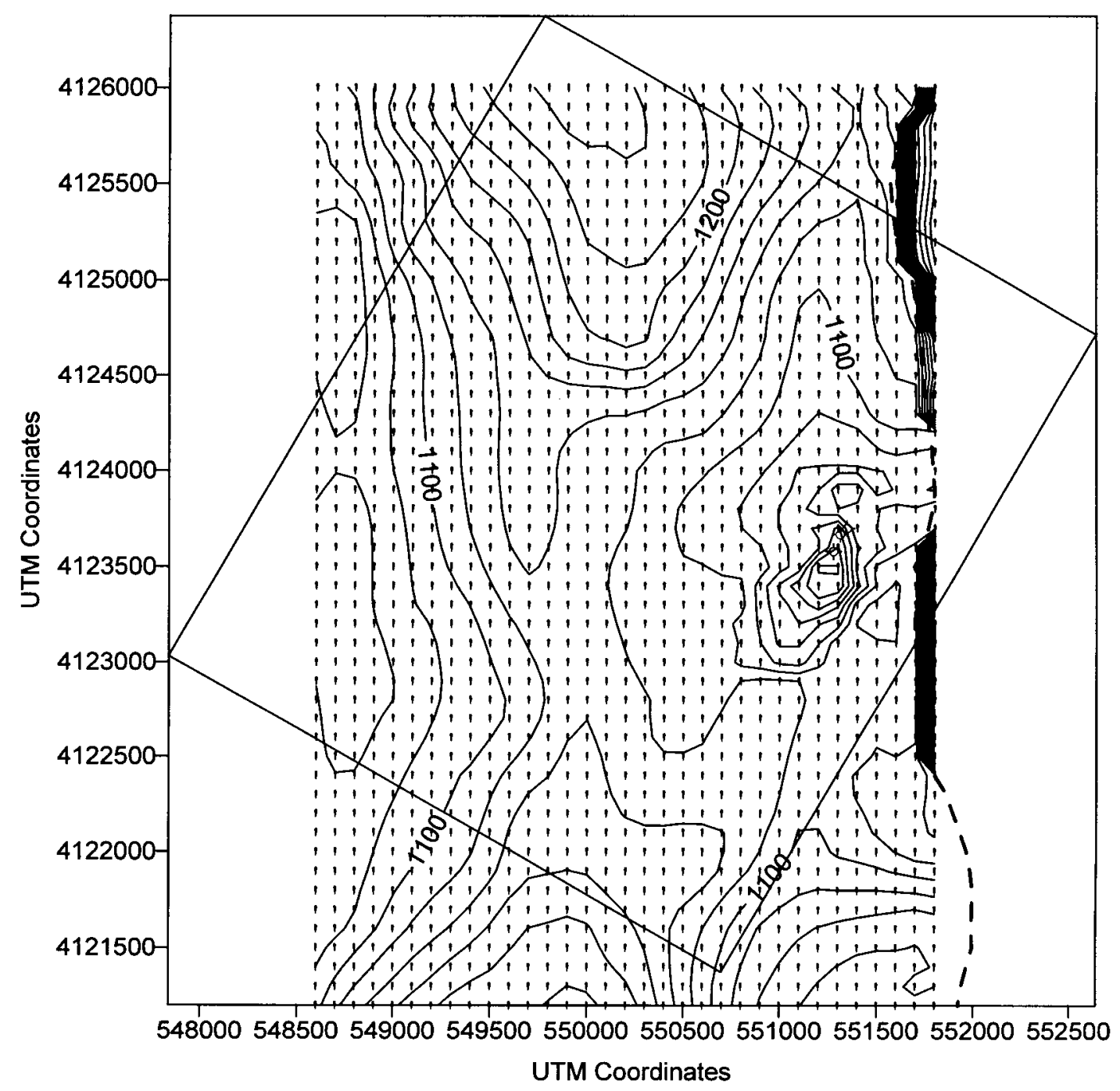

Figure $A-13$

Bottom of Layer 6 for BULLION FGE Model 


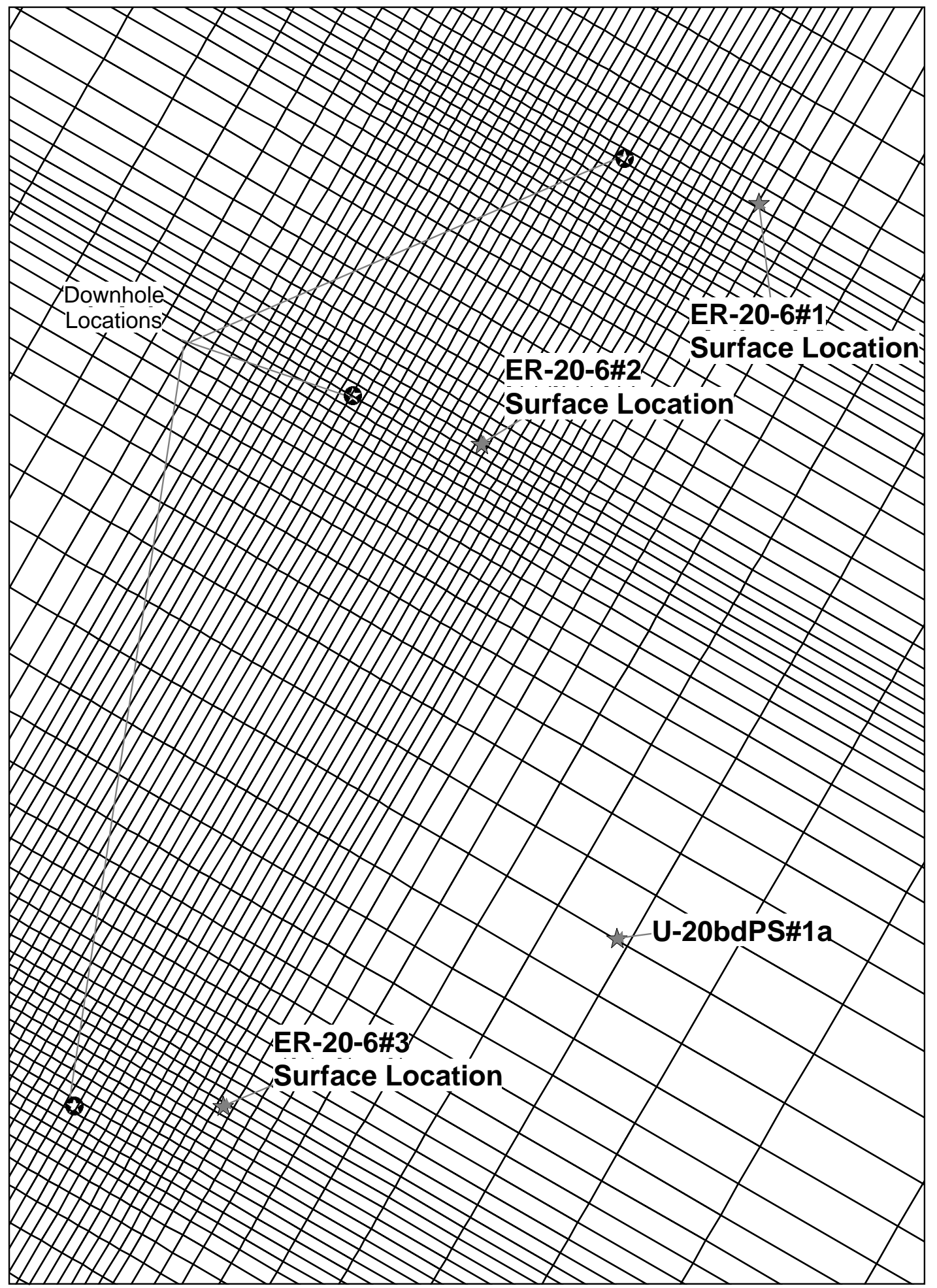

Figure A-14

Detail of the Downhole and Surface Locations of the Wells 


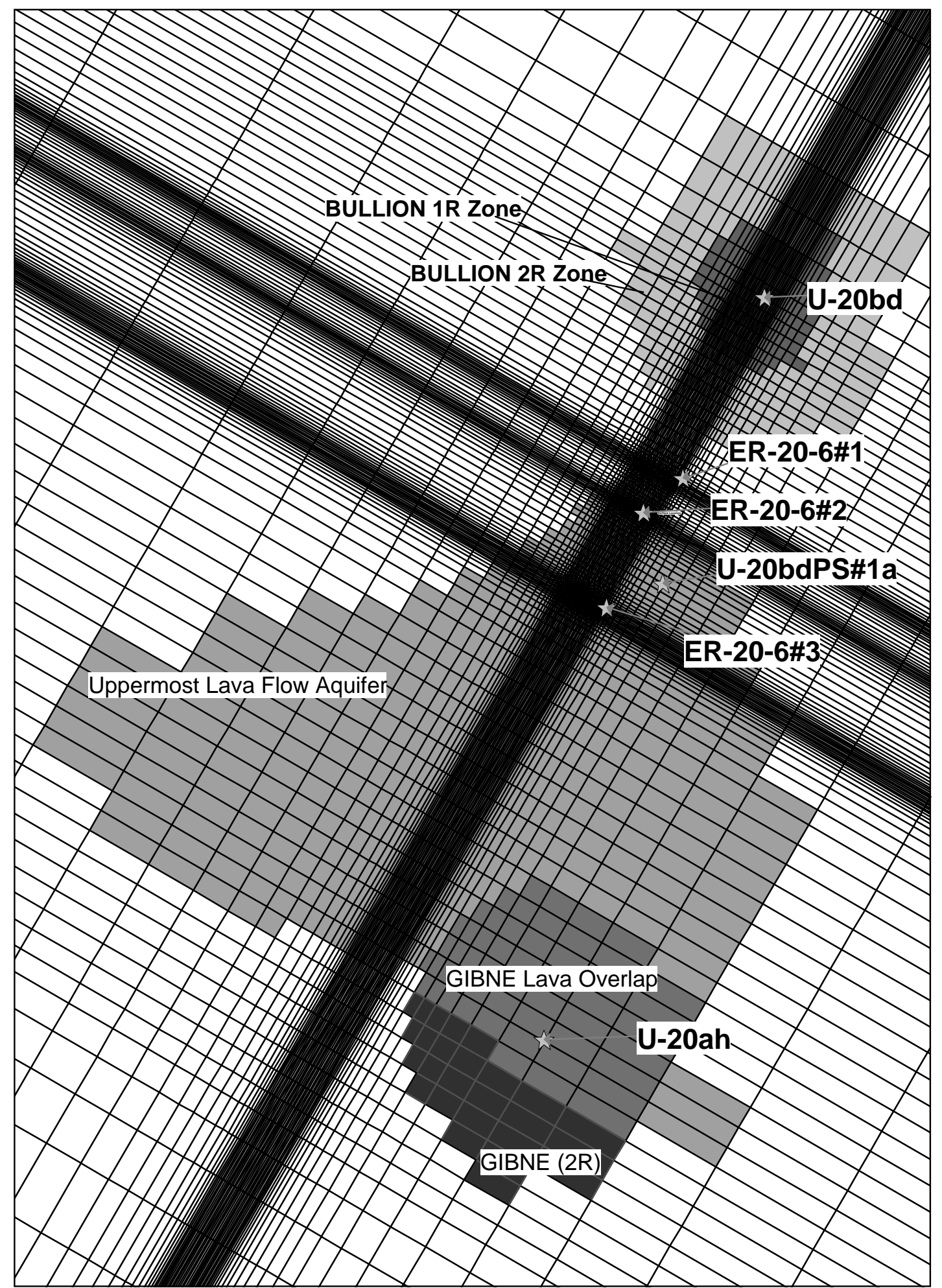

Figure A-15

Hydraulic Conductivity Zone for Model Layer 1 


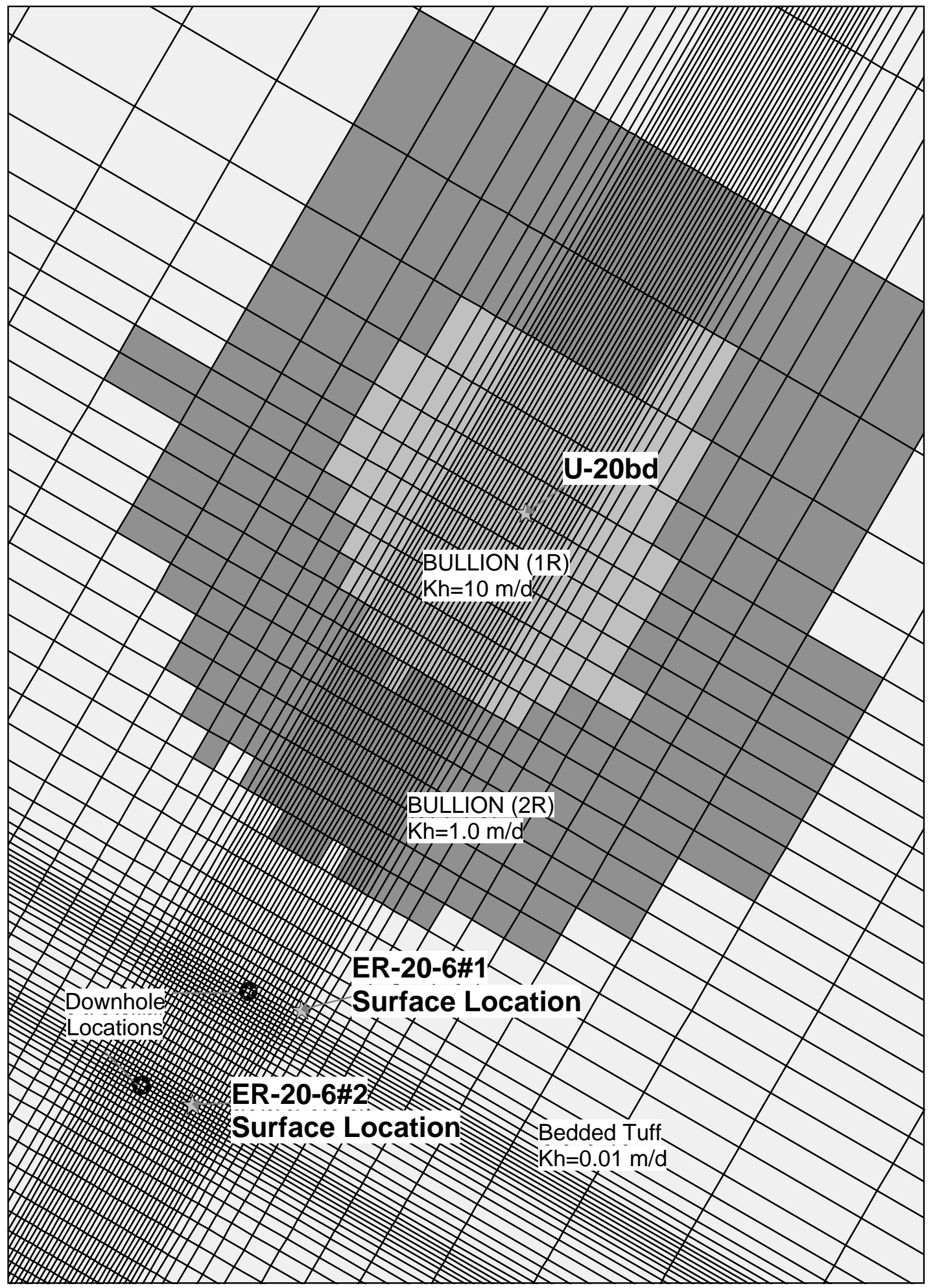

Figure A-16

Hydraulic Conductivity Zone for Model Layer 2 


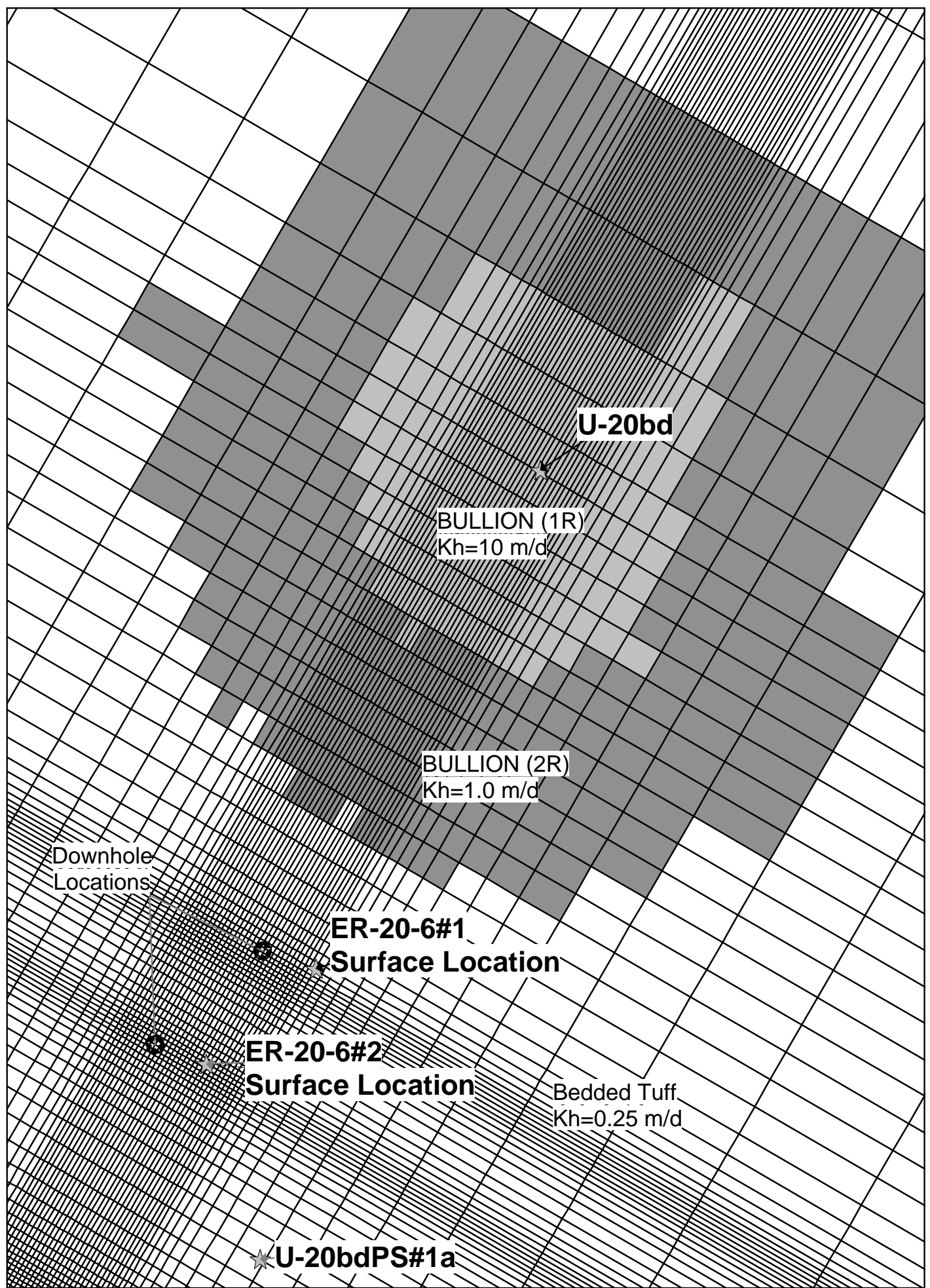

Figure A-17

Hydraulic Conductivity Zone for Model Layer 3 


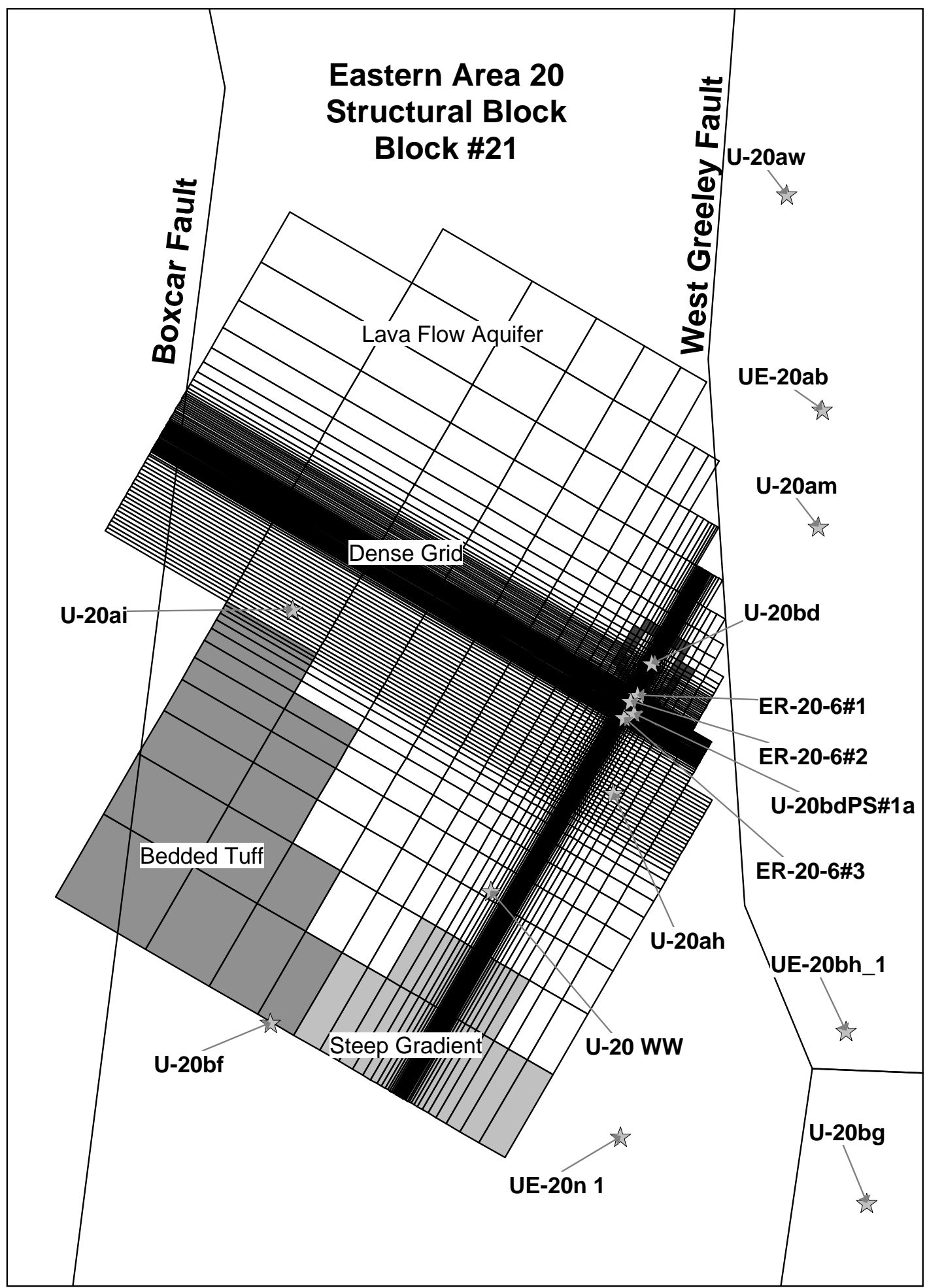

Figure A-18

Hydraulic Conductivity Zone for Model Layer 4, Large Scale Features 


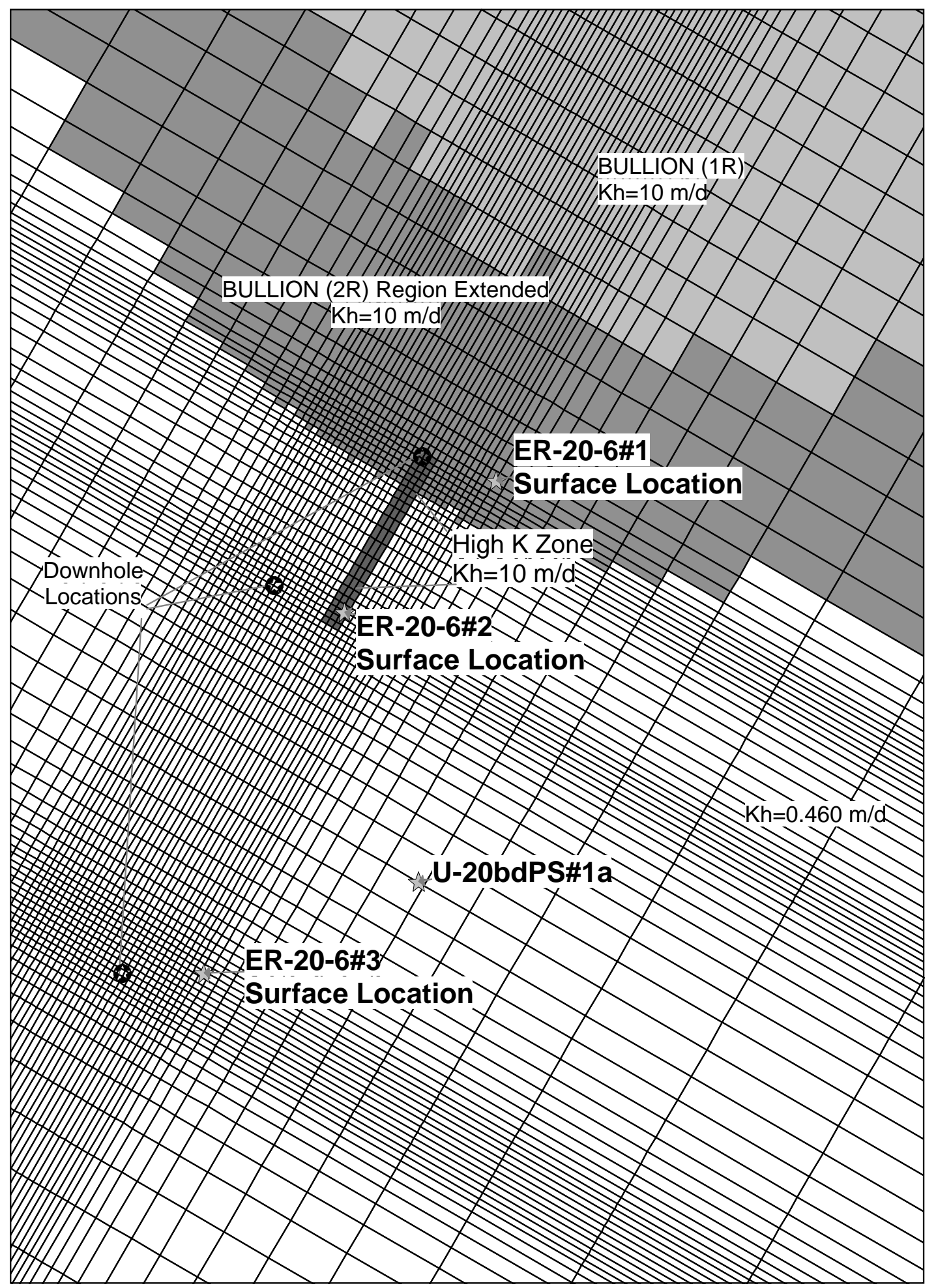

Figure A-19

Detail of the Hydraulic Conductivity Zones in Layer 4 Around the Injection Wells 


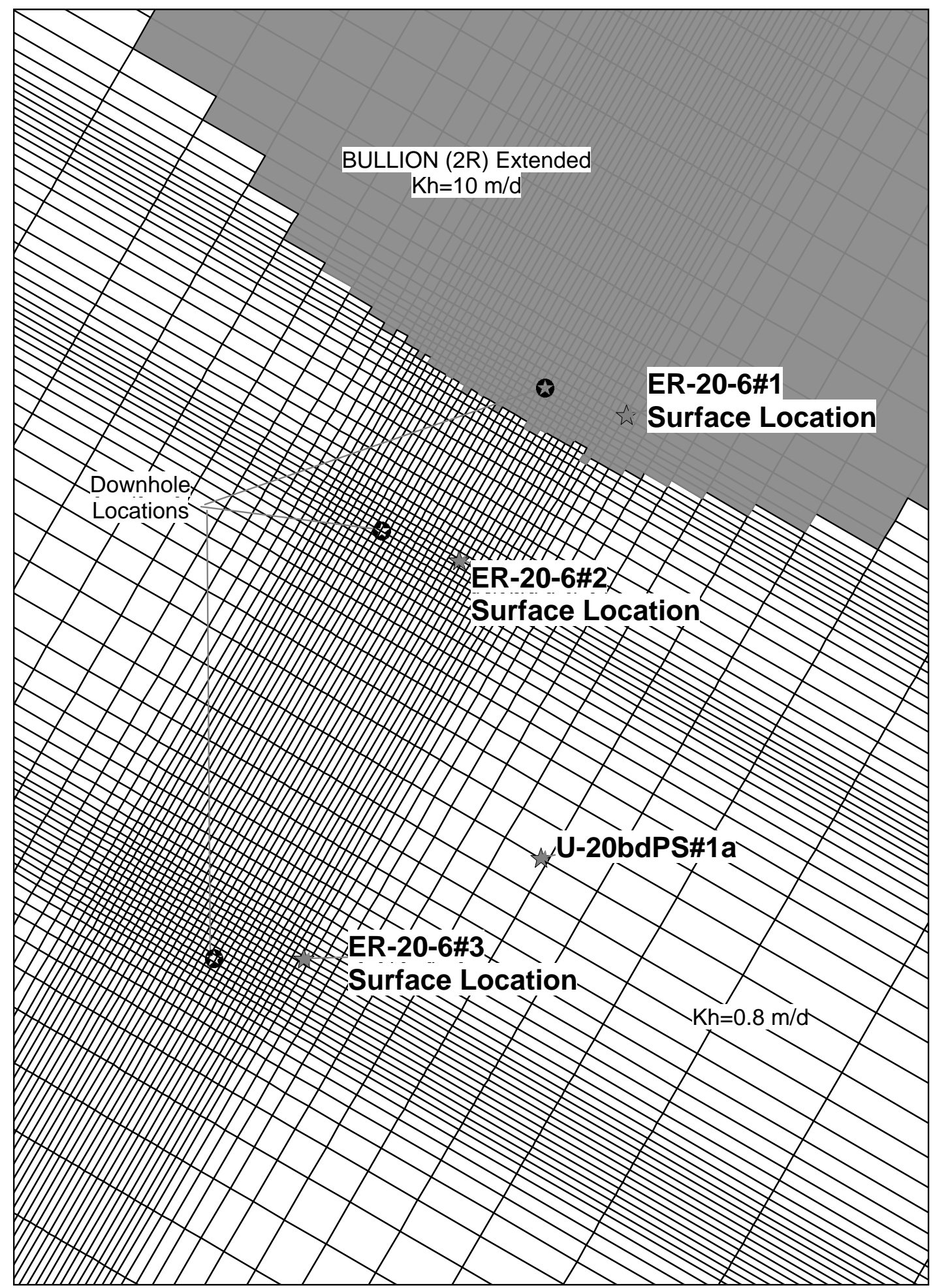

Figure A-20

Detail of the Hydraulic Conductivity Zones in Model Layer 6 


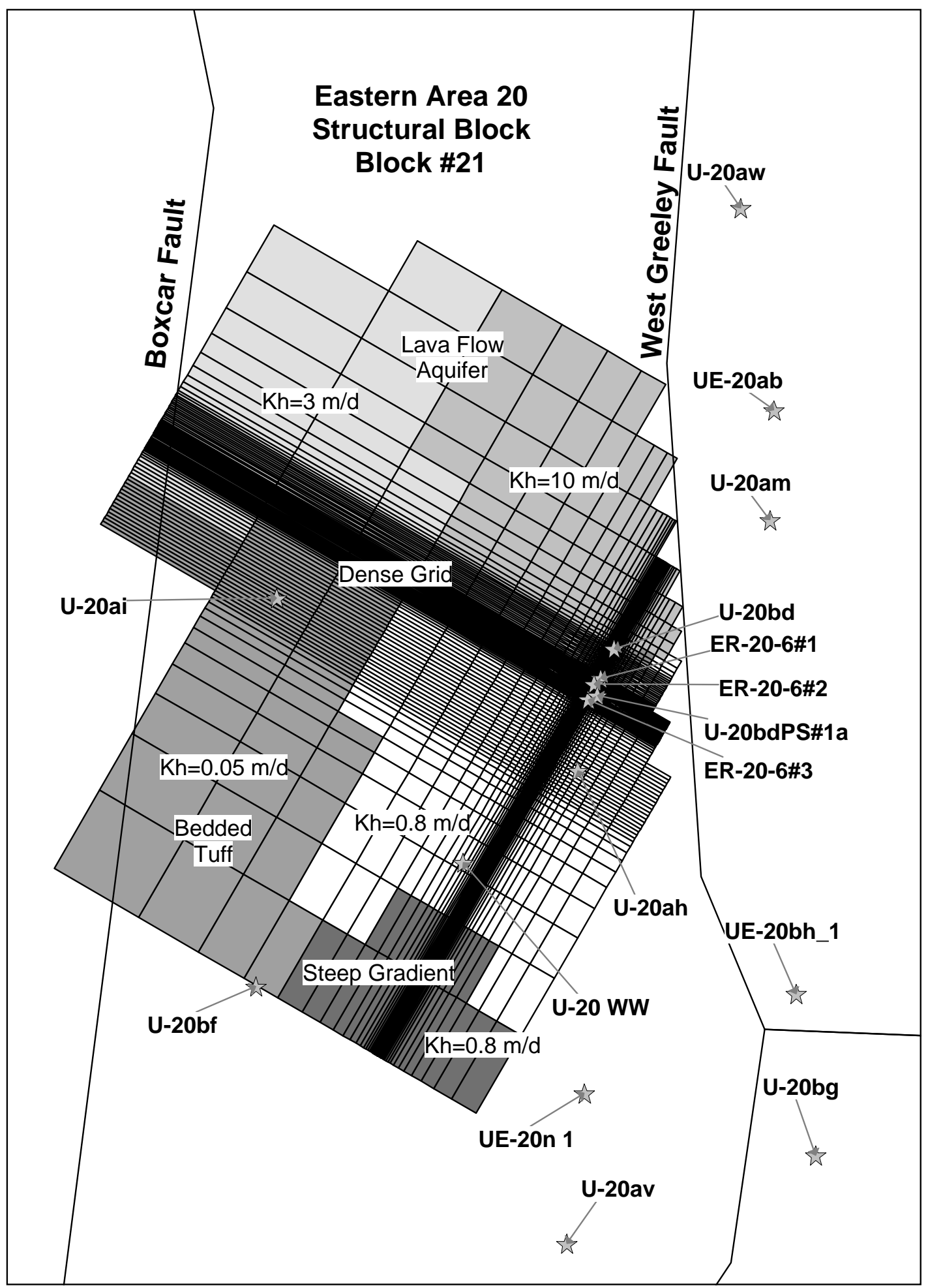

Figure A-21

Hydraulic Conductivity Zones for Model Layer 6 


\section{This Page Intentionally Left Blank}




\section{Distribution}

\section{$\underline{\text { Copies }}$}

Robert M. Bangerter, J r.

Environmental Restoration Division

DOE/Nevada Operations Office

P.O. Box 98518, M/S 505

Las Vegas, NV 89193-8518

Doug Duncan

DOE/Nevada Operations Office

P.O. Box 98518, M/S 505

Las Vegas, NV 89193-8518

Doug Trudeau

U.S. Geological Survey

Water Resources Division

6770 South Paradise Road

Las Vegas, NV 89119

Ward L. Hawkins

Los Alamos National Laboratory

P.O. Box 1663 - EES-1M/S F 659

Los Alamos, NM 87545

Gayle A. Pawloski

L awrence Livermore National Laboratory

P.O. Box 808, M/S L-221

700 East Avenue

Livermore, CA 94550

Paul K. Ortego

Bechtel Nevada

2621 Losee Road

M/S NLV082

Las Vegas, NV 89030

Chuck Russell

Desert Research Institute

755 E. Flamingo Road

P.O. Box 19040, M/S 505

Las Vegas, NV 89132-0040

$\mathrm{J}$ anet Wille

IT Corporation

2621 Losee Road, BIdg. B-1

M/S 439

North Las Vegas, NV 89030 
Dave Smith

Lawrence Livermore National Laboratory

Nuclear Chemistry

P.O. Box 808, M/S L-231

7000 East Avenue

Livermore, CA 94551

U.S. Department of Energy

Office of Scientific and Technical Information

175 Oak Ridge Turnpike

P.O. Box 62

Oak Ridge, Tennessee 37831

DOE/Nevada Operations Office

Technical I nformation Resource Center

P.O. Box 98518, M/S 505

Las Vegas, NV 89193-8518

DOE Public Reading Room

P.O. Box 98521, M/S NLV040

Las Vegas, NV 89193-8521 